Florida International University

FIU Digital Commons

$11-8-2018$

\title{
A Corpus-driven Approach toward Teaching Vocabulary and Reading to English Language Learners in U.S.-based K-12 Context through a Mobile App
}

Seyedjafar Ehsanzadehsorati

Florida International University, sehsa002@fiu.edu

Follow this and additional works at: https://digitalcommons.fiu.edu/etd

Part of the Curriculum and Instruction Commons, and the Language and Literacy Education Commons

\section{Recommended Citation}

Ehsanzadehsorati, Seyedjafar, "A Corpus-driven Approach toward Teaching Vocabulary and Reading to English Language Learners in U.S.-based K-12 Context through a Mobile App" (2018). FIU Electronic Theses and Dissertations. 3860.

https://digitalcommons.fiu.edu/etd/3860

This work is brought to you for free and open access by the University Graduate School at FIU Digital Commons. It has been accepted for inclusion in FIU Electronic Theses and Dissertations by an authorized administrator of FIU Digital Commons. For more information, please contact dcc@fiu.edu. 


\section{FLORIDA INTERNATIONAL UNIVERSITY}

Miami, Florida

\section{A CORPUS-DRIVEN APPROACH TOWARD TEACHING VOCABULARY AND READING TO ENGLISH LANGUAGE LEARNERS IN U.S.-BASED K-12 CONTEXT THROUGH A MOBILE APP}

A dissertation submitted in partial fulfillment of the

requirements for the degree of

DOCTOR OF PHILOSOPHY

in

CURRICULUM \& INSTRUCTION

by

Seyedjafar Ehsanzadehsorati 
To: Dean Michael R. Heithaus

College of Arts, Science and Education

This dissertation, written by Seyedjafar Ehsanzadehsorati, and entitled A Corpus-driven Approach toward Teaching Vocabulary and Reading to English Language Learners in U.S.-based K-12 Context through a Mobile App, having been approved in respect to style and intellectual content, is referred to you for judgment.

We have read this dissertation and recommend that it be approved.

Teresa Lucas

Haiying Long

Phillip M Carter

Eric Dwyer, Major Professor

Date of Defense: November 8, 2018

The dissertation of Seyedjafar Ehsanzadehsorati is approved.

Dean Michael R. Heithaus College of Arts, Sciences and Education

Andrés G. Gil

Vice President for Research and Economic Development and Dean of the University Graduate School

Florida International University, 2018 
(C) Copyright 2018 by Seyedjafar Ehsanzadehsorati

All rights reserved 


\section{DEDICATION}

I dedicate this dissertation to my mother, Leila, ليلا 


\section{ACKNOWLEDGMENTS}

I would like to give my endless thanks to my supervisor, Eric S. Dwyer, who taught me how to write a dissertation. He has given me huge support over the past four years of my $\mathrm{PhD}$ and I am greatly indebted to him, thank you. 
ABSTRACT OF THE DISSERTATION

\begin{abstract}
A CORPUS-DRIVEN APPROACH TOWARD TEACHING VOCABULARY AND
READING TO ENGLISH LANGUAGE LEARNERS IN U.S.-BASED K-12 CONTEXT
\end{abstract}

THROUGH A MOBILE APP

\author{
by \\ Seyedjafar Ehsanzadehsorati \\ Florida International University, 2018 \\ Miami, Florida \\ Professor Eric Dwyer, Major Professor
}

In order to decrease teachers' decisions of which vocabulary the focus of the instruction should be upon, a recent line of research argues that pedagogically-prepared word lists may offer the most efficient order of learning vocabulary with an optimized context for instruction in each of four K-12 content areas (math, science, social studies, and language arts) through providing English Language Learners (ELLs) with the most frequent words in each area. Educators and school experts have acknowledged the need for developing new materials, including computerized enhanced texts and effective strategies aimed at improving ELLs' mastery of academic and STEM-related lexicon.

Not all words in a language are equal in their role in comprehending the language and expressing ideas or thoughts. For this study, I used a corpus-driven approach which is operationalized by applying a text analysis method. For the purpose of this research study, I made two corpora, Teacher's U.S. Corpus (TUSC) and Science and Math Academic Corpus for Kids (SMACK) with a focus on word lemma rather than inflectional and derivational variants of word families. To create the corpora, I collected and analyzed a 
total of 122 textbooks used commonly in the states of Florida and California. Recruiting, scanning and converting of textbooks had been carried out over a period of more than two years from October 2014 to March 2017. In total, this school corpus contains 10,519,639 running words and 16,344 lemmas saved in 16,315 word document pages.

From the corpora, I developed six word lists, namely three frequency-based word lists (high-, mid-, and low-frequency), academic and STEM-related word lists, and essential word list (EWL). I then applied the word lists as the database and developed a mobile app, Vocabulary in Reading Study - VIRS, (available on App Store, Android and Google Play) alongside a website (www.myvirs.com). Also, I developed a new K-12 dictionary which targets the vocabulary needs of ELLs in K-12 context. This is a frequency-based dictionary which categorizes words into three groups of high, medium and low frequency words as well as two separate sections for academic and STEM words. The dictionary has 16,500 lemmas with derivational and inflectional forms. 


\section{TABLE OF CONTENTS}

CHAPTER

PAGE

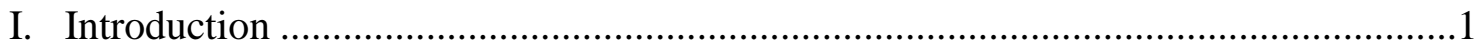

K-12 textbooks critique..............................................................................

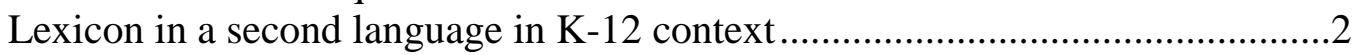

Context of K-12 vocabulary learning in a second language ..................................2

Academic vocabulary ...................................................................................

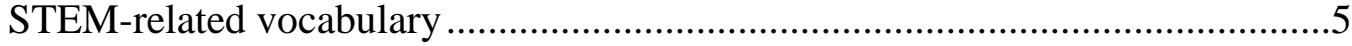

Fundamental issues with respect to vocabulary teaching and learning .................

Statement of the research problem.....................................................................

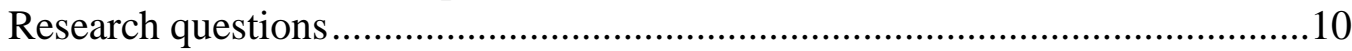

Overveiw of methods ................................................................................11

II. Conceptual framework and literature review...................................13

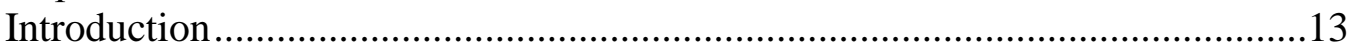

Conceptual framework for this dissertation ......................................................13

Text coverage as a criterion for learning burden ....................................14

Learning burden....................................................14

Learning burden of words in a second language......................15

Lemma vs. word family .............................................................................16

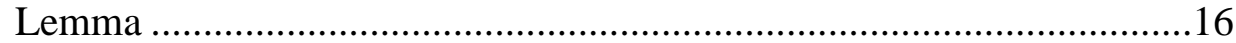

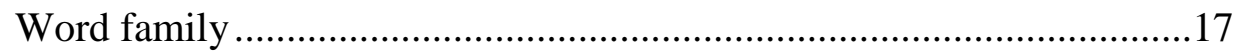

Causes of vocabulary learning burden in a second language .............................18

Frequency of lemma .......................................................................18

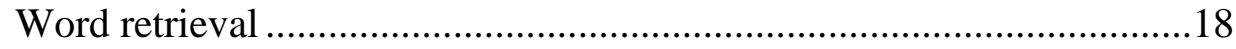

Patterns of word appearance ..............................................................19

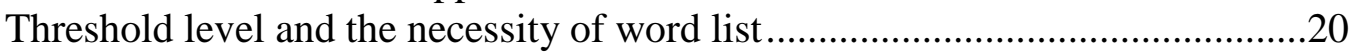

Typologies of academic and STEM-related vocabulary.....................................22

Vocabulary classification system for this study.....................................24

Word frequency list and vocabulary instruction .................................................24

Mental lexicon and word frequency ..................................................24

Word Frequency and vocabulary development .....................................25

A model for learning vocabulary in another language..........................................28

Encoding and internal specification.................................................29

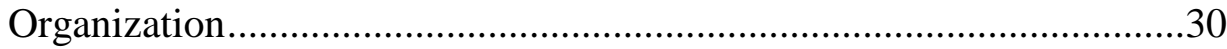

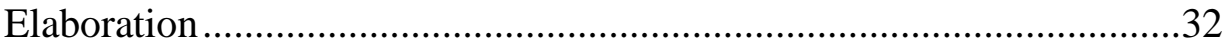

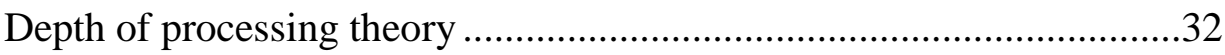

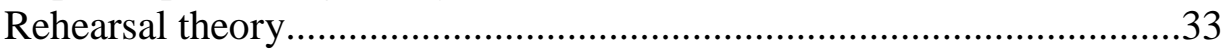




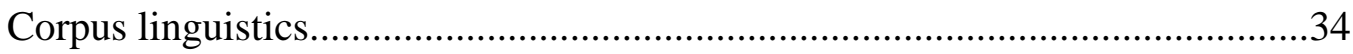

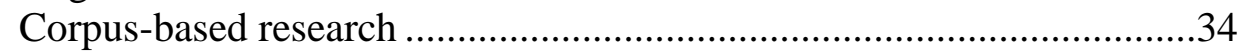

Corpus-driven research .....................................................................

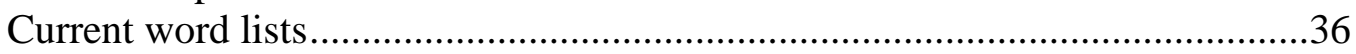

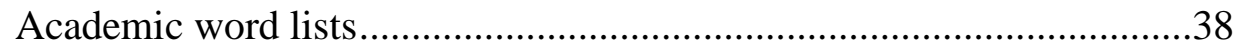

Sight word lists ...............................................................................

Problems of current word lists ......................................................................42

Teaching/learning implications of using word lists ............................................43

Principle of least effort in language learning ...........................................43

Significance of using word lists in language learning .............................44

Significance and purpose of this dissertation......................................................46

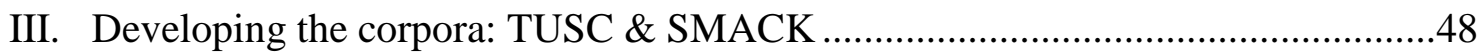

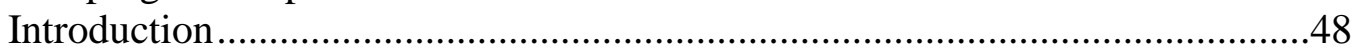

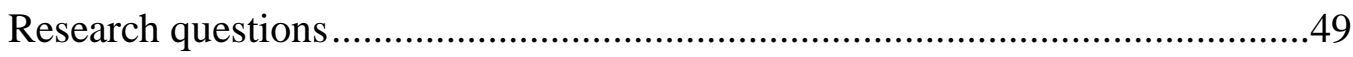

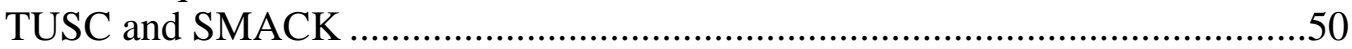

Procedure for developing the corpora - TUSC and SMACK..................50

Main issues in developing a corpus ...................................................52

Academic and STEM-related corpora ……………………..............................52

Analysis software used for developing the corpora ............................................57

LexTutor …….............................................................................57

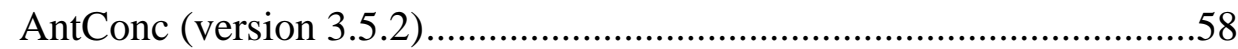

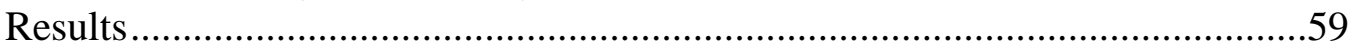

Teachers' U.S. Corpus - TUSC ………………………........................60

Science/ Math Corpus for K-12 Kids - SMACK ...................................64

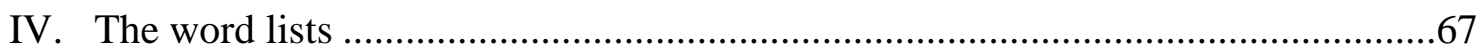

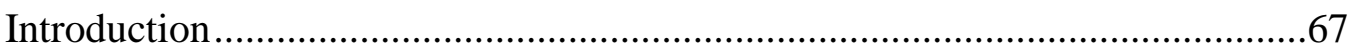

Procedure for making a word list.......................................................................68

Unit of counting ...............................................................................

Criteria for counting words and separate lists........................................72

Criteria for ordering words .................................................................72

How to count words for inclusion in a word list...................................73

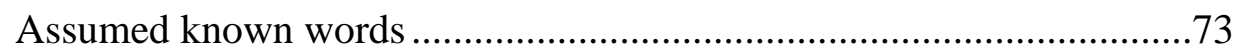

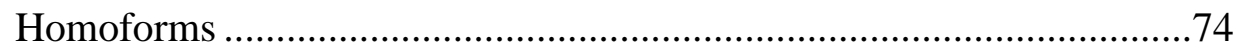

Proper nouns ...............................................................................

Compounds and hyphenated words ...................................................... 80

Idiomatic and phrasal expressions .......................................................82

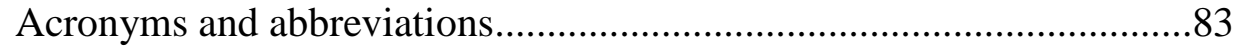

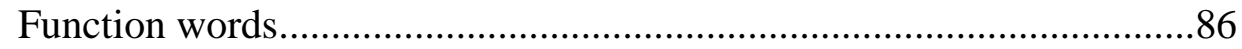

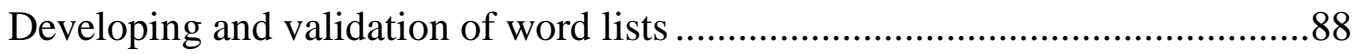

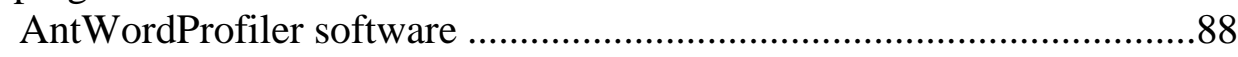




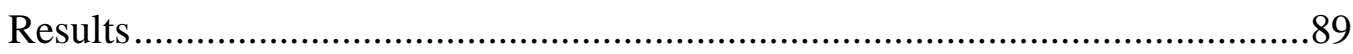

High Frequency Word List .................................................................90

Mid Frequency Word List.................................................................158

Low Frequency Word List..............................................252

K-12 Academic Word List.................................................................403

K-12 STEM-related Word Lists...........................................................412

Essential Word List (EWL) for K-12 ELLs...........................................420

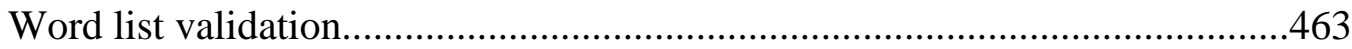

Essential Word List (EWL) considerations .....................................................467

V. The mobile app and website: Vocabulary in Reading Study - VIRS ....................469

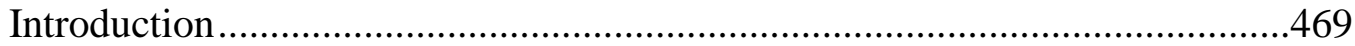

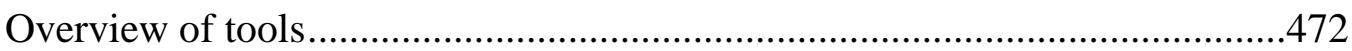

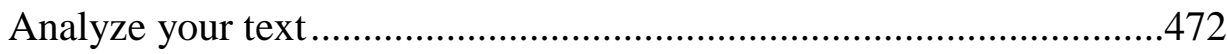

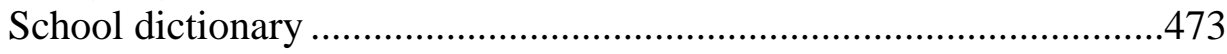

Pilot vocabulary tests ......................................................................474

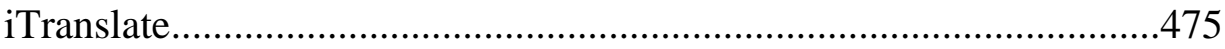

VI. Teaching-learning implications of this dissertation and conclusion......................477

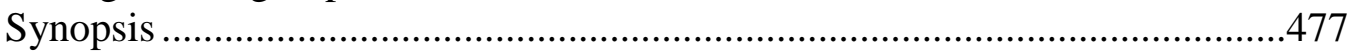

Implications for teaching English as a second language

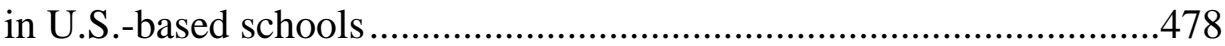

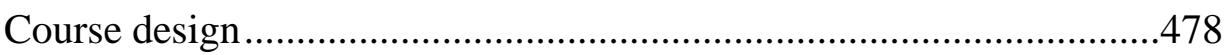

Reading material development for ELLs ............................................479

Readability measurement for ELLs ......................................................479

Developing K-12 vocabulary tests......................................................480

Classroom activities that focus on word lists

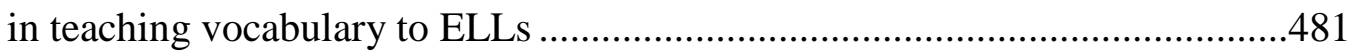

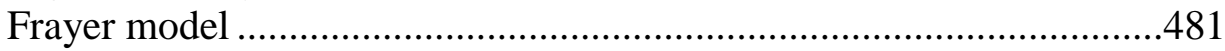

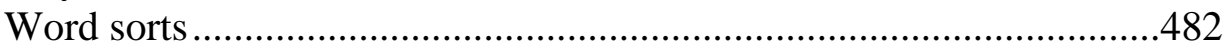

Triple-entry vocabulary journal ......................................................483

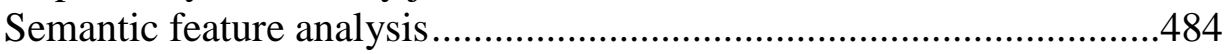

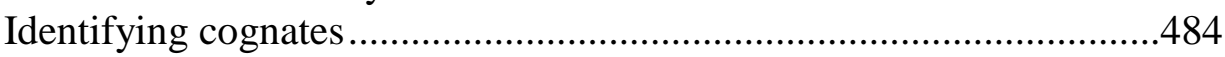

General implications for teaching English as a second language ......................485

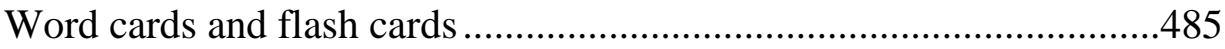

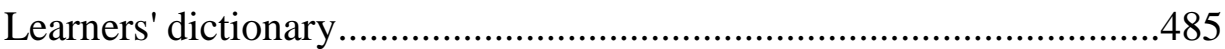

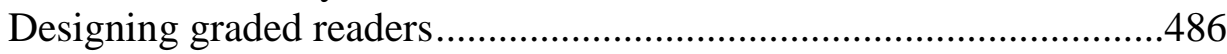

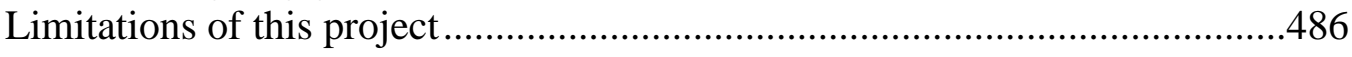

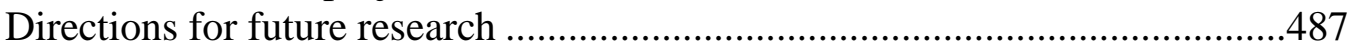

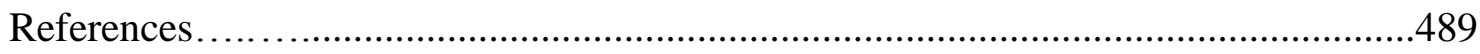

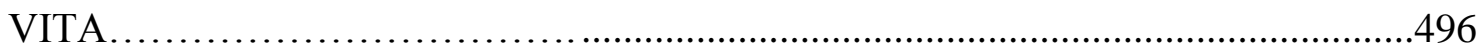




\section{LIST OF TABLES}

TABLE

PAGE

Table 1. Number of books and running words of Florida and California textbooks ..........................................................51

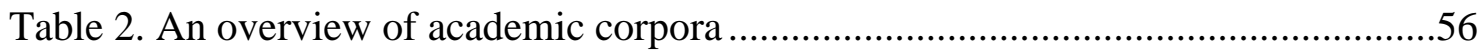

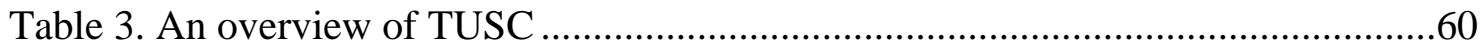

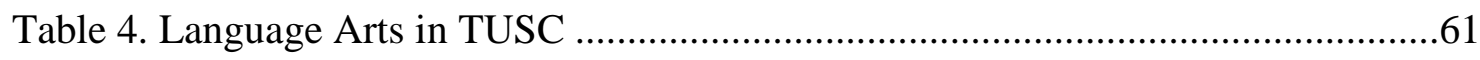

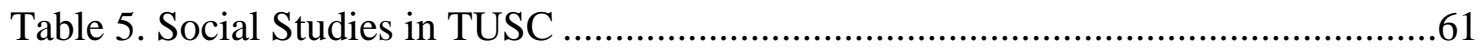

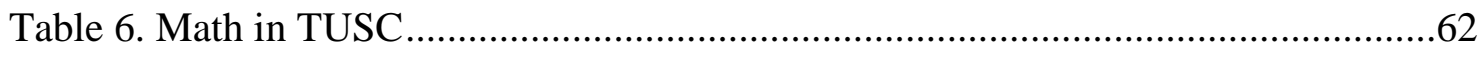

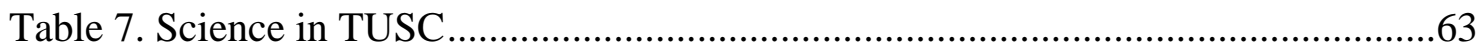

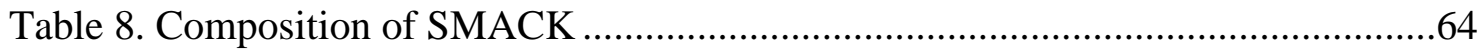

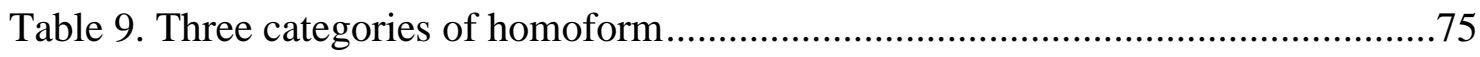

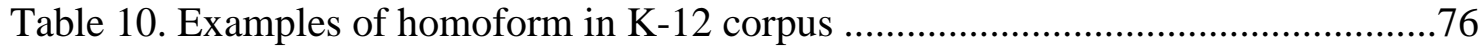

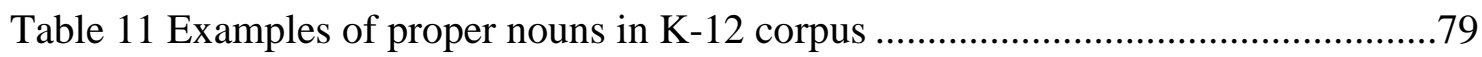

Table 12. A sample of hyphenated words in the five word

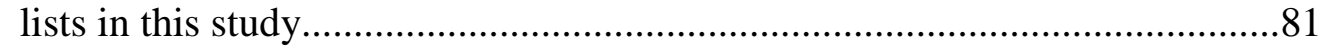

Table 13. Examples of idiomatic and phrasal expressions .....................................83

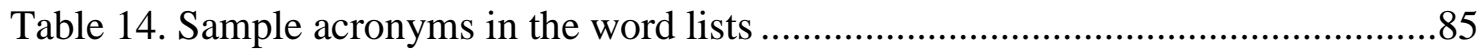

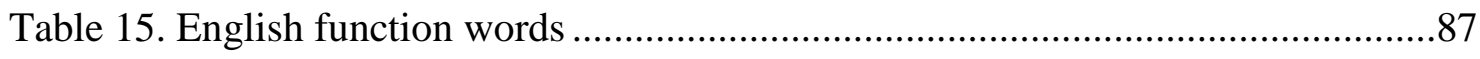

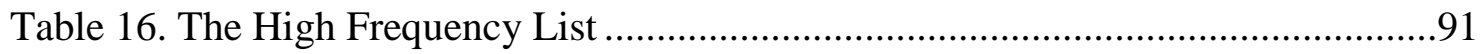

Table 17. Mid Frequency Word List.............................................................158

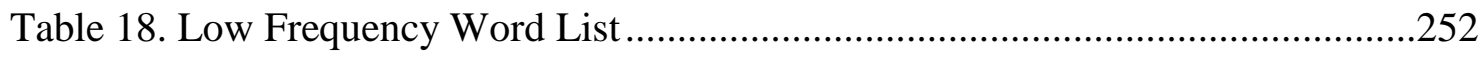


Table 19. K-12 Academic Word List....................................................................403

Table 20. K-12 STEM-related words: Math ......................................................412

Table 21. K-12 STEM-related words: Science .................................................416

Table 22. Essential Word List: K1 .............................................................420

Table 23. Essential Word List (EWL): K2 ...................................................440

Table 24. Essential Word List (EWL): Academic words .....................................458

Table 25. Text coverage of each word list in this study ......................................463

Table 26. Text coverage of three frequency lists against

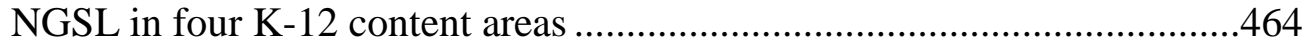

Table 27. Text coverage of Academic and STEM-related word Lists against AWL and AVL in four K-12 content areas ..................465 


\section{LIST OF FIGURES}

FIGURES

PAGE

Figure 1. Academic vocabulary classification system ........................................

Figure 2. A model for learning vocabulary in another language ...............................31

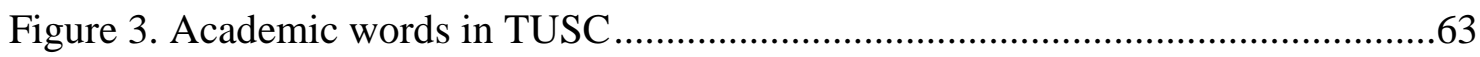

Figure 4. Academic vocabulary in SMACK .....................................................65

Figure 5. STEM words in TUSC and SMACK …............................................66

Figure 6. Text coverage vs lemma percentage of academic and high frequency words for the entire corpus......................................466

Figure 7. Academic vocabulary vs STEM vocabulary in TUSC and SMACK by percent.

Figure 8. EWL by K1, K2, and Basic Academic Words in TUSC and SMACK by percent .....................................................468

Figure 9. The home page of the app - VIRS ..............................................470

Figure 10. Color-coded system for reading comprehension ..................................472

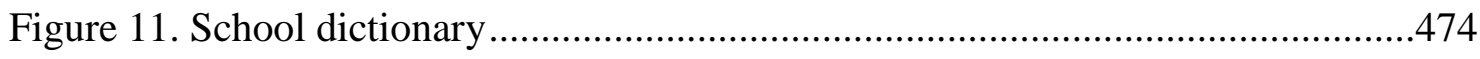

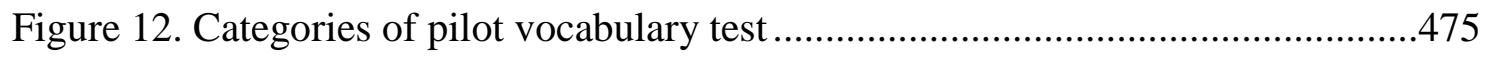

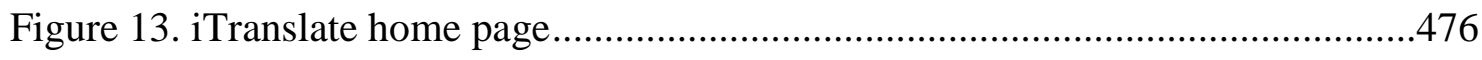




\section{Definitions of key terms}

For this dissertation, the following definitions are put forward:

Academic vocabulary: Are words that appear constantly across all four content areas, math, language arts, science, and social studies. Academic words are also words whose meaning often change across different subject matters (Baumann \& Graves, 2010).

Corpus: A large body of written or spoken natural language which is analyzed via computer-assisted programs (Stubbs \& Halbe, 2013).

Corpus-based research: The goal here is to investigate the systematic patterns that governs the linguistic features. This method of research is a top-down approach in which grammatical features are described (Biber, 2012).

Corpus-driven research: Corpus-driven analysis uses the unique features of a text to determine linguistic categories. Therefore, all linguistic categories are systematically derived from frequency distributions (Tognini-Bonelli, 2001).

Elaboration: Elaboration enhances encoding processes in WM through linking a new item to the conceptually related schemata in LTM. Elaboration improves word retrieval through linking a new word to the network of active vocabulary knowledge (Schunk, 2012).

Incidental learning: Incidental L2 learning is defined as learning that takes place without either intentionality or awareness. The line of research on incidental learning argues that L2 vocabulary learning does occur through reading (Chen \& Truscott, 2010).

Intentional learning: Ellis (1994) argues that intentional learning requires focal attention to be placed on linguistic form. Intentional learning is directly focusing on the learning item.

Learning burden: Is defined as the amount of effort that a learner usually puts to learn a word (Nation, 2016).

Lemma: Is the school dictionary that comes with some but not all the derivational and inflectional forms; however, word family has all the forms.

Retrieval: The ability to use the learned materials in everyday conversation. Retrieval is different from learning (Schunk, 2012).

Threshold level: A minimum amount of vocabulary knowledge that marks the boundary for gaining a successful comprehension (Nation, 2001). 
Text coverage: Is the number of words that the target students at a particular level of proficiency know. Nation (2013) claims that students should know every eight out of ten words in a text to be able to reach a successful reading comprehension. 


\section{CHAPTER I}

\section{Introduction}

\section{K 12 textbooks critique}

Imagine a kindergarten class where a new immigrant child has to study phonics, a lesson plan requiring students to learn swatches of words that rhyme. The initial assumption for most teachers is that children know the words. English Language Learners (ELLs), however, do not necessarily know these words. Here, not only do teachers then foist new language upon them; they pound them with words that all sound alike (Wyse \& Goswami, 2008), asking them to parse among them without assistance.

In a traditional teaching sequence, a lesson or chapter starts with new words and ends with vocabulary as a reference (Jameson, 2012). The reading passage is the first step that students are required to read followed by study questions and discussion materials. Florida Reading/Writing for Grades 4-5 (p. 69) is a good example of such a teaching sequence. The sequence is difficult for ELLs because they do not have the required cultural or even background knowledge needed for understanding the reading material; meanwhile, this method of presenting the content is in contrast with Krashen's (1989) ' $i+1$ ' that claims that input should be a little higher than the current proficiency level of the learners. However, this teaching sequence seems to be ' $i$ + many' for ELLs. According to Center of Applied Linguistics (Jameson, 2012), a possible answer to the above-mentioned problem is to Teach-the-Text-Backward in which teachers are recommended to first discuss the material in class in order to activate the ELLs' schemata. Study questions should be 
answered following the discussions and finally reading the text should be the last part of the class instruction.

\section{Lexicon in a second language in $K-12$ context}

Lexicon is one of the key building blocks in learning a language. The path toward vocabulary development in a second language (L2) takes time and requires enormous effort. To many language learners, vocabulary learning may seem endless, as they encounter new unknown words every day.

Moreover, many words that ELLs encounter in school are less common words that represent rare elements of a child's home life, but they may still only be selectively pertinent words to very specific situations that put further challenges in front of the ELL's learning path (Townsend and Collins 2009). The above-mentioned scenario seems to worsen as language learners, including EFL and international students, move toward advanced level of language proficiency.

\section{Context of K-12 vocabulary learning in a second language}

It is generally agreed that ELLs need more than five years, at least, to gain a fair command of academic English (Cummins, 1981; Hakuta, Butler, \& Witt, 2000). Since ELLs may have less experience with English language, as well as a lack of receiving proper academic English prior to their matriculation in mainstream classes, they could face additional challenges in the K-12 context compared to their peers who speak English as their first language. 
Unlike ELLs' orthographic knowledge in the L2 that apparently develops like native speaker ${ }^{1}$ s (Chiappe, Siegel, \& Wade-Woolley, 2002), Bialystok, Luk, and Kwan (2005) claim that young foreign language learners' semantic proficiency is far behind native speakers at the same age in K-12 setting. Since the ELLs' dual task of learning content area subjects while developing their language proficiency can be such a huge task, doing so may cause ELLs to score below state average on key standardized tests (Bialystok, et al., 2005). According to the Institute of Education Sciences (2007), ELLs' grades fourth, eighth, and twelfth in 2013 were constantly below the mean scores for the age groups. The gap that I explained here, as a result, yields to a higher rate of drop-out of ELLs and students from minority backgrounds (Snow \& Biancarosa, 2003).

In the same vein, the Sheltered Instruction Observation Protocol (SIOP) (2018), a commonly implemented instruction model for K-12, has repeatedly claimed the eminent need of academic language for K-12 ELLs and has practically shown the significance of addressing such a need in helping ELLs to move effectively toward their school success. SIOP workshop leader, Lydia Stack, (personal communication with Eric Dwyer, ${ }^{2}$ November 2017) reports that teachers regularly ask her what academic language is and what content and language objectives are. In other words, many teachers may feel insecure in their ability to select appropriate vocabulary on their own.

\footnotetext{
1-see Chapter 2 for a detailed description of lemma

2-the supervisor of this dissertation

3-gap refers to systematic difference between two entities including cultures or languages
} 


\section{Academic vocabulary}

Since, one’s academic prowess in English language discourse (à la Cummins, 1981, and Cook, 1989) seemingly is the crux of success with ELLs, academic vocabulary may be presumed to be an integral part of academic language, a register on its own which seemingly are the foundation of academic materials (Nation \& Kyongho, 1995; Scarcella, 2003). Academic words tend to be non-concrete words, low in frequency, carrying a semantically opaque nature that inadvertently pose a comprehension challenge for ELLs (Corson, 1997). More importantly, though, students' challenge with academic vocabulary appears to be one of input: Students tend only to encounter such language through textsnot everyday conversation or even public media. Thus, even mainstream students with good conversational skills who lack enough exposure to academic texts need the sources for improving academic vocabulary.

General academic vocabulary (known as academic vocabulary in this study) refers to the category of words that appear in a wider range of disciplines or subject matter. Townsend (2009) defined academic vocabulary as words that are a serious challenge for learners to master because they have abstract definitions. Hiebert and Lubliner (2008), however, focused on the semantic aspect of general academic vocabulary, defining it as words whose meanings regularly change across different subject matters. Textbook writers and teachers assume that ELLs notice this meaning change and know different meanings across content areas (Townsend \& Collins, 2009; Vacca \& Vacca, 1996), however, most ELLs fail to notice. In her study, Coxhead (2000, p. 218) defines academic vocabulary as 
words - e.g., estimates, overestimate, and underestimate - that uniformly occur in several academic subjects.

\section{STEM-related vocabulary}

For many outsiders - and even K-12 teachers - the difference between academic vocabulary and STEM-related words is confusing. Marzano and Pickering (2005) used domain-specific academic vocabulary to refer to STEM-related words. They believe that it is the most common kind of academic vocabulary that appears in academic settings. They suggest that direct teaching of STEM-related vocabulary is the most appropriate classroom teaching activity that a teacher could apply to make sure that students, including ELLs, have the required academic knowledge to grasp the subject matter they encounter through school textbooks (p. 1). Central tendency, mode, median, and range are examples of domain-specific academic words used in the subject matter of statistics.

However, Fisher and Frey (2008) use the term technical vocabulary to refer to these words; meanwhile, content-specific vocabulary is the term Hiebert and Lubliner (2008) use in referring to STEM-related vocabulary. In Figure 1, an academic vocabulary classification system for the present study is presented. As seen in the figure, the classification is founded on two criteria: meaning and frequency. Semantic aspects of words are applied to determine academic and STEM-related vocabulary; however, the frequency criterion is used to categorize words into three levels of high, mid, and low frequency. 
Figure 1. Academic vocabulary classification system.

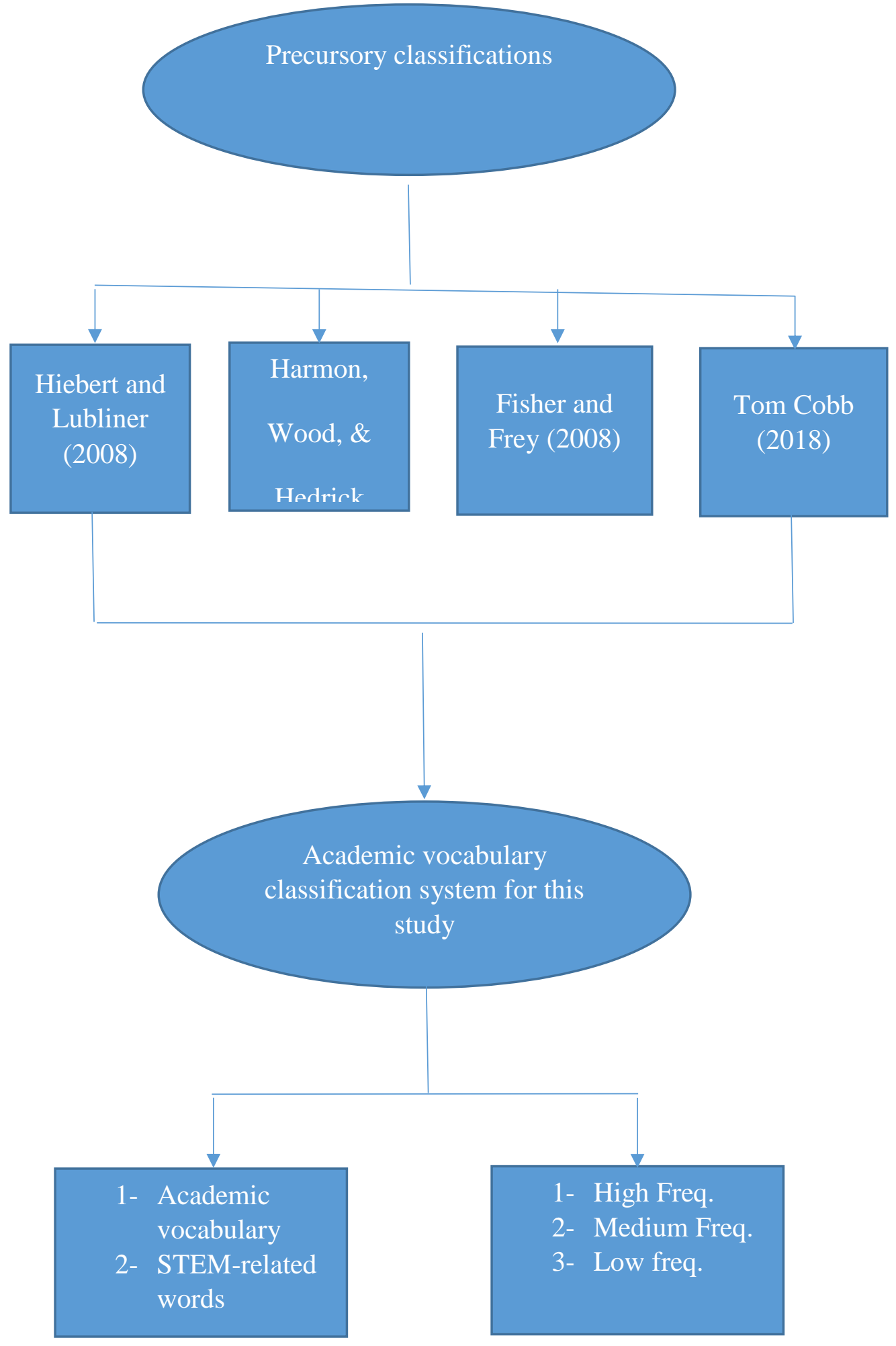




\section{Fundamental issues with respect to vocabulary teaching and learning}

Teachers are under heavy pressure to cover all the materials in textbooks during a limited amount of time over the school year (Snow \& Biancarosa, 2003; Townsend \& Collins, 2009). Therefore, teachers have many tasks to accomplish during class time rather than solely focusing on vocabulary. This pressure is compounded for ELLs in content area classes where they must learn the subject matter while simultaneously developing L2. Thus, class lesson plans can be so packed that adding in a vocabulary module almost seems inconceivable for most teachers. As vocabulary is generally considered a self-directed phenomenon (Nation, 2013; Nation \& Webb, 2011), there has been evidence that teachers sacrifice vocabulary instruction for other language related activities (Nation, 2016). As a result, learners are left to learn vocabulary and improve their mental lexicon on their own in most cases.

A further issue related to vocabulary instruction is the choice of strategy domain. Ellis (1990) and Long (1998) argue that intentional vocabulary instruction has always

yielded a better learning outcome in terms of breadth of word knowledge rather than only sticking to vocabulary developing through receptive modes of language. Incidental learning, however, is sometimes misinterpreted as unconscious way of learning new words. Therefore, Gass (1999) believes that the learner is not inactive in incidental learning, claiming that incidental learning should be the side effect of other learning activities. Along the same line, R. Ellis and Shintani (2014) investigated incidental vocabulary learning through exposing learners to input data. They argue that learners have acquired some L2 linguistic properties as a result of the indirect exposure. 
Likewise, Nation (2001) distinguishes intentional learning from that of incidental learning, arguing that intentional learning is form-focused while incidental learning is message-focused. However, N. Ellis (1999) sees the scenario from a different viewpoint, claiming that the type and amount of attention that students put on every lexical item makes a distinction between incidental and intentional learning. He further argues that, in incidental learning, students put their focal attention on meaning rather than on linguistic form in intentional learning.

In a nutshell, mainstream teachers with ELLs in their classes seemingly lack resources for assisting emergent bilinguals with vocabulary development. They also seemingly and simply may not feel they have the time to work on vocabulary as part of their content lesson planning. A key goal of this dissertation is create a tool that can potentially assist these teachers, and more importantly, their students when lexical features become impediments in students' work toward content understanding.

\section{Statement of the research problem}

Having reviewed the recent literature on vocabulary, one might wonders which vocabularies should be taught first. A further issue then would be what new academic and STEM-related word lists are designed for teaching vocabulary and reading that could work as a versatile tool for both teachers and learners? These questions point toward a focus on classified word lists and sub-lists (frequency-based, academic and STEM-related word lists) that may be matched with the common needs of K-12 students in heterogeneous classes. However, none of the existing word lists (Coxhead, 2000; De Gardner \& Davis, 2013, West, 1950) has ever focused on the K-12 context. Hopefully the current research 
study covers the gap of the existing lack of a validated word list for ELLs in the K-12 context and will advance field of vocabulary instruction.

On a pedagogical and curricular level, we should set reasonable goals at each level through which learners will be able to use an L2 efficiently. Such a goal should have a clear and meticulous plan in terms of the number of words that should be taught through a language course. However, there is not a fixed reasonable number of vocabulary words to pick up as an optimal number that should be covered during a particular time; the number of words is related to the learners' proficiency level and motivational aspects, as well (Waring \& Takaki, 2003). Research (for example, Goulden, Nation, \& Read, 1990) indicates that the vocabulary size of an educated native speaker is approximately 20,000 word families, including inflectional and derivational forms. Nation (2013) posits that, in each year of one's early years in life, native speakers add 1,000 word families to their vocabulary size. This statistical scenario would be different for ELLs with learning fewer words (Nation, 2013) at each level.

Another issue, in this regard, is that most mainstream classes are heterogeneous; in other words, students' language proficiency levels and their needs differ. Therefore, teachers will find it difficult to give a task to the whole class with the focus on a specific theme, and in some cases there is no other option but to use individualized instruction. Meanwhile, the lack of an appropriate diagnostic placement test in some schools even worsens the scenario. Also, teachers will not have access to a diagnostic test which yields an assessment of ELLs' proficiency. Or, even if they do, they may not have a sense of the degree to which their proficiency helps or harms their progress in a mainstream class. In such heterogeneous classes, teachers are then left with no option but to imagine the 
vocabulary that could be the common need of all students. As a result of teachers' decisions, language learning is not efficient and may discourage learners.

In order to improve teachers' decisions on which vocabulary should be the focus of the learning, recent lines of research (Greene \& Coxhead, 2015; Nation \& Webb, 2011; Nation, 2016) argues that pedagogically-prepared word lists can offer the most efficient way to learn English vocabulary with an optimized context for instruction in each of four $\mathrm{K}-12$ content areas through providing ELLs with the most frequent words in each area. The present dissertation examines word frequency in K-12 textbooks and how they may potentially foster effective vocabulary learning order.

\section{Research questions}

The purpose of the dissertation study is to develop new word lists as well as a mobile app alongside a website. The following research questions have been identified that will be the focus of the rest of this research study.

1) What is the frequency distribution of vocabulary in U.S.-based K-12 textbooks?

a) To what extent are

i) $\quad \mathrm{K} 1$ (1,000 most frequent words),

ii) $\mathrm{K} 2$ (second 1,000 most frequent words),

iii) academic words, and

iv) off-list words

represented in U.S.-based K-12 textbooks? 
2) What are the most commonly used lemmas in U.S.-based K-12 textbooks?

a) To what extent are

i) high-frequency,

ii) medium frequency, and

iii) low frequency lemmas, used in U.S.-based K-12 textbooks?

b) What are the new academic and STEM-related word lists in U.S.-based K12 content area textbooks?

3) What is a new mobile app alongside a website to teach vocabulary and reading to ELLs as well as mainstream students?

\section{Overview of methods}

For the purpose of this research study, I created two corpora, the Teacher's U.S. Corpus (TUSC) and the Science and Math Academic Corpus for Kids (SMACK). Each corpus yielded key vocabulary lists with lexical items ordered according to each item's frequency within each corpus. To create these corpora, I collected and analyzed a total of 122 textbooks. The recruiting, scanning and converting of textbooks had been carried out over a period of more than two years from October 2014 to March 2017. In total, this school corpus contains 10,519,639 running words and 16,344 lemmas saved in 16,315 word document pages (see Chapters 3 and 4 for information on the methods employed in the current study).

Finally, the resulting lists have been operationalized into a mobile app. Cooperating closely with a computer team over the past two years, I designed and developed a mobile 
app (Vocabulary in Reading Study - VIRS, available on iOS, Android, and Google Play) alongside a website (www.myvirs.com) that apply these new corpora and word lists to teach reading and vocabulary through a color coded system. The development of that app is described in Chapter 5 . 


\section{CHAPTER II}

\section{Conceptual framework and literature review}

\section{Introduction}

This corpus-driven study covers several topics ranging from word retrieval, text density and corpus development to word list validation. In this chapter, I review important theories that form the conceptual framework for this study. Specific topics include the following:

1) Typology of academic vocabulary,

2) Word frequency studies in the context of vocabulary instruction strategies and lexical development,

3) The necessity of new school word lists for ELLs, seminal studies on threshold level and text density,

4) Processes through which human being learns and develops vocabulary,

5) Problems with current word lists,

6) Academic word lists, and

7) A detailed definition of corpus linguistics and its application in classroom

\section{Conceptual framework for this dissertation}

The conceptual framework of this study is founded on three pillars: 1) text coverage and learning burden, 2) typology of vocabulary, and 3) a vocabulary learning model including word frequency. 


\section{Text coverage as a criterion for learning burden}

How much vocabulary does anyone need to know in order to read a text? According to Chall (1987), there is a bilateral relationship between vocabulary knowledge and successful reading. Koda (1989) examined the correlation between linguistic knowledge and reading comprehension. Results show that vocabulary knowledge has a correlation of $\mathrm{r}=.74$, which accounts for $55 \%$ of successful reading. In another study, Komori, Mikuni, and Kondo (2004) reported that $47 \%$ of reading success is accounted for by word knowledge.

Bernhardt (2005) claims that vocabulary knowledge accounts for $30 \%$ of successful comprehension. Hu and Nation (2000), however, claim that learners need to know $98 \%$ of the text to gain a reasonable comprehension. In this regard, we can relate text coverage, which is defined as the coverage percent of a text by different levels or tiers of vocabulary (Nation, 2013), to learning from meaning focused input which could be achieved by $95 \%$ text coverage (Nation, 2001). Thus, text coverage is an invaluable quantitative measurement to assess the value of a level of words as a sublist or domain-specific vocabulary (Coxhead \& Hirsh, 2007). Indeed, reading comprehension in L2 can be relatively improved by controlling vocabulary through word lists (Nation, 2016).

\section{Learning burden}

The same causal relationship has also been claimed with learning burden, as a low text coverage has a heavier learning burden (Nation, 2001). Nation (1990) argues that the amount of energy needed to learn a word is its learning burden. He thinks that L2 previously learned information and learners' L1 are the main sources that lead to learners' 
familiarity with word patterns which lightens the learning burden. If every word and every word part in the world were different, then the vocabulary learning burden would be abundantly thick. However, fortunately, words are made up of different parts, inflectional and derivational affixes, as well as a stem; thus, word knowledge involves composing the word parts. In terms of word coverage, then, many words with a low frequency of occurrence that have different parts will be reformed each time they are used. For example, the word unpleasantness is reformed from its parts (un, pleasant, and ness) where all the parts can work independently but also compose into a usable word.

\section{Learning burden of words in a second language}

There is evidence that the scenario of vocabulary learning is even worse at advanced levels of language learning. According to the ACTFL model of inverted pyramid (ACTFL Proficiency Guidelines, 2012), five proficiency levels have been delineated, namely distinguished, superior, advanced, intermediate, and novice. ACTFL model claims that progress from one proficiency level to the next requires a higher vocabulary size and sophisticated lexical network as well.

In my experience as an English language learner, which was the initial impetus leading me to this dissertation study, I remember that I was faced with more challenges when I was at my advanced level because I felt that I did not have reasonable progress in learning English. My own experience corresponds with the approach taken by ACTFL, not only as a student, but also as a language instructor. Years later, when I became an English teacher, I often heard that my students complained about their slower learning rate and heavier burden that they had in reading comprehension. To this end, indeed, some theorists 
(e.g., Nassaji, 2012; Nation, 2013) suggest that the phenomenon of heavy learning burden among second/foreign language learners is the result of a decrease in text coverage.

\section{Lemma vs. word family}

\section{Lemma}

Francis and Kucera (1982) argue that a headword is the main part of a lemma alongside only some of inflectional forms and reduced forms as well. Therefore, all the words that go under the platform of lemma are the same part of speech. Past tense, past participle, plural form, comparative and superlative are the major English inflections.

Lemma has been used in the literature on lexicon studies as the unit of counting. Thorndike \& Lorge (1944) used lemma in their study for frequency counts. Francis and Kucera (1982) developed a lemmatized list from a computerized version of Brown corpus. In the present study, comparative and superlative forms were not included in the definition

of lemma. However, different spellings are considered as the same lemma (e.g., favor and favour).

Nation (2013) believes that the learning burden of lexical items is correlated with the use of lemma and inflectional system. For example, if a learner knows the meaning of mend, the learning burden of mends then would be negligible. However, a challenge with regard to the definition of lemma and the question that which forms should go under a headword in lemma is our decision about irregular forms like best, mice, and went. There is no doubt that the learning burden of such irregular forms is heavier than that of regular verb forms such as talked, typed, cats, and easiest. However, it is still open whether irregular forms should be taken as a separate lemma or put under the same lemma group. 
A further issue with regard to the definition of lemma is the separation made between the adjective, noun and verb forms of related items such as bank, original, and display.

A further issue with regard to lemma in the lemma-based classification is the choice of headword whether it should be the base form of the entry or the most frequent one. Because lemma has fewer forms, applying lemma as the unit of counting of entries in a corpus will reduce the number of entries and consequently the final learning burden of a particular lexical item. Bauer and Nation (1993) converted the 61,805 word type-based corpus to a 37,617 lemma-base corpus showing an approximate $40 \%$ reduction.

\section{Word family}

Word families consist of a base word alongside its inflectional and closely related derivational forms. Some derivational forms in a word family such as -ness, -ly and unare the affixes that reduce the learning burden of words containing these derivational forms by being used systematically in word formation process.

A major issue with regard to the use of word family is the fact that the lexical items that should be included under a word family are not clear. In this respect, Nation (2013) claims that learners are different in terms of their current proficiency level; meaning that, second language learners' knowledge of suffixes and prefixes are different. Nation then argues that in developing a scale of word families in a corpus, we should start from easier words (words with less affixes) to more complicated ones.

In this regard, Nation (2013, p. 15) argues that the text coverage of first most frequent 1,000 lemmas (which refers to a particular form of a word family that represents the lexeme and is the main dictionary entry for a word family) is between 71-85\% in Brown 
corpus; however, this range plunges to $4-6 \%$ for the second most frequent 1,000 lemmas. Therefore, while one's vocabulary learning rate is most probably consistent at the advanced level, a huge drop in text coverage results in fewer encounters with learned words, consequently imposing a poor return on one's language learning effort, particularly with respect to vocabulary learning. While vocabulary coverage is problematic enough, one's retention rate in both intentional and incidental vocabulary learning can also be low (Ehsanzadeh, 2012; Nassaji, 2012; Nation, 2013), a phenomenon that indisputably affects students' learning motivation in general and their language learning passion in particular.

\section{Causes of vocabulary learning burden in a second language}

\section{Frequency of lemma}

Bauer and Nation (1993) used the criterion of frequency (among other criteria) to organize the patterns of word construction into different proficiency levels. They argue that the learning burden of a word is related to the knowledge of its word parts and the frequency of lemma. Therefore, one may argue that an important part of learning burden is related to the frequency of word family (Nation, 2013). Along the same line, Nagy, Anderson, Schommer, Scott, and Stallman (1989) believe that the total frequency of a word family (total frequency of all forms of a lemma including affixes and the word root) is a reliable predictor of the speed of word recognition.

\section{Word retrieval}

Word retrieval is the memory function that also causes a heavy learning burden. Baddeley (1990) argues that repeated opportunity is important to word retrieval. He 
believes that word frequency improves the quality of retrieval and thus strengthens the form-meaning link which subsequently leads to enhanced retrieval in future. With regard to learning vocabulary in an L2, word lists can be helpful tools in providing learners with the proper opportunity to encounter new words and strengthen its memory trace before it is sent deep down into long-term memory.

\section{Patterns of word appearance}

According to Schmitt (2014), depth is the quality of knowledge about how well different aspects of a word are known, while breadth of knowledge is the number of known words at a particular point. In other words, knowing a word is not unidimensional, as knowledge about a word involves syntagmatic and paradigmatic information about depth and breadth of word knowledge. As a result, another aspect of learning burden of words could be attributed to systematic patterns of word appearance.

A rule of thumb is that not all words in a language are equal in their role in comprehending the language and expressing thoughts. Word frequency research (Coxhead, 2011; D. Gardner \& Davies, 2013; Nation \& Webb, 2011) reveals that some high frequency words are more beneficial in helping learners to use an L2 effectively. Alongside, there is a small group of high frequency words that covers a big portion of everyday language use. This group should indisputably be the starting point in vocabulary instruction. While examining the Brown corpus, Nation (2013) claims that Level 1 vocabulary is the 1,000 most frequent words whose text coverage is about $72 \%$. This frequency level in Cobb's (2017) classification (Vocab profile through Lextutor website) is known as K1, which is the most frequent words (see later in this chapter for a detailed description of Cobb's 
classification). However, Level 2, the second 1,000 most frequent words that is known as K2 in Cobb's classification, covers only about $7.7 \%$ of data. Not surprisingly, the trend takes a downward movement by hitting $4.3 \%$ of text coverage for Level 3 of 1,000 most frequent words.

\section{Threshold level and the necessity of word list}

The question regarding whether there is a minimum amount of vocabulary knowledge that marks a make-or-break boundary for whether one achieves successful comprehension has always been an interesting issue for reading and vocabulary researchers. The boundary is referred to as a threshold level. Nation (2001) believes that a threshold level can be defined in either of these two ways: The first view is the strong view, and Nation argues that threshold level is an either-or (all or nothing) level; in other words, the learner will understand the text if he passes the threshold level; otherwise, he will have a vague comprehension of the text. The second view, however, takes the threshold level as a "probabilistic boundary" (p. 238) and states that if a learner passes the threshold level, then he stands a good chance for a successful comprehension.

Laufer and Sim (1985a) took the second view of threshold level and attempted to examine it with interviews and comprehension questions. Results of their research show that the threshold level is roughly 65 to $70 \%$ of text coverage. They further claim that vocabulary knowledge is the learners' primary need for successful comprehension. Laufer (1989b) later examined the needed percentage of vocabulary for successful comprehension. Results of her study show that a score of $95 \%$ and above on vocabulary will likely lead to the full comprehension of a text. However, results also show that the score of $90 \%$ on 
vocabulary did not result in successful comprehension. Moreover, Laufer attempted to determine the amount of vocabulary size which is needed to reach the score of $95 \%$ on vocabulary. She agrees with Ostyn and Godin (1985) claiming that knowledge of 4,839 words will result in a text coverage of 95 to $98 \%$ of newspaper articles in Dutch. In regard to this claim, however, there are three major problems: First, results of vocabulary studies in Dutch do not necessarily apply to English. The second issue is that the unit of measurement is not clear of what a word is: whether it's an individual word, a lemma, or a word family (Further discussion of these distinctions will be clarified in Chapter4. The final problem is the genre of the corpus as newspaper articles may not be a proper representative of academic language. Nevertheless, Laufer did not stop there: In another study (1992b), she investigated the effect of vocabulary size on reading comprehension. She looked at the issue from different angles (known/unknown word ratio and level of comprehension) and finally claimed that the 3,000 level of word family on the Nation's (2001) scale of word size $(1,000,2,000,3,000,5,000$, and 10,000 word levels) is the confirmed threshold level.

Hu and Nation (2000) believe that the coverage of $80 \%$ of the text is the threshold level for the all-or-nothing view (the ELL will be on the verge of losing the meaning of the text) and $98 \%$ for the probabilistic threshold level. They further claim that $95 \%$ is the threshold level for a minimum of adequate comprehension in which the ELL will comprehend the basics of the text. Nation then argues that the type and length of the text are main factors which affect desired text coverage (Nation, 2001). In a recent study, Schmitt, Jiang, and Grabe (2011) believe that there should be a positive relationship between reading scores and text coverage; however, they doubt the existence of a 
confirmed threshold level. Although precursory research is not clear about the existence of a numerical threshold level and the minimum number of needed vocabulary, we may wonder if the use of word lists might have a direct correlation with improving text coverage.

\section{Typologies of academic and STEM-related vocabulary}

The most recent typology of academic vocabulary divides into three categories, which have common grounds as well as some differences. Below, I give a brief description of these three typologies.

Fisher and Frey (2008) argue that words in a language should be grouped into three main categories: 1) general words which are high frequency words that people basically need for reading; 2) specialized words whose meanings are domain-specific and appear in a wide range of texts; and 3) technical words that are content-specific terms and appear only in a few content areas.

Harmon, Wood, and Hedrick (2008) divide academic vocabulary into four classifications: 1) word clusters; 2) symbolic representations; 3) academically technical terms; and 4) nontechnical terms. Their last two groups of words are similar to Fisher and Frey's (2008) technical and specialized vocabulary. The first category, word clusters, refers to clusters or phrases of words that appear only in a particular domain. Symbolic category are also symbols and special abbreviations related to a domain.

Taking a different point of view with regard to academic vocabulary, Hiebert and Lubliner (2008) classified the vocabulary system on the basis of frequency and dispersion. They define frequency as the number of times that a word appears in a given text. 
Dispersion, however, refers to how widely a word is used across different subject matters. A low dispersion value, thus, shows that a word appears within only a few content areas. Hiebert and Lubliner's (2008) classification system includes four vocabulary categories: 1) school task vocabulary, 2) general academic vocabulary, 3) content-specific vocabulary, and 4) literary vocabulary. The content-specific vocabulary in this system is close to domain-specific academic vocabulary. Hiebert and Lubliner's general academic vocabulary is also analogous to Coxhead's academic vocabulary.

Among the four classifications proposed by Hiebert and Lubliner's (2008), school task vocabulary is more related to my dissertation. This category includes the words appearing within English language arts as well as terms and expressions that classroom teachers use in their teaching. School task vocabulary also covers language that textbook writers use to describe educational concepts.

Since 1994, Tom Cobb has been developing a website—LexTutor (see Chapter 3 for a description of the website) — which gives a variety of options for lexical and textual analysis. Cobb argues that a comprehensive vocabulary profiler should divide a text into four basic word groups, including both frequency-based and content-based classification. Cobb's frequency-based classification has two categories-K1 which is 1,000 most frequent words, and K-2, the second 1,000 most frequent words. On his website's vocabulary profiler, $\mathrm{K} 1$ words are color coded as blue and K2 in green. Cobb's contentbased classification, AWL, mostly follow Coxhead's Academic Word List (AWL) and comes in yellow. In Cobb's classification system, there's also a category known as Offlist, which comes in red in the website's profiler, and presents words that are not represented in the $\mathrm{K} 1, \mathrm{~K} 2$, or AWL. 


\section{Vocabulary classification system for this study}

The line of literature on academic vocabulary divides it into two major categories: 1) domain-specific or content-specific words particularly used in a content area such as biology, geometry, physics, and algebra, and 2) general academic vocabulary which is an all-purpose category of academic words that appear across a range of academic content areas; however, their meanings may vary from one discipline to the other. For the purpose of this dissertation, I classify academic words into 1) academic vocabulary and 2) STEMrelated words.

\section{Word frequency list and vocabulary instruction}

\section{Mental lexicon and word frequency}

The mental mechanism of vocabulary learning through intentional learning (word list) and incidental learning (lexical inferencing) does not yet stand both theoretically and empirically clear. Within this line of research, as Baddeley (1998) claims, the mental status of lexical items and their retrieval is the area of neurological research that lags behind other related areas and needs more bodies of research. In this regard, an influencing factor on both incidental and intentional learning is word rehearsal. Alongside, there is a gap in literature with respect to the retrieval of learned lexical items through word lists. The line of research on lexical inferencing is fairly rich (Nassaji, 2004; Nation, 2001; Soria, 2001); however, few research studies on the effect of word lists on the retrieval of learning in the mental lexicon are available the mental dictionary represented in the mind through which individuals are able to engage in everyday processes of language use. 


\section{Word Frequency and vocabulary development}

One possible reason for a low rate of vocabulary learning might be a result of one's little exposure to language. Sometimes, L2 classroom exposure is the only chance that learners have in the process of language learning (Chen \& Truscott, 2010; Schmitt, Jiang, \& Grabe, 2011; Waring \& Takaki, 2003; Webb, 2007; Webb \& Chang, 2014). Zipf (1949) proposed a linear relationship between frequency rank and probability of its usage. He argued that more frequently used words are easier to process. Also, psycholinguistic research has repeatedly confirmed the influence of word frequency on language processing phenomena such as lexical decision tasks (Rubenstein, Garfield, \& Millikan, 1970), word naming tasks (Ellis, 1991; McLaughlin, 1990), phoneme monitoring (Nation, 2001), and lexical access (Balota \& Spieler, 1999). Gass, Behney \& Plonskey (2013) believe that the first encounter with a word may draw a learner's attention to that item. Subsequent encounters provide learners with further opportunities to determine relevant semantic and syntactic information. This further means that the salience of a word through frequency helps learners become aware of the word as an item they need. Nagy, Herman, and Anderson's (1985) study shows that native English speakers have about a 10\% chance of learning the meaning of a new word in their home language from context given a single exposure; however, second language learners likely require many exposures to a word in a context before understanding its meaning.

To explore the relationship between word frequency and retention trend, Rott (1999) argues that exposure frequency is the variable that influences the forgetting pattern of word learning. In another study on retention rate, Brown (1993) found a clear relationship between general word frequency and the words learned by learners. He used 
the Brown corpus as a norm of reference. Nation (2001) argues that word frequency directly affects learner's noticing through the salience of a word in the context. However, a key question arising from the research can lead one to propose that one should have a great deal of exposure, but only if one actually notices it before learning it. As a result, word salience and frequency seemingly affects a learner's realization that a word is significant in filling an existing gap in any person's knowledge (Schunk, 2012).

Webb (2007) examined the effect of word repetition of developing word knowledge. Participants were 121 Japanese EFL learners assigned randomly to one control group and four experimental groups. The design of the study uses one vocabulary comprehension task with 10 tests to measure different aspects of vocabulary knowledge, namely syntax, grammatical function, and association. Webb used pseudowords with 1, 3, 7, and 10 frequency of occurrences. Results of the study showed that repetition has a positive effect on at least one aspect of vocabulary knowledge. However, Webb claims that 10 encounters with a word or maybe more are required to learn all aspects of a word.

As a follow-up to Webb's (2007) study, Chen and Truscott (2010) also investigated the effects of repeated encounters with target words on the development of seven aspects of word knowledge. They used seven measures in their study, immediately after the treatment and again after a two-week delay. The design of the study was a follow-up of Webb's (2007) study but emphasized ecological validity over control and presenting genuine words in meaningful reading passages. Results for repetition largely supported Webb's findings while suggesting that the nature of his study led to an overestimation of learning. Chen and Truscott (2010) also argued that in the immediate posttest, repetition 
affected productive vocabulary knowledge somewhat more than receptive one, but this relation reversed on the delayed posttest.

Literature on optimal word frequency (Laufer, 2003; Nation, 2001; Nation \& Webb, 2011) argues that a range of 8 to 12 exposures of new words are needed for a learner to start using new lexical items in L2. Other studies (Kweon \& Kim, 2008; Waring \& Takaki, 2003) also reported that word frequencies greater than 20 are needed for incidental learning. In their study, Waring and Takaki used a multiple-choice, immediate posttest measure and found that of 25 new words available for learning in a graded reader, 11 words were learned, indicating a gain of $44 \%$. However, some studies have shown that vocabulary learning occurs from as few as five exposures (Webb, Newton, \& Chang, 2013) and even two exposures (Bisson, van Heuven, Conklin, \& Tunney, 2015).

With regard to word attrition trends in vocabulary learning, Ellis (2002) argues that incidental learning from extensive reading can sometimes be connected to the short-term memory processes, and the learner may be unable to recognize or use the word on future occasions. However, Ellis also suggests that higher frequency words in the incidental learning will create connections between short-term memory (STM) and long-term memory (LTM) which would diminish the word attrition trend. The rationale behind this is that the first few encounters serve as an attention raiser-that is, noticing. The subsequent encounters direct the learner's attention toward the word, and thus lead to the acquisition of the word meaning. Ellis argues that multiple rehearsals in unique situations will connect STM with LTM. He claims that if constructing word meaning through lexical inferencing is connected to STM, the reader cannot recognize the word and would not be able to retrieve it in future. 
Schunk (2012) argues that rehearsal is one of the situated factors that has a direct correlation with word learning. Also, Laufer (2003) believes that rehearsal should occur at least eight to 12 times in order for a learner to be able to retrieve an item. She thinks that the rehearsals should be in different situations through different learning activities. In a similar study, Horst (2005) claims that the reason behind this may be because the first few rehearsals attract the attention of the reader and further rehearsals give the chance to the reader to construct the meaning on the basis of the available clues that he/she has of the situation, the co-text of the reading passage. The further rehearsals of the word in different situations allow the reader to confirm or reject earlier inferences.

\section{A model for learning vocabulary in another language}

There are a number of studies attempting to formulate a model for the role of frequency categories in vocabulary learning and retrieval process (Coxhead, 2000; Crossley, Cobb, \& McNamara, 2013; D. Gardner \& Davies, 2013; De Bot, Paribakht, \& Wesche, 1997; Nation \& Webb, 2011; Schunk, 2012). In the present study, I focus on word frequency and the role of academic and STEM-related lists that provide learners with a content choice through corpus. The learning context in the model I designed for the purpose of the research study is reading in which K-12 students, including ELLs, receive input and can utilize contextual and situated clues to construct meaning. My perception is that the process of the development of lexicon through reading is a holistic process starting with inferring the meaning of unknown words. Successful inferencing seemingly leads to the comprehension of the reading text (in our case, K-12 textbooks). When students achieve comprehension and are able to synthesize and construct the whole meaning of the reading 
passage, this then means that they learned the unknown lexicon passively. It is here is where word frequency comes to play. Learning the new lexical items and transforming them into LTM occur simultaneously (Schunk, 2012). This does not necessarily guarantee that comprehension leads to the retrieval of lexicon for future use; thus, learners should encounter the word on an organized and regular basis. As is illustrated in the diagram below, vocabulary learning and its retrieval for future use are two distinct constructs (Schunk, 2012).

A number of factors seem to affect the retrieval of lexical items through both intentional and incidental learning, among which inferencing, depth of processing in the mental lexicon, and word frequency outstand the others. How word frequency affects the learning process is presented in the model in Figure 2.

\section{Encoding and internal specification}

Analyzing the new information in working memory (WM) and breaking it down in chunks to be stored in long term memory (LTM) is technically known as encoding (Schunk, 2012). Matlin (2009) believes that encoding is initially accomplished by giving a code to the received information and then that code is linked to the existing codes in the LTM. Meaningful encoding improves the retention rate of stored information in LTM and learning occurs even with meaningless encoding. Although teachers attempt to present words in meaningful ways and most students also attend to teachers' explanation (Greene \& Coxhead, 2015), there are things that still go unlearned in class-for example, ELLs' poor use of academic words in their writing samples). With this regard, Schunk (2012) 
argues that organization and elaboration are two main factors that affect encoding and internal specification.

Organization: Organization, as shown in Figure 1, has a direct effect on encoding and internal specification through depth of word processing (Schunk, 2012). Research (Anderson, 1990; Miller, 1956) showed that the more materials are organized, the easier they will be retained. When smaller bits of a whole information are linked together systematically and are also linked to stored information in LTM, remembering of one chunk stimulates other related items and thus makes it easier to recall the whole information. Using a hierarchy of information in which chunks are integrated is one way to organize the information. 
Figure 2. A model for learning vocabulary in another language.

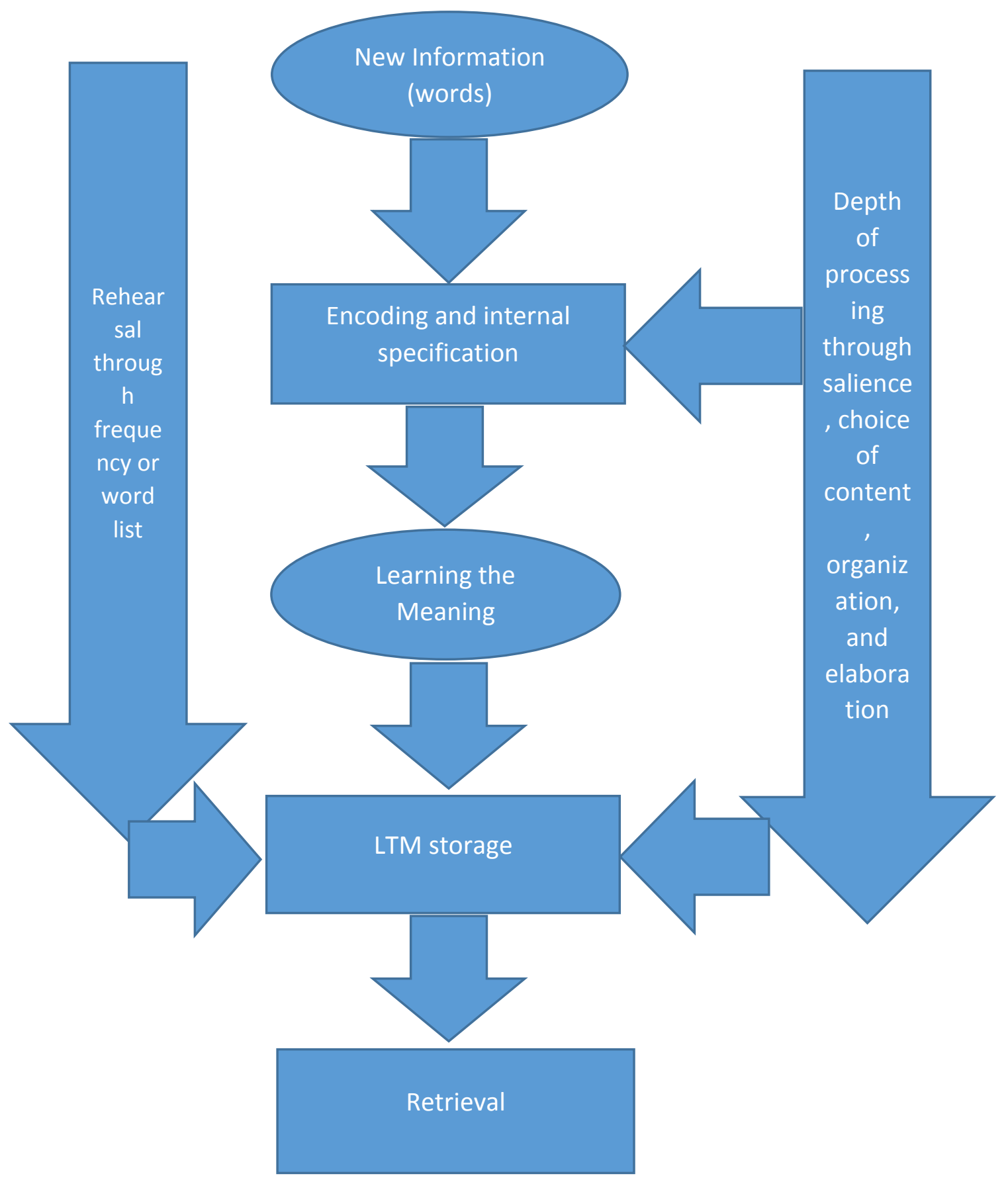


Elaboration: Schunk (2012) believes that elaboration is the procedure that enhances encoding processes in WM through linking a new item to the conceptually related schemata in LTM. Today, neurologists believe that elaboration improves word retrieval through linking a new word to the network of active vocabulary knowledge. In this regard, Anderson (1990) argues that sometimes people forget the message but elaboration helps to recall the key content. Elaboration is important because a problem that many students, including English language learners, have in developing their word knowledge is that they cannot appropriately elaborate the new vocabulary items because it is not easy to link every new vocabulary to the network of lexical repertoire Anderson, 1990).

\section{Depth of processing theory}

Depth of processing theory, also known as the Levels Theory, defines human memory on the basis of the nature or the type of the required processes through which brain receives information rather than the place of the information (Craik \& Tulving, 1975; Lockhart, Craik, \& Jacoby, 1976). Lockhart et al (1976) argued that depth of processing in learning vocabulary will occur better if students understand materials and process them at a deeper level. They further claimed that drawing on students' schemata will enhance learners' retrieval. According to depth of processing theory, one significant method in improving retrieval is through providing further processing at the same level. In this regard, Nelson (1977) provided his students with either one or two additional rehearsal for each word. He argued that two repetitions produced much better rehearsal.

Anderson (1990) in his activation model of memory rejected two separate structures and instead argued for a holistic model of memory with two activation states, namely as 
active and inactive. At every point of time, information may be processed at the active or inactive states of mind. According to Anderson's model, frequently encountering new words keeps the memory of the word traceable in the active state of the memory which consequently leads to a higher chance of learning. However, by shifting the direct attention, the memory activation state will then change.

\section{Rehearsal theory}

Spaced rehearsal strengthens the trace of memory. Schunk (2012) argued that rehearsal is of two types: maintenance rehearsal and elaborative rehearsal. Maintenance rehearsal is reviewing the new material repeatedly which could be accomplished through putting an exponential space between each rehearsal. In elaborative rehearsal, students relate the new information to what they already know and stored it in their LTM. A mnemonics approach to developing vocabulary (Ellis, 1994) is a form of elaborative rehearsal. For example, if a student is studying U.S. history, and for a number of times "DDay" is repeated that "D-Day" was June 6, 1944, this is maintenance rehearsal. However, if he relates it to the information that he knows (e.g., Roosevelt was selected for the fourth time in 1944), this will be elaborative rehearsal. When it comes to word learning, this process is more difficult because we have a huge number of abstract words whose linking to schemata needs students' effort and teachers' creativity, as well. 


\section{Corpus linguistics}

\section{Corpus-based research}

Corpus-based research has been shown to provide us with tools for explaining variation and use of linguistic patterns (Tognini-Bonelli, 2001). This means that the goal here is to investigate the systematic patterns that governs the linguistic features. Biber (2012) argues that corpus-based research has systematically illustrated that any language variant is distributed with a different frequency across different registers. The use of computer programs has caused corpus-based research to be highly reliable and with an acceptable validity (McEnery \& Hardie, 2013).

Corpus-based study is a top-down approach in which grammatical features are described. The term corpus-based is used to refer to a methodology that avails itself of the corpus mainly to expound, test, or exemplify theories and descriptions that were formulated before large corpora became available to inform language study. In this regard, Biber (2012) argues that corpus-based research is criticized for ignoring the evidence that fails to fit through the confirmed theories while mostly attaching to existing pre-corpus theories.

We could say, therefore, that corpus-based linguists adopt a "confident" stand with

respect to the relationship between theory and data in that they bring with them models of language and descriptions which they believe to be fundamentally adequate, perceiving and analyzing the corpus through these categories and sifting the data accordingly. The corpus is considered useful because, on occasions, it indicates where minor corrections and adjustments can be made to the model adopted, and it can also be valuable as a source of quantitative evidence (Hunston, 2006). In this case, however, corpus evidence is brought in as an extra bonus rather than as a determining factor with respect to the analysis, which 
is still carried out according to pre-existing categories; although it is used to refine such categories, it is never really in a position to challenge them as there is no claim made that they arise directly from the data.

\section{Corpus-driven research}

Corpus-driven analysis uses the unique features of a text to determine linguistic categories. This means that corpus-driven research considers corpus evidence (TogniniBonelli, 2001). Therefore, all linguistic categories are systematically derived from frequency distributions. Unlike corpus-based research, corpus-driven analysis only deals with words and syntax, and grammar has no place in this approach so that all inflectional and derivational morphemes of a single lemma are treated differently. This, however, does

not mean that all cases of corpus-driven studies are the same. They are different in one of these three ways: whether they analyze lemma or word family, the extent to which they use linguistic constructs, and the role of frequency in analyzing the data (Biber, 2012).

A corpus-driven approach aims to derive linguistic categories systematically from recurrent patterns and frequency distributions emerging from language in context (TogniniBonelli, 2001). This approach is similar to a holistic approach to language in that the cumulative effect of repeated instances is taken to reflect the semiotic system; the text is seen as an integral part of its verbal context and, ultimately, no discontinuity is assumed between this and the wider context of learning situation, and the even wider context of culture.

Using corpus evidence as the main source of analysis makes the corpus-driven research a bottom-up approach in which the researcher starts the analysis with having no 
assumption in mind. As a result, a major criticism to corpus-driven study is that it wholly adheres to the obtained data from the corpus, which in some cases is not necessarily a pure display of real language (Leech, 1991).

\section{Current word lists}

In curriculum design and material development, making word lists to provide new tools for teaching different genres of vocabulary has a long history. Early lists (nonfrequency lists) did not implement a frequency calculation. The word selection criterion then was determined by the word's significance in meaning conveyance. The Basic English word list (Ogden, 1936), for example, is one such attempt that focused on the words learners need to produce a wide range of linguistic output. In the Ogden's list, however, most words are high-frequency words (Nation, 2016).

The latest version of such non-frequency based lists is Carter's (1987) core vocabulary. His point of view is that determining core vocabulary with only a linguistic focus is insufficient. Carter believes that making pedagogical word lists needs a clear decision over which words should be taught first. He further claims that a rigorous selection of core vocabulary in making word list will lead to the grading of reading materials and lexical richness.

In the second category of word lists, frequency-based lists which emerged as a result of a collected corpus, the best known is West's (1953) General Service List (GSL) that presents levels of what he claimed were the 2,000 most frequent academic words in English. The GSL had been used extensively in ESL and ESP classes. West also used other

criteria beyond the frequency in developing his list as he was busy with developing graded 
readers. Ultimately, West included words that were not high frequency words but turned out to be words that are essential in producing basic meaning.

In an attempt to develop a content area corpus, Salager (1983) created a corpus of medical English with 100,000 running words. He divided the corpus into three subcorpora: basic English, fundamental medical words, and technical words. In developing his word list, Salager compared her medical corpus with another diverse corpus to analyze the role of semi-technical vocabulary in academic discourse.

In the hope of making a stronger word list with a higher text coverage, Xue and Nation (1984) combined four word lists developed by Campion and Elley (1971), Praninskas (1972), Lynn (1973), and Ghadessy (1979), thereby composing the University Word List (UWL). In developing the UWL, Xue and Nation for the first time used two computer programs, Vocabulary Profile and Range Program, developed by Nation and his colleagues. The list has 836 word families and had been widely welcomed and used for more than 15 years in academic settings.

Similarly, Farrel (1990), in his study, focused on semi-technical words and made a list that contains 467 family types and 160,000 running words. Farrel defines semitechnical words as those that are context independent and are beyond the words found in basic English courses. He attempted to exclude all general words from the list.

However, Ward (1999) criticized the idea of dividing a corpus into three subcategories of general, technical, and academic word levels. In other words, his notion was that dividing was not necessary-only context. Ward created an engineering corpus (Ward, 2009) from which he derived a list of frequent words. He then compared his list with a collection of engineering texts. Results of his study show that a list of 2,000 word 
families covering $95 \%$ of engineering texts. Ward claims that the coverage of his list is more effective than that of GSL.

\section{Academic word lists}

All the word lists developed after the GSL have never gained the reputation of Coxhead's (2000) Academic Word List (AWL), a seminal academic word list widely used in ESP programs. Through the process of developing the corpus, Coxhead applied four main criteria:

a) representation (a corpus must be a collection of texts that are representative of a variety of genres),

b) organization (words in a corpus should be selected evenly across subject areas),

c) size (word families with at least 100 occurrences were included in the corpus), and

d) word selection (the word family as the word unit for the corpus).

Coxhead collected 414 texts with approximately 3.5 million running words. She divided the corpus into four main areas of arts, law, science, and commerce. Each area contained roughly the same number of running words. In developing the academic word list, Coxhead used the Range program (Heatley \& Nation, 1996) to rank order the words of the corpus alphabetically. The Range program is software that accepts 32 different files and produces a list of individual words with their frequency. Coxhead then applied three criteria for choosing the words of the AWL. According to the first criterion, specialized occurrence, word families should not be any of the members of the first 2,000 words of the West's 
(1953) GSL. Range was Coxhead's second criterion, which placed a minimum of ten occurrences in each of the four areas for a word to be included in the word list. Through the third criterion, a minimum, Coxhead put a minimum of 100 occurrences in the Academic Corpus for all the members of a word family to be considered as a candidate for the AWL. After running the RANGE program (Nation, 2001) and comparing the results with West's GSL, 570 word families met these three criteria for inclusion in the AWL.

The AWL text coverage accounts for $10.0 \%$ of the total tokens of the Academic Corpus. Among the four subcorpora, commerce has the highest AWL coverage with 12.0\%. This amount is approximately the same for law and arts subcorpora with percentages of 9.4 and 9.3, respectively. Science, however, has the lowest AWL's coverage (9.1), revealing that science seems to be easier than other areas, in other words, the more AWL abstraction in a text, the more difficult the text is considered.

In order to validate the AWL, Coxhead further developed another corpus of fiction texts containing more than 3.5 million running words. In this corpus, the AWL covers only $1.4 \%$ of the total tokens, demonstrating that most of the word families in the AWL carry concepts that are mainly associated with academic genres.

Over the past decade, Coxhead's AWL has been used widely in efforts to reduce the gap between high and low second or foreign language learners in terms of academic word knowledge. However, Gardner and Davies (2013) argue that Coxhead's list suffers from two main problems. The first issue concerns the use of word family as the base for making the corpus and counting the items of the AWL. Gardner and Davies believe that all the members of a word family do not share the same meaning and this would be more intense across different academic disciplines. They posit that this problem is caused 
because word families in the list do not have parts of speech. Instead, they suggest that an academic word list should be arranged by lemmas (words which are from the same parts of speech and are related together through different grammatical inflections). Ultiamtely, they claim that a new academic core vocabulary is needed.

A further issue with respect to the validity of the AWL is its relationship to the GSL (West, 1953), as Coxhead extracted the words that were beyond the GSL's first 2,000 highfrequency word level. Gardner and Davies, however, argue that the GSL is old and the corpus from which West made his list is from early 1900s. Therefore, Gardner and Davies believe that the AWL should not be attached to the GSL as the AWL is a category of the high-frequency words of recent English, while the GSL is not a meticulous reflection of the high-frequency words.

They further argue that a validated list should be drawn from a large and representative corpus that covers significant academic disciplines to be able to distinguish high-frequency words from academic technical words as well as from academic core vocabulary. Materials chosen from contemporary English are the characteristics that Gardner and Davies emphasize, proposing that texts and materials from 20 to 100 years ago would not make a valid word list. Moreover, they think that the best way to determine the validity of a word list is through comparing it to both academic and non-academic corpora. In doing so, Coxhead tested the AWL against a corpus of fiction texts, while Gardner and Davies also tested their list against a subcorpus of non-academic texts from the Corpus of Contemporary American English (COCA) which is a public domain and free corpus of English. Davis (2012) argues that the COCA is the only balanced and representative corpus of contemporary American English widely used by researchers. 
COCA now has about 560 million words and Davis claims that 20 million words have been added to COCA annually since 1990 when it had first been appeared. COCA is also related to other existing corpora of English and contains different sections for fiction, magazines, newspapers, and spoken and academic texts. In developing their academic vocabulary list (AVL), Gardner and Davies (2013) used a corpus of 120 million words, taken from the academic subsection of the COCA. The AVL corpus is approximately 35 times larger than that of the AWL. Furthermore, the AVL corpus is $20 \%$ larger than the British National Corpus (BNC) (BNC has 100 million words and includes samples of both written and spoken language which is designed to represent British English) in terms of academic portion. Like the AWL, a limitation to the AVL is that there is no spoken sample of academic language.

In addition, Gardner and Davies (2013) excluded all high-frequency words and technical academic words. In making their list, they included the lemmas whose frequency were at least $50 \%$ higher in academic corpus compared to that of non-academic corpus (ratio criterion). In the next step, they collected the word lemmas that occurred in at least $20 \%$ of the expected frequency in seven domains. Gardner and Davies then chose lemmas with a dispersion of at least 0.80 . The final measure that they used in developing the list was the exclusion of all the domain specific words from the final list.

\section{Sight word lists}

Sight words are the highest frequency vocabularies. These are common words that no one needs focused attention to recognize and decode them. In school materials and especially for young children, sight vocabulary usually accounts for $75 \%$ of the written 
texts so that these are the words that should be the focus of early vocabulary instruction (Flesch, 1955).

There are a few sight word lists, among which Dolch's sight words (Dolch, 1936) list was developed in 1930s and '40s by examining the words that most frequently appeared in the books written for children. Dolch's word list contains 220 basic words alongside 95 high frequency nouns. Dolch's sight word list is the most famous one of such lists. However, his list is dated. No current sight word lists are recent or methodologically validated. To the best of my knowledge, no sight word list has ever been developed from recent K-12 school textbooks.

\section{Problems of current word lists}

A major problem of all the word lists, except than the one developed by Gardner and Davies (2013), is the fact that they use small size corpora, smaller than 5 million entries. Therefore, they lack the representative criterion. As a result of this small size, none of them, hence, is seemingly derived from a balanced corpus. A further issue is that texts from which these lists are made are relatively old and can not meet the needs of $21^{\text {st }}$ century language learners. Therefore, this criterion might disqualify Nation and Hwang's (1995) claim that GSL still works reasonably well. Seemingly, then, as a result of technological changes in the past two decades, no replacement to GSL and other word lists can result in a validated word list with a high text coverage and the scenario is much worse when it comes to K-12 settings.

The third problem concerns the way that the corpus materials were collected and analyzed. The scrutiny of most of these corpora had been affected because they were 
compiled by hand because of limited computer programs at the time. For example, Campion and Elley (1971) and Praninskas (1972) used basic principles of frequency in developing their lists. Meanwhile, Lynn (1973) and Ghadessy (1979) only collected words for which learners annotated in their first language in the academic texts. Another major problem of all the existing word lists is the lack of textbooks from which these corpora have been taken.

Over the past decade, learner autonomy (Gardner \& Miller, 1996; Holec, 1981) has attracted a good deal of attention as both a means and a goal in education. While learner autonomy in language learning has gained different forms, self-directed vocabulary learning through word lists has become a key in improving the lexical knowledge of children with limited proficiency as well as adults in ESP programs.

Research on vocabulary assessment (Read 1998; Schmitt, Schmitt, \& Claphan, 2001) indicates that high frequency words are seemingly learned first. Therefore, a word list based on frequency order can be valuable in determining the amount of vocabulary needed for an acceptable proficiency at a particular learning stage as well as mapping the best learning order.

\section{Teaching/learning implications of using word lists}

\section{Principle of least effort in language learning}

There is a general law in every language (Nation, 2013) that some words appear in spoken language and written texts more frequently than other. Initial data analysis for the present dissertation, alongside other corpus-driven studies (Coxhead, 2000; Nation \& Webb, 2011), reveal that a small percentage of words are high frequency and have a wide 
range of usage covering a larger part of written texts. Still, there is a large number of low frequency words whose text coverage is relatively small. This is also in alignment with the "principle of least effort" (Zipf, 1949, p. 5) which states that a constant figure will be gained if the rank order of an item is multiplied by its frequency. Thus, if we follow Zipf's general cost/benefit law which claims that the effort of learning high frequency words first will repay better compared to that of learning low frequency words, it stands reasonable that teaching high frequency words first will improve learners' reading proficiency and their general language comprehension. High frequency words are encountered more often and learning these words first may be more beneficial to learners.

\section{Significance of using word lists in language learning}

As a result, it is crucial for curriculum developers and textbook writers to know which words and core academic vocabularies should be given first at a particular proficiency level. To this end, and given the significance of teaching high frequency and core academic words through word lists, I review the significance of word list research here.

Nation and Web (2011) believe that word lists have clear benefits for learners, teachers, and textbook writers. They list seven values of word lists and argue that these values are not limited to only these seven:

1. Designing courses: Word lists provide us with the most valid source of sequencing words at different levels of language learning; therefore, learners will receive the most suitable content in accordance to their age and proficiency level. 
2. Setting learning goals: Each sub-list has a certain number of words and can be set as a goal for learners to achieve at the end of a stage. Nation (2006) attempted to find how many word lists with 1,000 words are needed to reach the goal of $98 \%$ coverage of a text.

3. Guiding the creation of simplified texts: Graded readers have been created and have become a form of simplified texts, which may be valuable sources for improving second language learner' reading proficiency (Woodinsky \& Nation, 1998). This further emphasizes the role of word lists in developing materials within a controlled vocabulary.

4. Analyzing the vocabulary in texts: Adjusting the vocabulary load of texts to the learners' proficiency level can be accomplished through frequency word lists. There are some websites (Cobb, 2017; Davies, 2012) that are used to analyze the text density in terms of word tiers.

5. Creating specialized word lists: Word lists are highly valuable in designing English for Specific Purposes (ESP) programs such as Business English, Medical English, Hotel English, Plumber English, English for Scuba Diving, and so forth.

6. Analysis of lexical richness: The learner corpus or texts produced by learners can be used as an educational tool through which we can gain a better understanding of learners' lexical repertoire (Granger \& Rayson, 1998). In doing so, word lists are used to analyze the learner corpus and will help us to know the amount of vocabulary the learners actively or passively use at a particular proficiency level. 
7. Guiding the construction of vocabulary tests: The Vocabulary Levels Test and the Vocabulary Size Test (Nation, 2001) are two procedures examining breadth of vocabulary knowledge that are constructed based on frequency lists.

Beyond these seven values listed by Nation and Webb (2011), the line of research on breadth of word knowledge (Beglar, 2010; Nation, 2001; Read, 1998) reports that there is a positive correlation between the frequency of a word and the possibility of knowing that word. This further substantiates the significance of frequency-based word lists in improving the retention rate of incidental vocabulary acquisition. In this regard, Ehsanzadeh (2012) found that words with a minimum text exposure of 20 stand a good chance (13.4\%) of being acquired incidentally through reading. Results of his study show that a word list of sight vocabulary can exponentially improve the text coverage and reading comprehension as well.

\section{Significance and purpose of this dissertation}

The line of research on reading comprehension (Gass, Behney, \& Plonskey, 2013; Nagy \& Townsend, 2012; Webb \& Chang 2012; Webb \& Chang, 2014) argues that academic vocabulary knowledge is the prerequisite ability for gaining an adequate understanding from academic texts. It seems that digesting academic texts has a direct correlation with academic achievement and future prosperity. This further emphasizes the key role of academic and STEM-related vocabulary knowledge in students' future career. It also argues that the significant role of this knowledge has been well credited in primary 
school (Chall, 1996; Biemiller, 2010), middle school (Townsend \& Collins, 2009), and high school (Vacca \& Vacca, 1996).

In the meantime, educators and school experts have acknowledged the need for developing new materials and effective strategies aimed at improving ELLs' academic and STEM-related lexicon (Beck, McKeown \& Kucan, 2002; Biemiller, 2010; Carter, 2012; Gardner, 2013). Materials focusing on academic vocabulary instruction, including academic word lists which are specifically designed for K-12 are highly needed (Gardner \& Davies, 2013; Graves, 2006). It seems that little evidence of the breadth of academic vocabulary learning has been dealt with in K-12. An outgrowth of this study, then, may be the extent to which academic vocabulary shows up throughout the K-12 world. 


\section{CHAPTER III}

\section{Developing the corpora: TUSC \& SMACK}

\section{Introduction}

As I explained in Chapter 2, using word lists have several benefits for ELLs in school contexts. In order to make a validated word list, it is essential to base the lexical data on a large representative corpus. Meanwhile, word lists provide data that can help vocabulary test developers in making new tests. Vocabulary tests that assess biased lexical data will lead to distorted results. Also, word lists can be beneficial in assessing the difficulty level of a text for ELLs. In the first step, therefore, it is important to create a corpus which is representative of the target domain and is derived from the learning purpose of K-12 ELLs. This chapter is built on these three pillars:

a) empirical examining language used in K-12 textbooks,

b) following the typology of words in creating the corpora with different purposes, and

c) using computer programs and software in compiling the corpora.

In Chapter 3, I review some main features in developing a corpus. Then, in Part 1, I explain the procedures for collecting textbooks, scanning and converting them into readable files for computer programs. LexTutor and AntConc software were used in the analysis of the lexical data. In Part 2 of Chapter 3, I delineate the method of developing the K-12 corpora: TUSC and SMACK. In the result section, I examine the statistical information of the corpora. I also report the coverage of STEM-related and academic words in each corpus. 


\section{Research questions}

As a review, I offer this reminder of the research questions:

1) What is the frequency distribution of vocabulary in U.S.-based K-12 textbooks?

a) To what extent are

i) K1 (1,000 most frequent words),

ii) $\mathrm{K} 2$ (second 1,000 most frequent words),

iii) academic words, and

iv) off-list words

represented in U.S.-based K-12 textbooks?

2) What are the most commonly used lemmas in U.S.-based K-12 textbooks?

a) To what extent are

(i) high-frequency,

(ii) medium frequency, and

(iii)low frequency lemmas,

used in U.S.-based K-12 textbooks?

b) What are the new academic and STEM-related word lists in U.S.-based K-12 content area textbooks?

3) What is a new mobile app alongside a website to teach vocabulary and reading to ELLs as well as mainstream students? 


\section{TUSC and SMACK}

For the purpose of answering the first three questions, I compiled two K-12 corpora, The Teacher's U.S. Corpus (TUSC) and the Science and Math Academic Corpus for Kids SMACK (see later this chapter for a detailed description of the corpora).

\section{Procedure for developing the corpora - TUSC and SMACK}

Conrad (1996) believes that the goals of a research study should be reflected in the design of the corpus. The primary goal of the present dissertation is to make an academic core vocabulary list and a list of STEM-related words. In the next step, I focus on what is hopefully the most appropriate path through which such lists should be incorporated into technology to teach reading to ELLs. To this end, I adopted a corpus-driven approach in designing and developing the corpora with a focus on word lemma rather than inflectional and derivational variants of word families (see Chapter 2 for a detailed reason for choosing lemma as the unit of analysis).

Textbooks and materials were recruited from two sources, representing the K-12 textbooks of States of Florida and California. The four most populated states in the U.S., California, Texas, New York, and Florida, lead textbook decisions, and I initially hoped to compile a K-12 corpus representing all the four states. As a result of many limitations in recruiting and converting the textbooks, I created the corpus using the textbooks from California and Florida.

In my first step, I collected as many K-12 textbooks as possible from State of Florida, covering the subject domains of language arts, social studies, science, and math from all grades from kindergarten to twelfth grade. However, the grades are not equally 
represented in textbooks. Then, I scanned the textbooks by using scanner machines and converted them into word document files with the ADOBE Reader Professional software. The recruiting, scanning and converting of Florida State textbooks were carried out over a period of more than two years from October 2014 to December 2016.

In the next step, I used the online library of CK-12 Foundation (www.ck12.com) to download the math and science textbooks of State of California. The content of the library is a free public domain and available for public use. The CK-12 Foundation was established in 2007 in California and is a non-profit organization whose mission is to facilitate the access to STEM education in the United States. During summer and fall of 2016, I converted the California State textbooks. After a meticulous analysis of a total of 122 textbooks from states of California and Florida, in the first stage of data coding, I filed the data into groups using subject matter and state. Then I ordered the total number of words $(10,519,639)$ according to the frequency of lemmas alongside their inflectional and derivational forms. Through the remainder of this chapter, I will explain in details the procedures of developing TUSC and SMACK.

Table 1. Number of books and running words of Florida and California textbooks.

\begin{tabular}{lll} 
States/ corpus & No. of books & No. of running words \\
\hline Florida & 49 & $3,298,508$ \\
California & 73 & $7,272,551$ \\
TUSC & 49 & $3,247,088$ \\
SMACK & 102 & $8,522,864$ \\
& & $10,571,059$ (total words)
\end{tabular}




\section{Main issues in developing a corpus}

Authenticity. It is clear that the linguistic materials is the starting point in the field of corpus research. Johansson (1995) argues that corpus linguistics deals with authentic language or language in use. Therefore, the need for updating the educational corpora and word lists for the purpose of authentication is a significant task (Biber, 194, Gardner \& Davies, 2013).

Nation (2016) argues that there are two sources of authentic data that can be used for corpus research: written materials such as journal articles, newspapers, and textbooks. In this study, I use K-12 textbooks as the authentic materials that ELLs use in schools. Research (Nation \& Webb, 2011) claims that K-12 textbooks is the main source through which ELLs receive academic words. Learner corpus (a corpus developed from learners' language) is another source that is used in corpus-based research and its focus is mainly on discovering the structural problems in learners' language.

Sampling. Biber (1994) claims that the most important issue in designing a corpus is defining the population for which the corpus is aimed to develop. In this way, the corpus will be also representative. Therefore, issues like the type of textbooks, the number of books at each level, the number of collected words are all sampling issues about which a corpus linguist should make a very clear decision before starting data collection.

\section{Academic and STEM-related corpora}

Sinclair (2005) argues that compiling a corpus founded on a principled foundation is the key idea behind the creation of any kind of corpus. To Sinclair, four core design principles of a corpus are 1) concepts that the corpus represents, 2) representativeness, 
3) communicative purpose of the content, and 4) controlling the subject matter of the corpus by comparing it with other corpora. In addition, Flowerdew (2004) suggests a set of parameters that could be used to identify and classify specialized corpora:

1) Size of the corpus (a range of 1-5 million words are required)

2) A particular variety of English

3) Specialized purpose for the compilation of the corpus

4) Type of the text and topic of the subject matter

5) Context of the corpus (setting and communicative purpose).

As a result, Sinclair (2005) divides the continuum of corpus into general and specialized corpora. A general corpus is compiled to investigate language use and reveals the holistic patterns of language. The National British Corpus (NBC) and the Corpus of Contemporary American English (COCA) are examples of general corpora. A specialized corpus, however, is designed to describe a particular register or variety of language (Sinclair, 2001). A major difference with regard to design characteristics between general and specialized corpora is that specialized corpora are designed for early human intervention (EHI) research. However, general ones are compiled for delayed human intervention (DHI) studies (Sinclair, 2001). In the case of EHI, the compiler has a particular goal in mind and then creates a corpus accordingly, whereas in DHI the researcher does not have a particular goal in mind and patterns of the whole language is intended.

A specialized corpus (academic and STEM-related corpora in the case of the present dissertation) focuses on technical words which belongs to a special area of knowledge featured in the related word lists (Sinclair, 2005). Beyond the genre of the corpus, the proportion of subcorpora and the type of texts should also represent the kind of 
language that ELLs meet in K-12 context. On average, the amount of reading for mainstream students varies but is under 100,000 tokens a year and about 2,000 tokens per day (Cunningham, 2005). Token is the number of words plus their repetitions. Therefore, this accounts for a small part of the language that they encounter and particularly the academic language that they receive (Nation, 2016). As a result, a corpus designed for ELLs should fill this gap and meet their school needs in K-12 contexts.

Table 2 represents seminal academic and STEM-related corpora since 2000. Table 1 also documents the text distribution with regard to Coxhead's AWL across the seminal academic and STEM-related corpora developed since 2000. Among the 15 corpora, the corpora number 12,14, and 15 (Coxhead, Stevens, \& Tinkle, 2010; Dwyer \& Ehsanzadeh, 2017; Ehsanzadeh \& Dwyer, 2017) have been derived from K-12 textbooks. As shown in the table, the AWL, on average, covers $10 \%$ of most the written academic corpora. However, this number is 7.05 for Coxhead, Stevens, and Tinkle's (2010) corpus of secondary school science textbooks. Surprisingly enough, the AWL's coverage is 6.05 in Ehsanzadeh and Dwyer's (2017) STEM-related corpus of California and Florida K-12 textbooks. This coverage again plunges down to 5.25 in Dwyer and Ehsanzadeh's (2017) corpus of Florida K-12 textbooks, showing that there is a clear gap of about 5\% in regard to academic vocabulary coverage between $\mathrm{K}-12$ textbooks and texts written for adults at college level.

Both corpora are written and there is no sample of spoken language data in regard to the K-12 context. As a result, the domain of research questions is limited to the word knowledge that ELLs need for reading comprehension, in other words, written receptive 
vocabulary knowledge. All the research questions of this dissertation study are answered in chapters 4,5 , and 6 , accordingly. 
Table 2. An overview of academic corpora

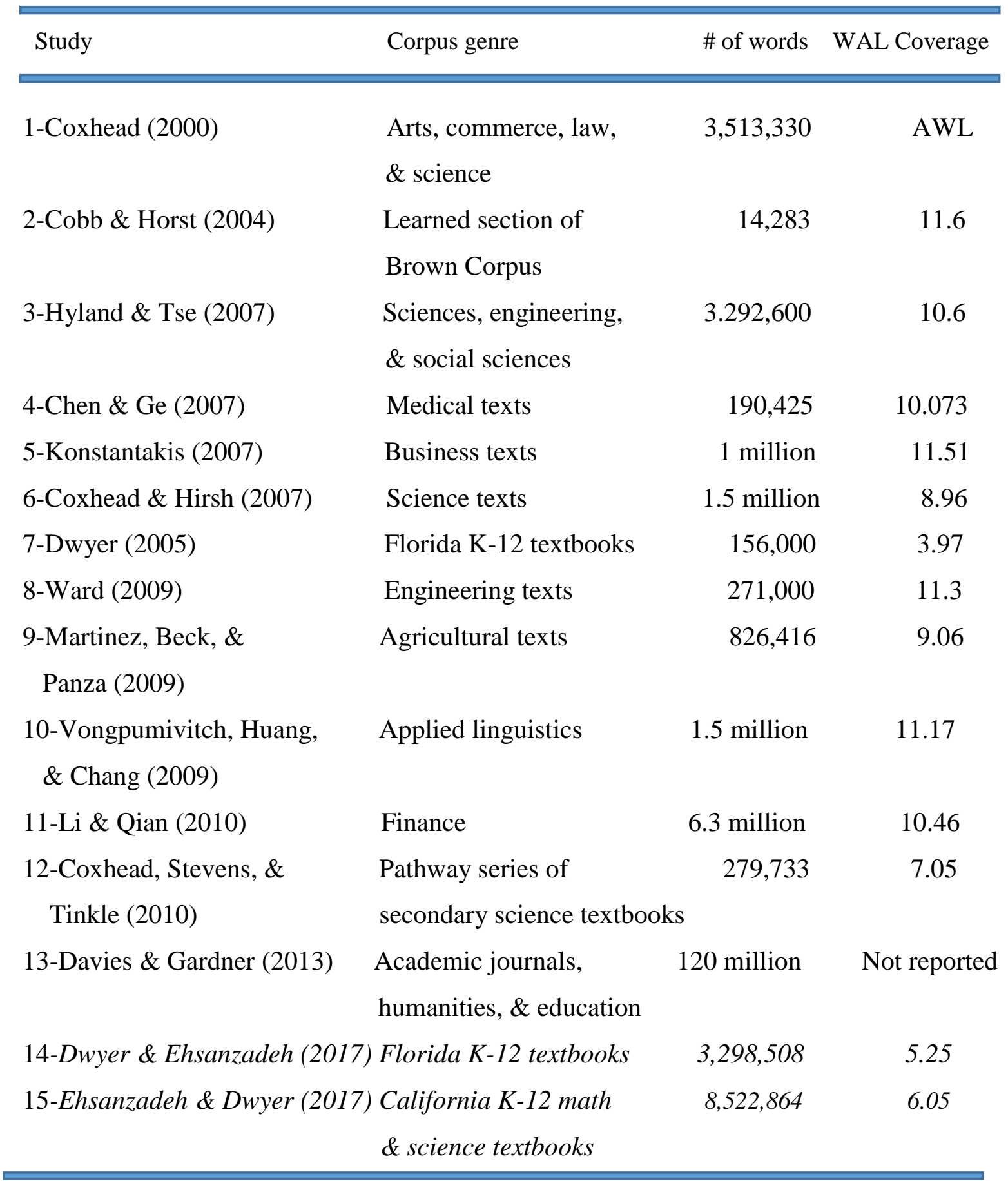




\section{Research question 1}

The first research question focuses on the coverage distribution of Cobb's (2017) word classification (see Chapter 2) across K-12 textbooks. The academic vocabulary knowledge in this classification follows Coxhead's (2000) AWL. K1 and K2 (first and second most common words) represent the extent to which words in K-12 books are from first 1,000 (K1) most frequent words or the second 1,000 (K2). Having a clear picture of these categories in K-12 textbooks will be an invaluable guide in designing supplementary materials. Here is the first question:

1) What is the vocabulary frequency distribution based on Cobb's (2017) classification in U.S.-based K-12 textbooks?

a) To what extent are

(i) K1 (first one thousand most frequent words),

(ii) $\mathrm{K} 2$ (second one thousand most frequent words),

(iii)academic words, and

(iv)off-list words

represented in U.S.-based K-12 textbooks?

\section{Analysis software used for developing the corpora}

\section{LexTutor}

Lextutor (www.lextutor.ca) is a vocabulary search tool. It is a complex and powerful web-based engine designed by Tom Cobb in late 1990s. He developed and has maintained the page since 1990s. The page has three main entries: tutorial, research, and teachers. The research section is where a student can begin his data analysis. The tutorial 
section provides the learner with interactive tools for self-directed learning, and teachers section is a source of classroom activities for teachers.

Vocab profile (VP) is the subsection of LexTutor that I have often used in making my initial word lists for the Florida textbooks. Vocab profile accepts files in rtf format and has a limited analysis capacity of no more than 30,000 words at a time. Vocab profile produces a statistical table of four tiers of vocabulary, namely as: K1 (1-1,000 most frequent words), K2 (1,001-2,000 most frequent words), AWL (a list of academic words mostly derived from Coxhead's AWL), and Off-list (words not appeared in any of these three tiers). Vocab profile is a versatile tool for evaluating the text difficulty. It can also be used for reviewing the core vocabulary.

\section{AntConc (version 3.5.2.)}

AntConc (Anthony, 2017) is a multiplatform software developed to conduct research in corpus linguistics and analyze corpus-driven data. The software may be run on both Microsoft Windows and Macintosh. To produce executables for a variety of operating systems, AntConc was developed in Perl, using different compilers.

AntConc is a versatile software with seven main analysis tools:

1. Concordance Tool (which analyzes the text and gives the results in a KWIC, Key Word In Context),

2. Concordance Plot Tool (which searches the text and gives the results in a barcode format or plotted), File View Tool (gives the results of the text in individual files), 
3. Clusters/N-Grams (which scans the whole corpus and then gives the results produced in the Concordance Tool or Concordance Plot Tool and the main feature of this tool is that it allows the researcher to find common expressions and words in a corpus),

4. Collocates Tool (which gives collocates and allows to examine the nonsequential patterns in a corpus),

5. Word List (which allows the researcher to find the most frequent words in a corpus and I used it for the analysis of frequency distribution of lemma in research question 2 , and

6. Keyword List (which compares the frequency distribution of words in the corpus with a target corpus).

\section{Results}

For the result of this chapter, I answer the first research question which asks about a classification of K-12 textbooks in terms of Tom Cobb's first and second thousand most common words plus academic vocabulary. The research question is in line with Cobb's classification in the K-12 context in USA. With respect to the classification of vocabulary in this study and the definition of academic and STEM words, I used AntConc software. Academic words are words that appear commonly in three out of four content areas (math, language arts, science, and social studies). Therefore, I extracted all common words in three content areas by the use of the software and label them academic words in AntConc. STEM words, however, are domain-specific words appearing mainly in one of the four 
content areas (see Chapter 4 for a complete list of academic and STEM-related words in this study).

\section{Teachers' U.S. Corpus - TUSC}

The Teachers' U.S. Corpus (TUSC) is the corpus of Florida State textbooks which contains 49 books. Teachers' U.S. Corpus is a general-purpose corpus representing all four K-12 content areas (language arts, math, science, and social studies). As a result of the heavy burden of recruiting textbooks and other related limitations that I had, TUSC is skewed towards middle school textbooks. With regard to the content area, TUSC represents more language arts and social studies. Table 3 gives more information about TUSC. The distinction of books is based on $\mathrm{K}-12$ content areas.

Table 3. An overview of TUSC.

Content area No. of books No. of running words

\begin{tabular}{lcc} 
Math & 15 & 741,950 \\
Science & 14 & 559,783 \\
Social Studies & 9 & 951,338 \\
Lang Arts & 11 & $1,045,437$ \\
& & $3,298,508$ (total) \\
\hline
\end{tabular}

Tables 4 and 5 give detailed information regarding the number of words in four tiers of word frequency according to LexTutor in the subject matter of Language Arts and Social Studies. I divided the textbooks in these content areas (11 textbooks in Language Arts and 
nine textbooks in Social Studies) into four grade groups, namely as K-2, 3-5, 6-8, and 9-12. The total number of words in Language Arts and Social Studies is 1,996,775.

Table 4. Language Arts in TUSC.

Lang \& Arts

(11 books)

K-2 (1 book)

290

4,261

3,756

37,062

9-12 (3 books)

Lang. Arts total: $\quad 45,371(4.33 \%)$

$892,315(85.35 \%)$

698,929
K1

K2

14,942

1,632

87,331

7,046

7,504

56,038

22,137

864

4,017

91,113

8,531
$35,531(3.39 \%)$

Total words: $\mathbf{1 , 0 4 5 , 4 3 7}$

Table 5. Social Studies in TUSC.

Social Studies

AWL

K1

K2

OFF-LIST

(9 books)

$\begin{array}{lrrrr}\text { K-2 (1 book) } & 575 & 16,438 & 1,167 & 1,392 \\ \text { 3-5 (3 books }) & 3,860 & 65,004 & 4,819 & 2,431 \\ \text { 6-8 (3 books }) & 8,191 & 127,124 & 8,026 & 3,612 \\ \text { 9-12 (2 books) } & 53,318 & 591,427 & 37,440 & 26,514 \\ \text { Social total: } & \mathbf{6 5 , 9 4 4}(\mathbf{6 . 9 3 \% )} & \mathbf{7 9 9 , 9 9 3}(\mathbf{8 4 . 0 9 \%}) & \mathbf{5 1 , 4 5 2}(\mathbf{5 . 4 0 \%}) & \mathbf{3 3 , 9 4 9}(\mathbf{3 . 5 6 \%}) \\ \text { Total words: } \mathbf{9 5 1 , 3 3 8} & & & & \end{array}$


Tables 6 and 7 represent STEM-related domain of TUSC with a total of 29 textbooks (15 Math and 14 Science textbooks) and a total number of 1,250,268 words. As could be seen in Table 6 and 7, Math is more intense than Science in terms of academic language. Surprisingly enough, Science has the least intensive academic language among the four content areas in Florida school system. Figure 2 shows the academic vocabulary trend in TUSC across four content area.

Table 6. Math in TUSC.

Math (15 books) $\begin{array}{llll}\text { AWL } & \text { K1 } & \text { K2 } & \text { OFF-LIST }\end{array}$

K-2 (1 book)

1,885

58,452

4,269

3,006

3-5 (3 books)

3,217

15,736

99,912

8,423

1,418

6-8 (6 books)

9-12 (5 books)

13,171

$34,009(4.58 \%)$

Total words: $\mathbf{7 4 1 , 9 5 0}$ 
Table 7. Science in TUSC.

\begin{tabular}{lcccr}
$\begin{array}{l}\text { Science } \\
\text { (14 books) }\end{array}$ & AWL & K1 & K2 & OFF-LIST \\
\hline K-2 (1 book) & 1,267 & 50,506 & 4,775 & 2,616 \\
3-5 (3 books) & 3,901 & 82,713 & 8,240 & 10,366 \\
6-8 (7 books) & 13,327 & 201,843 & 19,271 & 30,971 \\
9-12 (3 books) & 8,771 & 98,283 & 9,122 & 13,811 \\
$\begin{array}{l}\text { Science total: } \\
\mathbf{( 5 5 9 , 7 8 3 )}\end{array}$ & $\mathbf{2 7 , 2 6 6}(\mathbf{4 . 8 7 \% )}$ & $\mathbf{4 3 3 , 3 4 5}(\mathbf{7 7 . 4 1 \%})$ & $\mathbf{4 1 , 4 0 8}(\mathbf{7 . 3 9})$ & $\mathbf{5 7 , 7 6 4}(\mathbf{1 0 . 3 1})$ \\
\hline
\end{tabular}

Figure 3. Academic words in TUSC.

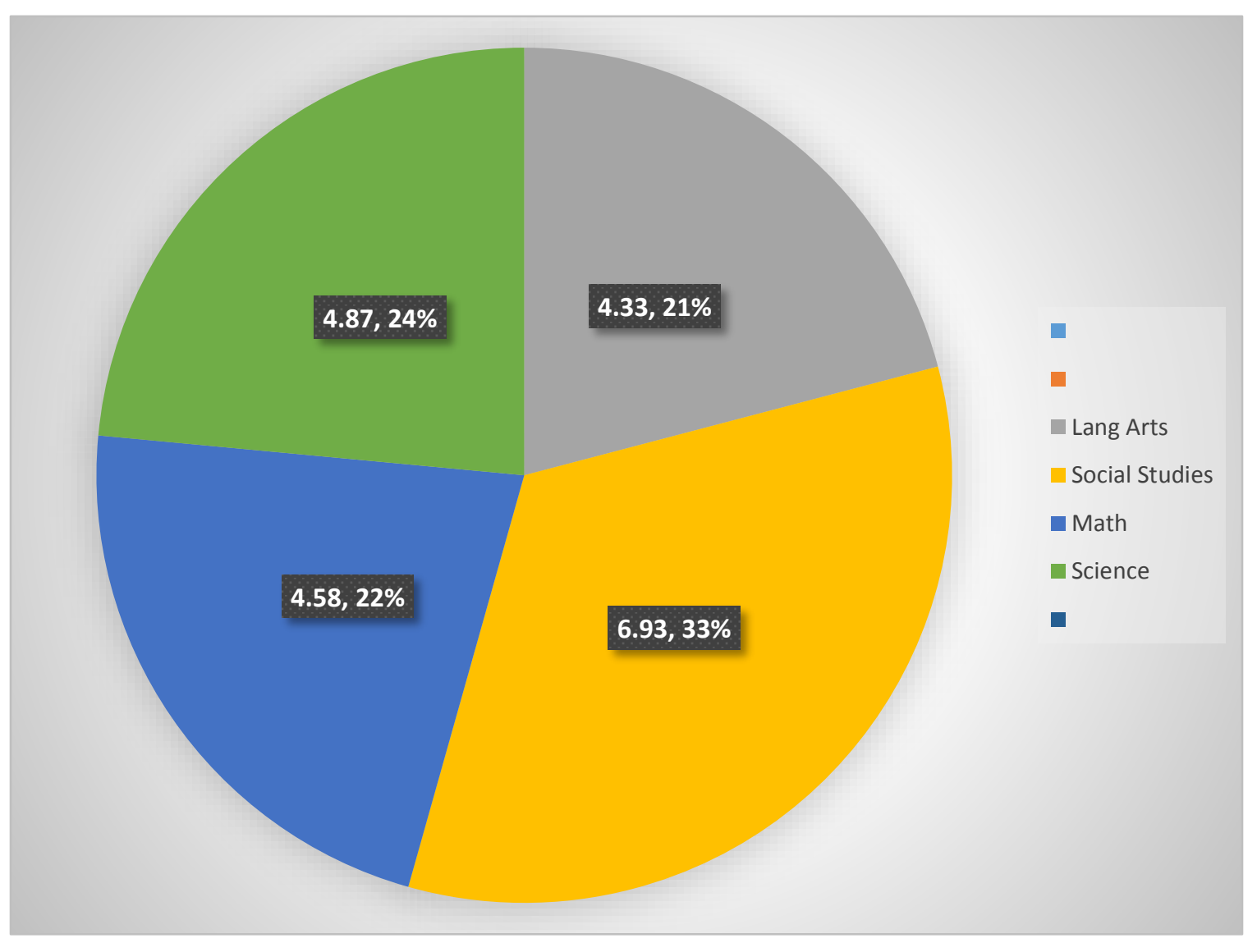




\section{Science/ Math Corpus for K-12 Kids - SMACK}

The Science/Math Corpus for K-12 Kids (SMACK) is a STEM-related corpus containing 102 books from States of California and Florida with only 29 books from Florida and 73 from California. The Science/Math Corpus for K-12 Kids is a corpus of middle and high school textbooks. In sampling the corpus, I attempted to choose the books from a wide range of STEM-related subject areas to make SMACK as representative as possible. The Science/Math Corpus for K-12 Kids includes the following subjects from school math and science domains: Math (15 books), Algebra (12 books), Analysis (2 books), Calculous (3 books), Geometry ( 8 books), Probability (6 books), Trigonometry (2 books), Astronomy (1 book), Biology (14 books), Chemistry (3 books), Earth science (4 books), Engineering (3 books), Science (19 books), Life science (2 books), Physical science ( 2 books), Physics ( 5 books), and Technology (1 book). All the textbooks are written for K-12 U.S. mainstream students.

Table 8. Composition of SMACK.

\begin{tabular}{lllr}
\multicolumn{4}{c}{ Content area } \\
\hline & Math & Science & SMACK \\
\hline Total text token & $4,547,909$ & $3,974,955$ & $8,522,864$ Words \\
Number of books & 48 & \multicolumn{1}{c}{54} & 102 Books \\
Subject areas & Math & Astronomy & 17 Subjects \\
& Analysis & Biology & \\
& Algebra & Chemistry & \\
& Calculous & Earth science & \\
& Geometry & Engineering & \\
& Probability & Science & \\
& Trigonometry & Life science & \\
& & Physical science & \\
& & Physics \& Technology &
\end{tabular}


When it comes to academic vocabulary in STEM-related domain in school textbooks, Math seems to be more intense than Science. As seen in Figure 4, the academic vocabulary in both Math and Science is less than 10\%. Though, there is no surprise that SMACK is richer than TUSC with respect to academic vocabulary.

Figure 4. Academic vocabulary in SMACK.

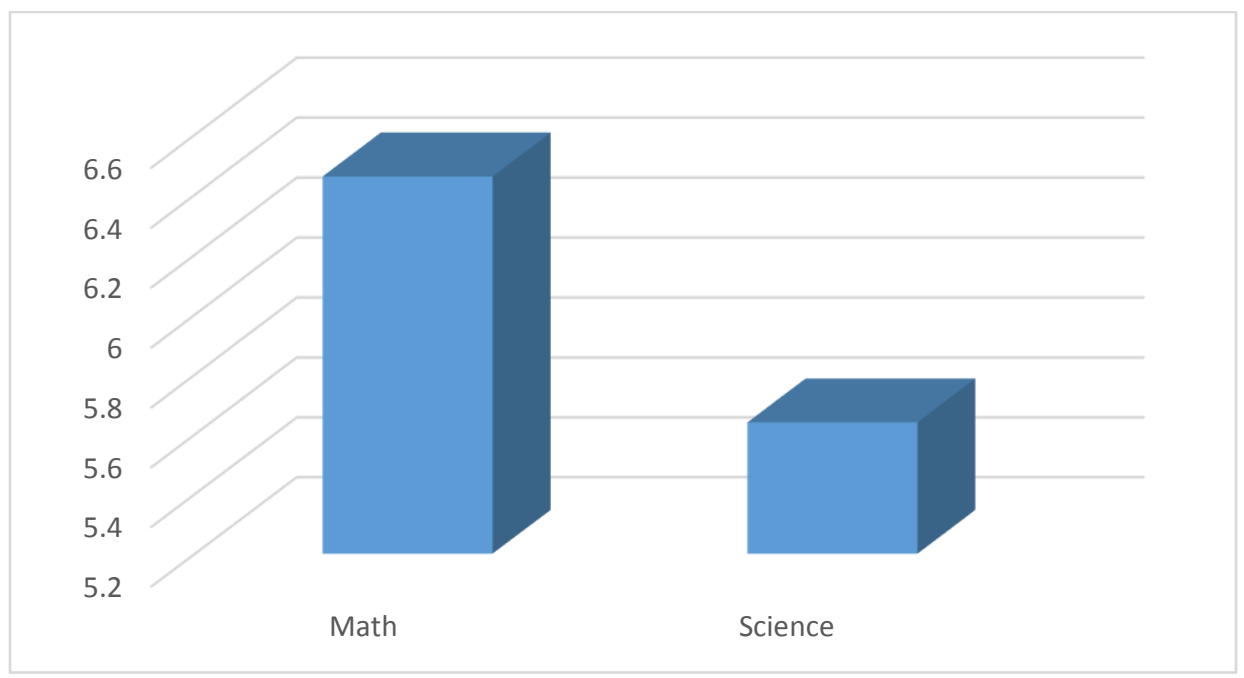


Figure 5. STEM words in TUSC and SMACK.

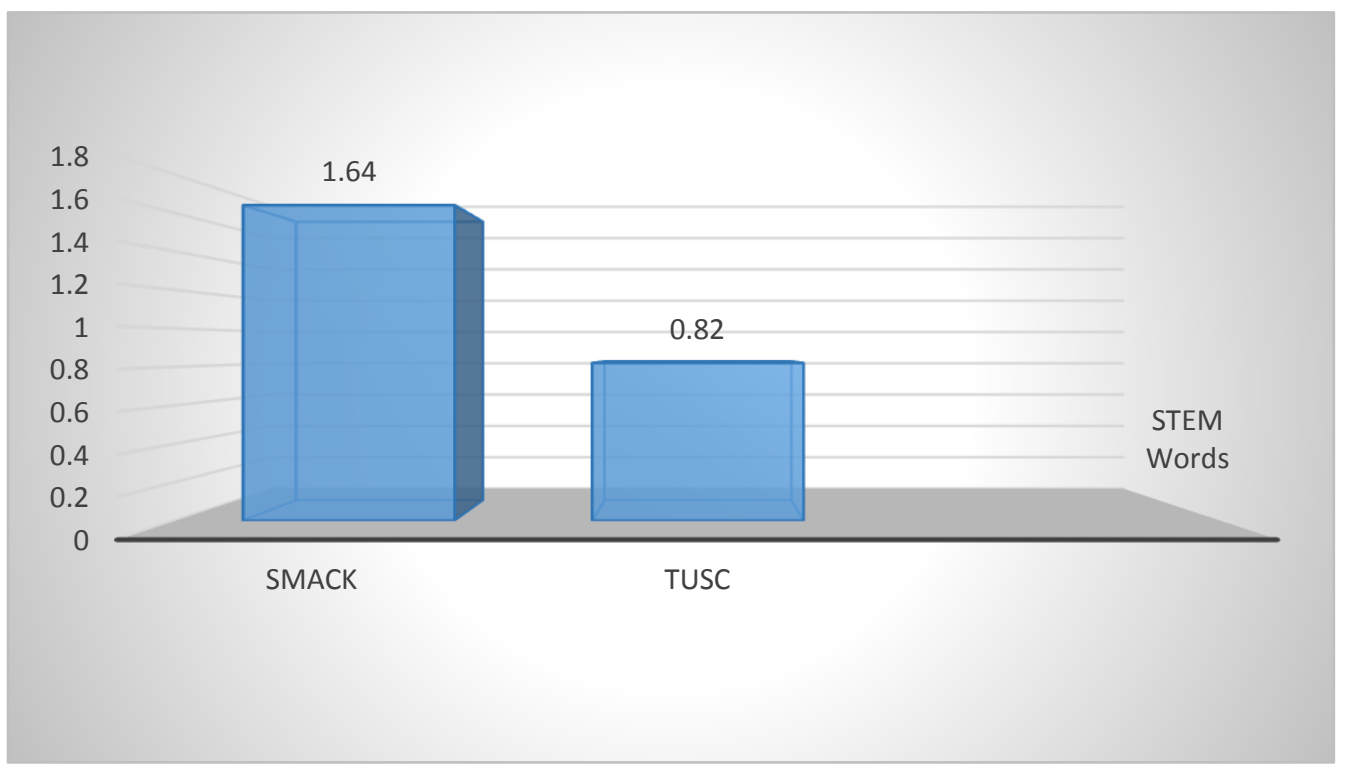




\section{CHAPTER IV}

\section{The word lists}

\section{Introduction}

\section{Research question}

The main research question that I will answer in Chapter 4 is the second one of the study through which I will develop three frequency word lists, one academic and STEMrelated, as well.

2) What are the most commonly used lemmas in U.S.-based K-12 textbooks?

b) To what extent are

i) high-frequency,

ii) medium frequency, and

iii) low frequency lemmas, used in U.S.-based K-12 textbooks?

b) What are the new academic and STEM-related word lists in U.S.-based K-12 content area textbooks?

As discussed in Chapter 2, incorporating word lists can offer many advantages into our second language classes. Gardner and Davies (2013) suggest that developing specialized word lists can be an essential step toward shortening the learning time and teaching ELLs words that they need for a particular purpose. For younger learners, such may be based on a corpus that reflects K-12 domains. Simultaneously, frequency rankings that consider dispersion seem to be an appropriate manner of learning vocabulary (Nation, 2013). 
Over the past decade, various word list have been developed for teaching academic and core vocabulary (see Chapter 3 for a detailed review). These lists (AWL, ALV, and UWL), however, have faced critique (see Chapter 2). To achieve the teaching implications and purposes mentioned above and earlier in this dissertation for teaching reading through a color-coded system, as featured in LexTutor, and making vocabulary instruction more efficient, I developed five word lists, namely three frequency lists (high, mid, low), academic, and STEM-related word lists to answer the second research question.

Chapter 4 is divided into two parts. In Part 1, I review the procedure and main techniques for making a word list. The guideline developed by Nation and Webb (2011) and Nation (2016) are also reviewed in the next step. A significant section in this part is the examination of what should be included in the word lists. I also give some examples showing the main pattern of the set criteria. Part 2 is the explanation of the validating method of the word lists and the final products as the word lists. The text coverage method is used to examine the validity of each word list.

\section{Procedure for making a word list}

Considering the proposed research questions for the present dissertation, a corpusdriven approach was selected as an appropriate model. In this dissertation, I followed text analysis design to develop and validate the word lists. Text analysis is not the same as content analysis design, whose focus is on linguistic properties and is mostly used in corpus-based research studies. 
Nation and Webb (2011) and Nation (2016) are principal sources who explain how to make word lists and validate them. Nation and Webb argue that creating an effective word list includes the following steps:

1. We should have a good reason for making a word list as well as appropriate research questions.

2. The unit of counting is the next important decision that a researcher should make before embarking the word selection process. As I explained in Chapter 2, the counting unit for this dissertation is lemma.

3. A corpus should be compiled according to the needs of the people who will use the word list. The makeup of the corpus should be representative and large enough to have an acceptable text coverage. In regard with the size of the corpus, Brysbaert and New (2009) believe that a corpus of 1,000,000 running words is acceptable for high frequency words. For low frequency words, however, at least $30,000,000$ tokens will be an acceptable size of the corpus.

4. Decisions regarding definitions of a words, as well as word types, and which ones should be counted as a word to be included in the corpus should be considerations. For example, should propositions or proper nouns be included in the corpus?

5. The criteria for ordering the words in the word list are an important issues that shape the form of the final product. There do exist frequency-based word lists (Campion \& Elley, 1971; Praninskas, 1972; Lynn, 1973; Ghadessy, 1979). Therefore, the decision about how to order words on the list based on whether frequency or dispersion is a critical issue in making a word list. 
6. Word lists should be examined against other independent corpora or word lists to check whether there may be any improper placement of words in a wrong list.

As mentioned in Chapter 2, there are many word lists in different languages, and most of them are frequency-based lists (BLI, 1986; Eaton, 1940; Juilland, Brodin, \& Davidovitch, 1970; Juilland \& Chang-Rodrigues, 1964; NLRI, 1962, 2006; Thorndike \& Lorge, 1944; Xiao, Rayson, \& McEnery, 2009). Additionally, some guidelines have been prepared on how to use or adjust these word lists (Gries, 2008; 2010). Most guidelines, however, explain procedures on how the word lists were made and argue for their validity and reliability. Particular issues with regard to word lists, including how they should be developed and validated alongside the teaching implications, have been extensively discussed in Nation and Webb (2011) and Nation (2016) which are the guidelines used in developing and validating the word lists for this study. Of the six steps involved in making and validating word lists, three of them - unit of counting, criteria for counting words and separate lists, and criteria for ordering words - are explained in further detail:

\section{Unit of counting}

The three main units of counting for designing a word list are word type, lemma, and word family (Nation, 2016). A good example of word type as the unit of counting is Carroll, Davies, and Richman's (1971) study. Leech, Rayson, and Wilson (2001), however, used lemma as the unit of counting and it only considers inflections. In another study, Vermeer (2004) also applied lemma as the unit of counting to assess productive knowledge. For the purpose of this study, I will use lemma as the unit of counting. To count receptive knowledge, a word family, which is an inclusive unit of counting is the best option (Nation 
$\&$ Webb, 2011). When a learner knows one or two members of a word family, little learning burden will be needed to use other family members receptively in reading comprehension. For example, if a learner knows the word accesses, understanding accessed, accessible, accessibility, or inaccessible and inaccessibility will not be difficult tasks for the learner. Many word lists have been developed with the word family as the unit of counting. Nation's (2004) word list developed from British National Corpus is a good example of this type.

With regard to derivational and inflectional forms, the main issue with this unit of counting is that it is difficult to be consistent about which forms should be included under a headword. However, it stands clear that all forms that require little learning should go under the related word family.

Another important issue with respect to counting is the concept of multiword, which is a sequence of two or three words like in spite of and so that. In this regard, Leech, Rayson, and Wilson (2001) argue that multiwords should be counted as single words, because in English grammar they are considered single words. Nation and Webb (2011) believe that learning of multiwords requires additional learning effort because these words do not have transparent meanings and learners should guess their meanings. However, a main problem with regard to multiword units is the lack of unified and consistent judgment about which words should be counted as a multiword. When it comes to a large-scale corpus, it would not be a feasible task for a researcher to go through it manually. Even if they are considered as single words, an additional problem would be counting the frequency of each of the components of a multiword. Without using a proper computer program, this would be a very tedious and time consuming task. 


\section{Criteria for counting words and separate lists}

Nation (2016) argues that the learning burden principle (see Chapter 1 for more details) determines whether a word should be considered as a headword. In other words, if a learner does not need previous knowledge to learn the meaning of a form (e.g., proper nouns), or if the learner can construct the meaning from previous knowledge (e.g., derivational and inflectional forms), then this form of the word should not be considered as a headword in the word list. As a result, Nation and Webb (2011) and Nation (2016) decided to look for non-words, proper names, abbreviations, marginal words (e.g., eh), homonyms and homographs (e.g., sow), transparent compounds (e.g., lifespan), foreign words (e.g., précis) to make a separate word list for these items. Nation (2016) believes that separate word lists are invaluable educational tools that allow learners to read what they need and make adjustments without referring to other word lists.

\section{Criteria for ordering words}

A main goal of this research study is to show what the best order of learning vocabulary should be for ELLs in K-12 context. In this regard, the criteria for ordering words, which is mostly applied for frequency word lists, will guide us in ordering the words. Nation and Webb (2011) and Nation (2016) argue, simply, that the best criterion is that the more words learners know, the more effective reading will be.

The implication, however, can be monumental with respect to list development: that a higher text coverage will certainly lead to a stronger chance for reading comprehension. Therefore, frequency is an important criterion for deciding what the most efficient word learning order may be. The question arising then is how frequency should 
be measured. Nation (2016) believes that compiling a corpus for each learner and then checking the frequency of each word would be the best strategy that suits the learners' needs. Creating a means for each person to develop their own word list ahead of their learning may be a valuable goal but is beyond the scope of this study. However, it may be more immediately possible to categorize the needs of learners and then create a corpus for each category of needs.

\section{How to count words for inclusion in a word list}

Among the first decisions that a researcher should make before taking any step in developing a word list is the decision about which words should be included in the word list as the final product. This decision itself is a complicated one that would no doubt affect the nature and quality of a word list. For example, do digits like 12 and 1397 showing up in math textbooks count as words? What about abbreviations like Max, Min, or $H Q$ that appear in science textbooks? Do forms mixing numbers and letters like Apollo13 or P3.4 showing up in math and science books count as separate words?

In sections below, I address these questions and other issues related to how to deal with what should be counted as a word and included in the word lists that I am developing in this study. Also, I will explain the rules and regulations that I applied in deciding whether a particular word should be included or not.

\section{Assumed known words}

Assumed known words (Nation \& Webb, 2011) are specific nouns and/or proper names, including geographical places and historical nouns, that require very little or no 
background knowledge to be understood in reading a text passage. Nation and Webb (2011) argue that whether a word should be counted in a list is mainly based on the degree to which the word contributes to the principle of learning burden (see Chapter 1 for definition of learning burden). Accordingly, Nation (2006) created separated word lists for known words of compounds and proper nouns. Since a goal of this dissertation is to establish lists that address learning burden, I did not include known words in the final word lists.

\section{Homoforms}

Lexicographers (Gardner, 2013; Nation, 2016) define homonyms as words that have the same spoken and written form but with different meanings (for example, bridge, miss, rest). Homographs, however, are words that have different spoken form with unrelated meanings that have the same written form (for example, lead, present, row). Also, homophones are words with the same oral form but with different written form and meaning (for example, eye/I, peacelpiece). To put these three types under one platform, Nation (2016, p. 41) uses the term homoform. Homoforms (all three types) are the linguistic features that are common and pervasive in any language including English. As a result, having a clear thought and well-decided approach towards the inclusion policy of honoforms in the word list is among the very first steps. 
Table 9. Three categories of homoform.

\begin{tabular}{lllll}
\hline & Written form & Spoken form & Meaning & Example \\
\hline Homograph & same & different & different & lead, minute, row \\
\hline Homonym & same & same & different & case, miss, rest \\
\hline Homophone & different & same & different & peacelpiece write/right \\
\hline
\end{tabular}

In an analysis of homoforms included in word lists, Wang and Nation (2004) reported that Coxhead's AWL has 60 homographs and homonyms (for example, decline, issue, volume). Considering the fact that AWL has 570 word families, it means that approximately one tenth (one word in every ten word family) contains a homoform. This further demonstrates that all three types of homoforms would have a considerable effect on the total number of entries in a word list. Because homophones have exactly the same written forms, they are usually put under different entries in written corpora. This would consequently increase the number of items in a word list. Nation (2016) argues that homonyms and homographs should be counted as two different lemmas, especially when the word list maker is interested in teaching and learning vocabulary in a second language, because each form of homograph or homonym has a different meaning and requires learning a new concept or recognizing one form with different meanings. One further issue here is the frequency of occurrence of pairs of homographs and homophones with one member of the pair has a much higher frequency compared to the other members. According to what I discussed in this section, I use different forms of homonyms and homographs as different items in my word lists. 
Table 10. Examples of homoform in K-12 corpus.

\begin{tabular}{|c|c|c|}
\hline Homoform & Freq. & Meaning \\
\hline Bar & 201 & pub, to exclude, bar exam, beam of steel \\
\hline Charge & 1094 & officially accuse of crime, electrical charge, a rushing attach \\
\hline Coast & 598 & coastline, move easily, not work hard \\
\hline Country & 2098 & far from city, nation \\
\hline Date & 680 & to see romantically, someone's age, a fruit \\
\hline Fall & 1023 & autumn, to descend \\
\hline Just & 310 & only, fair \\
\hline Kind & 3019 & gentle, a class \\
\hline Nature & 4012 & the natural world, inherent quality \\
\hline Park & 1029 & public area, to bring a car to a halt \\
\hline Passage & 2027 & travel, a passageway, passing (a law) \\
\hline Patient & 198 & a doctor's client, to have patience \\
\hline Second & 5210 & related to time, after the first \\
\hline Stage & 2013 & a place for actors, a part of development \\
\hline
\end{tabular}


Some corpus linguists and word list makers (Biemiller, 2010) took a step further, distinguishing members of homoforms by claiming that related senses of one word should be distinguished and counted as different words in a word list. For example, court in court of appeal should be seen as a different word from appeal relating to a request. In favor of this argument, Nation (2016) believes that different senses of a word might be translated using different words in a foreign language; therefore, for word lists developed for the purpose of teaching vocabulary in another language, including the ones that I am making through this dissertation, this could be a reasonable idea. However, Nation further argues that distinguishing different senses of one word will not help ELLs apply contextual clues while reading and therefore should not be used separately in a word list.

\section{Proper nouns}

In written English, proper nouns and names are usually identified by their first letter being capitalized; however, not every capitalized word is a proper noun. It seems that proper nouns are straightforward, but they have complications as well. For example, the first word of a sentence is capitalized and this should be distinguished from a proper noun in a word list. A further issue is that there is not consistency in the use of capitalization for some proper nouns like the game Monopoly is capitalized while chess is not.

The main feature of proper nouns is that they do not contribute to the comprehension of the text as they do not carry the key meaning beyond the meaning of the thing that they refer to. In this respect, Nation (2016) argues that ELLs require very little previous knowledge to learn some of proper nouns. According to National British Corpus (2018), the names of geographical and historical places, personal names including the 
names of famous people, and enterprises account for the biggest part of proper nouns in written texts. An important part of this category of proper nouns is the names of festivals and events, including wars, hurricanes, sporting events, and TV shows (Kobeleva, 2008). However, not every proper noun needs previous knowledge in order to be understood. Nagy and Anderson (1984) argue that there might be approximately 1000 of these proper nouns that you need to have a background knowledge to understand them in a sentence. These sentence are good examples of these proper nouns: "He is not Einstein. He is not another Gandhi." As a result, Nation (2016) argues that a list of such proper nouns will help improve ELLs reading and literacy because they entail stable meanings that ELLs need to learn. Some of these words are even unknown to mainstream students. 
Table 11 Examples of proper nouns in K-12 corpus.

\begin{tabular}{lcl}
\hline Idiom or phrase & frequency & word list type \\
\hline America & 2013 & high freq. \\
April & 48 & mid freq. \\
Bishop & 26 & mid freq. \\
Britain & 109 & high freq. \\
Europe & 173 & high freq. \\
Hong Kong & 6 & low freq. \\
King & 938 & high freq. \\
New York & 61 & high freq. \\
Obama & 23 & mid freq. \\
Saturday & 83 & high freq. \\
South America & 79 & high freq. \\
White House & 103 & \\
\hline \hline
\end{tabular}

Unlike the idea that most teachers think proper nouns do not create problems for ELLs in reading comprehension, Brown (2012) argues that this is not true. Similarly, Kobeleva (2012) reported that in a listening comprehension test of news texts, having previous knowledge of proper nouns improves the ELLs' comprehension significantly.

Nation and Webb (2011) carried out a careful analysis, focusing on words not included in the National British Corpus. They reported that almost half of the words not 
appearing in BNC/COCA were proper nouns. Fortunately, all proper nouns in English are distinguishable through AntConc WordProfiler (a free software I used for the purpose of text analysis in this dissertation) by using lists of proper nouns that have been uploaded into the software.

\section{Compounds and hyphenated words}

Hyphenated words are two words joined together with a hyphen (for example, lifespan, wife-less, long-term). Nation (2013) argues that the main reason for using a hyphen is to show that the two words are closely related. Interestingly enough, we have more than 10,000 hyphenated words with a frequency of at least 2 or higher in BNC.

A main issue in dealing with hyphenated words in developing a word list is a lack of consistency in the form of compound words. Sometime they appear with a hyphen (e.g., short-term), sometimes they appear without a hyphen (shortterm), and also in some cases they occur as spaced compound words (short term). Therefore, Nation (2016) argues that compound words shouldn't be taken as a grammatical category of items because there are three variations in whether they are written as two separated words, or with no space, or even as a hyphenated word. As a result, this makes the decision about how to include them in word lists very complicated. For example, lifespan, railway, shareholder are the compound words that have both hyphenated and non-hyphenated forms in BNC but with a considerable difference in terms of frequency between the two forms. 
Table 12. A sample of hyphenated words in the five word lists in this study.

\begin{tabular}{lcl}
\hline Idiom or phrase & frequency & word list type \\
\hline Full-time & 51 & mid freq. \\
Large-scale & 29 & mid freq. \\
long-term & 108 & high freq. \\
middle-class & 118 & high freq. \\
part-time & 23 & high freq. \\
video-taped & 41 & high freq. \\
short-term & 81 & mid freq. \\
so-called & 211 & high freq. \\
vice-president & 15 & mid freq. \\
well-known & 1723 & high freq. \\
\hline \hline
\end{tabular}

As a solution in counting compound words, Brysbaert, Stevens, Mandera and Keuleers (2016) split all the compound words that they collected in their corpus into their parts and count each component as a separate word so that their occurrences are counted separately. However, one problem to this approach is making a decision about which family the compound words should be counted under. For example, should we count weekend under end or week? Another issue is that it will misrepresent the frequency of weekend if we ignore the frequency of one component, for example, end in weekend. In this dissertation, I used compound nouns as a single word without hyphen or space with a separate frequency in the word lists. As a valuable source of compound nouns for making 
a word list, the Range and AntWordProfile programs have a list of more than 3,000 compound words, with about two members for each family. This list accounts for $0.1 \%$ of the text types and $0.36 \%$ of the text tokens in $\mathrm{BNC}$.

\section{Idiomatic and phrasal expressions}

Idioms and phrases are a group of words that come together frequently. They are also called formulaic sequences or lexical bundles. The main issue with regard to making a word list for ELLs and considering idiomatic expressions is coming up with a clear definition of what should be counted as an idiom and how to apply it consistently across the whole corpus (Nation, 2016). In order to decide about the inclusion of such expressions in a word list, Nation (2016) claims that we should consider these factors: 1) number of components of the expression, 2) discontinuity and adjacency of the components in the expression, 3) being grammatically fixed or variable, and 4) being cable of using lexically variable items.

Shin and Nation (2008) found that frequent idioms and phrases tend to be shorter than less frequent ones. They further claimed that the frequency of idiomatic expressions follow Zipf's law (see Chapter 1 for definition of this law) in that they tend to be more economic in terms of components. According to the nature of the K-12 corpora in this dissertation, there is not a high number of idiomatic expressions in the corpora, and I included most of the expressions in the high frequency word list. 
Table 13. Examples of idiomatic and phrasal expressions.

\begin{tabular}{|c|c|c|}
\hline Idiom or phrase & Freq. & Word list type \\
\hline a bit & 1091 & high freq. \\
\hline as a result & 1230 & high freq. \\
\hline as well & 901 & high freq. \\
\hline by and large & 219 & high freq. \\
\hline for instance & 711 & high freq. \\
\hline in addition to & 315 & high freq. \\
\hline on the other hand & 211 & high freq. \\
\hline out of hand & 124 & high freq. \\
\hline pulling your leg & 1 & low freq. \\
\hline the Big Apple & 3 & low freq. \\
\hline
\end{tabular}

\section{Acronyms and abbreviations}

An acronym is a word made of a group of letters that each is the first letter of a word. Acronyms and abbreviations usually do not contribute toward the core meaning of a text and consequently do not carry the significant meaning. Many acronyms refer to a unique entity and therefore they could be taken as proper nouns. Nation (2016) argues that acronyms that are a reduced form of a word ( $R d$ for $R o a d)$ should go under the items of that word family. When an acronym is used very often and is also easy to pronounce, it could stand as an independent word, for example, NASA and laser. In order to be included in a word list, Nation (2016) argues that 1) acronyms should be made of the first letters of 
a series of words, 2) all the words should be known by adult native speakers, and 3) the pronunciation of the acronym should sound out the letters (MIT), or pronounce it as a word (UNESCO). Below is a list of most frequent acronyms (above 2,000 frequency in BNC) that are considered high frequency words in the word lists in this study.

One argument in favor of having a separate list of acronyms (Nation and Webb, 2011) is that they are made of a series of words that are usually known and a separate list of acronyms will be helpful in improving the ELLs' receptive knowledge. However, another argument against the inclusion of acronyms is that such a list will be confusing without coming alongside homonymy words (Nation, 2016). 
Table 14. Sample acronyms in the word lists.

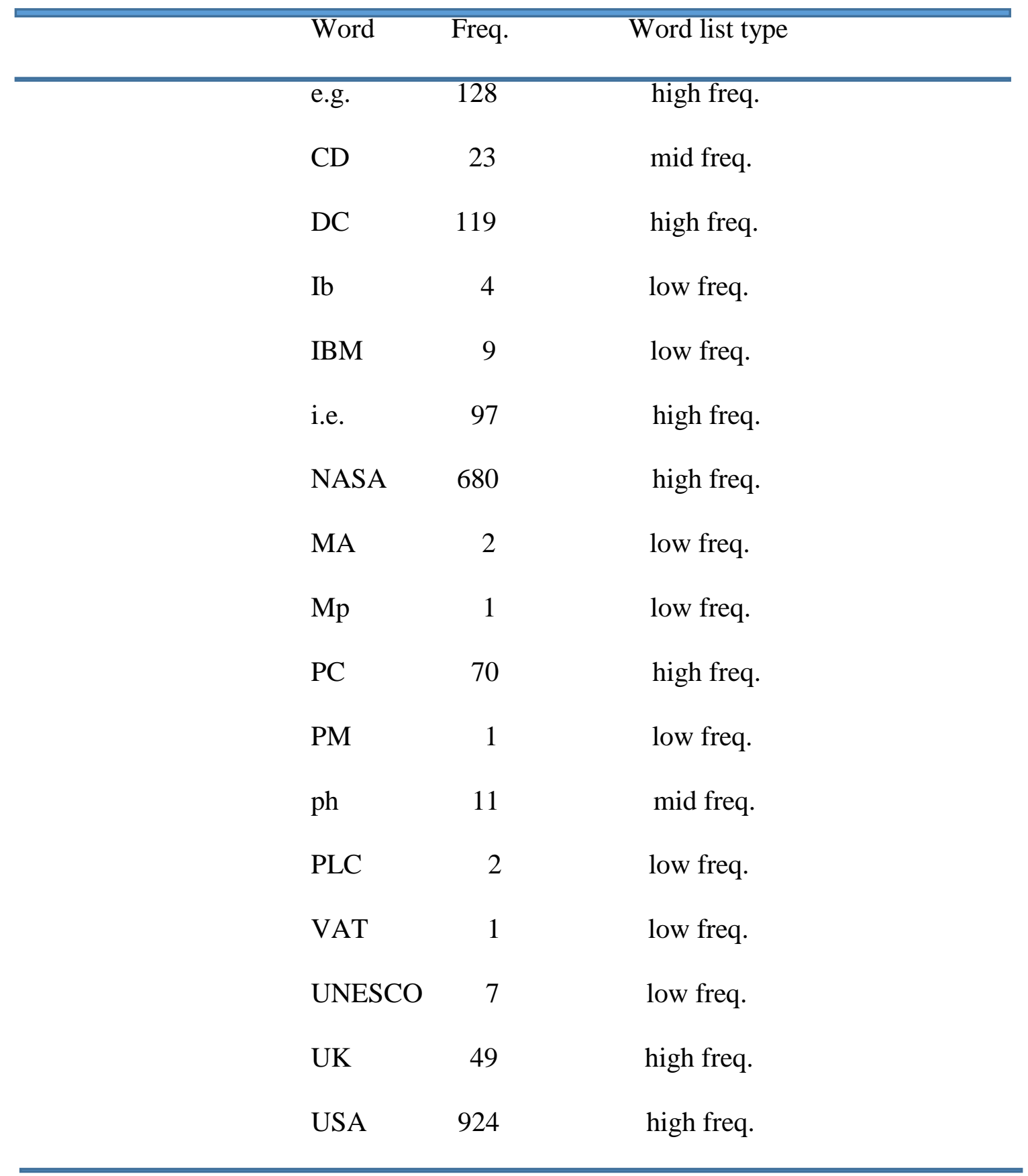




\section{Function words}

Lexical words in English are divided into two basic categories: content words and function words. Content words include verbs, nouns, adverbs, and adjectives. Function words, however, are the grammatical categories in English that include prepositions, articles, conjunctions, etc. (Merriam Webster, 2018). Function words have no meaning on their own and perform the grammatical functions of the language. However, some content words such as nevertheless and according to that play the role of function words. Another important feature of function words in making a word list is that it is a closed grammatical category where no new item will be added to it.

The strongest argument in favor of developing a separate list of function words is the idea that function words are qualitatively different from content words (Nation, 2016); the way that a content word is acquired is different from how a function is learned because learning function words is more dependent to acquiring grammatical knowledge (Nation, 2016). A further issue is that function words account for $51 \%$ of the token words in BNC showing that they are frequent. In Coxhead's AWL, there are six function words: albeit, despite, notwithstanding, plus, via, and whereas. However, eight function words are not in most of the English high frequency words: albeit, notwithstanding, whence, and whether. In this study, most function words in K-12 textbooks are placed in the high frequency list. Below is a random sample of such function words. 
Table 15. English function words.

\begin{tabular}{lcc}
\hline Word & Freq. & Word list type \\
\hline above & 5859 & high freq. \\
across & 2385 & high freq. \\
between & 13713 & high freq. \\
can & 50510 & high freq. \\
every & 3831 & high freq. \\
few & 3616 & high freq. \\
however & 4650 & high freq. \\
neither & 627 & high freq. \\
over & 2381 & high freq. \\
though & 1708 & high freq. \\
upon & 1079 & high freq. \\
unless & 363 & high freq. \\
via & 120 & high freq. \\
& 47797 & high freq. \\
\hline \hline
\end{tabular}




\section{Developing and validation of word lists}

The line of research on word lists has applied two major validation methods. Coxhead (2000), Coxhead and Hirsh (2007), Nation (2006), and Gardner and Davies (2013) are principal studies using text coverage as the validation method. The other method, however, used psychological reaction behavior to validate a word list (Gries, 2010; New, Brysbaert, Veronis, \& Pallier, 2007). Beyond frequency in this second method, reaction time is affected by a number of factors like eye movement ability, letter decoding speed, and semantic complexity, to name a few. As a result, the latter method doesn't fit the requirements of a corpus-driven approach in making a word list. Therefore, I used the text coverage type (see chapter 2 for a definition and literature review) as the validation method for the present dissertation study. In doing so, I used AntWordProfiler software (Anthony, 2014) to examine the text coverage provided by the word lists of this study.

\section{AntWordProfiler software}

AntWordProfiler is a software developed by Anthony (2014) to analyze corpus data on lexical profiling. The software has two main tools. The first one that appears in the middle of the window of the software is a tool for developing general vocabulary profiling. I used this tool to run the analysis in this section of the dissertation. Through this tool, I generated word lists statistics and frequency information about the five word lists of this study. This tool also uses the results of the research of Nation to compare the text coverage of a word list against a group of level lists that can be based on either word family or lemma. I also used vocabulary profile tool, the second main tool of the software, to load 
baseword files into the analysis section of the software. This tool also allows to search the words across a corpus.

\section{Results}

Research Question \#2 entails the following: What are the most commonly used lemmas in U.S.-based K-12 textbooks? Further subquestions incorporate

To what extent are

iv) high-frequency,

v) medium frequency, and

vi) low frequency lemmas, used in U.S.-based K-12 textbooks?

What are the new academic and STEM-related word lists in U.S.-based $\mathrm{K}-12$ content area textbooks?

This Results section, therefore, presents five word lists—High Frequency, Mid Frequency, Low Frequency, Academic, and STEM-related word lists, which address the research question. It also includes an Essential Word List (EWL). These six word lists include 17,565 lemmas from K-12 textbooks. The High Frequency Word List includes words appearing 100 times or more in the K-12 textbooks corpus. For the Mid Frequency Word List, the range of appearance through K-12 textbooks is between 99 and 10 occurrences. For the Low Frequency Word List, the range of appearance is between 9 occurrences and a single occurrence. The Academic and STEM-related word lists are also divided into two sub-lists of higher and lower frequency words. In High, Mid, Low, and EWL word lists, words are ordered in respect of frequency. In addition, all word lists with 
derivational and inflectional forms of lemmas are available at www.myvirs.com/dictionary/.

\section{High Frequency Word List}

The rationale behind the frequency word lists is based on frequency count (Sinclair, 2005; Nation \& Webb, 2011). Words appearing 100 times or more in the whole K-12 corpus are included in the high frequency word list. Coxhead (2000) also picked 100 as the baseline for the text token in her AWL. I decided to take 100 as the border line of high frequency words such that data would not skew toward sight words in my high frequency list. The middle frequency words are words with 10 to 99 tokens in both TUSC and SMACK. All words in low frequency word list have fewer than 10 text tokens.

The High Frequency Word List contains 3,606 lemmas. A complete list with derivational and inflectional forms is available at www.myvirs.com/dictionary. The High Frequency List is shown in Table 16. In the table, the term freq. refers to the number of times each lemma appeared in the corpus. 
Table 16. The High Frequency List.

\begin{tabular}{|c|c|c|c|}
\hline Freq. & Word & \multicolumn{2}{|c|}{ Freq. Word } \\
\hline 775747 & the & 431 & eclipse \\
\hline 378097 & be & 430 & pollinate \\
\hline 361295 & of & 429 & kinetic \\
\hline 297511 & $\mathrm{a}$ & 429 & prize-giving \\
\hline 247446 & and & 428 & beside \\
\hline 243373 & to & 428 & excite \\
\hline 185046 & in & 428 & fresh \\
\hline 118803 & way & 428 & gain \\
\hline 107940 & you & 428 & tens \\
\hline 105481 & that & 427 & border \\
\hline 73894 & have & 427 & pizza \\
\hline 63724 & this & 426 & geography \\
\hline 63014 & use & 425 & huge \\
\hline 62504 & they & 423 & beat \\
\hline 61359 & or & 423 & modeled \\
\hline 59402 & we & 423 & recycle \\
\hline 56463 & by & 423 & American \\
\hline 55294 & as & 422 & definite \\
\hline 55130 & on & 421 & astronomy \\
\hline 50510 & can & 421 & expose \\
\hline 49647 & with & 421 & quartile \\
\hline 47797 & what & 420 & everyday \\
\hline 45749 & from & 420 & haploid \\
\hline
\end{tabular}




$\begin{array}{ll}44462 & \text { home } \\ 41166 & \text { at } \\ 41010 & \text { how } \\ 35937 & \text { he } \\ 35336 & \text { not } \\ 33120 & \text { will } \\ 32618 & \text { one } \\ 31693 & \text { if } \\ 30657 & \text { each } \\ 29789 & \text { example } \\ 28771 & \text { equate } \\ 27267 & \text { find } \\ 26131 & \text { make } \\ 25125 & \text { when } \\ 24169 & \text { point } \\ 23958 & \text { which } \\ 22929 & \text { other } \\ 22798 & \text { more } \\ 22668 & \text { do } \\ 22455 & \text { about } \\ 22401 & \text { all } \\ 20163 & \text { so } \\ 18698 & \text { these } \\ 18504 & \text { there } \\ 18461 & \text { many } \\ 18412 & \text { differ } \\ 18356 & \text { write }\end{array}$

419 preimage

418 aquatic

418 catch

418 puberty

418 re-assign

417 coffee

416 fall

415 night-club

415 sub-sector

414 diamond

414 diet

413 amplitude

413 decline

412 desire

412 please

412 shore

412 smile

412 tropics

411 archaea

411 soft

410 mercury

409 homeostasis

407 flowed

406 fiber

405 feat

404 biochemist

404 endpoint 


$\begin{array}{ll}18231 & \text { nobody } \\ 18185 & \text { time } \\ 17947 & \text { water } \\ 17807 & \text { value } \\ 17728 & \text { form } \\ 17561 & \text { line } \\ 17458 & \text { figure } \\ 17171 & \text { than } \\ 17041 & \text { cell } \\ 16934 & \text { would } \\ 16855 & \text { function } \\ 16464 & \text { answer } \\ 16396 & \text { but } \\ 16323 & \text { may } \\ 16069 & \text { solve } \\ 15915 & \text { energy } \\ 15882 & \text { also } \\ 15855 & \text { into } \\ 15664 & \text { first } \\ 15631 & \text { graph } \\ 15553 & \text { see } \\ 15519 & \text { like } \\ 15402 & \text { problem } \\ 15091 & \text { it } \\ 15085 & \text { out } \\ 15082 & \text { below } \\ 14445 & \text { some }\end{array}$

404 title

403 breathing-space

403 immediacy

403 justice

403 succession

403 whenever

402 cry

402 lipid

401 bread-winner

401 stream-water

400 non-document

400 soldier

399 thermal

399 voluntary

398 corn

398 expanse

398 football

398 pet

398 route

397 medical

397 micro-instruction

396 butterfly

395 commute

394 cream

394 motor-vehicle

393 hydrocarbon

392 deposit 


$\begin{array}{ll}14414 & \text { up } \\ 14344 & \text { give } \\ 13714 & \text { follow } \\ 13713 & \text { between } \\ 13626 & \text { angle } \\ 13444 & \text { same } \\ 13311 & \text { area } \\ 12884 & \text { need } \\ 12829 & \text { people } \\ 12772 & \text { work } \\ 12660 & \text { numbers } \\ 12377 & \text { state } \\ 12258 & \text { table } \\ 11751 & \text { take } \\ 11737 & \text { system } \\ 11557 & \text { get } \\ 11538 & \text { change } \\ 11347 & \text { add } \\ 11186 & \text { look } \\ 11183 & \text { plant } \\ 11122 & \text { because } \\ 11020 & \text { help } \\ 10970 & \text { year } \\ 10913 & \text { most } \\ 10829 & \text { left } \\ 10778 & \text { quarter } \\ 10609 & \text { both }\end{array}$

392 induction

392 magma

392 mantle

392 network

392 push-bike

392 teacher-researcher

391 semi-conductor

391 wet

390 sir

389 chordate

389 grain

389 migration

389 photo-cd

389 tidal

388 secure

387 argue

387 non-executive

385 exterior

385 toxin

384 fence

384 slide

383 immigrant

383 repair

383 steel-worker

382 debate

382 drink

382 fund 


\begin{tabular}{|c|c|}
\hline 10568 & data \\
\hline 10439 & call \\
\hline 10299 & where \\
\hline 10151 & she \\
\hline 9899 & show \\
\hline 9885 & explain \\
\hline 9874 & why \\
\hline 9872 & lesson \\
\hline 9613 & such \\
\hline 9590 & through \\
\hline 9515 & right \\
\hline 9487 & move \\
\hline 9487 & new \\
\hline 9354 & relate \\
\hline 9354 & order \\
\hline 9297 & image \\
\hline 9277 & only \\
\hline 9258 & view \\
\hline 9238 & part \\
\hline 9214 & super-power \\
\hline 9153 & no \\
\hline 8935 & simple \\
\hline 8839 & term \\
\hline 8720 & could \\
\hline 8705 & now \\
\hline 8647 & word \\
\hline 8622 & include \\
\hline
\end{tabular}

382 perspective

382 swim

381 museum

380 sensor

380 terminal

380 wavelength

379 alter

$379 \mathrm{sec}$

379 stock-take

378 conic

378 decade

378 mar

378 nest

378 ounce

378 stone-thrower

377 confuse

377 elephant

377 gray

377 strand

376 propose

376 vitamin

375 deck

375 thank

374 alcohol

374 pie

374 postulate

373 beneath 


\begin{tabular}{|c|c|}
\hline 8572 & good \\
\hline 8537 & unit \\
\hline 8418 & open \\
\hline 8387 & earth \\
\hline 8357 & live \\
\hline 8273 & set \\
\hline 8270 & any \\
\hline 8208 & self-review \\
\hline 8175 & over \\
\hline 8143 & read \\
\hline 8125 & represent \\
\hline 8051 & factor \\
\hline 7927 & describe \\
\hline 7829 & day \\
\hline 7821 & force \\
\hline 7758 & square \\
\hline 7660 & determine \\
\hline 7655 & two-step \\
\hline 7645 & place \\
\hline 7602 & per \\
\hline 7533 & group \\
\hline 7520 & after \\
\hline 7493 & direct \\
\hline 7428 & know \\
\hline 7394 & great \\
\hline 7388 & grow \\
\hline 7367 & cause \\
\hline
\end{tabular}

373 loose-liver

373 workbook

372 enclose

372 photo-copy

372 poison

372 re-mark

372 review

371 authority

371 comprehend

371 lab

371 load

371 mistake

370 split

369 capability

369 solubility

369 whatever

368 target

367 ensure

367 prize

366 alike

366 anyone

366 dinosaur

366 disagree

366 multicellular

365 allergen

365 secrete

364 configure 


\begin{tabular}{ll}
7366 & much \\
7330 & chapter \\
7318 & length \\
7311 & who \\
7296 & probable \\
7272 & divide \\
7247 & high \\
7170 & test \\
7129 & body \\
7019 & result \\
6984 & life \\
6965 & must \\
6948 & equal \\
6943 & let \\
6912 & triangle \\
6894 & side \\
6836 & org \\
6835 & draw \\
6785 & common \\
6752 & still-large \\
6735 & very \\
6716 & food \\
6685 & another \\
6657 & learn \\
6634 & world \\
6618 & real \\
6450 & law \\
\hline
\end{tabular}

364 giant

364 skeletal

363 unless

362 calcium

362 sight

361 bicycle

361 govern

361 para-legal

360 commerce

360 flood

360 narrow

358 fun

358 mention

358 sit-up

358 stimulant

358 utilize

357 audience

357 rely

355 nucleotide

354 bacterial

354 button

354 exposed

354 rose-pink

353 appearance

353 capillary

353 council

353 revisit 


\begin{tabular}{|c|c|c|c|}
\hline 6429 & here & 352 & memory-jogger \\
\hline 6413 & express & 351 & currant \\
\hline 6375 & down & 351 & voltage \\
\hline 6375 & multiply & 350 & fell \\
\hline 6370 & atom & 350 & shop \\
\hline 6362 & small-animal & 350 & triple \\
\hline 6308 & process & 350 & verb \\
\hline 6249 & compare & 350 & warn \\
\hline 6227 & student & 350 & $\mathrm{I}$ \\
\hline 6129 & object & 349 & cotton-spinner \\
\hline 6126 & importance & 349 & happy \\
\hline 6103 & long & 349 & lava \\
\hline 6093 & measure & 349 & suffer \\
\hline 6085 & sub-process & 348 & doctor \\
\hline 6081 & distance & 348 & formal \\
\hline 6073 & just & 348 & minor \\
\hline 6060 & formula & 348 & reservation \\
\hline 6049 & product & 348 & command \\
\hline 5920 & name & 347 & declaration \\
\hline 5859 & above & 347 & discriminate \\
\hline 5795 & identified & 347 & feather \\
\hline 5790 & amount & 347 & push-button \\
\hline 5757 & population & 347 & replacement \\
\hline 5738 & should & 346 & mouse \\
\hline 5686 & human & 346 & rubber-stamp \\
\hline 5650 & temperature & 346 & self-assessment \\
\hline & scientific & 345 & declare \\
\hline
\end{tabular}




\begin{tabular}{|c|c|c|c|}
\hline 5635 & contain & 345 & punch-bowl \\
\hline 5630 & light & 344 & insulate \\
\hline 5629 & even & 344 & permission \\
\hline 5624 & total & 343 & impulse \\
\hline 5623 & rate & 343 & momenta \\
\hline 5598 & theory & 343 & verify \\
\hline 5592 & complete & 342 & displace \\
\hline 5572 & next & 342 & inclination \\
\hline 5553 & standard & 342 & prompt \\
\hline 5536 & practice & 342 & tape \\
\hline 5528 & increase & 341 & improper \\
\hline 5513 & occur & 341 & radio-isotope \\
\hline 5454 & personalize & 340 & edit \\
\hline 5440 & define & 340 & near-miss \\
\hline 5428 & since & 340 & panel \\
\hline 5388 & means & 340 & steam-train \\
\hline 5384 & thing & 340 & swing \\
\hline 5353 & found & 339 & constellation \\
\hline 5303 & end & 338 & destruct \\
\hline 5300 & become & 338 & electronics \\
\hline 5291 & gas & 338 & fine \\
\hline 5280 & re-found & 338 & meat \\
\hline 5230 & surface & 338 & vegetable \\
\hline 5218 & start & 337 & bounce \\
\hline 5197 & fraction & 337 & excrete \\
\hline 5189 & role-model & 337 & hammer-blow \\
\hline 5188 & base & 337 & hemisphere \\
\hline
\end{tabular}




\begin{tabular}{ll}
5186 & chemical \\
5167 & mean \\
5076 & during \\
5072 & center \\
5039 & hour \\
5037 & go \\
5023 & render \\
5018 & explore \\
5005 & circle \\
4982 & less \\
4981 & token \\
4948 & blood \\
4947 & type \\
4930 & begin \\
4923 & direction \\
4911 & around \\
4907 & therefore \\
4891 & small-scale \\
4883 & organic \\
4877 & want \\
4876 & domain \\
4849 & social-science \\
4838 & self-concept \\
4825 & gene \\
4811 & cost \\
4772 & act \\
4767 & produce \\
\hline 50 &
\end{tabular}

337 monthly

337 saturate

336 airplane

336 spin-up

335 diploid

335 equipment

335 excess

335 mollusks

335 symptom

334 passenger

334 penny

333 convection

333 hurricane

332 participate

332 sense

331 fusion

331 mold

331 phenomenon

330 echinoderm

330 explode

330 gradual

330 holiday-camp

330 lion

330 online

330 outlier

329 refuse

329 sevens 


\begin{tabular}{llll}
4760 & mass-murderer & 329 tight \\
4745 non-event & 329 trick \\
4742 & slope & 328 moist \\
4733 foot & 328 obtuse \\
4692 electron & 328 play-pen \\
4683 & sub-section & 328 whereas \\
4665 & sub-rule & 327 & criterion \\
4663 & summarize & 327 & that-clause \\
4650 & however & 327 & tower \\
4647 & check & 327 & lift \\
4605 & government & 326 & fur \\
4605 & watch & 326 & package \\
4585 & similar & 326 & patient \\
4567 & before & 326 & small-holding \\
4548 & create & 325 & spore \\
4538 & understand & 325 & television \\
4536 & click & 324 & equilateral \\
4511 & happen & 324 & mom \\
4504 & molecule & 323 & deal \\
4503 & low & 323 & hint \\
4498 & man & 323 & ignorance \\
4450 & together & 323 & pacific \\
4438 & ratio & 322 & compress \\
4431 & well & 322 & downward \\
4423 & re-heat & 322 & dramatic \\
4418 & hydro-carbon & 322 & peace-treaty \\
4402 & element & 322 & seafloor \\
& & \\
\hline
\end{tabular}




\begin{tabular}{|c|c|c|c|}
\hline 4357 & calculate & 322 & self-antigen \\
\hline 4332 & pair & 322 & vice \\
\hline 4315 & inequality & 321 & depress \\
\hline 4314 & back & 321 & tough-guy \\
\hline 4314 & tie-back & 320 & credit \\
\hline 4270 & true & 320 & escape \\
\hline 4255 & sample & 320 & whom \\
\hline 4252 & ask & 319 & beach-hut \\
\hline 4250 & re-calculate & 319 & chicken \\
\hline 4249 & apply & 319 & couple \\
\hline 4242 & far & 319 & gasoline \\
\hline 4238 & volume & 319 & incorrect \\
\hline 4230 & speed & 319 & rigid \\
\hline 4220 & scale & 319 & stream \\
\hline 4218 & idea & 319 & tube-nose \\
\hline 4207 & mile & 318 & adopt \\
\hline 4207 & public & 318 & advice \\
\hline 4181 & trust-me & 318 & church-warden \\
\hline 4157 & land & 318 & excellence \\
\hline 4157 & often & 318 & privacy \\
\hline 4151 & list & 318 & tension \\
\hline 4140 & type-case & 317 & cent \\
\hline 4115 & semi-negative & 317 & cheese \\
\hline 4111 & structure & 317 & fiction \\
\hline 4091 & $\sin$ & 317 & skeleton \\
\hline 4081 & wrist & 317 & $\operatorname{tank}$ \\
\hline 4067 & subject & 316 & asexual \\
\hline
\end{tabular}




\begin{tabular}{|c|c|}
\hline 4053 & compound \\
\hline 4050 & re-consider \\
\hline 4049 & three-inch \\
\hline 4045 & box \\
\hline 4034 & root \\
\hline 4028 & resource \\
\hline 4027 & $\cos$ \\
\hline 4024 & twin-car \\
\hline 4020 & material \\
\hline 4008 & species \\
\hline 4007 & subject-matter \\
\hline 4004 & level \\
\hline 3989 & rock \\
\hline 3963 & sun-worshipper \\
\hline 3950 & able \\
\hline 3941 & possible-world \\
\hline 3936 & original \\
\hline 3920 & always \\
\hline 3913 & page \\
\hline 3910 & class \\
\hline 3882 & distribution \\
\hline 3869 & keep \\
\hline 3831 & every \\
\hline 3823 & without \\
\hline 3815 & study \\
\hline 3801 & co-worker \\
\hline 3798 & red \\
\hline
\end{tabular}

316 loop

316 severe

316 slice

315 duty

315 emerge

314 farm

314 hand-bell

314 juice

313 domesticate

313 enable

313 grammar

312 blank

312 sick-room

312 sky-rocket

312 virtual

311 asteroid

311 clay

311 democracy

311 near-collision

311 pitch

310 backbone

310 irrational

310 truck

308 star-cluster

307 constrain

307 fee

307 strange 


\begin{tabular}{ll}
3783 & charge \\
3780 & those \\
3777 & choose \\
3770 & human-being \\
3739 & ocean \\
3706 & experiment \\
3702 & close \\
3690 & early \\
3685 & positive \\
3683 & half \\
3668 & property-owner \\
3660 & under \\
3659 & analyze \\
3656 & develop \\
3648 & involve \\
3633 & height \\
3628 & while \\
3616 & few \\
3611 & eat \\
3577 & plot \\
3559 & particle \\
3558 & space \\
3548 & re-unit \\
3520 & reason \\
3488 & exponent \\
3484 & provide \\
3477 & off \\
\hline 3
\end{tabular}

306 cross-appeal

306 disperse

306 phenotype

306 preserve

306 three-pack

306 trouble

305 accident

305 basketball

305 otherwise

304 impossible

304 sea-battle

304 steep

303 notebook

303 sitting-room

303 tech

303 gap

302 amaze

302 pipe

302 trout-rod

301 fetus

301 struggle

300 arise

300 counter-attraction

300 fortunate

300 jump

300 non-noble

300 stack 


$\begin{array}{ll}3474 & \text { continue } \\ 3457 & \text { ordinate } \\ 3453 & \text { try } \\ 3436 & \text { picture } \\ 3434 & \text { respond } \\ 3431 & \text { notice } \\ 3422 & \text { allow } \\ 3394 & \text { re-charge } \\ 3388 & \text { decimate } \\ 3377 & \text { activity } \\ 3363 & \text { guide } \\ 3353 & \text { again } \\ 3350 & \text { plan } \\ 3311 & \text { put } \\ 3302 & \text { limit } \\ 3283 & \text { refer } \\ 3253 & \text { diagram } \\ 3245 & \text { zero } \\ 3243 & \text { lead } \\ 3226 & \text { parallel } \\ 3197 & \text { foundation } \\ 3177 & \text { sound } \\ 3174 & \text { effect } \\ 3171 & \text { last } \\ 3162 & \text { plane } \\ 3138 & \text { average } \\ 3132 & \text { press } \\ \end{array}$

299 invent

299 metabolic

299 promise

298 attitude

298 officer

298 sulfur

297 spinner

296 non-employee

296 specify

296 sweat

296 tee-shot

296 trinomial

295 spectrum

295 wise

294 chair

294 goods

294 tea

293 combust

293 ramp-up

292 proceed

292 requirement

292 worry

291 baseball

291 cardiovascular

291 comment

291 extract

291 forget 


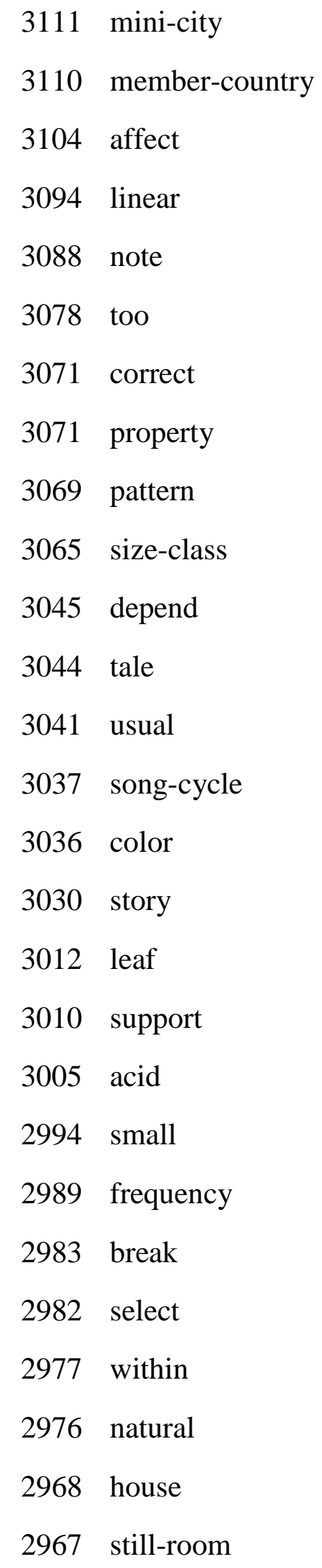

291 police

291 sedimentary

291 terrestrial

290 agency

290 blow

290 despite

290 manner

290 monitor

290 shift

289 aware

289 reverse

289 t-switch

288 exclusive

288 journey

288 peer

288 self-injury

287 clarify

287 facility

287 indeed

287 toe-nail

287 vibrate

286 anti-viral

286 fission

286 register

286 trig

286 turtle

285 chocolate 


$\begin{array}{ll}2965 & \text { sub-region } \\ 2964 & \text { main } \\ 2963 & \text { protein } \\ 2956 & \text { best-seller } \\ 2949 & \text { remember } \\ 2924 & \text { control } \\ 2916 & \text { oppose } \\ 2915 & \text { connect } \\ 2908 & \text { take-away } \\ 2906 & \text { least } \\ 2902 & \text { money-winner } \\ 2897 & \text { math } \\ 2890 & \text { disease } \\ 2885 & \text { electricity } \\ 2883 & \text { book } \\ 2878 & \text { actual } \\ 2875 & \text { predict } \\ 2871 & \text { come } \\ 2871 & \text { sit-com } \\ 2853 & \text { manage } \\ 2848 & \text { several } \\ 2836 & \text { north } \\ 2826 & \text { tree } \\ 2824 & \text { whole } \\ 2823 & \text { top } \\ 2823 & \text { travel } \\ 2822 & \text { remain } \\ & \end{array}$

285 commission

285 covering

285 humid

285 straw

285 dance

284 coat

284 everywhere

284 tie-beam

283 comfort

283 hexagon

282 beak

282 finance

282 myself

282 re-confirm

282 regulate

281 ant

281 intermediate

281 scatterplot

280 acute

$280 \mathrm{~kg}$

280 placenta

280 producer-entrepreneur

280 recess

279 approve

279 broad

279 interfere

279 pig 


\begin{tabular}{|c|c|}
\hline 2815 & congruence \\
\hline 2811 & constant \\
\hline 2809 & commons \\
\hline 2807 & observe \\
\hline 2788 & rectangle \\
\hline 2786 & substance \\
\hline 2765 & once \\
\hline 2756 & two-piece \\
\hline 2751 & field \\
\hline 2749 & denominate \\
\hline 2738 & detail \\
\hline 2733 & map \\
\hline 2714 & certain \\
\hline 2710 & free \\
\hline 2707 & sentence \\
\hline 2698 & special \\
\hline 2698 & child \\
\hline 2695 & age \\
\hline 2691 & solidify \\
\hline 2666 & vector \\
\hline 2663 & student-teacher \\
\hline 2660 & current \\
\hline 2649 & hold \\
\hline 2644 & old \\
\hline 2639 & paper \\
\hline 2634 & million \\
\hline 2633 & families \\
\hline
\end{tabular}

279 sharp-shooter

278 accuse

278 descend

278 genotype

278 prefix

278 raw

278 secant

277 enormity

276 bee

276 cavity

276 feeding-point

276 inter-county

276 quiet

276 rock-climb

275 adjust

275 depict

275 dice

275 ferment

275 genus

274 cite

274 classroom

274 spin

273 dream

273 lens-clip

273 mid-career

273 shine

273 shopping-basket 


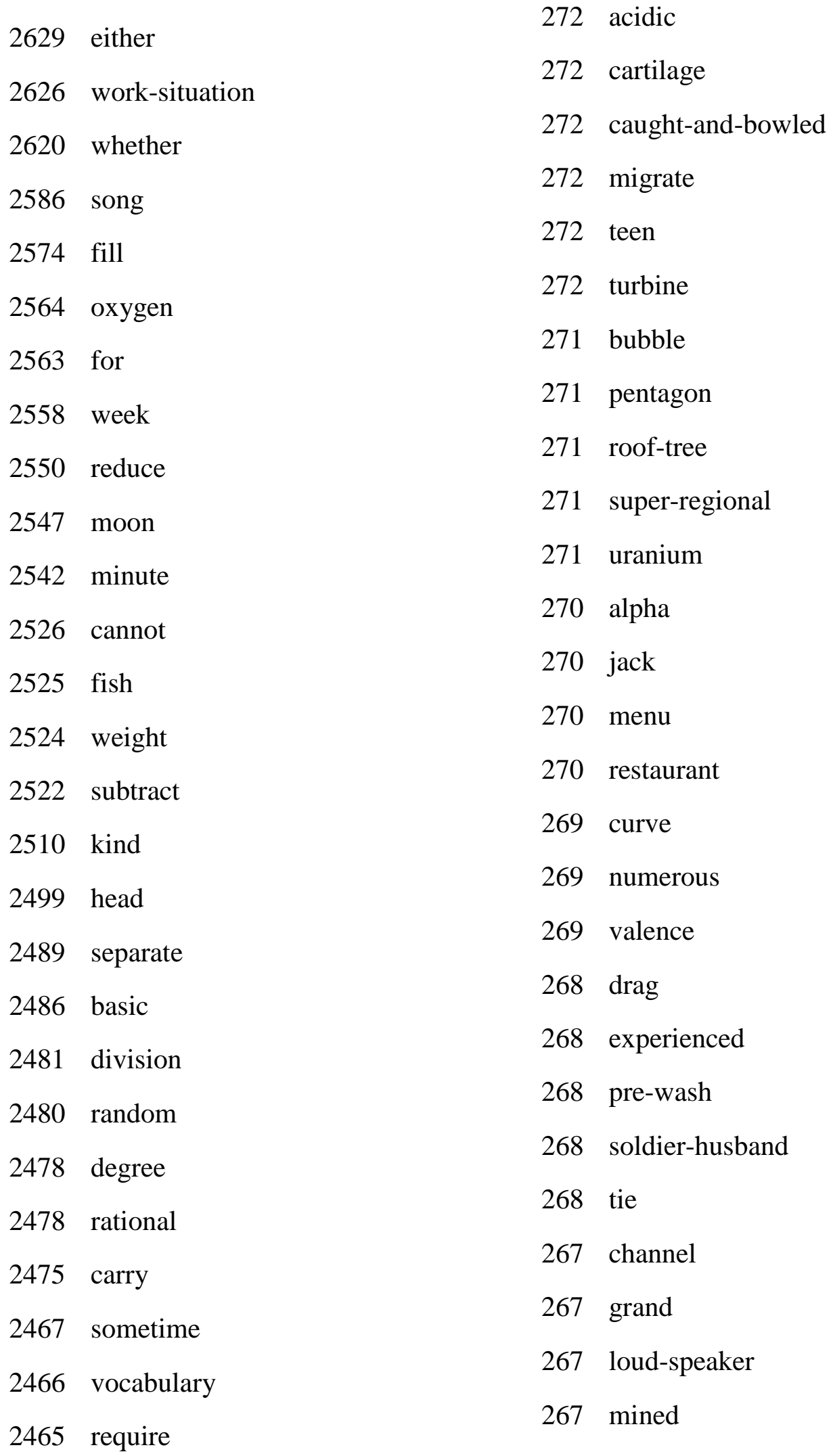




$\begin{array}{llll}2463 & \text { social-service } & 267 & \text { soup-kitchen } \\ 2462 & \text { inside } & 266 & \text { chord } \\ 2462 & \text { odd-job } & 266 & \text { liters } \\ 2461 & \text { sing-along } & 266 & \text { micro-film } \\ 2457 & \text { conclude } & 266 & \text { reactor } \\ 2447 & \text { mid-late } & 266 & \text { rhombus } \\ 2447 & \text { wind } & 266 & \text { telephone-call } \\ 2445 & \text { liquid } & 265 & \text { freshwater } \\ 2445 & \text { stamping-ground } & 265 & \text { gift } \\ 2443 & \text { cover } & 265 & \text { pore-canal } \\ 2431 & \text { protect } & 265 & \text { secrecy } \\ 2429 & \text { tennis-court } & 264 & \text { coast } \\ 2421 & \text { history } & 264 & \text { disappear } \\ 2417 & \text { design } & 264 & \text { hybrid } \\ 2412 & \text { secretary-general } & 264 & \text { larva } \\ 2410 & \text { re-form } & 264 & \text { shake } \\ 2407 & \text { vertical } & 264 & \text { southeast } \\ 2405 & \text { ball } & 263 & \text { absence } \\ 2395 & \text { bird } & 263 & \text { tract } \\ 2394 & \text { quadratic } & 262 & \text { coral } \\ 2387 & \text { bacterium } & 262 & \text { gender } \\ 2385 & \text { across } & 262 & \text { ordinary } \\ 2384 & \text { teach } & 262 & \text { pea } \\ 2382 & \text { horizon } & 261 & \text { peak-hour } \\ 2373 & \text { reach } & 261 & \text { quest } \\ 2360 & \text { enter } & 261 & \text { shelter } \\ 2359 & \text { inverse } & \text { tough } \\ & & \\ & & & \end{array}$




$\begin{array}{ll}2352 & \text { polynomial } \\ 2350 & \text { discuss } \\ 2349 & \text { individual } \\ 2342 & \text { text } \\ 2340 & \text { muscle } \\ 2336 & \text { introduction } \\ 2332 & \text { specific } \\ 2331 & \text { technology } \\ 2322 & \text { purple-blue } \\ 2316 & \text { mark } \\ 2313 & \text { major } \\ 2313 & \text { room-key } \\ 2312 & \text { bond } \\ 2304 & \text { record } \\ 2298 & \text { little } \\ 2294 & \text { rotate } \\ 2293 & \text { two-pound } \\ 2287 & \text { sure } \\ 2286 & \text { independence } \\ 2285 & \text { pay } \\ 2276 & \text { presidency } \\ 2272 & \text { video } \\ 2269 & \text { white } \\ 2265 & \text { woman } \\ 2263 & \text { consist } \\ 2261 & \text { axis } \\ 2260 & \text { outgoing } \\ & \end{array}$

260 gamma

260 negate

260 stuff

259 attribute

259 highlight

259 shelter-belt

258 filter

258 handle

257 collapse

257 illness

257 shallow

256 dress

255 john

255 music-hall

255 recycling

254 clothes

254 condense

254 elasticity

254 rice

253 assemblies

253 catalyze

253 margin

253 stead

253 suspend

253 tear

253 tour

252 lightness 


$\begin{array}{ll}2252 & \text { tell } \\ 2250 & \text { interval } \\ 2244 & \text { easy } \\ 2239 & \text { pseudo-operation } \\ 2237 & \text { friend } \\ 2236 & \text { enough } \\ 2236 & \text { exact } \\ 2234 & \text { characterize } \\ 2230 & \text { something } \\ 2227 & \text { west } \\ 2226 & \text { war } \\ 2221 & \text { temple-complex } \\ 2209 & \text { balance } \\ 2205 & \text { today } \\ 2204 & \text { over-correct } \\ 2197 & \text { indicate } \\ 2197 & \text { lonely-heart } \\ 2196 & \text { metal } \\ 2192 & \text { letter } \\ 2185 & \text { self-interest } \\ 2185 & \text { variety } \\ 2180 & \text { sex-role } \\ 2179 & \text { environment } \\ 2178 & \text { chromosome } \\ 2175 & \text { symbol } \\ 2174 & \text { intercept } \\ 2165 & \text { out-flow } \\ & \end{array}$

252 methane

252 governor

251 faith

251 helium

250 classic

250 entry

250 bat

250 hence

$250 \mathrm{mph}$

250 roundworm

249 basin

249 convince

249 hazard

249 imply

249 rush

249 uniform

248 agent

248 former

247 annelid

247 guarantee

247 hurt

247 pastry-cook

247 presentation

247 quart

247 rose-bush

247 tribute-payment

246 honor 


$\begin{array}{ll}2165 & \text { sense-organ } \\ 2163 & \text { evolution } \\ 2162 & \text { cross } \\ 2154 & \text { vote } \\ 2153 & \text { decide } \\ 2150 & \text { feel } \\ 2149 & \text { life-choice } \\ 2148 & \text { build } \\ 2148 & \text { motion-picture } \\ 2139 & \text { pass } \\ 2138 & \text { warm } \\ 2133 & \text { share } \\ 2127 & \text { light-curve } \\ 2127 & \text { until } \\ 2122 & \text { building } \\ 2122 & \text { soil } \\ 2122 & \text { station-building } \\ 2117 & \text { release } \\ 2116 & \text { three-month } \\ 2115 & \text { re-appear } \\ 2110 & \text { micro-electric } \\ 2103 & \text { green } \\ 2102 & \text { behave } \\ 2096 & \text { self-control } \\ 2093 & \text { evidence } \\ 2088 & \text { member } \\ 2085 & \text { approximate }\end{array}$

246 puzzle

246 sack-artist

246 skew

245 carrier

245 clothing

245 flame

245 flatworm

245 re-check

245 slip

244 angiosperm

244 brand

244 finite

244 homework

244 queen

244 rainforest

243 categorize

$243 \mathrm{dad}$

243 laugh

243 monkey

243 quasi-academic

243 sea-cliff

242 barrier

242 fighting

242 pulley

241 birthday

241 pendulum

241 revolve 


\begin{tabular}{llll}
2076 & drive & 240 cartoon \\
2076 & lose & 240 & manipulate \\
2072 & big-wig & 240 & pathway \\
2071 & sea-wind & 240 & re-appoint \\
2069 & magnet & 239 & adolescent \\
2067 & lifter & 239 & pregnancy \\
2065 & over-balance & 239 & proposal \\
2063 & sell & 238 & strip \\
2049 & am & 238 & aluminum \\
2048 & primary & 238 & enemy \\
2031 & hydrogen & 238 & inscribe \\
2029 & atmosphere & 238 & nice \\
2028 & gravity & 238 & noun \\
2027 & heart & 238 & pretty \\
2027 & position & 237 & adultery \\
2018 & transport & 237 & house-cow \\
2008 & normal & 237 & invention \\
2003 & dense & 236 & multi-vitamin \\
2001 & super-store & 236 & re-creation \\
1999 & ice & 236 & sub-rent \\
1997 & integer & 236 & textbook \\
1996 & fact & 235 & collide \\
1991 & egg & 235 & igneous \\
1990 & receive & 234 & cine-camera \\
1985 & plate & 234 & codon \\
1978 & hear & 234 & determinate \\
1976 & membrane & grandmother \\
& & \\
\hline
\end{tabular}




$\begin{array}{ll}1973 & \text { proportion } \\ 1958 & \text { eye } \\ 1955 & \text { round } \\ 1951 & \text { river } \\ 1950 & \text { run } \\ 1940 & \text { chart } \\ 1940 & \text { exist } \\ 1931 & \text { card } \\ 1931 & \text { flower } \\ 1929 & \text { perform } \\ 1928 & \text { discover } \\ 1928 & \text { reflect } \\ 1927 & \text { meaningful } \\ 1925 & \text { quick } \\ 1921 & \text { hard } \\ 1917 & \text { vertex } \\ 1915 & \text { source-text } \\ 1912 & \text { pie-chart } \\ 1912 & \text { row } \\ 1908 & \text { south-westerly } \\ 1907 & \text { meter } \\ 1906 & \text { never } \\ 1906 & \text { rise } \\ 1895 & \text { suppose } \\ 1893 & \text { plate-layer } \\ 1892 & \text { self-seed } \\ 1883 & \text { spend } \\ & \end{array}$

234 hydroxide

234 meal

234 rat

234 revenue

234 savings-and-loan

233 hand

233 rid

232 anaerobic

232 canyon

232 cation

232 heat

232 ore

232 shut

232 spiral

231 classmate

230 candle-stub

230 deer

230 internet

230 luck

230 over-extension

229 bay-window

229 clockwise

229 contaminate

229 harvest

229 mission

229 over-buy

229 refract 


\begin{tabular}{llll}
1876 & fossil & 229 & rent \\
1875 & physical & 229 & somewhat \\
1873 & particular & 229 & stock-pile \\
1869 & t-short & 228 & dozen \\
1868 middle & 228 & household \\
1865 & meet & 228 & jaw \\
1864 & planet & 228 & lymph \\
1861 & believe & 228 & over-borrow \\
1857 & tissue & 228 & spinning-top \\
1853 & weather & 228 & toe-cap \\
1851 & widen & 227 & defeat \\
1849 & algebra & 227 & diabetes \\
1845 & collect & 227 & symbiosis \\
1845 & house-hold & 226 & encounter \\
1845 & six-year-old & 226 & exam \\
1840 & bar & 226 & lord \\
1837 & substitute & 226 & railroad \\
1828 & life-history & 226 & sea-pink \\
1823 & instead & 226 & stiff-upper-lip \\
1822 & meaning & 225 & consecutive \\
1822 & think & 225 & mon \\
1819 & lot & 224 & groundwater \\
1818 & decrease & 224 & laboratory \\
1815 & translate & 224 & re-draft \\
1810 & face & 224 & republican \\
1810 & micro-climate & 224 & uncle \\
1810 & micro-fossil & 223 & indirect \\
& & \\
\hline & &
\end{tabular}




\begin{tabular}{ll}
1798 & parent \\
1796 & count \\
1795 & present \\
1792 & multiplication \\
1791 & author \\
1781 & deviate \\
1778 & female \\
1777 & previous \\
1775 & re-write \\
1767 & non-local \\
1764 & extend \\
1763 & care \\
1763 & game \\
1763 & room \\
1763 & block \\
1762 & pre-condition \\
1762 & short-fall \\
1761 & mix \\
1760 & play \\
1758 & near \\
1752 & nerve \\
1751 & non-national \\
1750 & focus \\
1747 & clear \\
1747 & geometry \\
1745 & repeat \\
1740 & bring \\
\hline
\end{tabular}

223 infinitely

223 mid-afternoon

223 overview

223 pot

223 quote

223 scalar

223 sweet

222 aerobic

222 dinner

222 glycolysis

222 occasion

222 spill

221 afford

221 aim

221 poet-critic

220 export

220 fits

220 flex

220 intend

220 mill

220 moon-landing

220 potassium

220 snow-drift

220 zero-crossing

219 antibiotic

219 deposition

219 emergence 


\begin{tabular}{|c|c|c|c|}
\hline 1724 & health & 219 & rainfall \\
\hline 1724 & necessitate & 219 & re-grant \\
\hline 1723 & research & 219 & toy \\
\hline 1719 & prose-character & 218 & antibody \\
\hline 1718 & seem & 218 & august \\
\hline 1708 & though & 218 & disturb \\
\hline 1708 & waste & 218 & entropy \\
\hline 1705 & die & 218 & exhibit \\
\hline 1705 & non-male & 218 & step-ladder \\
\hline 1704 & segment & 217 & activate \\
\hline 1695 & against & 217 & bend \\
\hline 1689 & young & 217 & convenience \\
\hline 1680 & re-buy & 217 & vaccine \\
\hline 1676 & culture & 217 & vesicle \\
\hline 1673 & potential & 216 & debt \\
\hline 1672 & bone & 216 & inform \\
\hline 1672 & organize & 216 & owe \\
\hline 1670 & walk & 216 & semi-permanent \\
\hline 1666 & obtain & 216 & side-pond \\
\hline 1665 & prove & 215 & con \\
\hline 1663 & politic & 215 & empirical \\
\hline 1655 & full & 215 & henry \\
\hline 1654 & spread & 215 & highway \\
\hline 1651 & statistic & 215 & mysterious \\
\hline 1650 & stop & 215 & re-insert \\
\hline 1650 & strong & 215 & squeeze \\
\hline 1647 & $\begin{array}{l}\text { octave- } \\
\text { combination }\end{array}$ & 214 & numbered \\
\hline
\end{tabular}




\begin{tabular}{ll}
1646 & correspond \\
1646 & significance \\
1645 & machine \\
1642 & run-up \\
1641 & near-synonym \\
1640 & absolute \\
1639 & east \\
1637 & expect \\
1625 & sense-unit \\
1624 & outside \\
1623 & label \\
1623 & radius \\
1622 & re-connect \\
1621 & top-to-bottom \\
1616 & over-fill \\
1615 & definition \\
1615 & over-exercise \\
1615 & strategic \\
1613 & convert \\
1604 & skin \\
1599 & advance \\
1597 & black \\
1594 & locate \\
1594 & step-mother \\
1593 & multiple-unit \\
1593 & stage \\
1592 & boy \\
\hline
\end{tabular}

214 resemble

214 sing

214 table-mat

213 comet

213 mine-sweeper

213 telephone

212 flag-pole

212 master

212 nutrition

212 pine-needle

212 pour

212 spider-web

212 suffice

212 tally

211 ace

211 carbonate

211 minimalist

211 semi-professional

210 aquifer

210 mini-budget

210 noon

210 protractor

210 reef

210 relieve

210 somewhere

209 accomplish

209 criminal 


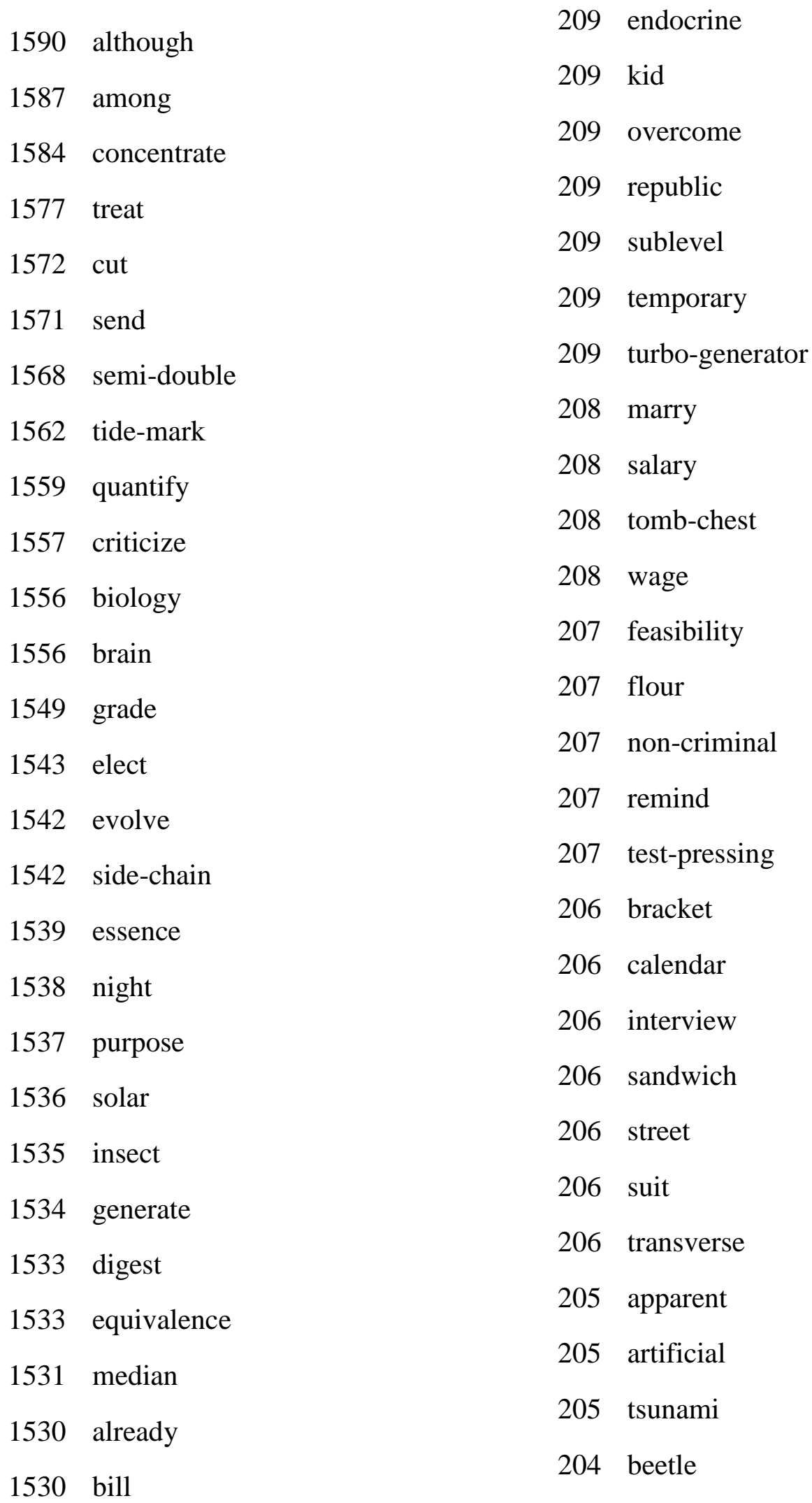




$\begin{array}{ll}1527 & \text { language } \\ 1525 & \text { dioxide } \\ 1521 & \text { turn } \\ 1520 & \text { pollute } \\ 1519 & \text { oil-spill } \\ 1518 & \text { due } \\ 1516 & \text { mineral } \\ 1514 & \text { cold-store } \\ 1513 & \text { construct } \\ 1509 & \text { nucleus } \\ 1509 & \text { slave-girl } \\ 1506 & \text { two-leg } \\ 1502 & \text { location } \\ 1496 & \text { tool } \\ 1487 & \text { safe } \\ 1486 & \text { rest } \\ 1484 & \text { dimension } \\ 1484 & \text { say } \\ 1483 & \text { cup } \\ 1482 & \text { replace } \\ 1478 & \text { efficiency } \\ 1475 & \text { stem } \\ 1474 & \text { ever } \\ 1474 & \text { pdf } \\ 1471 & \text { score } \\ 1468 & \text { polar } \\ 1467 & \text { trade } \\ \end{array}$

$\begin{array}{ll}204 & \text { gentle } \\ 204 & \text { pocket-borough } \\ 204 & \text { re-phrase } \\ 204 & \text { scenario } \\ 204 & \text { shell-burst } \\ 204 & \text { tribe } \\ 203 & \text { cnidarian } \\ 203 & \text { conjecture } \\ 203 & \text { crest } \\ 203 & \text { minister } \\ 203 & \text { out-accelerate } \\ 203 & \text { quantum } \\ 203 & \text { rub } \\ 202 & \text { anatomy } \\ 202 & \text { cold } \\ 202 & \text { herbal } \\ 202 & \text { mate } \\ 202 & \text { roll } \\ 201 & \text { assist } \\ 201 & \text { binary } \\ 201 & \text { biotechnology } \\ 201 & \text { desk } \\ 201 & \text { till } \\ 201 & \text { trail } \\ 200 & \text { anywhere } \\ 200 & \text { dry } \\ 200 & \text { emotion } \\ & \end{array}$


1467 serve

1463 coefficient

1460 perpendicular

1452 thousand

1447 skill

1441 survey

1440 talk

1437 removable

1434 bear

$1432 \operatorname{dog}$

1426 component

1420 contrast

1418 display

1413 earthquake

1408 ago

1392 accord

1388 ray

1388 return

1384 deep

1384 outline

1379 resist

1378 asymptote

1376 virus

1374 thus

1372 socialism

1371 succeed

1370 fit
$200 \min$

200 spell

200 spinal

200 track

199 concave

199 shark

199 tap

198 slant

197 crater

197 era

197 hatch

197 moral

197 out-compete

197 sac

197 stage-coach

196 advertise

196 drought

196 quiz

195 admit

195 china

195 dirt

195 exceed

195 landform

195 self-administration

194 drawings

194 non-expert

194 over-commit 


\begin{tabular}{|c|c|}
\hline 1364 & recall \\
\hline 1361 & party \\
\hline 1358 & tone-poem \\
\hline 1357 & nature \\
\hline 1354 & available \\
\hline 1354 & leave \\
\hline 1352 & $\operatorname{tax}$ \\
\hline 1351 & thought-content \\
\hline 1350 & typical \\
\hline 1344 & column \\
\hline 1340 & entire \\
\hline 1339 & team \\
\hline 1338 & super-company \\
\hline 1337 & front \\
\hline 1333 & death \\
\hline 1333 & finality \\
\hline 1333 & shall \\
\hline 1330 & pseudo-objective \\
\hline 1330 & raise \\
\hline 1330 & respiration \\
\hline 1329 & citizen \\
\hline 1328 & stay \\
\hline 1325 & match \\
\hline 1324 & engineer \\
\hline 1322 & vary \\
\hline 1320 & win \\
\hline 1318 & generalize \\
\hline
\end{tabular}

194 over-exert

194 participant

194 presidential

194 resolve

$194 \mathrm{sad}$

193 feedback

193 filament

193 multiplicative

193 pause

193 soda

193 tubule

192 childhood

192 pursuance

192 ridge-walk

192 space-fiction

192 tectonic

191 astronaut

191 exclude

191 menstrual

191 moss

191 narrate

191 non-lawyer

191 potato

191 sign

191 sparrow-hawk

191 tornado

190 biomass 


\begin{tabular}{|c|c|}
\hline 1313 & lake \\
\hline 1310 & parabola \\
\hline 1309 & continent \\
\hline 1308 & review-article \\
\hline 1308 & super-computer \\
\hline 1307 & retro-fit \\
\hline 1305 & throughout \\
\hline 1304 & branch \\
\hline 1304 & polygon \\
\hline 1304 & toward \\
\hline 1301 & photo-pass \\
\hline 1300 & fungus \\
\hline 1293 & fly \\
\hline 1291 & self-reflection \\
\hline 1290 & notable \\
\hline 1289 & derive \\
\hline 1288 & topic-shift \\
\hline 1287 & large \\
\hline 1285 & almost \\
\hline 1285 & item \\
\hline 1285 & trouser-front \\
\hline 1282 & source \\
\hline 1281 & run-past \\
\hline 1281 & tall \\
\hline 1277 & rain \\
\hline 1276 & dissolve \\
\hline 1276 & link \\
\hline
\end{tabular}

190 cardiac

190 chip

190 lack

190 quark

190 scarce

189 hotspot

189 intelligence

189 loud

189 stone

189 tilt

189 vacuole

188 bucket

188 campaign

188 heaven

188 heterotroph

188 molar

188 odds

188 passive

188 seal

188 soul

188 suck

188 taxonomy

187 ahead

187 conceptualize

187 deny

187 feed

187 ionize 
1275 account

1274 associate

1269 mammal

1266 short-change

1264 agree

1264 wood

1261 photo

1261 yes

1255 sexuality

1248 matrix

1243 electromagnet

1241 combine

$1240 \quad \log$

1240 recognition

1238 course

1236 extreme

1235 tail

1233 saw-mill

1229 wall

1228 fire

1228 wide

1226 non-essential

1224 accelerate

1224 prevent

1218 rule

1218 supply

1216 appropriate
187 lady-friend

$187 \max$

187 multiple

187 re-hire

187 uterus

186 angular

186 flavor

185 append

185 athlete

185 gradient

185 lighter

185 nickel

185 projectile

185 soup

185 stream-line

184 bur

184 dear

184 geothermal

184 hemoglobin

184 homogeneity

184 metamorphic

184 monarch

184 mushroom

184 physiological

184 rocky

184 soccer

184 weapon 


$\begin{array}{ll}1216 & \text { pump } \\ 1215 & \text { soil-nutrient } \\ 1212 & \text { cancer } \\ 1212 & \text { visit } \\ 1208 & \text { over-extend } \\ 1207 & \text { converge } \\ 1207 & \text { tangency } \\ 1205 & \text { ease } \\ 1203 & \text { re-discover } \\ 1202 & \text { industrial } \\ 1202 & \text { short-circuit } \\ 1202 & \text { wiki } \\ 1201 & \text { adult } \\ 1193 & \text { tri-gram } \\ 1192 & \text { spring } \\ 1188 & \text { non-identity } \\ 1188 & \text { re-build } \\ 1188 & \text { semi-final } \\ 1188 & \text { symmetry } \\ 1187 & \text { change } \\ 1183 & \text { numerator } \\ 1178 & \text { mechanic } \\ 1178 & \text { sugar } \\ 1177 & \text { pine-cone } \\ 1176 & \text { ion } \\ 1176 & \text { pull } \\ 1176 & \text { yellow } \\ & \end{array}$

184 winner

183 automate

183 book-binding

183 deposited

183 dictionary

183 landscape

183 lit

183 lone-pair

183 motor-habit

183 nineteenth

183 owl

183 recommend

183 roller-blind

183 side-drum

183 terminate

183 turkey

183 tutor

182 condensate

182 fellow-creature

182 polymerase

181 convex

181 discount

181 microorganism

181 photon

181 rust

181 silent

181 tortoise 


$\begin{array}{llll}1174 & \text { re-assume } & 181 \text { trunk } \\ 1173 \text { bag } & 181 \text { urine } \\ 1173 \text { trait } & 180 \text { awl } \\ 1170 & \text { volcano } & 180 & \text { phloem } \\ 1166 & \text { town } & 180 & \text { phosphate } \\ 1164 & \text { decay } & 180 & \text { sweep } \\ 1162 & \text { interpret } & 179 & \text { rose-petal } \\ 1161 & \text { congress } & 179 & \text { screw } \\ 1159 & \text { drop } & 179 & \text { sheep-track } \\ 1157 & \text { sunlight } & 178 & \text { captain } \\ 1155 & \text { religion } & 178 & \text { infinity } \\ 1155 & \text { stand } & 178 & \text { royal-watcher } \\ 1153 & \text { three-iron } & 178 & \text { software } \\ 1151 & \text { miss } & 178 & \text { thermometer } \\ 1147 & \text { sea-salt } & 178 & \text { tommy-gun } \\ 1146 & \text { net } & 177 & \text { engage } \\ 1146 & \text { rather } & 177 & \text { limb } \\ 1145 & \text { experience } & 177 & \text { refrigerator } \\ 1144 & \text { lie } & 177 & \text { semi-pro } \\ 1143 & \text { digit } & 177 & \text { spoon } \\ 1138 & \text { difficulty } & 177 & \text { throat } \\ 1138 & \text { hair } & 177 & \text { trigger } \\ 1136 & \text { weigh } & 176 & \text { anion } \\ 1134 & \text { composite } & 176 & \text { essay } \\ 1133 \text { shade } & 176 & \text { helix } \\ 1126 & \text { billion } & 176 & \text { irregular } \\ 1126 & \text { error } & 176 & \text { judicial } \\ & & \\ & & \end{array}$




$\begin{array}{ll}1125 & \text { semi-colony } \\ 1119 & \text { apart } \\ 1117 & \text { trouser-press } \\ 1116 & \text { ride } \\ 1115 & \text { tube } \\ 1111 & \text { issue } \\ 1108 & \text { hearing-aid } \\ 1107 & \text { slow-match } \\ 1105 & \text { favor } \\ 1104 & \text { king } \\ 1103 & \text { love } \\ 1100 & \text { long-hair } \\ 1099 & \text { floor } \\ 1097 & \text { non-native } \\ 1096 & \text { sea-floor } \\ 1095 & \text { transfer } \\ 1094 & \text { classified } \\ 1091 & \text { dark } \\ 1090 & \text { iniquity } \\ 1088 & \text { train } \\ 1081 & \text { maintain } \\ 1080 & \text { amendment } \\ 1080 & \text { damage } \\ 1079 & \text { modern } \\ 1079 & \text { upon } \\ 1078 & \text { yet } \\ 1073 & \text { report } \\ \end{array}$

176 plenty

175 capacitor

175 eagle

175 endotherm

175 envelop

175 foil

175 devil

175 lifetime

175 manager

175 rack-mount

175 runoff

175 wax

174 concrete

174 confederate

174 noise

174 queue

174 sensitive

174 temple

173 joy

173 dam

173 insight

173 spider

173 sunny

172 messenger

172 search

172 stove

172 format 


\begin{tabular}{|c|c|c|c|}
\hline 72 & guidance & 172 & tail-gate \\
\hline \multirow{2}{*}{1069} & \multirow{2}{*}{ courtesy } & 171 & affair \\
\hline & & 171 & afraid \\
\hline 1065 & totem-pole & 171 & crack \\
\hline 1063 & fair & 171 & hanging \\
\hline 1062 & suggest & 171 & initiate \\
\hline 1060 & resombine & 171 & re-arm \\
\hline 1060 & IC-comindinte & 171 & ribbon \\
\hline 1058 & 1Cprouction & 171 & slime \\
\hline & Sturage & 171 & wetland \\
\hline 051 & sub-project & 170 & citizenship \\
\hline 1050 & pseudo-device & & \\
\hline 1050 & re-examine & 170 & grandfather \\
\hline 1047 & lung & 170 & possess \\
\hline 1045 & whose & 170 & scheme \\
\hline 1043 & swimming-nool & 170 & switch \\
\hline 1042 & straight-iacket & 170 & tobacco \\
\hline & & 169 & alveoli \\
\hline 139 & chance & 160 & enidermis \\
\hline 1039 & semi-regular & & epidermis \\
\hline 1037 & sky & 169 & mere \\
\hline 1036 & cool & 169 & protozoa \\
\hline 1030 & non-decision & 169 & suspect \\
\hline & Hest & 168 & non-migrant \\
\hline & & 168 & recipient \\
\hline 1027 & business & & \\
\hline 1024 & sine & 168 & redox \\
\hline 1024 & trigonometry & 168 & stamp \\
\hline & rain-forest & 168 & witness \\
\hline 1022 & communicate & 167 & cactus \\
\hline
\end{tabular}




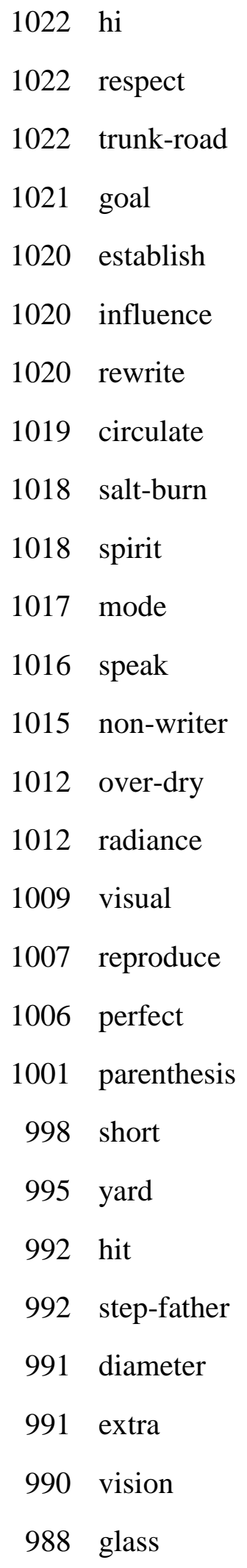

167 census

167 emphasize

167 aunt

167 insulin

167 mild

167 side-line

167 skin-diver

167 sub

167 tongue

167 voyage

166 assemble

166 bundle

166 entertain

166 newly-wed

166 plural

166 resolute

166 seed

166 static

166 walker

165 incidence

165 invite

165 judgment

165 lean

165 phrase

164 dime

164 nonvascular

164 outdoor 


\begin{tabular}{|c|c|c|c|}
\hline 986 & settle & 164 & terrible \\
\hline 981 & contribute & 164 & testis \\
\hline 981 & expand & 163 & compact \\
\hline 981 & introduce & 163 & conjugate \\
\hline 980 & ship & 163 & conscience \\
\hline 980 & kill & 163 & enhance \\
\hline 978 & island & 163 & heading \\
\hline 978 & themselves & 163 & membership \\
\hline 975 & attract & 163 & ourselves \\
\hline 975 & organization & 163 & pad \\
\hline 974 & attend & 163 & relax \\
\hline 973 & fat & 163 & semi-dwarf \\
\hline 973 & pyramid & 163 & stage-dive \\
\hline 971 & integral & 163 & swim-bladder \\
\hline 969 & unique & 163 & table-lamp \\
\hline 968 & century & 162 & cable \\
\hline 966 & core & 162 & circumstance \\
\hline 966 & eukaryote & 162 & over-concentrate \\
\hline 966 & thunder-cloud & 162 & pint \\
\hline 966 & wire & 162 & re-launch \\
\hline 963 & centimeter & 162 & roller-towel \\
\hline 963 & petro-dollar & 162 & snail \\
\hline 962 & date & 162 & tomato \\
\hline 962 & interest & 162 & underground \\
\hline 961 & opinion & 161 & bowl \\
\hline 959 & summer & 161 & gymnosperm \\
\hline 959 & harm & 161 & hummingbird \\
\hline
\end{tabular}




\begin{tabular}{|c|c|}
\hline 957 & hormone \\
\hline 957 & literacy \\
\hline 957 & velocity \\
\hline 954 & ten-foot \\
\hline 952 & park \\
\hline 952 & re-fuel \\
\hline 951 & exercise \\
\hline 951 & fast \\
\hline 951 & site \\
\hline 950 & benefit \\
\hline 950 & gold \\
\hline 949 & earn \\
\hline 949 & winter \\
\hline 947 & someone \\
\hline 947 & universe \\
\hline 946 & save \\
\hline 945 & cosine \\
\hline 943 & message \\
\hline 942 & habitat \\
\hline 940 & twice \\
\hline 936 & snow-bank \\
\hline 934 & binomial \\
\hline 933 & interact \\
\hline 931 & principle \\
\hline 931 & trial \\
\hline 929 & fertility \\
\hline 928 & tend \\
\hline
\end{tabular}

161 iron-founder

161 minus

161 starch

161 submit

161 wake

160 convey

160 hammer

160 lunar

160 mucus

160 non-earning

160 nut

160 oblique

160 outward

160 partly

160 phyla

160 re-classify

159 breakfast

159 director

159 embed

159 facilitate

159 harmonic

159 inertia

159 jar

159 milliliter

159 poll

159 re-acquire

159 swallow 
927 eventuality

927 go-fast

927 path

926 fix

925 except

924 magnitude

921 voice

920 challenge

918 consumption

917 surround

916 hole

914 cube

912 immune

908 inter-connection

908 proof

907 loss

905 photosynthesis

905 six-hit

904 tiny

903 self-description

900 dominance

900 isolate

899 office

897 vessel

895 six-cylinder

893 prism

892 intersect
159 traffic

158 chlorophyll

158 don't

158 guilt

158 microwave

158 self-doubt

158 sock

157 massive

157 penny-farthing

157 photovoltaic

157 re-fold

157 repetition

157 semi-dome

157 senior

156 cholesterol

156 custom

156 graduate

156 longitude

156 participant-observer

156 repel

156 role-mapping

156 skateboard

156 tent

156 territory

156 treasure

156 wheat

155 angry 


\begin{tabular}{|c|c|}
\hline 890 & big \\
\hline 890 & mountain-top \\
\hline 889 & recent \\
\hline 888 & proton \\
\hline 887 & arrive \\
\hline 886 & interior \\
\hline 885 & technique \\
\hline 883 & histogram \\
\hline 883 & prokaryote \\
\hline 882 & built-in \\
\hline 882 & sub-program \\
\hline 882 & ton \\
\hline 881 & plug \\
\hline 880 & bind \\
\hline 879 & dead \\
\hline 879 & shape \\
\hline 878 & wear \\
\hline 875 & pan \\
\hline 873 & improve \\
\hline 873 & door \\
\hline 872 & nation-state \\
\hline 870 & minimum \\
\hline 867 & danger \\
\hline 866 & sphere \\
\hline 865 & setting \\
\hline 863 & publish \\
\hline 862 & riding-crop \\
\hline
\end{tabular}

155 consent

155 ethane

155 lobe

155 motion

155 psycho-drama

155 reflex

155 thread

155 vein

154 ash-tray

154 cleaner

154 disk

154 fight

154 five-aside

154 flash

154 gill

154 philosopher

154 rabbit-warren

154 reservoir

154 retain

153 absorbance

153 butter

153 fever

153 halfway

153 hungry

153 khan

153 restore

153 strain 
862 sand

861 trumpet-player

856 advantage

856 counter-argument

856 rough

855 especial

854 enzyme

$853 \mathrm{bad}$

853 theme

852 arm

852 glucose

852 revolt

851 future

851 quadrilateral

849 invert

849 window

848 rose-garden

847 partner

846 heavy

844 behind

844 trouble-spot

841 edge

840 seven-year-old

839 instance

838 risk

837 accept

837 customer
152 apparatus

152 carboxylate

152 cerebrum

152 curiosity

152 employ

152 exert

152 firm

152 hearth-fire

152 non-metallic

152 serving-woman

152 warren

151 cheap

151 dipole

151 donate

151 explicit

151 ink

151 platform

151 refuge

150 award

150 pore

150 sole

150 torture-chamber

150 tumor

149 appreciate

149 celebrate

149 crowd

149 hang 
837 dimensional

837 touch

835 empire

835 slave

834 pathogen

830 boundaries

830 erode

830 tying

829 input-output

828 trip

827 internal

827 polka-dot

827 race

827 signal

826 hill

825 fish-farm

825 freeze

825 sand-hill

824 coin-op

824 gallon

823 subtraction

819 shadow

818 infinite

818 power

818 station

817 battery

816 conserve
149 incomplete

149 marc

149 segregate

149 strict

149 verbal

148 crowd-puller

148 kite

148 pituitary

148 spontaneity

148 wasp

147 affiliation

147 cellulose

147 double

147 gulf

147 nonliving

147 premise

147 trash

146 cytokinesis

146 enthalpy

146 hate

146 ingredient

146 koala

146 biologist

146 non-resistant

146 peripheral

146 prohibit

146 shoulder-width 


\begin{tabular}{|c|c|c|}
\hline 815 education & 146 & verse \\
\hline host & 145 & axle \\
\hline intersection & 145 & bloom \\
\hline noor & 145 & chromatid \\
\hline adant & 145 & counterclockwise \\
\hline 809 thin & 145 & follicle \\
\hline 804 bisect & 145 & innovate \\
\hline 804 steam-engine & 145 & memorize \\
\hline 802 outer & 145 & $\mathrm{mg}$ \\
\hline molecular & 145 & orientation \\
\hline tradition & 145 & ox-cart \\
\hline 797 join & 145 & doubled \\
\hline 797 super-market & 145 & soap \\
\hline 796 allele & 144 & brake \\
\hline 796 ipg & 144 & calling-card \\
\hline 795 sales-force & 144 & cave \\
\hline 795 semi-desert & 144 & contour \\
\hline 793 poet & 144 & dig \\
\hline 793 representative & 144 & disadvantage \\
\hline 791 ear & 144 & flashlight \\
\hline 791 hypotenuse & 144 & footprint \\
\hline 790 mind-reader & 144 & molted \\
\hline 790 orbit & 144 & punishment \\
\hline 789 art & 144 & sage \\
\hline 789 spy-fly & 144 & website \\
\hline 788 ancient & 143 & amp \\
\hline 788 deliver & 143 & assign \\
\hline
\end{tabular}




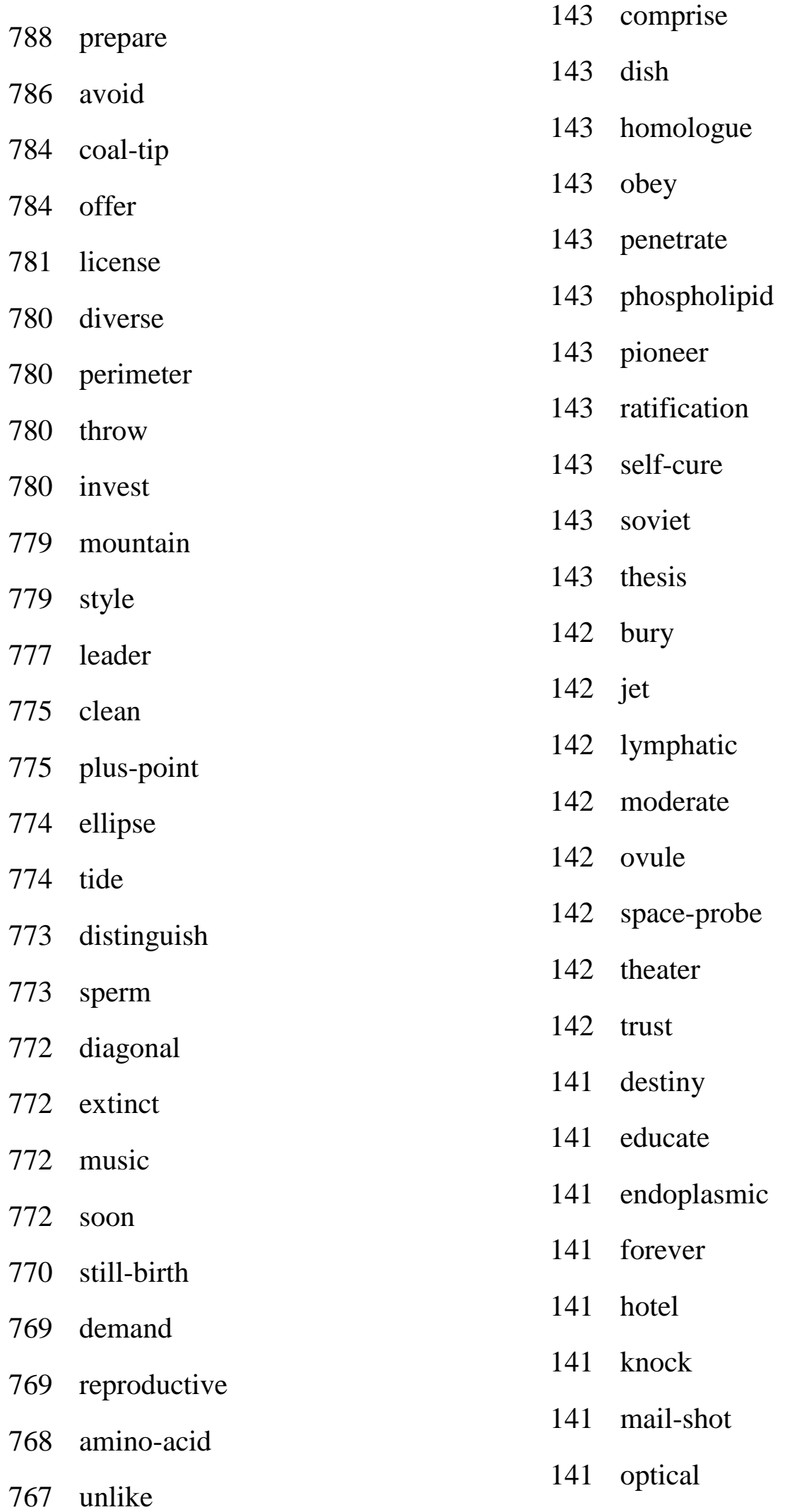


767 vertebrate

766 ready

766 topic

765 everything

764 anything

764 red-brown

761 strike

760 ax

760 output

759 option

759 sea-flat

758 geology

758 season

757 gland

757 numeric

755 else

754 distinct

752 kingdom

752 minute-book

751 paragraph

750 classification

750 ion-exchange

750 midpoint

750 southern

748 re-arrange

748 renewable

745 thick
141 shout

141 sing-song

141 tick

141 tomorrow

140 autotrophy

140 backward

140 backwards

140 bare

140 cathode

140 delay

140 discharge

140 grassland

140 heredity

140 lecture-demonstration

140 magazine

140 mood-swing

140 pod

140 re-impose

140 scoop

140 southwest

140 tremendous

140 wolf

139 blue-jean

139 diary

139 fool

139 japan

139 mini-holiday 
744 election

744 god

740 meiosis

739 supplement

734 colonize

734 ticket

733 eliminate

731 familiar

730 defend

730 guess

727 official

726 mole

725 marble

725 sea-coast

724 sketch-pad

724 union

723 dilate

723 mouth

722 fuel

721 re-gain

$720 \mathrm{~cm}$

719 board

719 nation

719 over-control

719 physician

717 consume

717 self
139 remarkable

139 self-quotation

139 sentence-fragment

139 shuttle

139 weed

138 abolish

138 carnivore

$138 \cot$

138 defect

138 hurry

138 lever

138 metalloid

138 oak-wood

138 reticulum

138 cloth

138 tooth-brush

137 crew

137 esophagus

137 faculty

137 house-guest

137 receiving-station

137 self-improvement

137 stain

137 super-tyrant

137 thumb

136 amniotes

136 caterpillar 


\begin{tabular}{ll}
716 & erupt \\
712 & babies \\
712 & formation \\
708 & destroy \\
708 & emit \\
707 & distribute \\
707 & neighbor \\
707 & northern \\
707 & radio-phone \\
703 & endings \\
701 & sunshine \\
701 & tan \\
698 & boil \\
697 & snow-wreath \\
699 & fing \\
696 & foreign \\
696 & sex-war \\
695 & re-attach \\
694 & attack \\
694 & breathe \\
693 & step-son \\
692 & web \\
691 & pick-up \\
690 & proper \\
699 luid \\
\hline 69
\end{tabular}

136 cattle-yard

136 disaster

136 hollow

136 hook

136 inventor

136 oil

136 six-bedroom

136 social-revolutionary

136 sporophyte

135 altogether

135 arrest

135 beta

135 diatom

135 editor

135 lateral

135 likewise

135 liter

135 polymer

135 quilt

135 shield

135 trophic

135 welcome

135 shower

134 bite

134 cumulate

134 filter-feeder

134 instruct 


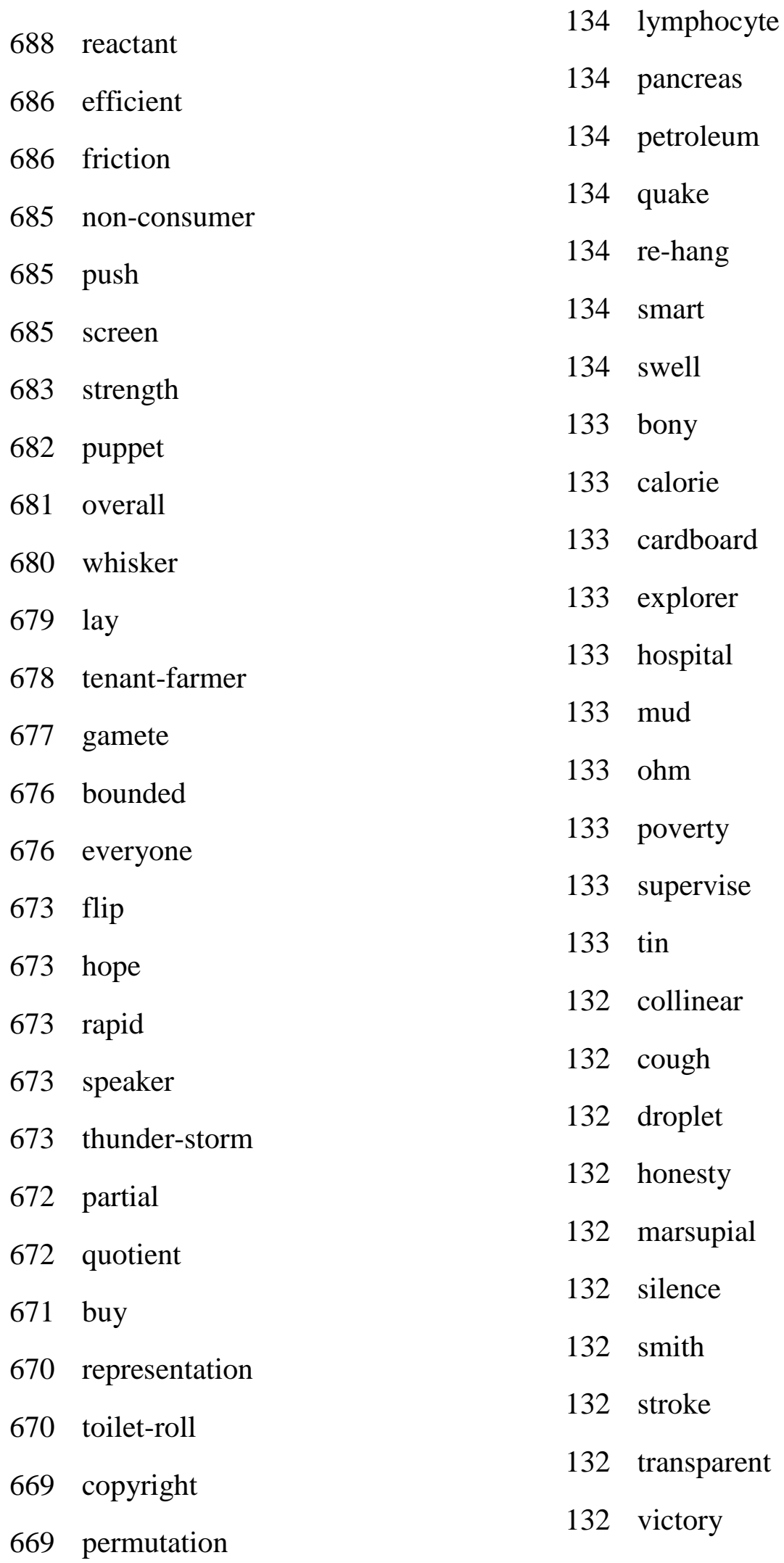




$\begin{array}{llll}668 \text { mega-deal } & 132 \text { whisper } \\ 667 \text { belong } & 131 \text { biography } \\ 666 \text { fold } & 131 \text { chimney-breast } \\ 666 \text { microscope } & 131 \text { cortex } \\ 666 \text { progress } & 131 \text { counter-claim } \\ 666 \text { speech } & 131 \text { dive } \\ 666 \text { upper } & 131 \text { exothermic } \\ 662 \text { inherit } & 131 \text { brick } \\ 661 \text { pre-adaptation } & 131 \text { pascal } \\ 661 \text { substitution } & 131 \text { raccoon } \\ 660 \text { prefer } & 131 \text { sliding-scale } \\ 659 \text { quite } & 131 \text { testosterone } \\ 656 \text { bottle } & 131 \text { thunderstorm } \\ 655 \text { milk-yield } & 131 \text { worldwide } \\ 654 \text { checkpoint } & 130 \text { announce } \\ 653 \text { weak } & 130 \text { axon } \\ 652 \text { honey-guide } & 130 \text { bold } \\ 649 \text { nothing } & 130 \text { delegate } \\ 648 \text { fail } & 130 & \text { epicenter } \\ 648 \text { slight } & 130 \text { guideline } \\ 648 \text { vehicle } & 130 \text { inconsistent } \\ 646 \text { offspring } & 130 \text { priority-dispute } \\ 646 \text { purchase } & 130 \text { pulmonary } \\ 646 \text { toffee-apple } & 130 \text { sea } \\ 646 \text { toss } & 130 \text { staff } \\ 645 \text { exchange } & 130 \text { vast } \\ 645 \text { investigation } & 129 \text { bunch } \\ & & \\ 6 & & \end{array}$




\begin{tabular}{|c|c|c|c|}
\hline 645 & perhaps & 129 & dash \\
\hline 643 & background & 129 & furnish \\
\hline & compute & 129 & josh \\
\hline 643 & stand-alone & 129 & jumping \\
\hline 642 & & 129 & misleading \\
\hline 642 & yield & 129 & rabbit \\
\hline 641 & profit & 129 & seismogram \\
\hline 640 & onto & 129 & shock-wave \\
\hline 636 & diffuse & 129 & singular \\
\hline 635 & procedural & 129 & skate \\
\hline 635 & self-interaction & 129 & tune \\
\hline 634 & eating-disorder & 129 & yeast \\
\hline 634 & regression & 128 & amuse \\
\hline 634 & wheel & 128 & biofuel \\
\hline 632 & sit & 128 & blade \\
\hline 632 & wonder & 128 & cereal \\
\hline 631 & concern & 128 & crush \\
\hline 630 & moment & 128 & flagella \\
\hline 629 & experiment & 128 & gametophyte \\
\hline 629 & possibility & 128 & re-amend \\
\hline 628 & precise & 128 & remote \\
\hline 627 & animate & 128 & scaffold \\
\hline 627 & equilibrate & 128 & shelf \\
\hline 627 & neither & 128 & side-shoot \\
\hline 627 & trapezoid & 127 & admire \\
\hline 626 & news-stand & 127 & align \\
\hline & predator & 127 & commander \\
\hline
\end{tabular}




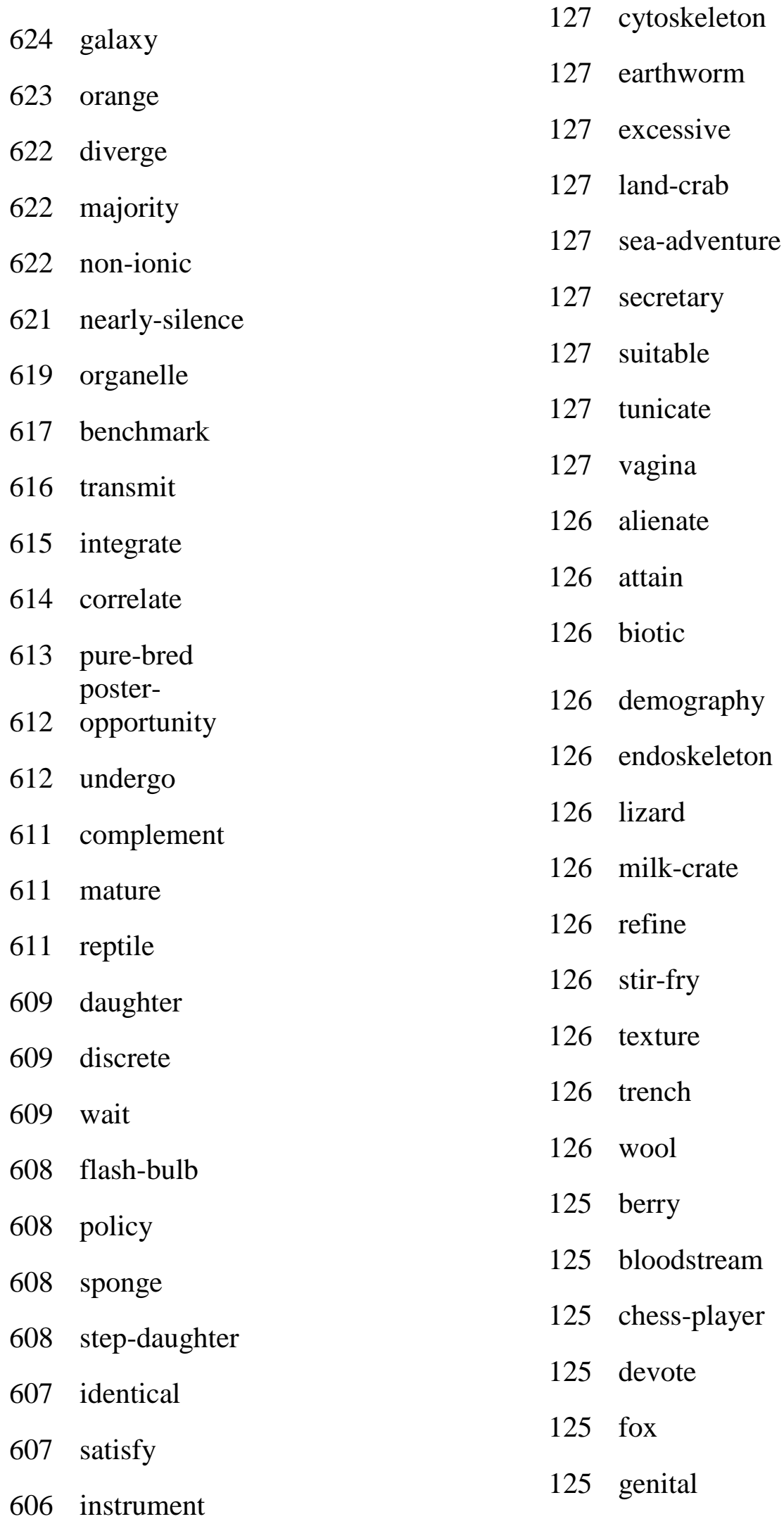




\begin{tabular}{ll}
605 & college \\
605 & crust \\
605 & intestinal \\
603 & ideal \\
603 & serious \\
603 & smoke \\
601 & tip \\
600 & wish \\
599 & prey \\
597 & tom-cat \\
596 & candy \\
596 & daily \\
596 & quadrant \\
594 & telescope \\
593 & over-determine \\
593 & vapor \\
591 & candidate \\
590 & biome \\
590 & pencil \\
590 & sheet \\
589 & crystal \\
589 & sample \\
589 & sleep \\
588 & modify \\
588 & transit \\
587 & nitrogen \\
\hline $580 u p$ \\
\hline 50
\end{tabular}

125 hydroelectricity

125 informal

125 moreover

125 near-contemporary

125 originate

125 pot-lid

125 retire

125 spacecraft

125 stage-manage

125 strawberry

125 stripe

124 benzene

124 complain

124 curriculum

124 dip

124 golf

124 grandpa

124 micro-electrode

124 radial

124 rearrange

124 regularity

124 rift

124 topography

123 array

123 calm

123 chaparral

123 chi 
586 mass

585 covalent

585 international

585 p-orbital

584 string

583 confide

583 depth

583 tit-bit

583 university

582 brighten

581 biodiverse

581 literature

578 mid-year

578 re-absorb

578 scatter

577 alga

577 drug

577 push-up

577 vascular

576 media

576 parameter

576 step-sister

575 intense

575 mitosis

575 portion

575 smart-drug

574 investigate
123 designate

123 elsewhere

123 goggle

123 lily

123 notochord

123 sand-dune

123 single-coil

123 sore

123 stat

123 tessellate

123 urchin

123 youth

122 anti-woman

122 coelom

122 genre

122 heterozygote

122 infancy

122 inhabit

122 magnify

122 sickle

122 troop

121 abundance

121 ammonia

121 blood-bead

121 bureau

121 busy-body

121 urge 
574 stick

573 felt

573 regard

573 sixth-former

572 space-arc

571 beyond

571 reciprocal

571 paint

571 passage

571 slow

570 brother

569 arrow

568 conduct

568 wrong

567 balloon

567 melt

567 smooth

566 circumference

565 capital

565 trace

564 own

563 solute

562 morning

559 coming

556 adjacent

556 precipitate

555 income
121 watt

120 approval

120 bi-focal

120 crash

120 crucial

120 deform

120 guard

120 infrared

120 novel

120 semi-colon

120 spindle

120 via

120 video-recording

119 banana

119 expedition

119 fracture

119 headed

119 miller

119 mind

119 photosynthetic

119 sigma

119 spot-kick

119 capsule

119 welfare

118 counterexample

118 cruelty

118 diagnose 
555 metric

555 pack

554 cancel

553 prep

553 sport

553 tile

552 newton

552 truth-claim

551 compete

551 spoon-feed

550 mirror

550 pick

550 print

550 zone

549 bake

549 grass

549 radio-wave

548 detect

548 revise

547 price

546 size

545 valley

544 empty

544 lock

544 pre-arthropod

544 village

543 ten-year-old
118 dilemma

118 preview

118 scope

117 ben

117 carrot

117 centripetal

117 ether

117 funny

117 hike

117 lemon

117 syndrome

116 abuse

116 acre

116 contraption

116 coyote

116 decorate

116 diaphragm

116 echo

116 elementary

116 glossary

116 meteor

116 nonpolar

116 reply

116 scholar-critic

116 stargaze

116 weekend

115 chew 
542 district

542 himself

542 manufacture

542 restrict

542 ribosomal

541 fundamental

541 obvious

541 wing

540 land-bridge

540 sub-shell

539 fault

539 rolling-pin

539 wash

538 radioactive

537 re-arrangement

536 movie

535 carbohydrate

534 flight

534 listen

533 agriculture

532 stomach

531 violate

530 fear

529 grid

528 compose

527 rich

526 cook
115 evil

115 fantasy

115 funds

115 high-explosive

115 nonrenewable

115 phosphoric

115 polyp

115 re-cast

115 robot

115 salad

115 seismic

115 systematic

114 cage

114 confine

114 crustacean

114 equiangular

114 fern

114 shah

114 steal

114 wedge

113 adequacy

113 clip

113 everybody

113 flu

113 hey

113 lithosphere

113 medication 
525 street-woman

524 para-military

524 band

522 attempt

522 plastic

522 sea-grass

522 simulate

521 effort

521 ended

520 inner

520 rope

518 hunt

517 mentally

516 oxidation

516 realize

516 wild

515 justify

515 soft-drink

514 oxide

514 san

513 proctor

511 altitude

511 copper

510 index

510 tooth

509 clue

509 newspaper
113 mollusk

113 motivate

113 multimedia

113 spittle-bug

112 anxiety

112 anyway

112 cherry

112 clot

112 fork

112 geyser

112 hypothalamus

112 invisible

112 metamorphosis

112 paw

112 proud

112 salt-marsh

112 troposphere

112 twist

111 bud

111 creep

111 enlarge

111 fright

111 induce

111 issued

111 jury

111 mobile

111 salt 


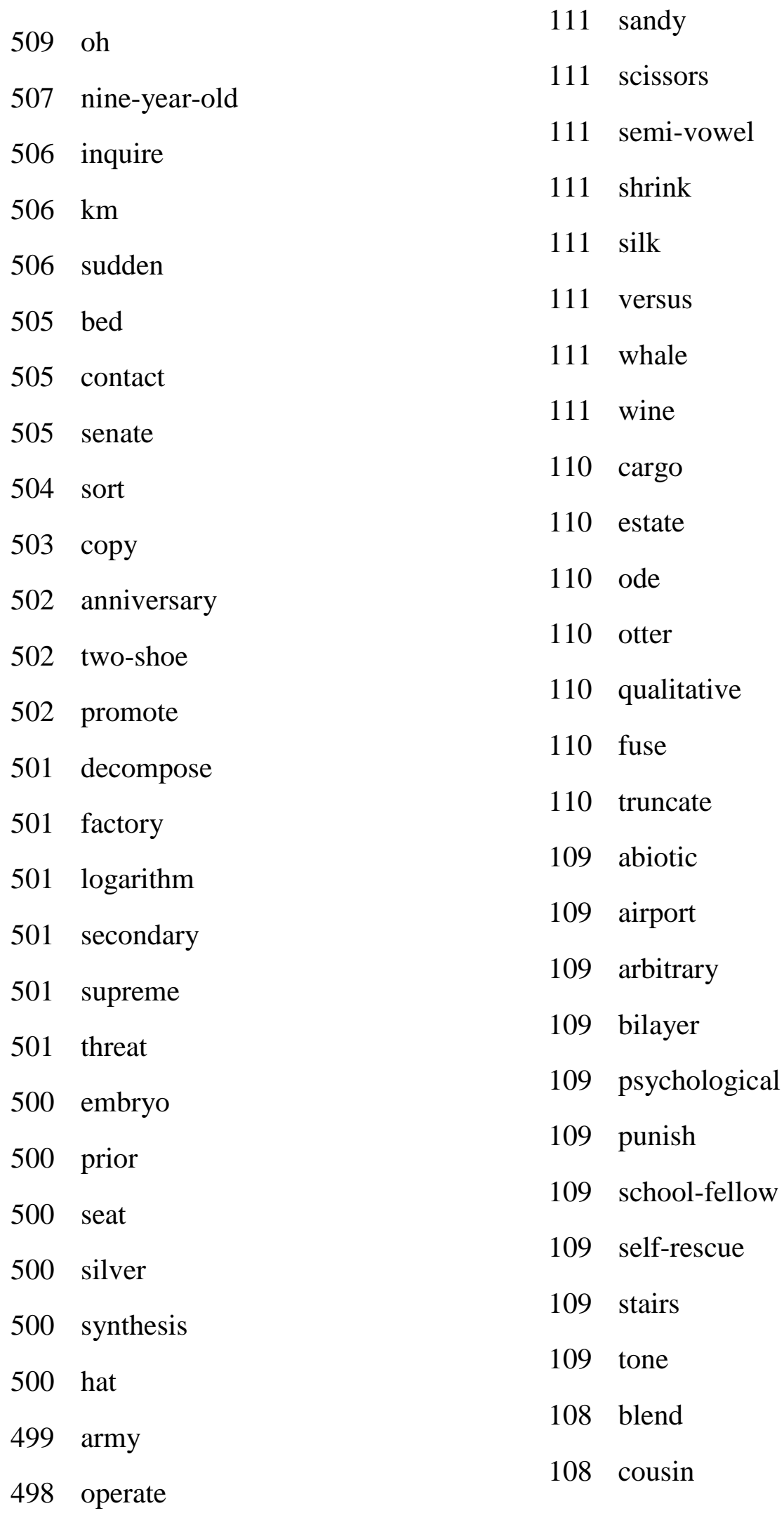




\begin{tabular}{|c|c|c|}
\hline reveal & 108 & intent \\
\hline 498 search-party & 108 & interrupt \\
\hline cord & 108 & master-manufacturer \\
\hline isosceles & 108 & mow \\
\hline satellite & 108 & program \\
\hline worth & 108 & swimming-bath \\
\hline 496 contract & 108 & vacation \\
\hline expend & 108 & yesterday \\
\hline burn & 107 & cape \\
\hline 495 lack-of-pulse & 107 & crow \\
\hline photo-story & 107 & embody \\
\hline assess & 107 & encyclopedia \\
\hline bus-ticket & 107 & exoskeleton \\
\hline houses & 107 & germ \\
\hline sodium & 107 & malaria \\
\hline radian & 107 & meteorite \\
\hline aspect & 107 & meteorologist \\
\hline surprise & 107 & non-emergency \\
\hline colonial & 107 & nurse \\
\hline non-customer & 107 & orient \\
\hline transcribe & 107 & precede \\
\hline parasite & 107 & sting \\
\hline staging-post & 107 & tail-fin \\
\hline cytoplasm & 107 & top-knot \\
\hline pump-prime & 107 & urban \\
\hline 487 wrap & 106 & climb \\
\hline 5 neutron & 106 & electrolyte \\
\hline
\end{tabular}




\begin{tabular}{|c|c|}
\hline 484 & glacier \\
\hline 483 & crime \\
\hline 483 & persuade \\
\hline 483 & pollen \\
\hline 482 & address \\
\hline 482 & carrying-on \\
\hline 482 & medium \\
\hline 482 & purple \\
\hline 482 & reverse-punch \\
\hline 481 & chloroplast \\
\hline 481 & street-fight \\
\hline 480 & convention \\
\hline 480 & neuron \\
\hline 480 & rare \\
\hline 480 & re-capture \\
\hline 480 & taste \\
\hline 480 & t-shirt \\
\hline 479 & institute \\
\hline 479 & sale-room \\
\hline 479 & stretch \\
\hline 478 & co-act \\
\hline 476 & gather \\
\hline 476 & hide \\
\hline 476 & journal \\
\hline 476 & $\begin{array}{l}\text { overlap } \\
\text { sub-sub- }\end{array}$ \\
\hline 476 & committee \\
\hline
\end{tabular}

106 equidistant

106 jelly

106 machinery

106 milk

106 municipal

106 octagon

106 peanut

106 phylogenetic

106 seize

106 stoichiometry

106 subduction

106 towel

105 arctic

105 biosphere

105 cement

105 daylight

105 deficit

105 emphasis

105 germinate

105 harbor

105 impress interpretation-

105 computation

105 lend

105 monomial

105 operon

105 roller-coaster 


$\begin{array}{ll}474 & \text { plasma } \\ 473 & \text { infect } \\ 472 & \text { condition } \\ 472 & \text { forward } \\ 472 & \text { presence } \\ 472 & \text { snake } \\ 471 & \text { labor } \\ 470 & \text { pain } \\ 470 & \text { principal } \\ 469 & \text { consider } \\ 469 & \text { worm } \\ 468 & \text { hyperbola } \\ 468 & \text { reject } \\ 467 & \text { occupy } \\ 467 & \text { upward } \\ 466 & \text { coin } \\ 466 & \text { frog } \\ 466 & \text { wife } \\ 465 & \text { cake } \\ 465 & \text { sink } \\ 465 & \text { wealth } \\ 463 & \text { letter-collection } \\ 462 & \text { clock } \\ 462 & \\ 460 t i c \\ 460\end{array}$

105 sailor

105 soma

105 span

105 turbo-charger

105 dove

105 upside

105 zoo

104 adjective

104 appoint

104 corrode

104 counsel

104 entrance

104 grind

104 incinerate

104 irrigate

104 lithium

104 ox-bow

104 pm

104 prophase

104 request

104 rhythm

104 ridge

104 sacred

104 shrimp

104 whip

103 aloud

103 burrow 


\begin{tabular}{|c|c|c|}
\hline broad-bean & 103 & injure \\
\hline 460 elevate & 103 & jellyfish \\
\hline kidney & 103 & likelihood \\
\hline 459 dust & 103 & mines \\
\hline genome & 103 & niche \\
\hline greenhouse & 103 & squid \\
\hline judge & 103 & tennis \\
\hline library & 103 & zygote \\
\hline evanorate & 102 & appliance \\
\hline raporat & 102 & caption \\
\hline houcino & 102 & cast \\
\hline 110usmg & 102 & dew \\
\hline beauty & 102 & glow \\
\hline department & 102 & grane \\
\hline 456 photograph & & \\
\hline 455 ancestor & 102 & herpes \\
\hline 454 scene & 102 & hut \\
\hline 453 complicate & 102 & inhalable \\
\hline 453 kilometer & 102 & meat-hook \\
\hline 453 medicine & 102 & osmosis \\
\hline chief & 102 & placemat \\
\hline artery & 102 & schedule \\
\hline compass & 102 & shed \\
\hline fish-finger & 102 & trachea \\
\hline marine & 102 & tundra \\
\hline playing-field & 101 & anus \\
\hline 451 reside & 101 & asthma \\
\hline 450 smell & 101 & courage \\
\hline
\end{tabular}




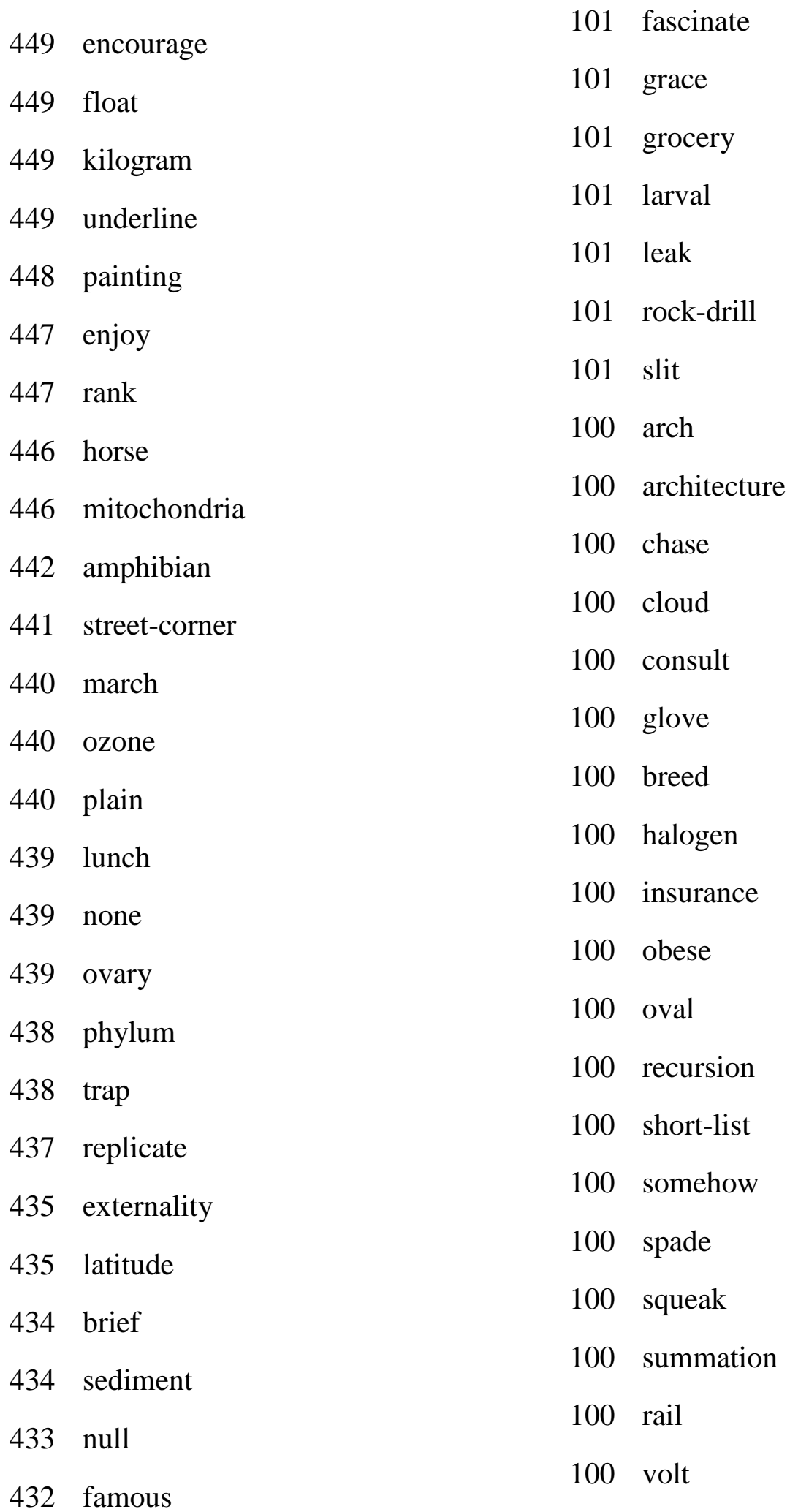




\section{Mid Frequency Word List}

The Mid Frequency Word List has 5,006 lemmas ordered in respect of frequency. The list represents lemmas that appeared between 99 and 10 times within the corpus. For a complete list of mid-frequent words with derivational and inflectional forms, check www.myvirs.com/dictionary.

Table 17. Mid Frequency Word List.

Freq. Word

Freq. Word

99 adenine

99 alphabet

99 bobcat

99 deplete

99 designer

99 dilute

99 discontinuity

99 enforce

99 counts

99 goat

99 indirectly

99 isomer

99 kiss

99 oven

99 puppy

99 roman

99 bark

99 snake
27 stepping-stone

27 streamline

27 subarctic

27 tie-breaker

27 toast-rack

27 translucent

27 transplant

27 tulip

27 twig

27 ventral

27 wedding

27 wingspan

26 anticyclone

26 autism

26 bobby

26 boll

26 boring

26 burden 
99 sorry

99 subsequent

99 suppress

99 bomb

99 trough

98 anaphase

98 automobile

98 beg

98 chandler

98 cookie

98 creek

98 currency

98 dolphin

98 download

98 knife

98 magnificence

98 marrow

98 microscopic

98 monomer

98 nevertheless

98 notion

98 penguin

98 penis

98 pronounce

98 protest

98 re-incorporate

98 subunit
26 caffeine

26 cannonball

26 carousel

26 cervix

26 chin-up

26 chromosphere

26 clade

26 cocoon

26 concise

26 condemn

26 cooperate

26 cornea

26 deceive

26 de-couple

26 detritivore

26 drummer

26 earlobe

26 earnest

26 echo

26 fang

26 faraday

26 flowchart

26 gabbro

26 ginkgo

26 gnomon

26 handlebar

26 harness 


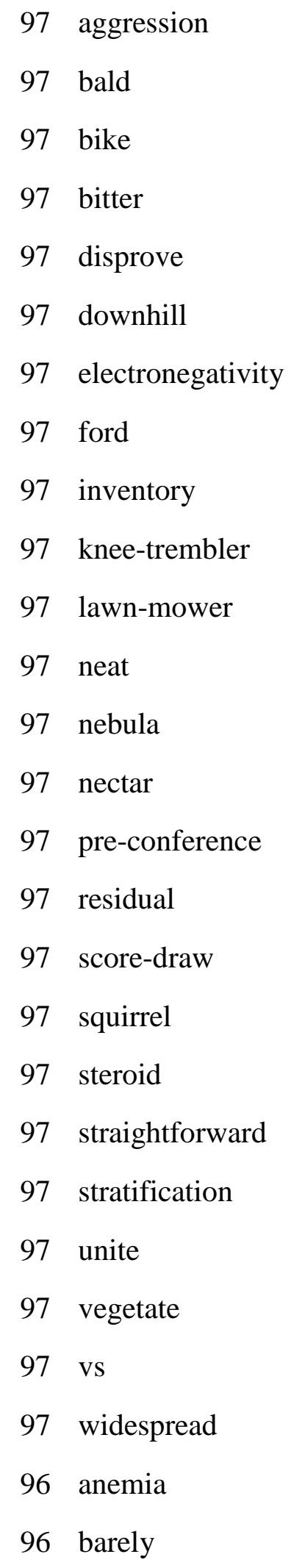

26 hearth

26 hydrostatic

26 iceberg

26 intimacy

26 intolerance

26 isotonic

26 ivy

26 keystone

26 knight

26 locust

$26 \mathrm{~m}$

26 mantis

26 meantime

26 micronutrient

26 milkweed

26 neon-sign

26 ovum

26 peel

26 perch

26 phlogiston

26 picture-gallery

26 pipeline

26 plank

26 pox

26 preposition

26 presently

26 provoke 
96 cardinal

96 confess

96 dissociate

96 equinox

96 heal

96 inorganic

96 kit-bag

96 mad-house

96 menstruate

96 mini-league

96 node

96 persist

96 pest

96 purchase

96 servant

96 subset

96 thermostat

96 trillion

95 bilateral

95 broadcast

95 cascade

95 cucumber

95 embryonic

95 guanine

95 latter

95 longitudinal

95 murder
26 pseudopod

26 purse-string

26 quit

26 re-box

26 regroup

26 roam

26 roger

26 scold

26 scorn

26 sea-monster

26 sextant

26 shelf-grip

26 shellfish

26 shuffle

26 singer-songwriter

26 sleeping-pill

26 steel-casting

26 synthase

26 tomb

26 tonsil

26 tryptophan

26 univariate

26 venom

26 victor

26 vivid

26 von

26 winged 
95 nominate

95 qualify

95 stair-well

95 sundial

94 bank

94 brittle

94 buoyant

94 dermis

94 dodder

94 cabinet

94 homozygote

94 inject

94 intermolecular

94 intrude

94 invasion

94 maple

94 metaphase

94 pharynx

94 polypeptide

94 pretend

94 propel

94 sea-port

94 shortage

94 therapy

94 toe

93 complexion

93 cure
26 writ

25 anaconda

25 antecedent

25 brood

25 bugle

25 burst

25 calcite

25 campground

25 casual

25 charity

25 circumscribe

25 command

25 contractor

25 counter-warning

25 curb

25 deploy

25 dial

25 duce

25 dumbbell

25 epiglottis

25 flare

25 folktale

25 frond

25 gigantic

25 beast

25 heritable

25 impair 


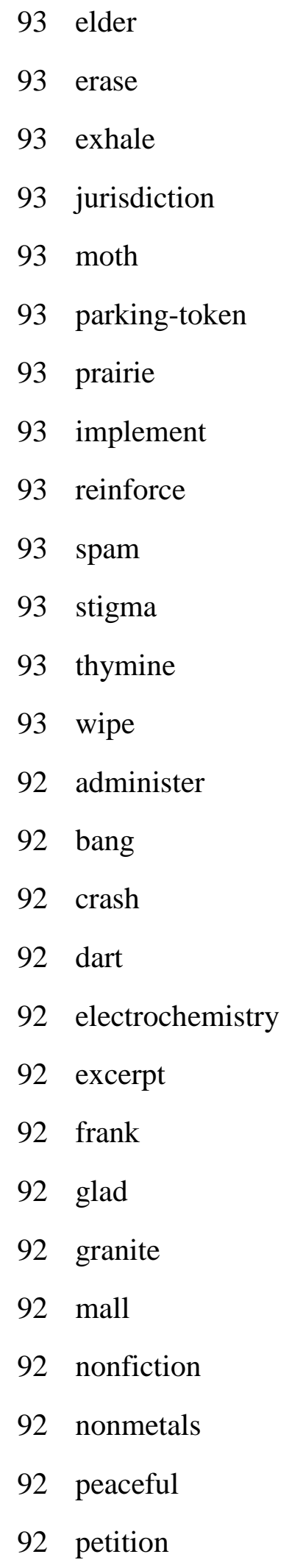


92 pit-bull

92 recreate

92 sand-castle

92 sewage

92 wherever

91 attach

91 backyard

91 duct

91 expand

91 inland

91 invade

91 meanwhile

91 molarity

91 nonsense

91 oocyte

91 parliament

91 playground

91 process

91 radar

91 sharp

91 simultaneous

91 steer

91 tense

91 veil

91 ventricle

90 ally

90 bud
25 round-wound

25 rude

25 sausage

25 septa

25 shave

25 situate

25 slam

25 spicule

25 subsequently

25 subway

25 tame

25 ten-millionth

25 thigh

25 triceratops

25 tyrosine

25 unconscious

25 video-recorder

25 viewpoint

25 state

24 accent

24 acne

24 alkane

24 astrology

24 auditorium

24 auditory

24 aurora

24 barbarian 


\begin{tabular}{|c|c|c|c|}
\hline & caste & & \\
\hline 90 & cytosine & 24 & caecilian \\
\hline 90 & dare & 24 & carter \\
\hline 90 & fin & 24 & centrifuge \\
\hline 90 & forbid & 24 & cerevisiae \\
\hline 90 & lactic & 24 & champion \\
\hline 90 & limestone & 24 & coarse \\
\hline 90 & peach & 24 & contend \\
\hline 90 & pine-tree & 24 & coop \\
\hline 90 & primitive & 24 & corps \\
\hline 90 & radioisotope & 24 & crisscross \\
\hline 90 & spine & 24 & decree \\
\hline 89 & atrium & 24 & denature \\
\hline 89 & batch & 24 & diction \\
\hline 89 & carton & 24 & dignity \\
\hline 89 & hepatitis & 24 & distress \\
\hline 89 & pleasant & 24 & dizzy \\
\hline 89 & pride & 24 & doc \\
\hline 89 & prototype & 24 & drosophila \\
\hline 89 & roar & 24 & dusk \\
\hline 89 & rom & 24 & enthusiasm \\
\hline 89 & salmon & 24 & gametogenesis \\
\hline 89 & scent & 24 & ganglion \\
\hline 89 & side-glance & 24 & gate \\
\hline 89 & stadium & 24 & gibbon \\
\hline 89 & token-reflexive & 24 & globule \\
\hline 89 & & 24 & guardian \\
\hline
\end{tabular}




\begin{tabular}{|c|c|c|c|}
\hline 88 & antonym & 24 & gypsum \\
\hline 88 & booklet & 24 & ham \\
\hline 88 & celestial & 24 & headline \\
\hline 88 & coincide & 24 & imperial \\
\hline 88 & fabric & 24 & inconclusive \\
\hline 88 & mesoderm & 24 & infiltrate \\
\hline 88 & odor & 24 & kitten \\
\hline 88 & sound & 24 & lady \\
\hline 88 & tablet & 24 & lice \\
\hline 88 & talent & 24 & lifelong \\
\hline 88 & unify & 24 & luminescence \\
\hline 87 & activate & 24 & lysogenic \\
\hline 87 & administrate & 24 & macroscopic \\
\hline 87 & camouflage & 24 & mess-tin \\
\hline 87 & cholera & 24 & miniature \\
\hline 87 & clever & 24 & miserable \\
\hline 87 & cursor & 24 & monsoon \\
\hline 87 & detector & 24 & multinomial \\
\hline 87 & devise & 24 & nanometer \\
\hline 87 & disjoint & 24 & newt \\
\hline 87 & dormancy & 24 & nineteen-year-old \\
\hline 87 & exhaust & 24 & ovarian \\
\hline 87 & faint & 24 & photo-album \\
\hline 87 & fate & 24 & pixel \\
\hline 87 & fierce & 24 & porch \\
\hline 87 & fluctuate & 24 & prenatal \\
\hline & free-associate & 24 & rainstorm \\
\hline
\end{tabular}


87 giraffe

87 integrand

87 investigate

87 lichen

87 proto-oncogene

87 sex

87 tentacle

87 terrify

87 tonight

87 underwater

87 vital

86 astrolabe

86 brave

86 circle

86 dean

86 dull

86 gorilla

86 handle

86 horn

86 hot

86 lancelet

86 markup

86 participation

86 pearl

86 pro-catholic

86 sketch

86 sound-pulse
24 ranch

24 rap

24 recombination

24 relocate

24 reprint

24 restate

24 restrain

24 safeguard

24 saltwater

24 self-revelation

24 semi-luxury

24 slab

24 snowball

24 spatially

24 stance

24 staple

24 startle

24 stein

24 stink

24 suction

24 supersaturated

24 sur

24 tar

24 transgress

24 vacancy

24 viscous

24 wart 
86 spit

86 super-glue

85 ambiguity

85 barrel-organ

85 bump

85 carpet-bagger

85 coupon

85 flat

85 late

85 loaf

85 package

85 parent

85 phagocyte

85 rot

85 summer

84 boycott

84 breakdown

84 cash-register

84 crisis

84 delicate

84 exhibit

84 merchant

84 obligation

84 paddle

84 starfish

84 stratosphere

84 subphylum
23 accessory

23 anemometer

23 arterial

23 arthritis

23 bailey

23 beaver

23 bioluminescence

23 bipedal

23 board

23 boxing-match

23 breakwater

23 buddy

23 chill

23 clack

23 combat

23 comp

23 conquest

23 counteract

23 cumbersome

23 dance

23 decipher

23 decode

23 deoxygenate

23 der

23 detergent

23 diff

23 divorce 
84 weave

83 airway

83 beach

83 beef

83 coastline

83 comma

83 conifer

83 crayon

83 cyanobacteria

83 estrogen

83 gear

83 huff

83 immunodeficiency

83 incredible

83 joseph

83 leap

83 lifestyle

83 pace

83 sixteenth

83 taxi

83 vinegar

82 banana-skin

82 crocodile

82 dipper

82 duplicate

82 extraneous

82 grandparent
23 dual

23 ethylene

23 exon

23 eye

23 fireplace

23 flourish

23 foul

23 gault

23 glance

23 gunpowder

23 headlight

23 hedgehog

23 helmet-plate

23 herbaceous

23 high-flyer

23 hydride

23 intricate

23 jug

23 lane-end

23 lengthen

23 lethal

23 leucoplast

23 levy

23 lumen

23 measles

23 merge

23 midrange 


\begin{tabular}{|c|c|c|c|}
\hline 82 & $\begin{array}{l}\text { mid-seventeenth- } \\
\text { century }\end{array}$ & 23 & mono-poly \\
\hline 82 & pin & 23 & mop \\
\hline 82 & prison-ship & 23 & non-eligible \\
\hline 82 & sculpt & 23 & nonnegative \\
\hline 82 & sense-perception & 23 & nucleolus \\
\hline 82 & stock & 23 & nucleon \\
\hline 82 & van & 23 & nursing-home \\
\hline 81 & anti-inflammatory & 23 & od \\
\hline 81 & arid & 23 & orthocenter \\
\hline 81 & ballot & 23 & osteoclast \\
\hline 81 & blueberry & 23 & pail \\
\hline 81 & cheap-thrill & 23 & pandemic \\
\hline 81 & concurrent & 23 & pants \\
\hline 81 & convict & 23 & parrot \\
\hline 81 & deliberate & 23 & pheromone \\
\hline 81 & dialogue & 23 & phoenix \\
\hline 81 & eager & 23 & photographed \\
\hline 81 & fetal & 23 & purine \\
\hline 81 & impeach & 23 & quarrel \\
\hline 81 & incentive & 23 & raft \\
\hline 81 & motor & 23 & re \\
\hline 81 & musician & 23 & re-capitalize \\
\hline 81 & navigate & 23 & recombine \\
\hline 81 & ovulate & 23 & rhizoid \\
\hline 81 & retail & 23 & ripen \\
\hline 81 & suffix & 23 & rook \\
\hline 80 & assort & 23 & sapiens \\
\hline
\end{tabular}


80 chemosynthesis

80 cope

80 cyclone

80 grasp

80 indoor

80 inflammation

80 laying

80 mileage

80 navy

80 pale

80 powder

80 remark

80 rug

80 sailing-ship

80 scroll

80 seawater

80 seaweed

80 spirit

80 stomata

80 sunspot

80 supercontinent

80 thorough

80 veto

79 ample

79 chimpanzee

79 compromise

79 email
23 scrotum

23 simplex

23 skunk

23 smallpox

23 snap-shot

23 snowfall

23 sofa

23 spermatid

23 splash

23 spleen

23 stoichiometric

23 subtle

23 super-ministry

23 syncline

23 systole

23 kettle

23 textile

23 toll-booth

23 touchdown

23 tranquil

23 vocal

23 waitress

23 ward

23 warehouse

23 waterborne

23 wen

23 whereby 
79 fallopian

79 gal

79 grasshopper

79 id

79 knees-up

79 lattice

79 monoxide

79 offshore

79 platelet

79 polyhedron

79 prisoner-of-war

79 prominence

79 rebel

79 romance

79 sixteen-year-old

79 skip

79 spot

79 step-sibling

79 taproot

79 tray

79 versa

78 ascend

78 builder

78 church

78 coronary

78 dent

78 disrupt
23 wildflower

23 yell

23 zooplankton

22 adjourn

22 aerospace

22 agenda

22 agonize

22 alchemy

22 apartheid

22 apical

22 atop

22 autocracy

22 backup

22 barbecue

22 barter

22 baryon

22 boat

22 buoy

22 celery

22 cervical

22 chimney

22 cocaine

22 confer

22 crank

22 desktop

22 dissect

22 dopamine 
78 forecast

78 guitar

78 humor

78 non-economist

78 numbery

78 ought

78 paraphrase

78 patch

78 pig-tail

78 plankton

78 print

78 rake-off

78 relativity

78 renew

78 sail

78 substantial

78 top

78 twin

78 upright

78 wildlife

77 dorsal

77 dye

77 fibrous

77 fulcrum

77 holy

77 landslide

77 ninth
$22 \mathrm{dub}$

22 ductile

22 elf

22 embrace

22 eubacteria

22 farce

22 fluency

22 fluoride

22 frameshift

22 frontier

22 goodbye

22 grant

22 hammer

22 herb

22 hermaphrodite

22 hind

22 horsepower

22 hove

22 hub

22 iguana

22 instituted

22 intrigue

22 jot

22 keen

22 lane

22 legume

22 lobby 
77 pigeon

77 professor

77 repulsion

77 scrape

77 secretion

77 skull

77 sour

77 stalk

77 stir

77 sympathy

77 terror

77 thyroid

77 titrate

77 toe-rag

77 tony

77 top-seller

77 whichever

76 beverage

76 capsize

76 cheer

76 contest

76 cultivate

76 hippocampus

76 inspire

76 iodine

76 land-drain

76 midnight
22 heel

22 magnetometer

22 mayflower

22 mini-tripod

22 moan

22 naval

22 nephew

22 neutrino

22 nighttime

22 non-detection

22 non-naturalist

22 oath

22 opportunistic

22 orchid

22 outstanding

22 override

22 pawn

22 peacock

22 precaution

22 precedence

22 prion

22 processor

22 propane

22 quasi-monopoly

22 que

22 reagent

22 rectum 
76 mike

76 pepper

76 petrol-station

76 pumpkin

76 rifle-pit

76 roof

76 rule-follower

76 scan

76 scratch

76 semen

76 shock

76 straightedge

76 personality

76 trigonal

76 underneath

75 antennae

75 bio-technology

75 burger

75 camp

75 chronology

75 discipline

75 duck

75 feces

75 fog

75 grandma

75 gravel

75 harsh
22 remedy

22 re-provision

22 resin

22 rhombi

22 rip

22 roadway

22 rose-grower

22 rumor

22 scarf

22 sermon

22 service-provider

22 shy

22 slew

22 solenoid

22 spreadsheet

22 spruce

22 stratigraphy

22 summon

22 sunglasses

22 superstition

22 syllogism

22 terrace

22 thermophile

22 threes

22 tory

22 trickle

22 trisomy 
75 hero

75 hyperbole

75 monosaccharide

75 mucous

75 outbreak

75 pilot

75 plaque

75 profile

75 proto

75 saliva

75 shrub

75 skim

75 tapeworm

75 tolerance

74 breeding-ground

74 bullet

74 carcinogen

74 craft-worker

74 evolve

74 interpolate

74 meridian

74 mistletoe

74 mosquitoes

74 mouthpart

74 myth

74 opossum

74 peak
22 tusk

22 uracil

22 vole

22 warranty

22 whoever

21 albeit

21 alveolus

21 app

21 augment

21 await

21 baboon

21 bac

21 bacon

21 bar

21 barge

21 beloved

21 benthic

21 bioethanol

21 brit

21 butch

21 buzzer

21 byzantine

21 cadmium

21 campus

21 catastrophe

21 chain

21 chaperone 
74 predation

74 prevail

74 session

74 ticket-collector

74 tumble-dryer

73 annoy

73 anybody

73 apartment

73 bathroom

73 bless

73 bracelet

73 dicot

73 dissipate

73 doubt

73 drip

73 eject

73 elongate

73 execute

73 exit

73 innate

73 mosquito

73 over-charge

73 prose-writing

73 resign

73 ring

73 sea-boot

73 shoulder
21 chilly

21 cobalt

21 corpse

21 crusade

21 cumulonimbus

21 disappearance

21 disintegrate

21 disregard

21 encase

21 endospore

21 entomology

21 fashion

21 fine

21 fingertip

21 flock

21 fluff

21 footage

21 forestry

21 garden

21 gasp

21 gloss

21 grandchildren

21 grove

21 grumble

21 hallway

21 hatchling

21 hydrothermal 
73 submarine

73 suspicion

73 toad

73 turbo-diesel

72 alexander

72 alley

72 ape

72 attorney

72 barometer

72 bronchi

72 coated

72 cytosol

72 dot

72 dough

72 glory

72 hagfish

72 heron

72 pa

72 pardon

72 possession

72 pyruvate

72 scalene

72 self-criticism

72 shoot

72 shortcut

72 step

72 sulfate
21 hygiene

21 insecticide

21 intact

21 irregularly

21 kilocalories

21 lap-top

21 laureate

21 license

21 lonesome

21 lumber

$21 \mathrm{mac}$

21 magnetosphere

$21 \mathrm{mal}$

21 menopause

21 meteoroids

21 methadone

21 mislead

21 monk

21 monocline

21 monocots

21 multimodal

21 non-intimate

21 obstruct

21 osteocyte

21 over-emphasize

21 palmitate

21 pancake 
72 upset

72 vertebra

71 adverb

71 anemone

71 blanket

71 char

71 conceive

71 credit

71 delta

71 downstream

71 engulf

71 fancy

71 land-grant

71 mini-lecture

71 occupation

71 project

71 sucker

71 sue

71 swirl

71 pointer

70 fungal

70 arteriole

70 catch

70 cease

70 centipede

70 cephalochordate
21 par

21 parallax

21 perpetual

21 posture

21 pot

21 poultry

21 preside

21 proboscis

pseudo-

21 homophone

21 puma

21 puritan

21 pyroclastic

21 quantile

21 radium

21 rearrangement

21 re-cap

21 rickets

21 ridicule

21 rotten

21 rubric

21 saccharide

21 saguaro

21 screenshot

21 scud-c

21 sebum

21 seer 
70 chlamydia

70 collar

70 curtain

$70 \operatorname{dim}$

70 eccentricity

70 hail

70 harry

70 heterogeneous

70 hypha

70 import

70 intercourse

70 makeup

70 nourish

70 oral

70 petition-drawer

70 porta-cabin

70 ray-ban

70 silver-grey

70 tent-peg

70 thrive

69 asleep

69 crude

69 diffract

69 eared

69 endosymbiosis

69 headache

69 hierarchy
21 seismologist

21 shed

21 snow-flake

21 spearman

21 spectrometer

21 splendid

21 spoil-sport

21 steak

21 street-gang

21 stun

21 summit

21 sunburn

21 superfund

21 superposition

21 sympatric

21 taper

21 dodge

21 transmembrane

21 tree-stump

21 tubeworms

21 tween

21 tyranny

21 upcoming

21 uplift

21 varsity

21 vase

21 violin 
69 hillside

69 milligram

69 mite

69 monomials

69 ours

69 plasmid

69 priest

69 pronoun

69 re-compile

69 sleet

69 spell

69 tremble

69 valve

68 age

68 amine

68 artistry

68 bleed

68 cafeteria

68 clump

68 coli

68 colloid

68 conform

68 cork-stopper

68 cupcake

68 debris-flow

68 dendrite

68 employer
21 witch

20 abyss

20 affirm

20 antioxidant

20 blaze

20 bouquet

20 bowel

20 braid

20 chime

20 chimp

20 chop

20 cinder

20 coagulation

20 cockroach

20 collage

20 compulsory

20 consonance

20 corridor

20 crystallize

20 cycad

20 cytochrome

20 defy

20 diethyl

20 dimethyl

20 ding

20 disconnect

20 discrepancy 


\begin{tabular}{|c|c|c|c|}
\hline \multicolumn{2}{|c|}{68 endure } & \multicolumn{2}{|c|}{20 downside } \\
\hline 68 & extrema & 20 & epoch \\
\hline 68 & fallacy & 20 & expire \\
\hline 68 & gel & 20 & extremophile \\
\hline 68 & glide & 20 & fame \\
\hline 68 & inter & 20 & famine \\
\hline 68 & jog & 20 & filmmaker \\
\hline 68 & nonetheless & 20 & fir \\
\hline 68 & oscillate & 20 & firefight \\
\hline 68 & philosopher-scientist & 20 & fling \\
\hline 68 & phytoplankton & 20 & forehead \\
\hline 68 & pi & 20 & fugitive \\
\hline 68 & possess & 20 & fur \\
\hline 68 & pray & 20 & g-cramp \\
\hline 68 & primate & 20 & germline \\
\hline 68 & ration & 20 & gesture \\
\hline 68 & redwood & 20 & gooseberry \\
\hline 68 & scare & 20 & hill \\
\hline 68 & shoe-horn & 20 & homeroom \\
\hline 68 & siphon & 20 & hunter-fisher \\
\hline 68 & sixty-year-old & 20 & icon \\
\hline 68 & streak & 20 & impartial \\
\hline 68 & synapse & 20 & impatience \\
\hline 68 & template & 20 & interrogate \\
\hline 68 & urethra & 20 & iris \\
\hline 68 & wander & 20 & kit \\
\hline 67 & anticipate & 20 & knob \\
\hline
\end{tabular}


67 autoimmune

67 carl

67 centriole

67 diarrhea

67 document

67 elapse

67 enforced

67 fade

67 fatality

67 gadget

67 heritage

67 honey

67 hunger-strike

67 hydrate

67 kelvin

67 lysosome

67 mediate

67 nonlinear

67 octopi

67 olive

67 omission

67 pedigree

67 permanence

67 plow

67 rainbow

67 re-qualify

67 sanitary
20 lamblia

20 leeward

20 legitimate

20 levee

20 lightbulb

20 marshmallow

20 meat-eater

20 myopia

20 nicotine

20 nipple

20 nose-bleed

20 nymph

20 oversee

20 pennyroyal

20 pharmacogenomics

20 phenyl

20 pilgrim

20 plaster

20 playoff

20 podcast

20 policeman

20 popsicle

20 preface

20 profound

20 prolong

20 propriety

20 pry 
67 sheet-anchor

67 soak

67 stare

67 strait-jacket

67 swim

$67 \mathrm{tab}$

67 upstream

66 adhere

66 advocate

66 aqueous

66 cosecant

66 dug

66 epididymis

66 furthermore

66 gauge

66 hardy

66 hydrochloride

66 incorporate

66 increment

66 locomotion

66 millipede

66 picnic

66 plateau

66 pot-boiler

66 pouch

66 assure

66 undo
20 puff

20 ragweed

20 raptor

20 relocation

20 rep

20 rescue

20 reverence

20 ribose

20 ringworm

20 salmonella

20 sandpaper

20 school

20 semicircular

20 semipermeable

20 shove

20 side-aisle

20 sidebar

20 socket

20 sous-chef

20 spectator

20 spinach

20 sprawl

20 spy

20 steam

20 steamboat

20 straight

20 stride 
66 weaken

66 woodland

65 abroad

65 alert

65 antenna

65 anther

65 aquarium

65 blame

65 chunk

65 claw

65 collaborate

65 crack-up

65 dialect

65 drain

65 drill

65 duck-pond

65 electrolysis

65 gonorrhea

65 gross

65 intake

65 interphase

65 lignin

65 ma

65 non-communist

65 populate

65 purification

65 quarter
20 stroma

20 strontium

20 tablecloth

20 thaw

20 toddle

20 trajectory

20 trampoline

20 transmutation

20 tyrannosaurus

20 vertebrata

20 vest

20 workplace

20 mule

19 acquire

19 agitate

19 air

19 antheridia

19 antimatter

19 aspire

19 assimilate

19 assonance

19 aureus

19 barbed

19 benny

19 brad

19 bye

19 carboniferous 
65 raindrop

65 re-coil

65 shelve

65 somebody

65 stern

65 transduce

64 aldehyde

64 ammunition

64 arachnid

64 bolt-rig

64 bungee

64 capita

64 cardioid

64 corpus

64 crane

64 crazy

64 devastate

64 dispersal

64 extrapolate

64 folk

64 forcing

64 framework

64 gastropod

64 gym

64 incorrectly

64 interchange

64 nephron
19 carnation

19 carnival

19 catfish

19 cemetery

19 ceramic

19 chairman

19 chorus

19 clown

19 clutch

19 congregate

19 conspire

19 craton

19 crisp

$19 \mathrm{dc}$

19 decelerate

19 demo

19 depot

19 dimer

19 dishwasher

19 dock

19 donut

19 embryology

19 enterprise

19 eradicate

19 ere

19 eucalypt

19 eyelid 
64 neurotransmitter

64 paint

64 pneumonia

64 praise

64 rewriting

64 rose-hip

64 sand-martin

64 scavenger

64 swamp

64 tem

64 tiger

64 triglyceride

64 wholesale

63 aid

63 alligator

63 basalt

63 candle

63 captivate

63 conquer

63 crawl

63 dancer

63 database

63 dispose

63 distort

63 donor

63 effuse

63 fluke
19 fore

19 frigid

19 gemstone

19 gloom

19 groin

19 harass

19 hyperopia

19 hypertension

19 inappropriate

19 incapable

19 inlet

19 javelin

19 joey

19 kiddie

19 leg

19 leucine

19 ligation

19 macromolecule

19 masturbate

19 maxillae

19 mayonnaise

19 mint

19 mockingbird

19 moonlight

19 multiplier

19 nanoscale

19 neural 
63 fluoresce

63 fundraise

63 giardia

63 grave

63 holder

63 landfill

63 offense

63 ping

63 plume

63 profit

63 self-evaluation

63 self-reward

63 shop-fitting

63 solstice

63 spare

63 zebra

62 adrenal

62 bighorn

62 canvas

62 carpet

62 chromatin

62 cluster

62 crystalline

62 deciduous

62 epidemic

62 epithelia

62 explode
19 nitrogenous

19 oil-burner

19 onset

19 orgasm

19 palm

19 panther

19 parachute

19 pare

19 paycheck

19 p-bass

19 pentane

19 periosteum

19 pertain

19 photosystem

19 piracy

19 plague

19 platinum

19 poppy-seed

19 preconception

19 prod

19 pyrimidine

19 query

19 ram

19 reconsider

19 redraw

19 regret

19 rehearsal 
62 frost

62 garbage

62 leveled

62 neglect

62 non-manual

62 outlet

62 prospect

62 python

62 retina

62 schematic

62 scrub

62 seep

62 stationary

62 surge

62 telophase

62 thylakoid

62 timeline

62 tom

61 anymore

61 autosome

61 bile

61 ceil

61 chronic

61 commit

61 conjunction

61 corollary

61 delight
19 reset

19 resume

19 ritual

19 sailboat

19 self-congratulation

19 shirt-dress

19 reel

19 side-foot

19 slosh

19 soy

19 spaghetti

19 spectral

19 sprint

19 stereo-type

19 stromatolite

19 subdivision

19 submerge

19 synapsis

19 tanker

19 tempore

19 testify

19 tetanus

19 toothbrush

19 tuba

19 tuber

19 underside

19 uphold 
61 deserve

61 discard

61 dose

61 estuary

61 falcon

61 fortune

61 fountain

61 gonad

61 hibernate

61 incandescent

61 input

61 involuntary

61 junior

61 land-grab

61 larynx

61 leech

61 myosin

61 non-alcoholic

61 opponent

61 peristalsis

61 popcorn

61 quartz

61 sierra

61 silicon

61 spray

61 subscript

61 sunset
19 vague

18 accrue

18 adage

18 adverse

18 airborne

18 anole

18 asbestos

18 ascent

18 assassinate

18 autonomy

18 auxin

18 basal

18 binge

18 bliss

18 blot

18 bombard

18 brainstorming

18 browse

18 bum

18 caboose

18 campers

18 canine

18 carne

18 caucus

18 censor

18 chaos

18 chirp 

61 surgery
18 codominant
61 transpire
18 console
61 wastewater
18 cougar
60 abrasion
18 counterpart
60 advertise
18 critter
60 atherosclerosis
18 crop
60 autumn
18 croton
60 boldface
18 curie
60 bottle
60 brainstorm
18 cute
18 detriment
60 comic
18 discomfort
60 concert
60 damp
60 degrade
60 dessert
60 dictate
60 dragon
60 elbow
60 endanger
60 graphite
60 leukocyte
60 octet
60 pave
60 pharyngeal
18 duckweed
18 dune-buggy
18 dwarf
18 dystrophy
18 endothelium
18 epistasis
18 esterify
18 exosphere
18 faraway
18 fingernail
18 fist
18 floodplain
18 glycoprotein
60 pop-up
18 godwit
18 graviton
60 position
60 province
18 grizzly 
60 racial

60 re-circulate

60 reform

59 bivalve

59 bookstore

59 bulge

59 collagen

59 crane-boulder

59 desert

59 discount

59 flag

59 hydrophobic

59 joule

59 lactose

59 mask

59 mayor

59 mound

59 mycelia

59 nonzero

59 omnivore

59 over-exploit

59 permeability

59 prayer-stool

59 precession

59 resonance

59 seesaw

59 shoreline
18 grouse

18 helmet

18 hexane

18 hostile

18 hotdog

18 hum

18 idiom

18 ignite

18 ineffective

18 insignificant

18 isocline

18 isometric

18 jail

18 katydid

18 latex

18 lazy-bed

18 leukemia

18 loudspeaker

18 lynx

18 lyric

18 mangrove

18 mast

18 merit

18 meteoroid

18 micrograph

18 motor-glider

18 murphy 
59 spoil

59 supernova

59 tag

59 thorax

58 advent

58 airline

58 alloy

58 back

58 biofilm

58 boost

58 buyer

58 ceremony

58 deed

58 delete

58 endocytosis

58 enumerate

58 funnel

58 hare

58 hay

58 hemophilia

58 inspect

58 ketone

58 lac

58 luster

58 memorial

58 meristem

58 moon-daisy
18 nanometers

18 nee

18 nickname

18 non-linearity

18 non-linguist

18 nonparametric

18 northeastern

18 northwestern

18 numeral

18 object

18 ordain

18 ordinance

18 overturn

18 pat

18 patty

18 penumbra

18 peridotite

18 pier-head

18 pin-curl

18 piston

18 platter

18 portal

18 prodigy

18 radio

18 reabsorb

18 redistribution

18 redo 
58 oogenesis

58 plantation

58 punctuate

58 ruin

58 sprout

58 sublimation

58 synonym

58 theme-pub

58 toppings

58 update

57 antiderivative

57 artifact

57 biogeochemical

57 blizzard

57 climax

57 dancing-teacher

57 daytime

57 despair

57 dogma

57 dream

57 duodenum

57 freight

57 fulfill

57 crown

57 hesitate

57 inflate

57 melanin
18 rex

18 rile

18 ruby

18 rusty

18 sand-eel

18 scare-story

18 sea-gull

18 self-restraint

18 semi-joke

18 sergeant

18 setup

18 shell

18 shock-absorber

18 sovereign

18 spew

18 step-granddaughter

18 stony-iron

18 stool

18 studio

18 sturdy

18 substantially

18 suite

18 sun-bathe

18 sunken

18 surgeon

18 syntax

18 transcend 
57 mesosphere

57 misconception

57 nonmetal

57 oar

57 ongoing

57 pistil

57 privilege

57 red

57 slide

57 slug

57 vacuum

57 vulture

56 appeal

56 buildup

56 centromere

56 chitin

56 contradict

56 detach

56 entitle

56 exploit

56 flagellate

56 fluorine

56 fuse

56 horror

56 hula-hoop

56 intraplate

56 methyl
18 traverse

18 triplet

18 triumph

18 twitch

18 und

18 vanadium

18 virgin

18 wright

17 absurd

17 actinide

17 align

17 aniline

17 ankle-strap

17 annuity

17 antiparticle

17 armband

17 armor

17 asymmetry

17 audacity

17 aura

17 azimuth

17 banish

17 bark

17 bay

17 bed

17 blowup

17 bock 
56 micro

56 microtubule

56 optimistic

56 overseas

56 photo-op

56 pianist

56 presume

56 sally

56 scholar

56 scorpion

56 self-peptide

56 staircase

56 subatomic

56 subordinate

55 afterward

55 amazon

55 astronomer-priest

55 caldera

55 centroid

55 compensate

55 cuticle

55 cystic

55 ectoderm

55 inwards

55 kinase

55 lepton

55 mosaic
17 bolt

17 boreal

17 buckwheat

17 bun

17 bushy

17 catastrophic

17 cephalothorax

17 charity-school

17 chromium

17 chronometer

17 concession

17 convene

17 counter-accusation

17 crackle

17 crumple

17 crunch-point

17 cur

17 decoy

17 dichotomy

17 dielectric

17 disguise

17 dishonest

17 diurnal

17 emulsion

17 epic

17 facultative

17 firewood 
55 muffin

55 mutates

$55 \mathrm{mx}$

55 nowhere

55 poke

55 polyatomic

55 preamble

55 role-reversal

55 script-writer

55 semester

55 ski

55 spark

55 supermarket

55 thermodynamics

55 wagon

55 zoom

54 almond

54 amoeba

54 anytime

54 archive

54 arrange

54 barrel

54 bother

54 capacitance

54 cigarette

54 clam

54 dedicate
17 freeway

17 fume

17 garter

17 geo

17 glial

17 google

17 growl

17 hamper

17 hand-cuff

17 impose

17 impure

17 injustice

17 insufficient

17 interdependence

17 interdependent

17 interviewer

17 itch

17 jealous

17 keystroke

17 lithification

17 lurk

17 lutein

17 melanocyte

17 meningitis

17 metropolitan

17 micrometer

17 mnemonic 
54 ectotherm

54 exclaim

54 fibrosis

54 flesh

54 generous

54 goose

54 info

54 mammary

54 matt

54 mini-boom

54 motorcycle

54 mutant

54 naked

54 optional

54 plausible

54 plumb

54 polysaccharide

54 quasi-partnership

54 sprinkle

54 starship

53 arena

53 ash

53 barrage

53 blog

53 carbonyl

53 carve

53 cerebellum
17 modem

17 mum

17 mycobacteria

17 nomadic

17 golfer

17 nutritious

17 outcrop

17 oyster-catcher

17 patent-holder

17 pho

17 phone

17 photographic

17 photosphere

17 ply

17 polonium

17 polymorphism

17 proclaim

17 propulsion

17 psi

17 puffball

17 quadruple

17 quota

17 rabies

17 ralph

17 rarefaction

17 erect

17 regain 
53 ciliate

53 cotangent

53 courtship

53 coward

53 decorated

53 diminish

53 finish

53 hydronium

53 laptop

53 leftover

53 mercy

53 okay

$53 \mathrm{p}$

53 poster

53 rake

53 rape

53 re-import

53 relay

53 rob

53 self-contradiction

53 sign-post

53 sooner

53 spring

53 swear

52 autobiography

52 carnivorous

52 chick
17 reign

17 repro

17 retard

17 retrofit

17 reusable

17 revenge

17 rhesus

17 routinely

17 rumble

17 runaway

17 serine

17 shepherd

$17 \mathrm{sim}$

17 sparkle

17 spice

17 sputnik

17 stakeholder

17 stoma

17 strap-end

17 sugarcane

17 supervisor

17 suzette

17 swap

17 swift

17 taco

17 tampon

17 teepee 
52 clerk

52 contingent

52 cosmic

52 crescent

52 downtown

52 endoderm

52 firework

52 ghost-fleet

52 glaze

52 helicopter

52 horse-brass

52 inflection

52 midst

52 nematode

52 nitrate

52 outermost

52 painter

52 paleontologist

52 peregrine

52 polygenic

52 reluctance

52 self-examination

52 sewing-machine

52 sick

52 skating-rink

52 systemic

52 thrust
17 theta

17 threonine

17 tiffany

17 toolbox

17 transact

17 truffle

17 truss

17 typeset

17 utter

17 vanish

17 visceral

17 weekday

17 wheelchair

17 wildcat

17 workman

16 acetyl

16 ach

16 ache

16 albino

16 alkylate

16 aneroid

16 anglerfish

16 apostrophe

16 aviation

16 barren

16 battle

16 beanstalk 
52 tunnel

52 wildfire

52 workshop

51 aerosol

51 alarm

51 avocado

51 babysit

51 ban

51 blast

51 blastocyst

51 bookcase

51 causality

51 cheek

51 disc

51 doorbell

51 enrich

51 immense

51 insertion

51 intervention

51 lobster

51 locale

51 lottery

51 modulate

51 non-gay

51 over-caution

51 pin-cushion

51 pluck
16 blink

16 bowman

16 campsite

16 candida

16 cate

16 checklist

16 cigar

16 climatology

16 craven

16 crease

16 cristae

16 crouch

16 crystallization

16 debrief

16 dengue

16 despot

16 diaper

16 dihedral

16 dissent

16 dodecagon

16 dover

16 drake

16 edge

16 electromotive

16 elegant

16 epilepsy

16 escalator 
51 predatory

51 prince

51 pup

51 recombinant

51 reward

51 rival

51 sensation

51 sled

51 spite

51 sword

51 tarantula

$51 \mathrm{cab}$

51 termite

51 tetrahedron

51 transistor

50 anterior

50 appendix

50 atria

50 autotroph

50 bagel

50 blueprint

50 bryophyte

50 campfire

50 carmen

50 cattail

50 concord

50 contact
16 fabricate

16 fireside

16 forage

16 forest

16 forum

16 furious

16 glassware

16 gleam

16 glimpse

16 goalpost

16 gratitude

16 gravitropism

16 groan

16 halt

16 hamster

16 hand-clap

16 homeland

16 horsetail

16 hygrometer

16 incandescence

16 incisor

16 infield

16 inn

16 intrinsic

16 invariably

16 isoelectric

16 jam 
50 dehydrate

50 deoxyribonucleic

50 discourage

50 driveway

50 evacuate

50 fridge

50 graze

50 halide

50 hello

50 hinge

50 hose

50 inhibit

50 medusa

50 molality

50 morphology

50 new

50 obstacle

50 breeder

50 photosynthesize

50 pie

50 plantae

50 predominate

50 protostome

50 retreat

50 sake

50 sidewalk

50 sonar
16 jeopardize

16 jungle

16 kudzu

16 lavender

16 legislate

16 ling

16 lore

16 lowercase

16 masteries

16 mend

16 micro-kernel

16 microvilli

16 migratory

16 mockingbirds

$16 \mathrm{mw}$

16 nap

16 nick

16 orchestra

16 outlaw

16 ow

16 parabens

16 parcel

16 part

16 passageway

16 peat

16 pedestrian

16 pinworm 
50 spurt

50 stratum

50 substrate

50 superior

50 thereby

50 thereof

50 timer

50 trim

50 tuberculosis

50 victim

50 second

49 angel

49 biodiesel

49 brilliance

49 chambered

49 charter

49 child

49 colleague

49 coplanar

49 counter-assertion

49 curl

49 deflect

49 deuterostome

49 disappoint

49 drastic

49 drift

49 flagpole
16 polio

16 polynucleotide

16 pons

16 preimages

16 proficiency

16 radish

16 razor

16 realtor

16 recruit

16 rehearse

16 offend

16 repository

16 revive

16 rhino

16 rhinoceros

16 roentgen

16 secretariat

16 sequester

16 shipwreck

16 sinusoidal

16 skateboarder

16 sleeve

16 slender

16 small-businessman

16 snowstorm

16 soar

16 squish 
49 hamburger

49 hydro

49 inter-glacial

49 lighthouse

49 livestock

$49 \log 0$

49 long-hop

49 meadow

49 monument

49 multiplicity

49 nomenclature

49 pinch

49 rash

49 sauce

49 self-referral

49 self-serving

49 skirt-length

49 smog

49 splice

49 sunrise

49 tadpole

49 thorium

49 titan

49 totter

49 tournament

49 tropism

49 vanilla
16 staphylococcus

16 suffrage

16 superconductor

16 thot

16 topple

16 upload

16 venture

16 wainwright

16 waiter

16 warfare

16 whirl

15 adorn

15 affluence

15 allopatric

15 amateur

15 ambitious

15 apposite

15 arbor

15 arcade

15 arrogance

15 attenuation

15 axial

15 bacteriophage

15 bas-relief

15 beep

15 blastopore

15 bot 
49 volleyball

48 acknowledge

48 bivariate

48 cabbage

48 canoe

48 childbirth

48 coevolution

48 companion

48 consciousness

48 cub

48 disinfect

48 drown

48 eardrum

48 everglades

48 evergreen

48 exocytosis

48 fisherman

48 glycogen

48 heartbeat

48 humane

48 hydrolyze

48 infrastructure

48 intertidal

48 la

48 lagoon

48 litter

48 microphone
15 boxcar

15 bribe

15 broccoli

15 broth

15 bust-up

15 canister

15 carp

15 cavern

15 cecum

15 chili

15 cladogram

15 concussion

15 cosmetic

15 creak

15 custody

15 deadline

15 decentralize

15 deem

15 deteriorate

15 diphosphate

15 donkey

15 duster

15 egret

15 electrophoresis

15 elodea

15 eloquence

15 envy 


\begin{tabular}{llll}
48 & partition & 15 & eutrophication \\
48 & psych & 15 & evenings \\
48 & sacrifice & 15 & eyepiece \\
48 & scale & 15 & feldspar \\
48 & softball & 15 & fieldwork \\
48 & solemn & 15 & footwall \\
48 & stupid & 15 & forceps \\
48 & sucrose & 15 & foreshadow \\
48 & sulfide & 15 & fuchsia \\
48 & swarm & 15 & gatherer \\
48 & tap-penalty & 15 & glimmer \\
48 & telegraph & 15 & glomerulus \\
48 & terrain & 15 & groom \\
47 & bicep & 15 & habeas \\
47 & bonus & 15 & canopy \\
47 & brown & 15 & haw \\
47 & checker & 15 & hell \\
47 & clarity & 15 & housefly \\
47 & comb & 15 & hydropower \\
47 & degenerate & 15 & hypersecretion \\
47 & diplomacy & 15 & hypertrophy \\
47 & endometrium & 15 & inert \\
47 & felsic & 15 & jasper \\
47 & freshman & 15 & jay \\
47 & gauss & 15 & jell \\
47 & gizmo & 15 & joyful \\
47 & ingest & 15 & kilo \\
& & \\
\hline & &
\end{tabular}


47 inherent

47 joke

47 kelp

47 nuclide

47 onion

47 overhead

47 potter

47 prom

47 pubic

47 regime

47 retrieval

47 saddle-tank

47 sandstone

47 sew

47 silicate

47 sneak

47 teeter

47 temper

47 thermosphere

47 trilobite

47 veteran

47 vulnerable

47 waterway

46 aircraft

46 badly

46 barnacle

46 bathymetry
15 landlord

15 liable

15 lifecycle

15 lowland

15 lynch

15 mainland

15 malleable

15 matter

15 mesa

15 mesodermal

15 mesophyll

15 mil

15 mismatch

15 neritic

$15 \operatorname{nod}$

15 non-diabetic

15 obedience

15 osteoarthritis

15 outreach

15 over-compensate

15 overeat

15 papilloma

15 papillomavirus

15 paralysis

15 para-relation

15 parlor

15 persevere 
46 blood

46 bob-wig

46 bristle

46 carol

46 charm

46 dealer

46 dietary

46 dung

46 eco-system

46 elaborate

46 encountering

46 esters

46 flap

46 glutamine

46 goody

46 graduate

46 hallucinate

46 hectare

46 index

46 newborn

46 ninety-year-old

46 orangutan

46 pedal

46 phage

46 pong

46 re-dedicate

46 rock-climber
15 perspire

15 phosphorylation

15 piecewise

15 pillow-fight

15 pluton

15 polygonal

15 portable

15 proximate

15 pulverize

15 racecar

15 railway

15 randy

15 raven

15 ravine

15 realm

15 recede

15 reclaim

15 recur

15 reed-warbler

15 refill

15 refute

15 re-house

15 rejoin

15 repeal

15 restoration

15 sack

15 sanction 
46 salvia

46 self-questioning

46 skin

46 sneeze

46 snow

46 subphyla

46 synapsid

46 thymus

46 topsoil

46 undertake

45 abdomen

45 bail

45 banner

45 bet

45 biochemistry

45 botany

45 brazil

45 buffalo

45 catalog

45 curvature

45 dash-pot

45 deoxyribose

45 dimorphism

45 exotic

45 expel

45 facial

45 fingerprint
15 scarecrow

15 scout

15 sebaceous

15 sept

15 sequoia

15 shampoo

15 shays

15 sherry

15 silkworm

15 sloth

15 stage

15 standby

15 standpoint

15 starburst

15 stardust

15 stingray

15 stopper

15 daddy

15 super-sprinter

15 surfboard

15 surplus

15 swamp-dweller

15 swan

15 ta

15 tandem

15 temp

15 thereafter 


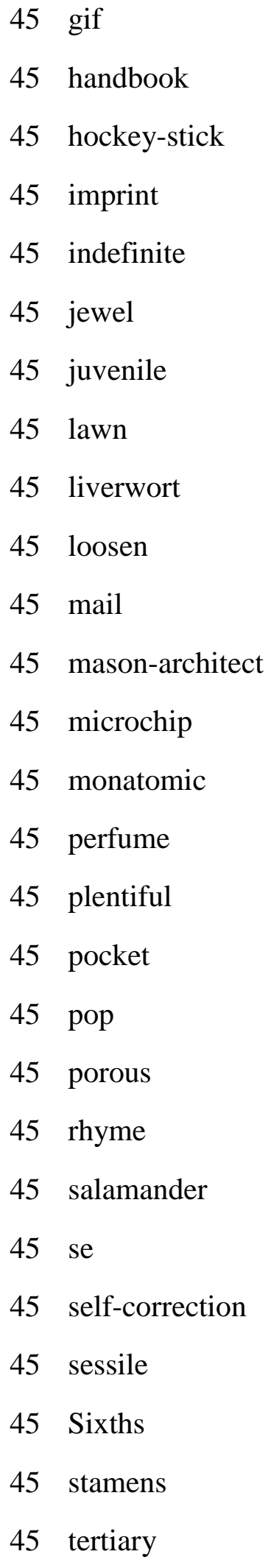


45 therian

45 Toast

45 Toilet

45 Vine

44 ashamed

44 Atlas

44 Biker

44 blindness

44 buoyancy

44 cathedral

44 chat-up

44 decagon

44 dressing

44 Feast

44 Fest

44 Grin

44 gymnast

44 hill-fort

44 inferior

44 influenza

44 irritate

44 Italic

44 lawmaker

44 legend

44 loyalist

44 mankind

44 packet
14 blockade

14 bottlenose

14 brane

14 burr

14 busy

14 byproduct

14 carcass

14 casino

14 centigram

14 chemotherapy

14 chrysalis

14 chuck

14 churn

14 cleanup

14 clubmoss

14 coelenteron

14 colorblind

14 competence

14 conceal

14 congressman

14 consolidate

14 consul

14 copepod

14 courtier

14 crevice

14 dame

14 dataset 
44 pity

44 placeholder

44 plasmodium

44 play-reading

44 plum

44 posterior

44 prone

44 rear

44 roast

44 salinity

44 self-rating

44 shaft

44 sic

44 slipper

44 southwestern

44 specimen

44 spike

44 squirt

44 star

44 starvation

44 subdivide

44 supper

44 syphilis

44 tetrapod

44 miner

44 villi

44 vowel
14 decent

14 detritus

14 didelphis

14 dirk

14 discern

14 disjunction

14 disposition

14 disrespect

14 dissatisfaction

14 enact

14 endow

14 enlist

14 eve

14 eyebrow

14 farsighted

14 femur

14 ferromagnetic

14 footstep

14 forelimb

14 fraud

14 frown

14 fudge

14 gallop

14 gastrulation

14 geocentric

14 girlfriend

$14 \mathrm{grad}$ 
43 algorithm

43 awake

43 breeze-block

43 cane

43 cephalization

43 cleavage

43 clinic

43 closure

43 coulomb

43 deuterium

43 emphysema

43 extraordinary

43 flux

43 fuel-dump

43 grateful

43 homo

43 impedance

43 integumentary

43 jones

43 lamprey

43 master

43 nth

43 pear-tree

$43 \mathrm{rad}$

43 recharge

43 recommendation

43 rock
14 handgun

14 handheld

14 hardwood

14 hobby

14 howl

14 hydrofoil

14 indict

14 inductor

14 inflict

14 intermittent

14 intro

14 jagged

14 jejunum

14 jess

14 keyboard

14 lantern

14 lar

14 layout

14 leaflet

14 leash

14 lineup

14 lingua

14 litmus

14 loneliness

14 longshore

14 lubricant

14 lunchtime 
43 scream

43 seafood

43 silt

43 sophistication

43 haven

43 torque

43 watershed

43 whistle

43 wounded

42 alley-way

42 alright

42 backpack

42 belly

42 bout

42 carpel

42 citric

42 conquistador

42 dermal

42 diode

42 emigrate

42 exaggerate

42 flick

42 flush

42 fuzz

42 herein

42 hertz

42 histamine
14 lush

14 malnutrition

14 mam

14 maneuver

14 manganese

14 medal-winner

14 memoir

14 methionine

$14 \mathrm{mf}$

14 microbiology

14 mini-conglomerate

14 miscible

14 mist

14 misunderstanding

14 monohybrid

14 moose

14 moraine

14 mush

14 nautical

14 neocortex

14 neutrophil

14 nonsmoker

14 nuisance

14 oak

14 ocher

14 oligarchy

14 orchard 
42 hitchhike

42 ice

42 intuitive

42 maritime

42 night-fighter

42 ok

42 outfit

42 over-celebrate

42 paste-up

42 plastid

42 positron

42 rate

42 rover

42 screen

42 section

42 semicircle

42 shield

42 striate

42 ted

42 withstand

42 wow

41 acetic

41 afterwards

41 alliteration

41 allure

41 ambassador

41 anecdote
14 outrage

14 overflow

14 overnight

14 oxbow

14 paperclip

14 paraben

14 parenchymal

14 payload

14 pervade

14 pinpoint

14 planter

14 playful

14 playlist

14 plaza

14 pleiotropic

14 post-acquisition

14 premature

14 prewriting

14 prosecute

14 pylorus

14 rattle

14 re-acquaint

14 rechargeable

14 redefine

14 refrain

14 relaxation

14 repatriate 
41 aorta

41 appetite

41 applet

41 beagle

41 bison

41 bluebird

41 butter-blob

41 climatic

41 congestion

41 dihybrid

41 dining

41 dragonfly

41 epiphyte

41 forgive

41 fructose

41 fry

41 gilt-bronze

41 greet

41 gum

41 haul

41 hector

41 highland

41 hornwort

41 hydrosphere

41 judge

41 keratin

41 magic
14 replant

14 rhyolite

14 rubbish

14 rubisco

14 runway

14 saint

14 sclerosis

14 scour

14 seaside

14 selfish

14 showerhead

14 shriek

14 shrine

14 shrivel

14 skyscraper

14 snack

14 snatch

14 staff

14 stagger

14 stoop

14 stray

14 subinterval

14 systolic

14 tapestry

14 tesla

14 testcross

14 theodolite 
41 mussel

41 neo-liberal

41 noisy

41 non-conservative

41 non-entity

41 paramecia

41 planetary

41 pre-announcement

41 pupil-teacher

41 quartic

41 sensible

41 shiver

41 silica

41 smash

41 sow

41 spermatogenesis

41 sponsor

41 toothpick

41 vain

41 viscosity

41 worship

41 wreck

40 adenosine

40 albert

40 ampere

40 aromatic

40 awkward
14 thumbtack

14 toluene

14 tread

14 triton

14 turgor

14 turnip

14 usurp

14 venous

14 vicinity

14 wherein

14 yarn

13 aftershock

13 aloe

13 amid

13 amide

13 anima

13 apprehend

13 apron

13 aquaculture

13 arcsine

13 asparagine

13 assertive

13 auction

13 awe

13 barley

13 barrack

13 battlefield 
40 barn

40 chimney-sweeper

40 code

40 coercion

40 costa

40 cottage

40 cottontail

40 cretaceous

40 cylindrical

40 decibel

40 default

40 deforest

40 depart

40 doorknob

40 fare

40 fasten

40 gardener

40 gastroenteritis

40 gluon

40 hydrophilic

40 icosahedral

40 indo

40 mother-goddess

$40 \mathrm{ng}$

40 nitric

40 non-juror

40 offset
13 beard

13 behold

13 berlin

13 biomedical

13 blackboard

13 blacksmith

13 blonde

13 boxplot

13 breach

13 breadth

13 bruise

13 buffer

13 bully

13 bully-boy

13 campylobacter

13 carapace

13 cheddar-type

13 chickenpox

13 chlorofluorocarbon

13 clubhouse

13 coelomate

13 commend

13 commensal

13 compassionate

13 contraception

13 cookbook

13 crankshaft 
40 over-expose

40 palm-tree

40 pepperoni

40 pose

40 prejudice

40 provision

40 radula

40 reputation

40 rodent

40 shame

40 snowy

40 stamen

40 stiff

40 tedious

40 slot

39 aboard

39 abort

39 abstain

39 alongside

39 astonish

39 awful

39 batter

39 boson

39 broaden

39 bronchiole

39 carriage

39 chalk
13 cricket

13 cricket-writer

13 crumble

13 curvilinear

13 cyclin

13 cypress

13 deflate

13 deity

13 deport

13 deter

13 dinitrogen

13 directories

13 elude

13 eternity

13 evade

13 excision

13 forge

13 formaldehyde

13 frack

13 fragrance

13 gastritis

13 gelatin

13 gibberellin

13 gibbous

13 ginger

13 goalie

13 gob 
39 confront

39 deprive

39 dinoflagellate

39 electronegative

39 fashioning

39 fig

39 furnace

39 grab

39 greed

39 hawthorn

39 insure

39 ken

39 laser

39 life-guard

39 macro-cannon

39 market

39 missile

39 modest

39 necklace

39 nocturnal

39 ordinal

39 prop

39 re-constitute

39 re-formulate

39 renal

39 replenish

39 repressor
13 gossip

13 gyre

13 hailstone

13 handy

13 heir

13 helm

13 heterocyclic

13 husky

13 immerse

13 indies

13 indivisible

13 interbreed

13 interconnector

13 intermembrane

13 internationally

13 intimidate

13 isotherm

13 jade

13 jewel-case

13 lactate

13 leach

13 luggage

13 lysine

13 lysis

13 man

13 mare's-tail

13 misunderstand 
39 self-excuse

39 someday

39 spawn

39 tabular

39 thirst

39 thorn

39 voltaic

39 waterproof

39 windmill

38 anomaly

38 attic

38 behalf

38 bible

38 boron

38 brook

38 can

38 chessboard

38 cytotoxic

38 dandelion

38 deaf

38 desperate

38 diastole

38 enslave

38 extrude

38 frustrate

38 graham

38 gut
13 moat

13 modal

13 monastery

13 monoecious

13 motif

13 nationwide

13 nematocysts

13 nines

13 ninths

13 non-homosexual

13 nostril

13 objectivity

13 occlude

13 ocelli

13 orthogonal

13 outnumber

13 overwhelm

13 pacemaker

13 pansy

13 pant

13 pear

13 pedometer

13 pelvic

13 photocopy

13 piccolo

13 pillar 


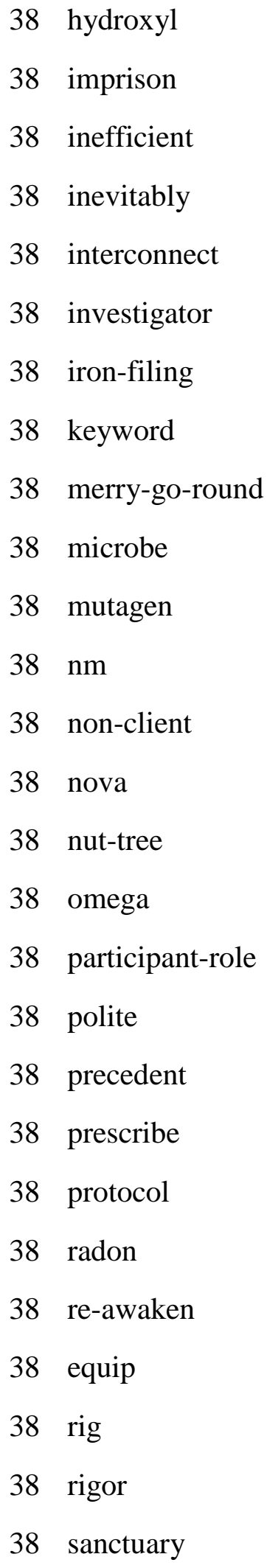

13 pimple

13 pine

13 polyadenylation

13 pony-tail

13 pope

13 porcupine

13 prank

13 prison

13 prolactin

13 proline

13 prong

13 protrude

13 proverb

13 pulp

13 pumice

13 radicand

13 reap

13 recap

13 recite

13 redundancy

13 reintroduce

13 retention

$13 \mathrm{rev}$

13 roasting-pan

13 rosemary

13 salol

13 sandal 
38 semi-profession

38 shoe-polish

38 statue

38 sterile

38 sunflower

38 superscript

38 tender

38 thief

38 trapdoor

38 withdraw

37 acme

37 affinity

37 angle

37 anorexia

37 arouse

37 bathtub

37 blind

37 caliphate

37 camel-train

37 capitol

37 caramel

37 catabolic

37 cheetah

37 chelicerate

37 closet

37 comedies

37 commissioner
13 sawmill

13 servitude

13 slim

13 sol

13 sot

13 stalactite

13 stockholder

13 strenuous

13 subside

13 suburb

13 sun

13 surrender

13 syllable

13 tarnish

13 tendril

13 testicle

13 testimony

13 threadlike

13 ting

13 toke

13 trey

13 triploid

13 trivia

13 tuck

13 vestigial

13 villus

13 vulva 
37 compel

37 compost

37 confirm

37 corona

37 corrupt

37 countryside

37 curse

37 cuttlefish

37 depreciate

37 divinity

37 dump

37 electrostatic

37 eon

37 ethyl

37 flaw

37 funeral

37 gall

37 gizzard

37 indeterminate

37 inevitable

37 interquartile

37 interspecific

37 kangaroo

37 lifespan

37 livelihood

$37 \mathrm{mc}$

37 milestone
13 wobble

13 yahoo

13 zenith

12 abide

12 abominable

12 accredit

12 accustomed

12 acoustic

12 aeronautics

12 aesthetics

12 affirmation

12 afghan

12 aftermath

12 altocumulus

12 ambulance

12 amorphous

12 anthem

12 antidiuretic

12 antinode

12 antitrust

12 appalled

12 applause

12 arch

12 awesome

12 azurite

12 bachelor

12 bacillus 
37 musher

37 mycorrhiza

37 nobility

37 obligate

37 photoelectric

37 scuba

37 seldom

37 sheath

37 siren

37 slate

37 solitary

37 stud

37 subgroup

37 subscription

37 tendon

37 terry

37 theirs

37 signature

37 upwell

37 wrinkle

37 zip

36 abrupt

36 allege

36 baron

36 blur

36 brace

36 caution
12 badger

12 ballpoint

12 bankruptcy

12 beech

12 billboard

12 bioengineer

12 blond

12 bob

12 body

12 bologna

12 bract

12 bulldoze

12 burdock

12 bypass

12 cade

12 calf

12 casework

12 caudal

12 centiliter

12 cesium

12 cheesecloth

12 chia

12 chink

12 chromatography

12 clash

12 clove

12 coma 


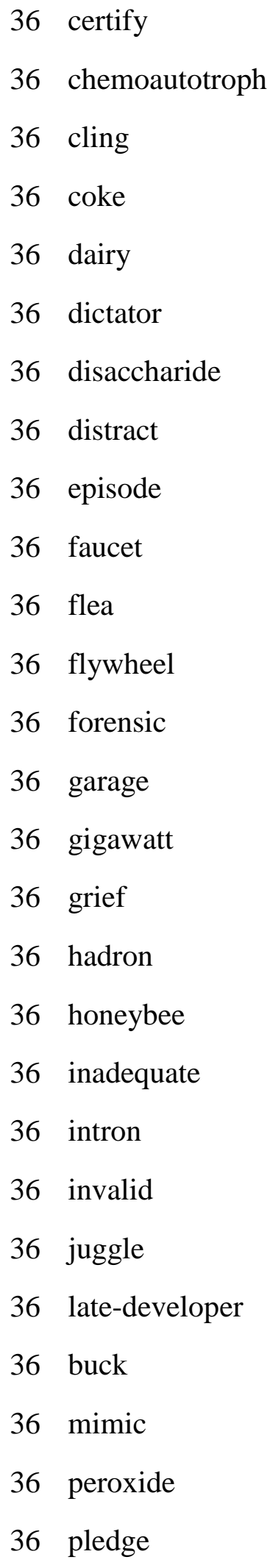

12 comer

12 commence

12 congenital

12 courthouse

12 courtyard

12 cowbird

12 cramp

12 creole

12 cripple

12 dangle

12 denitrification

12 denounce

12 dire

12 disapproval

12 dispute

12 distil

12 dodo

12 drumlin

12 earthshine

12 electro

12 empower

12 encircle

12 endosymbiont

12 energize

12 evoke

12 eyeball

12 fan 


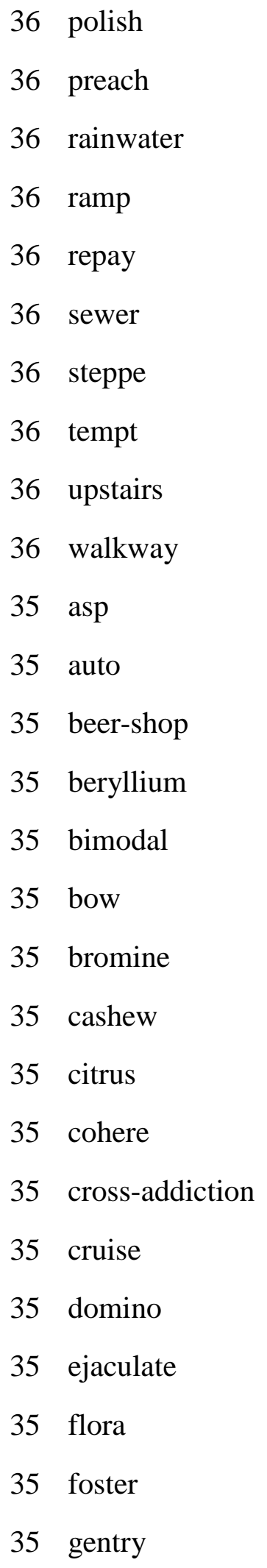

12 farewell

12 fetch

12 fibrin

12 fire-extinguisher

12 florid

12 frantic

12 furry

12 galactose

12 gee

12 gent

12 glob

12 gummy

12 hale

12 halophiles

12 handwriting

12 hazel

12 heartburn

12 heliocentric

12 heterosexual

12 hexapod

12 holler

12 holly

12 horrible

12 horsefly

12 hos

12 humpback

12 hyena 
35 grandson

35 groove

35 haste

35 helical

35 hen

35 hypotonic

35 instinct

35 insult

35 invest

35 irreversible

35 jersey

35 landmark

35 leather

35 macroevolution

35 muon

35 nanotechnology

35 negotiate

35 oceanographer

35 pebble

35 pictograph

35 pivot

35 plywood

35 pool

35 portray

35 preliminary

35 progesterone

35 propaganda
12 hysteria

12 incur

12 indigenous

12 inmate

12 intercontinental

12 irony

12 isobar

12 jazz

12 ligase

12 lithospheric

12 littoral

12 lungfish

12 lymphoma

12 macadamia

12 manure

12 mas

12 matinee

12 medal

12 mega-store

12 metro

12 microprocessor

12 minicomputer

12 misery

12 monocot

12 morocco

12 motility

12 mural 
35 quaternary

35 rattlesnake

35 scoot

35 shear

35 sheng

35 southeastern

35 subheading

35 susceptible

35 tetrahedral

35 tip

35 trademark

35 tub

35 tum

35 widow

34 acetate

34 anticline

34 antiviral

34 arctic-alpine

34 aspirin

34 asthenosphere

34 avenue

34 bargain-hunter

34 bench

34 benthos

34 bilaterally

34 bi

34 bite
12 musculoskeletal

12 muse

12 myofibrils

12 nail

12 nelson

12 niece

12 nitrite

12 non-elite

12 onshore

12 opiate

12 orogeny

12 orthodoxy

12 oscula

12 overly

12 oxidative

12 pancreatic

12 paralyze

12 parthenogenesis

12 pasture

12 peek

12 perish

12 peroxisomes

12 piggy-bank

12 pinocytosis

12 playwright

12 plummet

12 pol 
34 borrow

34 buzz-word

34 calibrate

34 capture

34 cheat

34 circumcenter

34 cyst

34 cytokine

34 dawn

34 emperor

34 felony

34 grate

34 halite

34 heptagon

34 humble

34 insist

34 inversion

34 lobbyist

34 mafic

34 microclimate

34 motile

34 nekton

34 optimal

34 osteoporosis

34 password

34 peninsula

34 photography
12 populist

12 possum

12 pow

12 powerhouse

12 pseudo-intellectual

12 pyroxene

12 quadriceps

12 rediscover

12 redress

12 rem

12 reshape

12 retrograde

12 rheumatoid

12 rho

12 rinse

12 rotor

$12 \mathrm{rpm}$

12 rudder

12 scorch

12 screwdriver

12 seashore

12 second-rower

12 self-adhesive

12 self-deception

12 sever

12 sill

12 sinkhole 
34 primer

34 protozoan

34 puddle

34 radiometric

34 rally

34 ranger

34 revere

34 riddle

34 root

34 scrap

34 sea-fairy

34 shop-assistant

34 submersible

34 submission

34 sub-routine

34 tablespoon

34 tee-time

34 tragedy

34 uphill

34 viable

34 xylem

33 annex

33 band

33 barium

33 bathing-suit

33 bedrock

33 bloody
12 smelting

12 smokestack

12 sophomore

12 sox

12 span

12 sparse

12 speck

12 starling

12 straddle

12 stumble

12 subjective

12 supercapacitors

12 super-ferry

12 superheated

12 supernatural

12 tactic

12 tailor

12 tat

12 tempera

12 tenure

12 thalamus

12 lag

12 tome

12 torture

12 tot

12 tower

12 treason 
33 bronchitis

33 bulletin

33 cam

33 chin

33 chore

33 commission

33 compliment

33 dale

33 dialysis

33 dismiss

33 dog-rose

33 donna

33 drawback

33 drier

33 echelon

33 echolocation

33 enforcement

33 enriched

33 extracellular

33 gen

33 gourd

33 guinea

33 inexpensive

33 jerk

33 lytic

33 mandible

33 md
12 trout

12 trypsin

12 tuatara

12 tubulin

12 updraft

12 uppermost

12 vault

12 volatile

12 waffle

12 weep

12 whilst

12 wholly

12 wilt

12 workout

12 yep

11 acquaintance

11 acquiesce

$11 \mathrm{ad}$

11 airship

11 airtight

11 allegory

11 allot

11 allover

11 alto

11 ammeter

11 anneal

11 anthracite 
33 medieval

33 mudslide

33 osteoblast

33 overweight

33 oyster

33 peculiar

33 photoautotrophs

33 pierce

33 plunge

33 pork

33 preservation

33 prince-bishop

33 remnant

33 ripe

33 script

33 shingles

33 single-decker

33 sis

33 spare-rib

33 spermatocyte

33 sphincter

33 storm

33 subintervals

33 sundae

33 teaspoon

33 tribute

33 tuna
11 anthrax

11 anthropology

11 antislavery

11 aphid

11 arable

11 archer

11 arctangent

11 artwork

11 asphalt

11 aspirate

11 autobiographical

11 baggage

11 bantu

11 baobab

11 bicyclist

11 biodegrade

11 birch

11 black

11 bleak

11 blouse

11 blub

11 bombardment

11 bon

11 book

11 boom

11 bronchus

11 bubonic 
33 zodiac

32 anchorage

32 anticodon

32 aqueduct

32 argon

32 baseline

32 beard-shaving

32 bicarbonate

32 biogeography

32 brush

32 byte

32 carta

32 clog

32 clone

32 commensalism

32 connotation

32 costume

32 craft

32 cranium

32 disapprove

32 edible

32 euro

32 exoplanet

32 facto

32 finch

32 foliate

32 hydraulic
11 bunk

11 cava

11 centrosome

11 chant

11 chap

11 charcoal

11 cheerleader

11 cheesecake

11 chlorate

11 choir

11 clockwork

11 cloy

11 coalesce

$11 \mathrm{cod}$

11 colligative

11 columnist

11 commune

11 compo

11 contempt

11 corrugated

11 counterforce

11 creepy-crawly

11 darling

11 daunting

$11 \mathrm{del}$

11 dichromate

11 dieter 
32 imbalance

32 indefinitely

32 inspiration

32 interstate

32 jenny

32 latency

32 ligament

32 lowers

32 loyal

32 lunch

32 mammoth

32 mount

$32 \mathrm{mv}$

32 ne

32 near-certainty

32 nominee

32 non-durable

32 nonspecific

32 onward

32 oppress

32 packaged

32 paintbrush

32 parade

32 photic

32 prostate

32 rag-doll

32 recount
11 dihydrogen

11 din

11 dunk

11 dynasty

11 echinoid

11 elk

11 emulsify

11 endemic

11 epidemiology

11 epiphyseal

11 equity

11 eyedropper

11 falsify

11 fauna

11 filibuster

11 fissure

11 fortify

11 fours

11 freckle

11 freeman

11 fringe

11 galvanic

11 gamble

11 genuine

11 gestation

11 gilbert

11 glycol 
32 oxygenated

32 rim

32 semiconductor

32 shorthand

32 sigh

32 slash

32 southward

32 space-occupant

32 spectacle

32 spiny

32 squat

32 string

32 strive

32 subclass

32 subject

32 supergiant

32 synovial

32 thrill

32 timber

32 tinker

32 toothpaste

32 triphosphate

32 unprecedented

32 waist

32 wales

32 waterfall

32 yogurt
11 gneiss

11 goat-antelope

11 goo

11 gospel

11 grill

11 headquarter

11 healthcare

11 hematite

11 high-brow

11 hiss

11 hoe

11 hostage

11 hover

11 hydra

11 icosahedron

11 impost

11 impoverish

11 inconsistency

11 infraclass

11 jpeg

11 keck

$11 \mathrm{kin}$

11 knit

11 laxative

11 ledge

11 leftmost

11 les 
31 alkaline

31 amber

31 apothem

31 blister

31 brute

31 cochlea

31 confound

31 couch

31 den

31 differentiate

31 dosage

31 doughnut

31 farmland

31 fatigue

31 fiery

31 hardware

31 hookworm

31 horseshoe

31 imitate

31 innocence

31 interneuron

31 intracellular

31 krill

31 laughter-line

31 lawsuit

31 lime

31 macronutrients
11 lest

11 liar

11 lioness

11 litigant

$11 \operatorname{lux}$

11 mea

11 meditation

11 mega-flop

11 meiotic

11 melanoma

11 meniscus

11 metamorphose

11 microbial

11 miracle-worker

11 misinterpret

11 missense

11 monocyte

11 multi-millionaire

11 mumps

11 murmur

11 myriad

11 nanoscience

11 napkin

11 nausea

11 near-drowning

11 nearsightedness

11 nitrous 
31 meander

31 messy

31 molly

31 octahedron

31 oligochaete

31 ossification

31 ostrich

31 over-ambition

31 photographer

31 premium

31 reliance

31 ribonucleic

31 rupture

31 savannah

31 scallop

31 scarlet

31 sedentary

31 self-portrait

31 semi-consonant

31 sepal

31 shale

31 shopper

31 skeptical

31 skydive

31 slug-pellet

31 snack-bar
11 noncoding

11 non-delinquent

11 noontime

11 oat

11 octant

11 oddly

11 oneself

11 orphan

11 outlying

11 overfish

11 palace

11 palette

11 panama

11 paradox

11 paternal

11 peasant-proletarian

11 pelican

11 phot

11 pickle

11 pike

11 pinna

11 poach

11 ponder

11 pool-liner

11 pounce

11 precinct

11 propagate 
31 southerner

31 spaceship

31 speculate

31 sporangia

31 subsidy

31 substituent

31 subtropical

31 sway

31 syrup

31 cue

31 tor

31 unification

31 ureter

31 vomit

31 wick

30 abridge

30 abscisic

30 acetone

30 aphorism

30 apologize

30 ashore

30 assert

30 authentic

30 bargain

30 breakthrough

30 breeze

30 bulimia
11 protactinium

11 protease

11 pulsar

11 puncture

11 pupal

11 pupil

11 raffle

11 rage

11 re-bait

11 recoil

11 refuel

11 regrow

11 rejoice

11 salter

11 scyphozoan

11 semi-finalist

11 shack

11 she-ass

11 sheer

11 shrug

11 shun

11 siege-tower

11 skit

11 snapshot

11 spear

11 spec

11 squint 


\begin{tabular}{|c|c|c|}
\hline 30 camel & 11 & statewide \\
\hline 30 cloaca & 11 & statute \\
\hline clownfish & 11 & storyteller \\
\hline 30 crick & 11 & stunt \\
\hline 30 deference & 11 & suckle \\
\hline 30 dislike & 11 & suicide \\
\hline disobey & 11 & surf \\
\hline 30 ditch & 11 & tallgrass \\
\hline 30 doctorate & 11 & taxpayer \\
\hline dolly & 11 & teammate \\
\hline downstairs & 11 & teddy \\
\hline dread & 11 & telomere \\
\hline 30 fragment & 11 & terra \\
\hline gaze & 11 & theft \\
\hline geodesy & 11 & threshold \\
\hline 0 ghost & 11 & thunder \\
\hline grease & 11 & timescale \\
\hline gitease & 11 & tremor \\
\hline lale & 11 & trimester \\
\hline insoluble & & \\
\hline 30 installation & 11 & trimethylamine \\
\hline 30 interface & 11 & trophy \\
\hline joe & 11 & undersea \\
\hline kick & 11 & unroll \\
\hline magenta & 11 & vigil \\
\hline menarche & 11 & viper \\
\hline 30 mortal & 11 & wallet \\
\hline $0 \mathrm{mpg}$ & 11 & warship \\
\hline
\end{tabular}


30 mythology

30 nanotube

30 nonnative

30 nylon

30 outlook

30 overpopulation

30 overthrow

30 parliamentary

30 patio

30 penicillin

30 pudding

30 pure

30 putter

30 rime

30 robin

30 rural

30 savanna

30 semi-automatic

30 shovel

30 slump

30 spy-hole

30 squash

30 stratus

30 tackle

30 thou

29 amylase

29 anabolic
11 weird

11 wont

11 workspace

11 yeah

11 youngster

11 zigzag

10 head-count

10 filing-cabinet

10 aching

10 addict

10 adobe

10 affix

10 afloat

10 ammonite

10 amnesty

10 animalcule

10 antagonize

10 antipodal

10 anvil

10 apiece

10 articulate

10 ascertain

10 balboa

10 bask

10 bat

10 bellow

10 benzoate 
29 apprentice

29 archegonia

29 bamboo

29 bodily

29 brine

29 burial

29 chipmunk

29 circadian

29 cirrus

29 coconut

29 codominance

29 communism

29 condom

29 consensus

29 cotyledon

29 discontinuous

29 dowry

29 embarrass

29 encompass

29 eyesight

29 fake

29 fractal

29 fragile

29 gem

29 glycine

29 hood

29 hoof
10 betray

10 birthrate

10 bizarre

10 blunt

10 bod

10 booby-trap

10 brisk

10 bust

10 cafe

10 cant

10 caravel

10 caress

10 caricature

10 carina

10 cedar

10 certiorari

10 chairperson

10 chuckle

10 chug

$10 \mathrm{col}$

10 coolant

10 coordinate

10 cop

10 corkscrew

10 cove

10 daffodil

10 daydream 
29 humus

29 hydrozoa

29 intervene

29 java

29 junk

29 lump-sum

29 manatee

29 manifest

29 marathon

29 maze

29 muddy

29 nasal

29 om

29 peat-bog

29 photo-finish

29 pound

29 pupa

29 pyruvic

29 quad

29 radically

29 re-board

29 resent

29 ripple

29 roly-poly

29 sarcomere

29 scramble

29 silly
10 derail

10 detoxify

10 diner

10 dinucleotide

10 draft

10 droop

10 drumstick

10 dwindle

10 echidna

10 electroplate

10 ell

10 encephalitis

10 endosperm

10 entree

10 eudicot

10 euglena

10 ex-boyfriend

10 exterminate

10 eyeglass

10 eyespot

10 fellow-commoner

10 fend

10 finder

10 firefly

10 firsthand

10 flit

10 foal 
29 slag-heap

29 soybean

29 sunscreen

29 triathlete

29 urea

29 warrior

28 acorn

28 alkali

28 audio-visual

28 balcony

28 ballpark

28 bioterrorism

28 bleach

28 blossom

28 boast

28 brew

28 brochure

28 carload

28 choke

28 chromo

28 claim

28 compilation

28 concentric

28 contagious

28 cumulus

28 cupboard

28 dine
10 foreshocks

10 gale

10 gecko

10 gigabyte

10 giggle

10 gin

10 girdle

10 glare

10 glorify

10 goldenrod

10 grapple

10 grope

10 grout

10 gulp

10 guzzle

10 haircut

10 handkerchief

10 hash

10 heroin

10 hippo

10 hometown

10 hoot

10 hurdle

10 hush

10 hydrologic

10 impel

10 indifference 


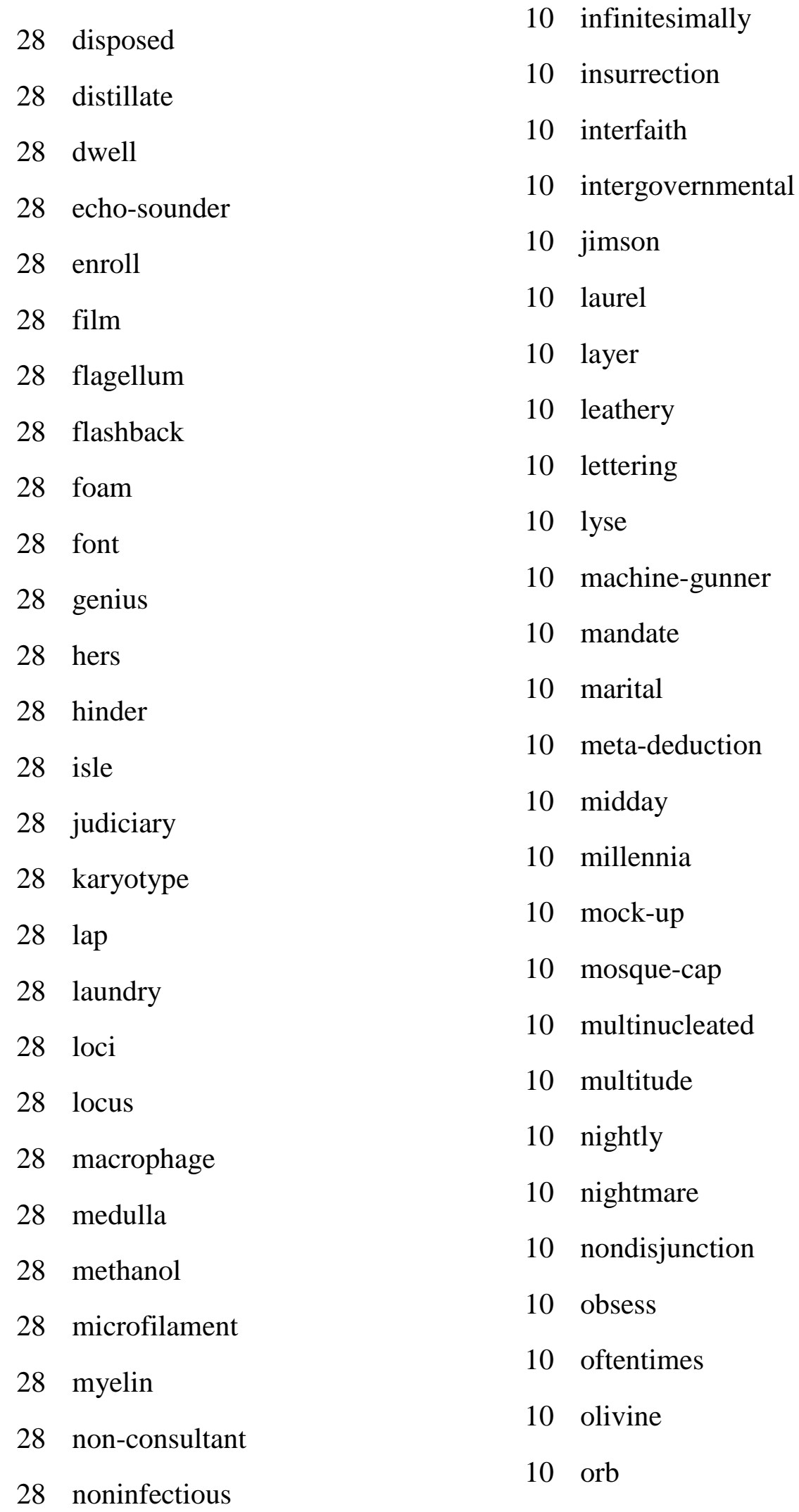


28 ogive

28 passion

28 pasta

28 pepsin

28 peptidoglycan

28 percolate

28 permafrost

28 pharmacist

28 pre-ispose

28 prescription

28 pyrite

28 ram-raid

28 rearranging

28 rebound

28 rebuild

28 reckon

28 rhetoric

28 roadrunner

28 saprotroph

28 scar

28 self-install

28 self-justification

28 seminiferous

28 sincere

28 snap

28 sonnet

28 sovereignty
10 oxoacid

10 oxy

10 pact

10 parathyroid

10 pee

10 pentachloride

10 pep-talk

10 percussion

10 perplex

10 persecute

$10 \mathrm{pf}$

10 photochemical

10 piglet

10 pilus

10 placer

10 planetarium

10 playa

10 plop

10 polo

10 pone

10 portfolio

10 posterity

10 preexist

10 prehistoric

10 primula

10 problematic

10 profess 
28 stopwatch

28 subfamily

28 tern

28 tic

28 cyclist

28 tug

28 tumble

28 librarian

28 uptake

28 vane

28 vigor

28 warrant

27 anal

27 antacid

27 antique

27 appellate

27 banquet

27 barber-surgeon

27 broom

27 champagne

27 cinnamon

27 crinoid

27 demon

27 desalinate

27 disgust

27 doorway

27 endeavor
10 quantize

10 quilter

10 raspberry

10 reabsorption

10 re-bore

10 recalculate

10 recycler

10 redshift

10 ref

10 re-format

10 regent

10 rendition

10 replica

10 revival

10 rick

10 rill

10 rite

10 roadside

10 salicylic

10 salt-cellar

10 scavenge

10 scrabble

10 seabird

10 sea-green

10 seahorse

10 seashell

10 seduce 
27 enlighten

27 esteem

27 expertise

27 flee

27 fond

27 gang-boss

27 glycerol

27 gnu

27 goldfish

27 herd

27 hive

27 hoover

27 hug

27 hypertonic

27 indistinguishable

27 innermost

27 instability

27 intraspecific

27 ism

27 iteration

27 kneel

27 lettuce

27 lightweight

27 lollipop

27 luteum

27 maglev

27 manually
10 self-citation

10 sesame

10 sidekick

10 sidereal

10 single

10 skipping-rope

10 slogan

10 sludge

10 smear

10 snapdragon

10 snowshoe

10 socioeconomic

10 sorrow

10 spaceflight

10 spar

10 spirogyra

10 spook

10 spouse

10 squad

10 staghorn

10 stalagmite

10 stealth

10 stegosaurus

10 stereotype

10 stitch

10 strangeness

10 strap 
27 maternal

27 mem

27 microevolution

27 mister

27 nematocyst

27 nervosa

27 nonagon

27 non-stranger

27 nowadays

27 overtime

27 patent

27 patriot

27 phototropism

27 pile

27 prickly

27 prosper

27 raisin

27 refinery

27 renaissance

27 salesman

27 sap

27 seamount

27 seismometer

27 semi-opaque

27 sideways

27 sip

27 skirt
10 subscribe

10 tack

$10 \operatorname{tarp}$

10 throne

10 thunderhead

10 tidy

10 timothy

10 tokay

10 tow-truck

10 tungsten

10 typewriter

10 typhoon

10 underlie

10 varicella

10 velvet

10 vernal

10 vow

10 wane

10 watermelon

10 weary

10 webpage

10 wed

10 whereof

10 whiskey

10 worksheet

10 worthwhile

10 no-go 
27 snowflake

27 stanza
10 pollen-tube

10 silk-screen 


\section{Low Frequency Word List}

The Low Frequency Word List, shown in Table 18, has 8,080 lemmas. Words in this list had between nine occurrences and a single occurrences in the corpus. For a complete list of low-frequent words with all derivational and inflectional forms, check wWw.myvirs.com/dictionary.

Table 18. Low Frequency Word List.

\begin{tabular}{lll}
\hline Freq. Word & Freq. Word \\
\hline
\end{tabular}

9 aberration

9 acer

9 acronym

9 adjustable

9 adore

9 agrarian

9 ambience

9 amethyst

9 ankle

9 antifreeze

9 apathy

9 apex

9 apportion

9 auto

9 autumnal
2 capo

2 carbolic

2 caretaker

2 carnelian

2 carny

2 carob

2 carpe

2 carrageenan

2 carrousel

2 case

2 castigate

2 castor

2 catchword

2 cationic

2 caustic 


$$
\begin{aligned}
& 9 \text { avian } \\
& 9 \text { axel } \\
& 9 \text { ballast } \\
& 9 \text { banjo } \\
& 9 \text { barb } \\
& 9 \text { beam } \\
& 9 \text { beckon } \\
& 9 \text { bedside } \\
& 9 \text { beery } \\
& 9 \text { bel } \\
& 9 \text { benign } \\
& 9 \text { berg } \\
& 9 \text { beryl } \\
& 9 \text { billiard-table } \\
& 9 \text { biogas } \\
& 9 \text { bioremediation } \\
& 9 \text { biosynthesis } \\
& 9 \text { birthright } \\
& 9 \text { biscuit } \\
& 9 \text { blight } \\
& 9 \text { blimp } \\
& 9 \text { bloodroot } \\
& 9 \text { bowerbird } \\
& 9 \text { brag } \\
& 9 \text { broil } \\
& 9 \text { bromeliad } \\
& 9 \text { burgess }
\end{aligned}
$$

2 centerpiece

2 centerpieces

2 cep

2 cessation

2 cession

2 chai

2 chalet-bungalow

2 chamberlain

2 chares

2 chariot

2 chasm

2 chastity

2 checkout

2 cheekbone

2 chemo

2 chestnut

2 chevalier

2 chiasma

2 chickpea

2 chieftain

2 chine

2 chis

2 chlorinate

2 chopstick

2 choro

2 churchyard

2 chute 

9 burrito
2 cider
9 candid
2 ciliary
9 canker
2 circumpolar
9 canon
2 cirrhosis
9 cardio
9 caribou
2 cirrostratus
2 cisterna
9 casa
2 clayton
9 catamaran
2 clientele
2 cline
2 clock
9 chameleon
2 clod
9 chat
2 clothespins
9 circus
2 clueless
9 cisternae
2 coach
9 clap
9 clasp
9 cleave
9 cleft
9 clench
9 clipper
9 clutter
9 cocoa
9 colitis
9 combinatory
9 commotion
9 concur
9 congested
9 corner
2 coattails
2 cobb
2 cochineal
2 cockatoo
2 coffeehouse
2 cogeneration
2 cognitive
2 collarbone
2 collate
2 colleen
2 collenchyma
2 collisional
2 cologne 


\begin{tabular}{llll}
9 & cosmos & 2 colorectal \\
9 & counterargument & 2 & colugo \\
9 & crayfish & 2 & columbaria \\
9 & cremate & 2 & combo \\
9 & crook & 2 & comfy \\
9 & cropland & 2 & commonsense \\
9 & culver & 2 & compart \\
9 & dander & 2 & comport \\
9 & deli & 2 & concha \\
9 & delve & 2 & conciliate \\
9 & depositor & 2 & concoct \\
9 & deputy & 2 & concourse \\
9 & desolate & 2 & confetti \\
9 & dimple & 2 & confluence \\
9 & dioecious & 2 & congeal \\
9 & diploblast & 2 & consanguinity \\
9 & disdain & 2 & cookout \\
9 & disorder & 2 & copious \\
9 & displease & 2 & copulation \\
9 & disseminate & 2 & coquina \\
9 & dungeon & 2 & cordon \\
9 & dysplasia & 2 & corer \\
9 & earplugs & 2 & cornucopian \\
9 & earring & 2 & corral \\
9 & emancipate & 2 & corsage \\
9 & embark & 2 & corticosteroid \\
9 & entail & 2 & cottonwood \\
& & \\
\hline & &
\end{tabular}




\begin{tabular}{|c|c|c|c|}
\hline 9 & etymology & 2 & counterclaim \\
\hline 9 & excise & 2 & countrywide \\
\hline 9 & facet & 2 & covet \\
\hline 9 & faction & 2 & cowgirl \\
\hline 9 & $\mathrm{fad}$ & 2 & cowries \\
\hline 9 & feminine & 2 & crab \\
\hline 9 & fimbria & 2 & cranial \\
\hline 9 & fizz & 2 & cranky \\
\hline 9 & flank & 2 & crass \\
\hline 9 & fletcher & 2 & craw \\
\hline 9 & flint & 2 & credo \\
\hline 9 & flutter & 2 & creosote \\
\hline 9 & foodborne & 2 & crib \\
\hline 9 & foothill & 2 & crinkle \\
\hline 9 & foreground & 2 & crock \\
\hline 9 & foreman & 2 & crossover \\
\hline 9 & foxglove & 2 & crosspiece \\
\hline 9 & fraternal & 2 & crosswalk \\
\hline 9 & gallium & 2 & crossway \\
\hline 9 & garlic & 2 & crummy \\
\hline 9 & garment & 2 & crystallography \\
\hline 9 & gateway & 2 & cuddle \\
\hline 9 & genesis & 2 & cumber \\
\hline 9 & gerund & 2 & curfew \\
\hline 0 & glitter & 2 & curry \\
\hline & glucagon & 2 & cutler \\
\hline & glycolipid & 2 & cyan \\
\hline
\end{tabular}



9 gown
9 grana
9 granular
9 grip
9 gush
9 gutter
9 hack
9 hairpin
9 heed
9 helicase
9 helicobacter
9 hemichordate
9 hem lymph
9 hemorrhage
9 hermit
9 hitch
9 hog
9 holothurian
9 honeycomb
9 hospitable
9 humiliate
9 hump
9 hurl
9 hyphen
9 hypochlorite
9 immiscible
9 impart

2 cyanobacterial

2 cybercrime

2 daft

2 dag

2 dainty

2 daises

2 dally

2 darn

2 dater

2 debar

2 debut

2 deciliters

2 decry

2 deft

2 degeneracy

2 dele

2 delineate

2 delinquency

2 delude

2 deluxe

2 demagnetized

2 demarcation

2 dementia

2 demist

2 demote

2 dendrochronology

2 depersonalize 

9 inalienable
2 depose
9 inaugural
2 deprotonate
9 indexed
2 dermatitis
9 inflamed
2 desaturase
9 infrequent
2 devalue
9 inoculate
2 dexterity
9 jackal
2 diadem
9 jackrabbit
2 diffidence
9 jimmy
2 difluoride
9 lactobacillus
2 dinghy
9 ladybird
2 diocese
$9 \quad$ lag
9 lamb
2 diphtheria
2 dirigible
9 landmass
9 laterite
9 lease
9 lengthwise
9 letter
9 lodge
9 loosestrife
9 lovelock
9 lupus
9 lustrate
9 lye
9 malacostraca
9 maltose
9 manly
2 disarray
2 disavow
2 disclaim
2 discoloration
2 disconsolate
2 disempower
2 disenfranchisement
2 disgruntled
2 disillusion
2 disinherit
2 dispatch
2 dissemble
2 dissident
2 disused 


$$
\begin{array}{ll}
9 & \text { mead } \\
9 & \text { melanogaster } \\
9 & \text { melon } \\
9 & \text { methanogen } \\
9 & \text { microbiologist } \\
9 & \text { midline } \\
9 & \text { mighty } \\
9 & \text { millisecond } \\
9 & \text { mod } \\
9 & \text { mononucleosis } \\
9 & \text { mortar } \\
9 & \text { mothball } \\
9 & \text { panda } \\
9 & \text { moxie } \\
9 & \text { oatmeal } \\
9 & \text { mustard } \\
9 & \text { nonspontaneous } \\
9 & \text { mysid } \\
9 & \text { clipping } \\
9 & \text { neurologist } \\
9 & \text { nom } \\
9 & \text { no-man } \\
9 & \\
9 & \\
9 & \\
9 & \\
9 & \\
9 & \\
9 & \\
9 & \\
9 &
\end{array}
$$

2 ditty

2 divination

2 divulge

2 dizygotic

2 dodecahedron

2 dodge

2 doggedly

2 dogwood

2 don

2 doomster

2 dopey

2 dosimeter

2 doughty

2 douse

2 downgrade

2 downpour

2 downright

2 downslope

2 dram

2 drawstring

2 dray

2 driftwood

2 drowse

2 duchess

2 duh

2 dunce

2 duo 
9 paperback

9 passport

9 pastime

9 patron

9 peck

9 pertinent

9 phenylketonuria

9 pic

9 pickup

9 picky

9 plagiarism

9 plea

9 podia

9 pointless

9 post

9 preinitiation

9 preservative

9 prophage

9 psalm

9 purge

9 quarterback

9 raid

9 ravage

9 reassure

9 re-commence

9 contra

9 recrystallization
2 dupe

2 dysmenorrhea

2 earthwork

2 ectopic

2 edema

2 effluent

2 egg

2 eggbeater

2 eighties

2 electrodynamic

2 electroweak

2 elixir

2 elm

2 embankment

2 embassy

2 embattled

2 embolus

2 empress

2 encapsulate

2 encasement

2 enclave

2 endgame

2 endosomes

2 engravings

2 enigma

2 enliven

2 enteric 


\begin{tabular}{|c|c|c|c|}
\hline 9 & refinement & 2 & enterococci \\
\hline 9 & refrigeration & 2 & entourage \\
\hline 9 & regurgitate & 2 & entrails \\
\hline 9 & resurrect & 2 & envious \\
\hline 9 & retroviruses & 2 & envisage \\
\hline 9 & reunion & 2 & epicardium \\
\hline 9 & rewrote & 2 & epipelagic \\
\hline 9 & rightward & 2 & Equimolar \\
\hline 9 & riparian & 2 & ergo \\
\hline 9 & rotifer & 2 & esophageal \\
\hline 9 & roundabout & 2 & ethnobotany \\
\hline 9 & samosas & 2 & evict \\
\hline 9 & sanger & 2 & ewe \\
\hline 9 & sarcoma & 2 & exalt \\
\hline 9 & scoliosis & 2 & expletive \\
\hline 9 & secede & 2 & extracurricular \\
\hline 9 & secondly & 2 & exuberance \\
\hline 9 & seltzer & 2 & exude \\
\hline 9 & septic & 2 & eyewash \\
\hline 9 & shanghai & 2 & eyewear \\
\hline 9 & shatter & 2 & fab \\
\hline 9 & shoe-lace & 2 & facsimile \\
\hline 9 & shortcoming & 2 & fairground \\
\hline 9 & shroud & 2 & fallout \\
\hline 9 & silvery & 2 & fanatic \\
\hline 9 & slang & 2 & fanfare \\
\hline 0 & slideshow & 2 & fart \\
\hline
\end{tabular}




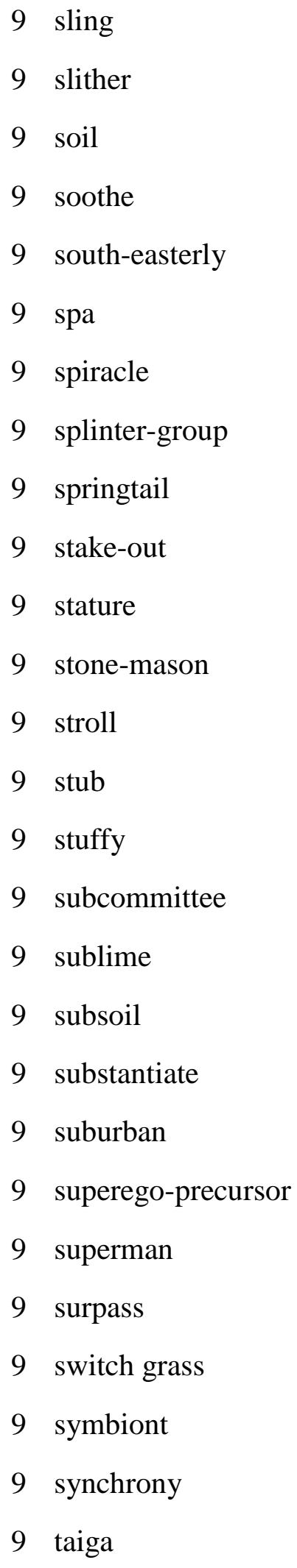

9 sling

9 slither

9 soil

9 soothe

9 south-easterly

9 spa

9 spiracle

9 splinter-group

9 springtail

9 stake-out

9 stature

9 stone-mason

9 stroll

9 stub

9 stuffy

9 subcommittee

9 sublime

9 subsoil

9 substantiate

9 suburban

9 superego-precursor

9 superman

9 surpass

9 switch grass

9 symbiont

9 synchrony

9 taiga

2 fastidious

2 fellow-countryman

2 fellowship

2 fen

2 ferret

2 fetter

2 feu

2 feudal

2 fiasco

2 fibula

2 fiddle

2 field

2 fil

2 filmmaking

2 firestone

2 firth

2 flab

2 flagella

2 flannel

2 flappy

2 fledgling

2 flinch

2 flocculants

2 flor

2 flotsam

2 flulike

2 flurry 


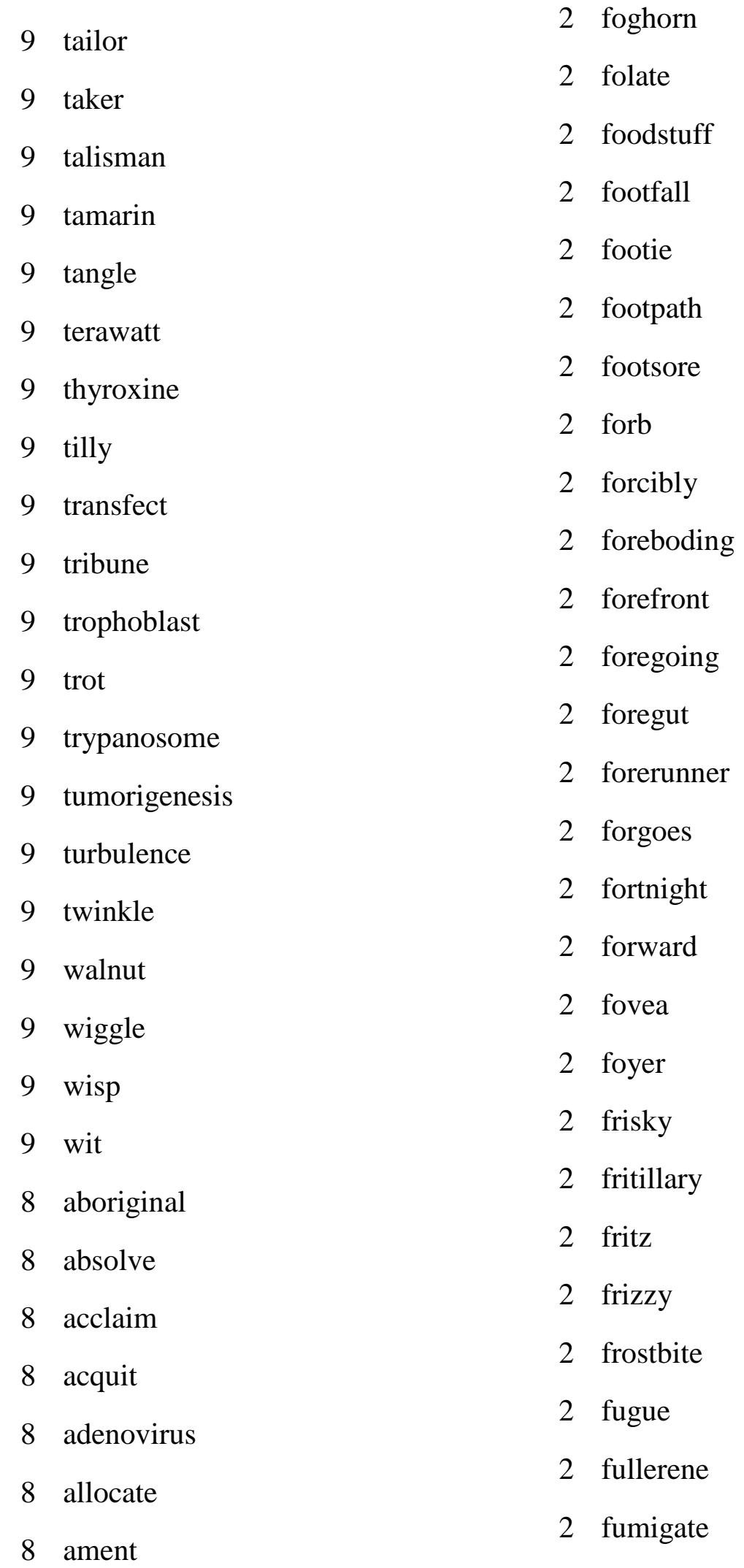




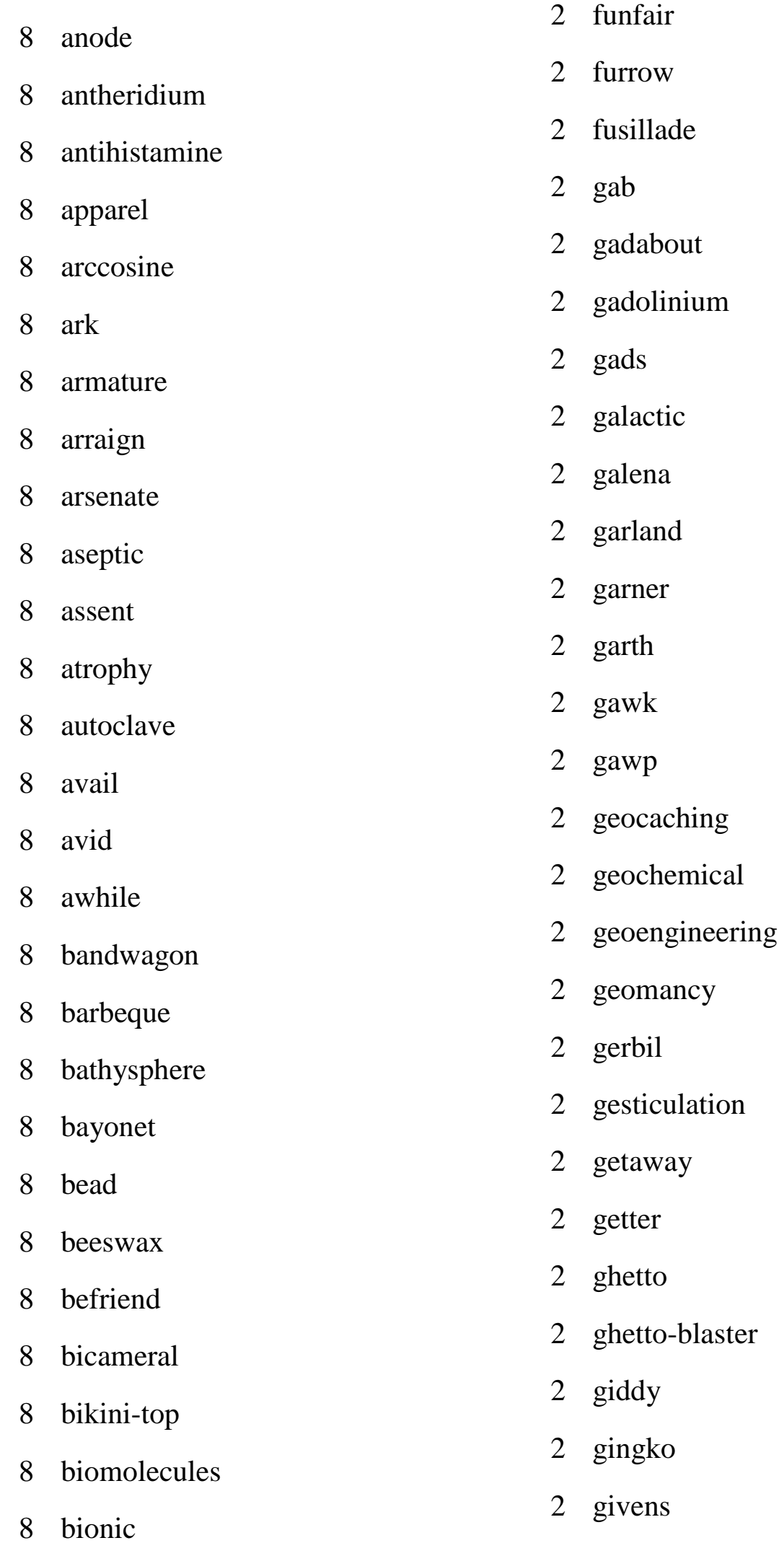




\begin{tabular}{llll}
8 & bituminous & 2 & gladiolus \\
8 & blackbird & 2 & glean \\
8 & blanc & 2 & glim \\
8 & blower & 2 & glint \\
8 & bluenose & 2 & globin \\
8 & bluish & 2 & glossopteris \\
8 & blush & 2 & glug \\
8 & bonfire & 2 & gluten \\
8 & boo & 2 & glycan \\
8 & boor & 2 & glyceraldehyde \\
8 & borealis & 2 & glycogenesis \\
8 & bottleneck & 2 & glyph \\
8 & braille & 2 & goblet \\
8 & burke & 2 & goof \\
8 & bustle & 2 & gore \\
8 & cairngorm & 2 & gouache \\
8 & cambium & 2 & graffiti \\
8 & cantor & 2 & granary \\
8 & caravan & 2 & granulocytic \\
8 & carillon & 2 & grassroots \\
8 & carpool & 2 & gravis \\
8 & cartography & 2 & gravy \\
8 & cartridge & 2 & greenbelt \\
8 & cartwright & 2 & griddle \\
8 & cashier & 2 & grille \\
8 & cello & 2 & grist \\
8 & cellphone & 2 & grot \\
& & \\
\hline & & & \\
& &
\end{tabular}




\begin{tabular}{|c|c|}
\hline & chatter \\
\hline & checkup \\
\hline & chemiosmosis \\
\hline 8 & chondrocytes \\
\hline 8 & cilium \\
\hline 8 & cleanse \\
\hline 8 & clergyman \\
\hline 8 & clip \\
\hline 8 & clostridium \\
\hline 8 & cloture \\
\hline 8 & cock \\
\hline 8 & codswallop \\
\hline 8 & coelacanth \\
\hline 8 & colossal \\
\hline 8 & confocal \\
\hline 8 & congratulate \\
\hline 8 & contemplate \\
\hline 8 & convict \\
\hline 8 & cornerstone \\
\hline 8 & covenant \\
\hline 8 & coworker \\
\hline 8 & crimson \\
\hline 8 & crossword \\
\hline 8 & cunning \\
\hline 8 & cutaway \\
\hline 8 & dazzle \\
\hline & dell \\
\hline
\end{tabular}

2 grotto

2 groundhog

2 groundskeeper

2 gruffly

2 guacamole

2 guesswork

2 guidebook

2 guile

2 hade

2 hafiz

2 hailstorm

2 hairspray

2 handiwork

2 handyman

2 hardworking

2 harpacticoid

2 harpy

2 hawkmoth

2 haymow

2 hazmat

2 headlamp

2 headstone

2 headway

2 heartbroken

2 hedgerow

2 hemp

2 henceforth 


\begin{tabular}{|c|c|}
\hline 8 & demise \\
\hline 8 & detain \\
\hline 8 & devoid \\
\hline 8 & discontent \\
\hline 8 & distrust \\
\hline 8 & dorm \\
\hline 8 & drear \\
\hline 8 & duke \\
\hline 8 & dumb \\
\hline 8 & dwarfism \\
\hline 8 & ellipsoid \\
\hline 8 & eminence \\
\hline 8 & emirates \\
\hline 8 & empanada \\
\hline 8 & endorse \\
\hline 8 & engagement \\
\hline 8 & eosinophil \\
\hline 8 & errand \\
\hline 8 & excuse \\
\hline 8 & exile \\
\hline 8 & exotoxin \\
\hline 8 & expo \\
\hline 8 & fabulous \\
\hline 8 & figurine \\
\hline 8 & firearm \\
\hline 8 & francium \\
\hline 8 & freefall \\
\hline
\end{tabular}

2 heptane

2 hereafter

2 heresy

2 hereunto

2 heterochromatin

2 heyday

2 hibiscus

2 hick

2 hickory

2 hidalgo

2 highroad

2 hipped

2 hoard

2 homegrown

2 hon

2 honeymoon

2 honeysuckle

2 hoodoo

2 hopper

2 hornlike

2 hornworm

2 horsehair

2 horticulture

2 hothouse

2 hotline

2 hotpot

2 housekeeper 


\begin{tabular}{|c|c|c|}
\hline 8 & geode & 2 housewife \\
\hline 8 & geosphere & 2 hoy \\
\hline 8 & gerrvmander & 2 humanoid \\
\hline 8 & 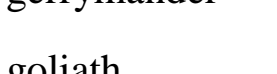 & 2 hummus \\
\hline 0 & 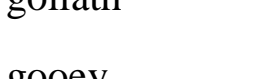 & 2 husbandry \\
\hline 0 & goocy & 2 hymenoptera \\
\hline 0 & gothic & 2 hypercholesterolemia \\
\hline 8 & greenstone & - M \\
\hline 8 & gumball & 2 hypersalıne \\
\hline 8 & hardcover & 2 hyperspace \\
\hline 8 & haunt & 2 hypocotyl \\
\hline 8 & heartworm & 2 hypocrisy \\
\hline 8 & hefty & 2 hyponatremia \\
\hline 8 & hem & 2 hypostatic \\
\hline 8 & hereby & 2 icebox \\
\hline 8 & herpesvirus & 2 ichthyosaurs \\
\hline 8 & 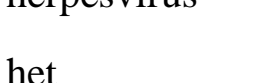 & 2 ick \\
\hline 8 & histidine & 2 icky \\
\hline & & 2 iguanodon \\
\hline 8 & hoc & 2 illicit \\
\hline 8 & holdfast & \\
\hline 8 & homer & 2 imbed \\
\hline 8 & homograph & 2 immunoglobulin \\
\hline 8 & homology & 2 impudence \\
\hline 8 & honk & 2 inattentiveness \\
\hline 8 & huddle & 2 inaudible \\
\hline & & 2 incense \\
\hline 8 & hummer & \\
\hline 8 & hurtle & 2 inception \\
\hline 8 & hypersensitivity & 2 incompetent \\
\hline
\end{tabular}




\begin{tabular}{ll}
8 & iframe \\
8 & incompletely \\
8 & inconvenient \\
8 & indigo \\
8 & infamous \\
8 & influx \\
8 & infrasound \\
8 & inoperative \\
8 & intel \\
8 & intermittency \\
8 & intertwine \\
8 & intramural \\
8 & iridium \\
8 & juniper \\
8 & kersey \\
8 & labia \\
8 & labium \\
8 & ladybug \\
8 & lame \\
8 & lance-corporal \\
8 & lazily \\
8 & lieutenant \\
8 & lima \\
8 & linger \\
8 & linotype \\
8 & lipase \\
8 & loft \\
\hline
\end{tabular}

2 inconceivable

2 indiscriminately

2 indistinct

2 indulge

2 inefficiently

2 inequitable

2 inescapably

2 infallible

2 infanticide

2 infarction

2 inflexibility

2 ingle

2 ingot

2 inkling

2 inlay

2 inning

2 insane

2 insecticidal

2 insensible

2 insignia

2 integrase

2 intercity

2 interconvertible

2 interlace

2 interleukin

2 interlink

2 interlock 


\begin{tabular}{ll}
8 & loop \\
8 & lump \\
8 & macronutrient \\
8 & malachite \\
8 & malnourished \\
8 & marigold \\
8 & marijuana \\
8 & marketplace \\
8 & masculine \\
8 & bid \\
8 & meltwater \\
\hline 8 & merchandise \\
8 & merry \\
8 & mesquite \\
8 & muntilus \\
8 & midway \\
8 & mill \\
8 & millennium \\
8 & milo \\
8 & modus \\
\hline 8 & monogamous \\
\hline 8 monotype \\
\hline 8 mode \\
\hline 8 \\
\hline 8
\end{tabular}

2 intermarry

2 intermix

2 interrelationship

2 intersperse

2 interviewee

2 intonation

2 intoxicate

2 intramembranous

2 intrepid

2 inventive

2 irreducible

2 isopropyl

2 isothermal

$2 \mathrm{jab}$

2 jargon

2 jeez

2 jimmies

2 jostle

2 joystick

2 jukebox

2 junctional

2 jus

2 kabbalah

2 kaon

2 kart

2 ked

2 keepers 


\begin{tabular}{ll}
8 & neck \\
8 & negligible \\
8 & neurobiology \\
8 & nodule \\
8 & noodle \\
8 & notorious \\
8 & nudge \\
8 & octave \\
8 & overboard \\
8 & overdose \\
8 & overexploitation \\
8 & overgrowth \\
8 & overhang \\
8 & overheat \\
8 & overwhelming \\
8 & oxford \\
8 & palpitate \\
8 & pam \\
8 & parakeet \\
8 & parch \\
8 & parish \\
8 & past \\
8 & peasant \\
8 & pedant \\
8 & pelvis \\
8 & pend \\
8 & perennial \\
\hline
\end{tabular}

2 kern

2 kestrel

2 ketchup

2 ketoacidosis

2 khaki

2 kilowatt-hour

2 kimberlite

2 kindred

2 kip

2 kismet

2 kneecap

2 komatiite

2 labyrinth

2 lacewing

2 lad

2 ladle

2 lamppost

2 lanai

2 lash

2 lashing

2 lass

2 lasso

2 lather

2 latte

2 laud

2 lavish

2 lawman 


\begin{tabular}{llll}
8 & periscope & 2 & lawrencium \\
8 & piece & 2 & lecithin \\
8 & pipette & 2 & leopard \\
8 & pistol & 2 & lepidopteran \\
8 & planula & 2 & lieu \\
8 & pneumatic & 2 & lifeguard \\
8 & pollen & 2 & lifesaver \\
8 & pollster & 2 & ligate \\
8 & polyethylene & 2 & lignified \\
8 & postal & 2 & liken \\
8 & prosthetic & 2 & lilac \\
8 & pseudopodia & 2 & limnetic \\
8 & puffy & 2 & limp \\
8 & pushpin & 2 & limpet \\
8 & pyloric & 2 & linoleic \\
8 & qc & 2 & liquor \\
8 & radiocarbon & 2 & lire \\
8 & rainier & 2 & listings \\
8 & raja & 2 & livery \\
8 & rand & 2 & lix \\
8 & reactivate & 2 & llama \\
8 & re-badge & 2 & lockjaw \\
8 & reckless & 2 & loggerhead \\
8 & reconcile & 2 & loll \\
8 & recyclable & 2 & longboard \\
8 & red-herring & 2 & longboards \\
8 & redness & 2 & longhand \\
& & \\
\hline
\end{tabular}




\begin{tabular}{ll}
8 & reformer \\
8 & refreeze \\
8 & refresh \\
8 & remodeling \\
8 & reptilian \\
8 & repulse \\
8 & rifle \\
8 & roadster \\
8 & robust \\
8 & rooftop \\
8 & rum \\
\hline 8 & sag \\
\hline 8 & saucer \\
8 & slay \\
8 & sinkholes \\
8 & savage \\
8 & scurry \\
8 & seam \\
\hline 8 & secondicosis \\
\hline 8 shilling \\
\hline 8
\end{tabular}

2 loony

2 loti

2 lousy

2 lovable

2 lude

2 lunchbox

2 luncheon

2 lycophytes

2 machos

2 macro

2 macro-structure

2 magneto

2 mainline

2 makeshift

2 malign

2 malnourishment

2 malodorous

2 mamba

2 mange-tout

2 mangle

2 mangos

2 mania

2 manpower

2 marasmus

2 maries

2 marinate

2 marshy 


\begin{tabular}{ll}
8 & snout \\
8 & snowmelt \\
8 & soggy \\
8 & solo \\
8 & spermatophyte \\
8 & splinter \\
8 & spur \\
8 & stale \\
8 & stall \\
8 & stillness \\
8 & stirrup \\
8 & stonewort \\
8 & strew \\
8 & tariff \\
8 & sub-sect \\
8 & subspecies \\
8 & synopsis \\
8 & suitcase \\
8 & sulfides \\
8 & summand \\
\hline 8 & sunfish \\
\hline 8 superimpose \\
\\
8
\end{tabular}

2 martial

2 martini

2 mash

2 masonry

2 masterpiece

2 matriarchal

2 maw

$2 \mathrm{mcc}$

2 meatless

2 medial

2 medic

2 megakaryocyte

2 megalomania

2 megaspore

2 melaleuca

2 meltdown

2 mendelevium

2 mentation

2 meshwork

2 mesophilic

2 mesospheric

2 methylamine

2 micks

2 microelectronics

2 microfossil

2 microscale

2 midbrain 


\begin{tabular}{ll}
8 & teamwork \\
8 & tease \\
8 & telecommunication \\
8 & tetraploid \\
8 & thanksgiving \\
8 & theatre-goer \\
8 & therein \\
8 & treadmill \\
8 & trematode \\
8 & trio \\
8 & tryout \\
8 & tubby \\
8 & twos \\
8 & two-seater \\
8 & unto \\
8 & upgrade \\
8 & urn \\
8 & utensil \\
8 & verdict \\
8 & vide \\
8 & virtuous \\
8 & virulence \\
8 & voltmeter \\
8 & voracity \\
8 & warbler \\
8 & weightlifter \\
8 & whoop \\
\hline
\end{tabular}

2 midlands

2 midsize

2 midwinter

2 militant

2 mime

2 mindset

2 minibus

2 minivan

$2 \min x$

2 mire

2 miscalculate

2 miscalculation

2 mischief

2 misinformation

2 mislabeling

2 misleadingly

2 mitted

2 mockup

2 mockups

2 moiety

2 mommy

2 monazite

2 money-grabber

2 monitory

2 monocarpic

2 monoclines

2 monoclinic 


\begin{tabular}{|c|c|c|c|}
\hline 8 & willow & 2 & monograph \\
\hline 8 & worsen & 2 & monolingual \\
\hline 8 & zoology & 2 & monopolize \\
\hline 8 & zucchini & 2 & monorail \\
\hline 7 & abode & 2 & monotheism \\
\hline 7 & almanac & 2 & monozygotic \\
\hline 7 & ambush & 2 & moonquakes \\
\hline 7 & amen & 2 & morn \\
\hline 7 & andesite & 2 & morphine \\
\hline 7 & anesthesia & 2 & morphism \\
\hline 7 & anguish & 2 & mort \\
\hline 7 & anhydrous & 2 & mortuary \\
\hline 7 & anopheles & 2 & mossy \\
\hline 7 & anthology & 2 & motherhood \\
\hline 7 & antiretroviral & 2 & mourner \\
\hline 7 & antler & 2 & mousetrap \\
\hline 7 & anyhow & 2 & mucosa \\
\hline 7 & apatite & 2 & muffle \\
\hline 7 & appease & 2 & mug \\
\hline 7 & aptly & 2 & multicultural \\
\hline 7 & aqua & 2 & multiethnic \\
\hline 7 & ascetic & 2 & muscipula \\
\hline 7 & assault & 2 & muscovite \\
\hline 7 & assets & 2 & mutter \\
\hline 7 & astrophysics & 2 & myoblast \\
\hline 7 & avarice & 2 & myocyte \\
\hline 7 & bacilli & 2 & nadir \\
\hline
\end{tabular}




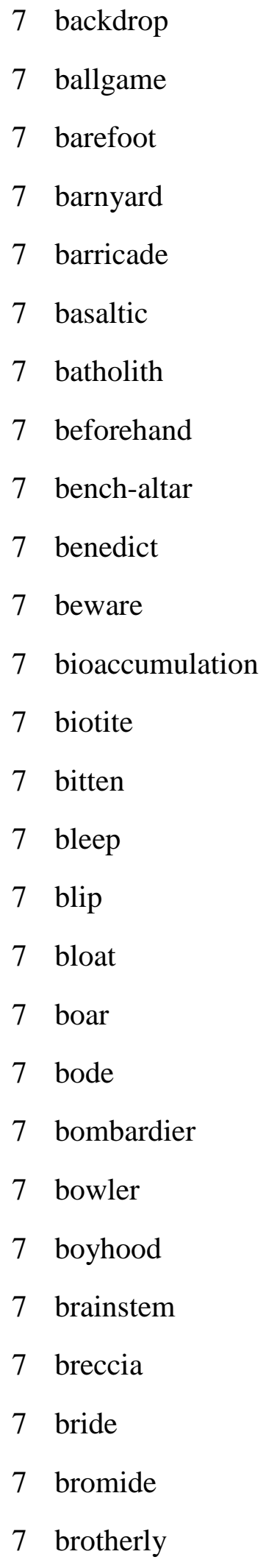

2 nag

2 nanotech

2 nape

2 napoleon

2 nary

2 nascent

2 nastic

2 nautili

2 nave

2 navigable

2 nays

2 neb

2 needlework

2 neoliberal

2 nervine

2 neuroanatomy

2 neurofibromatosis

2 neuroscientist

2 newbie

2 newfoundland

2 niacin

2 nick

2 nightshade

2 nitrogen-fixer

2 nobleman

2 nociceptor

2 noel 


\begin{tabular}{llll}
7 & budget & 2 & non-cichlid \\
7 & butt & 2 & nonfat \\
7 & buttress & 2 & nonfictions \\
7 & cache & 2 & nonfunctional \\
7 & calorimeter & 2 & nonhomogeneous \\
7 & candidiasis & 2 & nonmaterial \\
7 & caregiver & 2 & nonpareil \\
7 & carrack & 2 & nonpartisan \\
7 & carrion & 2 & nonreligious \\
7 & casket & 2 & nonresident \\
7 & casserole & 2 & nonsmoking \\
7 & catheter & 2 & norovirus \\
7 & cavalry & 2 & north-easterner \\
7 & cede & 2 & notepad \\
7 & centrum & 2 & novelty \\
7 & chad & 2 & nucleobase \\
7 & charlotte & 2 & nucleoplasm \\
7 & checkerboard & 2 & nucleoprotein \\
7 & checkmate & 2 & numbness \\
7 & chinook & 2 & nun \\
7 & chiton & 2 & oblast \\
7 & chorine & 2 & oblate \\
7 & cicada & 2 & obliterate \\
7 & circumnavigate & 2 & obstinate \\
7 & cistern & 2 & oddball \\
7 & clamor & 2 & offish \\
7 & clarification & 2 & offshoot \\
\hline & & \\
\hline & &
\end{tabular}


7 clink

7 clothe

7 coccus

$\begin{array}{ll}7 & \operatorname{cog}\end{array}$

7 coil

7 commonplace

7 compliance

7 comply

7 conduce

7 conjure

7 contiguous

$7 \operatorname{coot}$

7 coronavirus

7 cosmopolitan

7 counter

7 countertop

7 croak

7 crustal

7 cuboid

7 culprit

7 cyanobacterium

7 dana

7 debunk

7 decaffeinate

7 Dee

7 defibrillation

7 denim
2 oft

2 okra

2 oleic

2 oligotrophic

2 omicron

2 oncolytic

2 oncoming

2 onetime

2 onomatopoeia

2 oospores

2 orient

2 origami

2 orthographic

2 out-class

2 outcroppings

2 outcry

2 outlandish

2 outmoded

2 outpatient

2 outputted

2 outright

2 outrun

2 outskirts

2 outweigh

2 overconsumption

2 overdraft

2 over-dramatize 


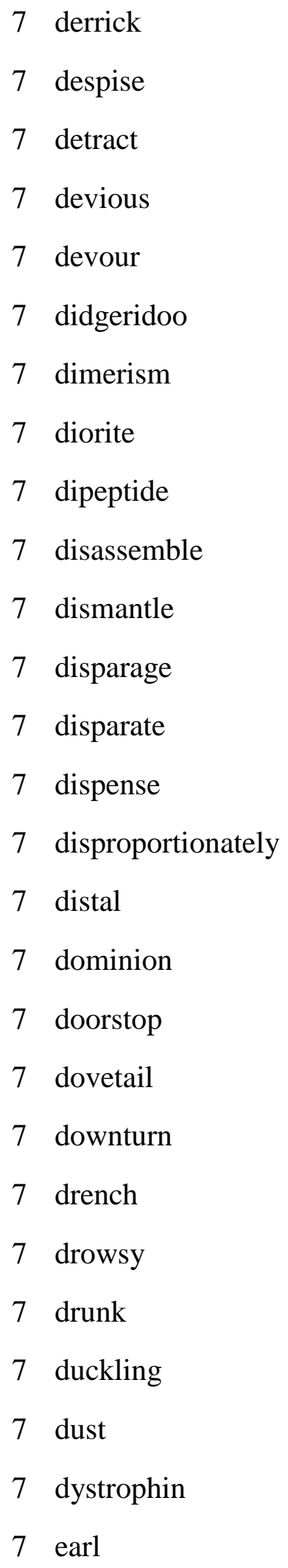

2 overdrawn

2 overgrazing

2 overhanging

2 overharvesting

2 overland

2 overpower

2 overran

2 oversimplify

2 overstate

2 overwhelmingly

2 painstakingly

2 paintball

2 paisley

2 paleness

2 paleo

2 paleogeography

2 pallid

2 pallidum

2 pampa

2 pang

2 pangolin

2 pantothenic

2 paper

2 papery

2 papillomaviruses

2 papyrus

2 paracrine 
7 elicit

7 emblem

7 enchanted

7 encyst

7 endomembrane

7 endonuclease

7 engage

7 ensue

7 epinephrine

7 epiphysis

7 eugenics

7 ex-boxer

7 exocrine

7 extinguish

7 extraterrestrial

7 eyelash

7 fairway

7 fathom

7 feline

7 fermions

7 ferocious

7 fibrinogen

7 filthy

7 firebreak

7 fixture

7 flask

7 floodwater
2 paranoid

2 parenthood

2 parity

2 parody

2 partisan

2 passbook

2 paste

2 pasteurization

2 pastor

2 pastureland

2 pate

2 patella

2 patellar

2 patronage

2 payroll

2 peacetime

2 pecan

2 pedagogy

2 pensive

2 pentene

2 peppermint

2 peptidoglycans

2 periodontal

2 perm

2 permanganate

2 permeate

2 perp 
7 flop

7 flute

7 footwear

7 forearm

7 foresight

7 foreword

7 frail

7 freak

7 frigate

7 frugal

7 gaggle

7 gasify

7 gearshift

7 glace

7 glaciate

7 glamorous

7 glee

7 gnaw

7 gonadotropin

7 gorgeous

7 grandchild

7 ground

7 groundwork

7 gumdrop

7 hallmark

7 handsome

7 harem
2 pesky

2 pester

2 petunia

2 pewter

2 phantom

2 pharmacology

2 phasmid

2 phobia

2 phonograph

2 phosphine

2 phosphodiester

2 phosphoglycerate

2 phospholipase

2 photogenic

2 photo-montage

2 photoreceptor

2 photosynthesizes

2 phototropic

2 physique

2 pickers

2 picturesque

2 piedmont

2 piety

2 pi-meson

2 pinball

2 pinky

2 pinner 


\begin{tabular}{|c|c|c|c|}
\hline 7 & hart & & \\
\hline 7 & header & 2 & pipedream \\
\hline 7 & heap & 2 & pirouette \\
\hline 7 & herd & 2 & pizzeria \\
\hline 7 & hindgut & 2 & plantain \\
\hline 7 & homeowner & 2 & plate \\
\hline 7 & homerun & 2 & playtime \\
\hline 7 & hominid & 2 & plena \\
\hline & & 2 & pliers \\
\hline 7 & hone & 2 & ploidy \\
\hline 7 & hydrant & & pioiay \\
\hline 7 & hydrofluoric & 2 & pluripotent \\
\hline 7 & indentation & 2 & poise \\
\hline 7 & inelastic & 2 & poleward \\
\hline 7 & injunction & 2 & polychlorinated \\
\hline 7 & interim & 2 & polycyclic \\
\hline 7 & internment & 2 & polyglot \\
\hline 1 & 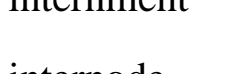 & 2 & ponderous \\
\hline 7 & internode & 2 & poop \\
\hline 7 & intoxicating & & \\
\hline 7 & intravenous & 2 & poop-scoop \\
\hline 7 & invaluable & 2 & popper \\
\hline 7 & jasmine & 2 & poppycock \\
\hline 7 & jellybean & 2 & porphyrin \\
\hline 7 & 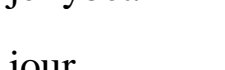 & 2 & porphyritic \\
\hline & (jour & 2 & porpoise \\
\hline 7 & karate & 2 & nortent \\
\hline 7 & kilocalorie & & \\
\hline 7 & kinetochore & 2 & postgraduate \\
\hline & & 2 & postponing \\
\hline
\end{tabular}




\begin{tabular}{|c|c|c|c|}
\hline 7 & knot & & postscript \\
\hline 7 & lactase & 2 & posttest \\
\hline 7 & lacy & 2 & powerboat \\
\hline 7 & landowner & 2 & power line \\
\hline 7 & lea & 2 & praiseworthy \\
\hline 7 & lecturer & 2 & prance \\
\hline 7 & lesion & 2 & prearranged \\
\hline 7 & lib & 2 & preconceived \\
\hline 7 & liquefy & 2 & predicament \\
\hline 7 & lizzie & 2 & prehypertension \\
\hline 7 & lure & 2 & premier \\
\hline & mocronuclous & 2 & premolar \\
\hline 7 & macronucleus & 2 & preposterous \\
\hline 7 & maggot & 2 & preposterous \\
\hline 7 & mainframe & 2 & presage \\
\hline 7 & majesty & 2 & presenter \\
\hline 7 & malignant & 2 & presentment \\
\hline 7 & malleahility & 2 & preserver \\
\hline 7 & Malleavinty & 2 & pretest \\
\hline 7 & margarıne & 2 & priesthood \\
\hline 7 & marshal & & \\
\hline 7 & mascot & 2 & primrose \\
\hline 7 & masquerade & 2 & proactive \\
\hline 7 & mastodon & 2 & proffer \\
\hline 7 & megawatt & 2 & pro-forma \\
\hline 7 & mellitus & 2 & progeny \\
\hline 7 & (netros & 2 & prosaic \\
\hline & & 2 & proteome \\
\hline I & microcontinents & 2 & prothrombin \\
\hline
\end{tabular}




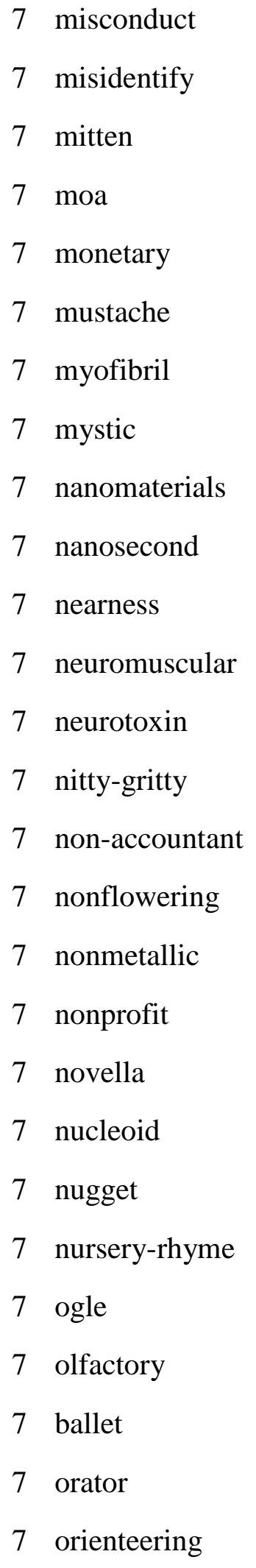

2 proviso

2 pseudogene

2 pseudonym

2 puck

2 puffin

2 pula

2 pullet

2 pulmonic

2 pulsate

2 punter

2 purr

2 putida

2 putrefy

2 pyridine

2 quadrat

2 quartet

2 quiver

2 racetrack

2 rachis

2 radicle

2 radiosonde

2 radix

2 raggedy

2 raintree

2 rani

2 ravel

2 reacquaint 


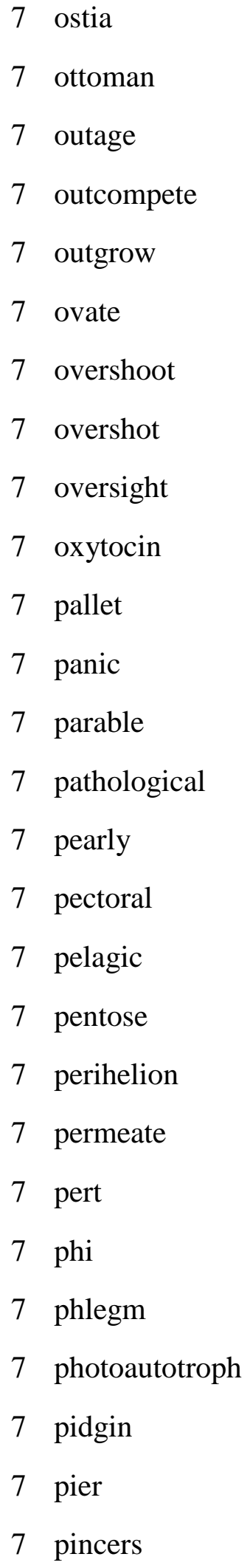

2 reattaches

2 re-booking

2 reborn

2 recalculation

2 recalibrate

2 recheck

2 recidivism

2 reclassification

2 recollection

2 redeem

2 redevelopment

2 redirection

2 redoubt

2 reedy

2 referendum

2 reflux

2 refold

2 reforestation

2 reformulation

2 refrigerates

2 refurbish

2 refurbishment

2 regimen

2 regolith

2 regrowth

2 reimburse

2 rein 
7 pineal

7 pinhole

7 pinkish

7 pinwheel

7 pion

7 pistachio

7 pith

7 plagioclase

7 plaintiff

7 plication

7 plight

7 podium

7 polyester

7 ponce

7 postpone

7 prerequisite

7 proofread

7 propanol

7 protagonist

7 protoplanetary

7 pseudomonas

7 pumpernickel

7 punch

7 pupae

7 racquet

7 reactance

7 readability
2 rejuvenate

2 relaunch

2 relive

2 rend

2 reorientation

2 repass

2 repentant

2 replay

2 replotted

2 reprehensible

2 repressive

2 reprisal

2 reproducibility

2 repugnant

2 requisite

2 resize

2 restock

2 restructure

2 restructuring

2 ret

2 retest

2 reticular

2 retort

2 retouch

2 retrial

2 reverie

2 revitalize 


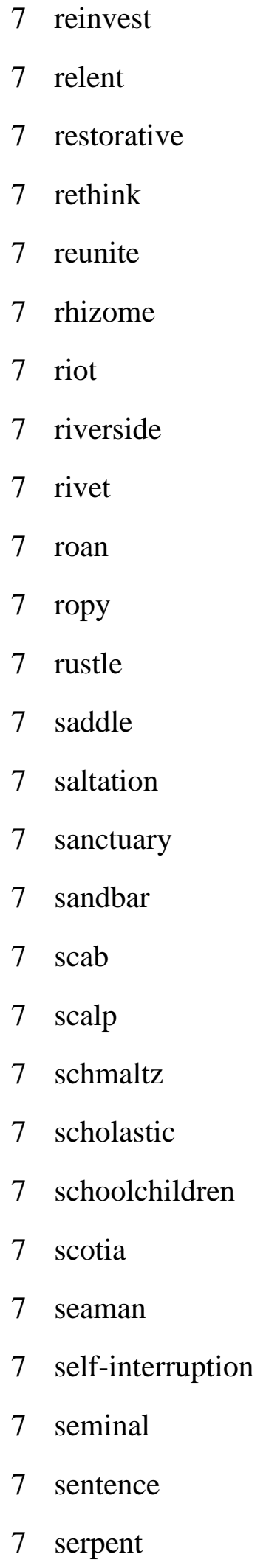

2 revoke

2 reweigh

2 reweighed

2 rewind

2 reword

2 rhododendron

2 ribonucleoprotein

2 rickety

2 ridgeline

2 roadbed

2 rocket

2 roebuck

$2 \operatorname{rog}$

2 rollerblades

2 ropelike

$2 \operatorname{rosin}$

2 rostrum

2 router

2 roving

2 rubbly

2 rubicund

2 rubidium

2 rucksack

2 rudimentary

2 rugged

2 rump

2 safari 


\begin{tabular}{llll}
7 & short-working & 2 & safranin \\
7 & sieve & 2 & salami \\
7 & sift & 2 & saleswoman \\
7 & silk & 2 & salicylate \\
7 & sliver & 2 & salmonellosis \\
7 & smack & 2 & saloon \\
7 & solicit & 2 & salve \\
7 & sparrow & 2 & sandblast \\
7 & spear & 2 & sandboarding \\
7 & spermicide & 2 & sapling \\
7 & sporangium & 2 & saprophytic \\
7 & spotlight & 2 & sash-window \\
7 & sprite & 2 & sassed \\
7 & stamina & 2 & satin \\
7 & stereo & 2 & sawing \\
7 & stew & 2 & sax \\
7 & stilt & 2 & scald \\
7 & stockpile & 2 & scant \\
7 & stomp & 2 & scanty \\
7 & stout & 2 & schoolteacher \\
7 & strep & 2 & scone \\
7 & subjugation & 2 & scorecard \\
7 & subsidence & 2 & scoundrel \\
7 & summa & 2 & scribal \\
7 & sunblock & 2 & scrumptious \\
7 & supercharger & 2 & scrunch \\
7 & superlative & 2 & scrutinize \\
& & \\
\hline
\end{tabular}




\begin{tabular}{|c|c|}
\hline 7 & surveillance \\
\hline 7 & swoon \\
\hline 7 & sycamore \\
\hline 7 & tact \\
\hline 7 & tangible \\
\hline 7 & teem \\
\hline 7 & tendinitis \\
\hline 7 & thermos \\
\hline 7 & thoracic \\
\hline 7 & thumbnail \\
\hline 7 & tonnage \\
\hline 7 & torsion \\
\hline 7 & transcontinental \\
\hline 7 & translocate \\
\hline 7 & transposon \\
\hline 7 & treacherous \\
\hline 7 & tricycle \\
\hline 7 & turf \\
\hline 7 & turgid \\
\hline 7 & typhimurium \\
\hline 7 & unanimous \\
\hline 7 & uncoil \\
\hline 7 & unmanned \\
\hline 7 & unravel \\
\hline 7 & vampire \\
\hline 7 & vie \\
\hline 7 & void \\
\hline
\end{tabular}

2 sea-kayak

2 searing

2 seascape

2 sedan

2 selenium

2 semifluid

2 sentence-grammarian

2 sepia

2 sequitur

2 serrated

2 shamanic

2 shantytown

2 shanty-town

2 shape-changer

2 shard

2 sharecropper

2 shew

2 shippers

2 shockwave

2 shoplift

2 shorebirds

2 shortfall

2 shrill

2 shuffleboard

2 shush

2 sideboard

2 sig 


\begin{tabular}{llll}
7 & walrus & 2 & signpost \\
7 & ware & 2 & silliness \\
7 & wean & 2 & silty \\
7 & weasel & 2 & silversmith \\
7 & wheeze & 2 & simmer \\
7 & whew & 2 & singe \\
7 & whoosh & 2 & sinister \\
7 & whore & 2 & sinus \\
7 & withhold & 2 & sisterhood \\
7 & workforce & 2 & sixes \\
7 & wrestle & 2 & sixties \\
7 & zappy & 2 & sizable \\
7 & zoster & 2 & sketchbook \\
6 & abdicate & 2 & sky \\
6 & abound & 2 & skylight \\
6 & afterlife & 2 & skyrocket \\
6 & afterschool & 2 & slacken \\
6 & agave & 2 & slat \\
6 & airbag & 2 & slather \\
6 & aldosterone & 2 & slaveholder \\
6 & aloft & 2 & sledge-hammer \\
6 & alt & 2 & slippage \\
6 & amiodarone & 2 & slot \\
6 & amylose & 2 & slurry \\
6 & ancillary & 2 & smarten \\
6 & angus & 2 & smooshed \\
6 & anteater & 2 & smudge \\
\hline & & \\
\hline & &
\end{tabular}




$\begin{array}{ll}6 & \text { antiseptic } \\ 6 & \text { apoptosis } \\ 6 & \text { apprentice } \\ 6 & \text { ardent } \\ 6 & \text { aristocrat } \\ 6 & \text { armadillo } \\ 6 & \text { armpit } \\ 6 & \text { arrest } \\ 6 & \text { artic } \\ 6 & \text { articular } \\ 6 & \text { artifice } \\ 6 & \text { artillery } \\ 6 & \text { ascribe } \\ 6 & \text { assess } \\ 6 & \text { atrioventricular } \\ 6 & \text { bastralopithecines } \\ 6 & \text { baseman } \\ 6 & \text { avatar } \\ 6 & \text { aver } \\ 6 & \text { babn } \\ 6 & \text { backboard } \\ 6 & \text { ballad-writer } \\ 6 & \\ 6 & \text { bandage } \\ 6 & \\ 6 & \\ 6 & \\ 6 & \end{array}$

2 smut

2 snapper

2 snickerdoodle

2 snore

2 snort

2 snowdrift

2 snuck

2 snuggle

2 somersault

2 songbird

2 sonic

2 sooners

2 soya

2 spacelab

2 spacesuit

2 spaniel

2 specie

2 specious

2 spectrophotometer

2 sphagnum

2 spindly

2 spinet

2 spire

2 spongiform

2 sportswriter

2 spotter

2 spyglass 


\begin{tabular}{ll}
6 & bassoon \\
6 & benevolent \\
6 & bin \\
6 & bioethics \\
6 & biohazard \\
6 & biophysics \\
6 & biweekly \\
6 & blowfly \\
6 & blue-stocking \\
6 & bollard \\
6 & bonnie \\
6 & booker \\
6 & bough \\
6 & chiasmata \\
6 & bread \\
6 & buckle \\
6 & bunny \\
6 & chardensome \\
6 & buss \\
6 & butanol \\
6 & cadastral \\
6 & cajole \\
6 & caller \\
\hline 6 chish \\
\hline 6
\end{tabular}

2 staccato

2 staminate

2 staphylococci

2 stasis

2 statesman

2 stele

2 stellar

2 stench

2 stewardship

2 stinkbugs

2 stipe

2 stonework

2 stoppage

2 storehouse

2 stork

2 stovetop

2 straightway

2 stranglehold

2 streetlamp

2 stricture

2 strife

2 strikeouts

2 strum

2 stubby

2 stylet

2 subcontinent

2 subdued 


\begin{tabular}{ll}
6 & chromite \\
6 & churros \\
6 & cinema \\
6 & cinnabar \\
6 & clammy \\
6 & clonal \\
6 & cockpit \\
6 & coexist \\
6 & commemorate \\
6 & companionate \\
6 & con \\
6 & conflagration \\
6 & conscript \\
6 & consortium \\
6 & coppice \\
6 & cormorant \\
6 & cortisol \\
6 & cotransport \\
6 & countercurrent \\
6 & counterfeit \\
6 & courtroom \\
6 & cowboy \\
6 & crevasses \\
6 & \\
6 & crunch \\
\hline 6 & \\
6 &
\end{tabular}

2 subfield

2 subjugate

2 subkingdom

2 sublittoral

2 submicroscopic

2 submissive

2 subordination

2 subsist

2 subtest

2 subtitle

2 succumb

2 sudoriferous

2 summands

2 sundown

2 sundry

2 suntan

2 sunwards

2 supercomputer

2 superconducting

2 superfamily

2 superficial

2 superfine

2 superhighway

2 superimposable

2 superset

2 supersize

2 supertanker 


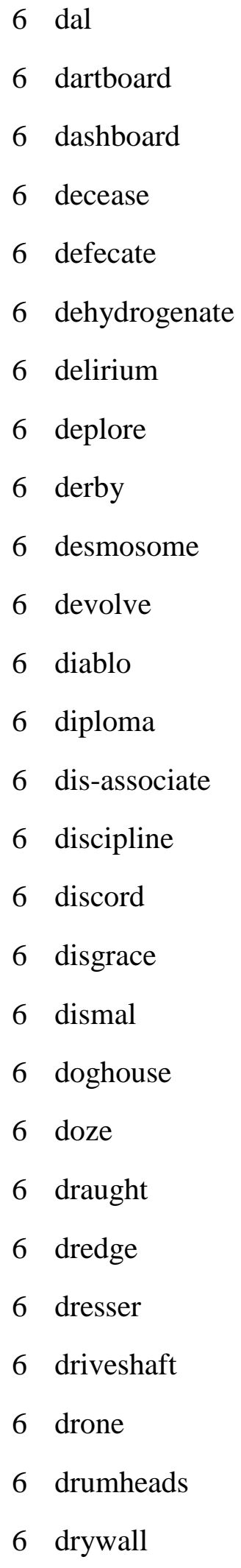




$\begin{array}{ll}6 & \text { dummy } \\ 6 & \text { dun } \\ 6 & \text { dynamo } \\ 6 & \text { earphone } \\ 6 & \text { electroluminescence } \\ 6 & \text { electrometallurgy } \\ 6 & \text { emolument } \\ 6 & \text { end-effector } \\ 6 & \text { endochondral } \\ 6 & \text { endotoxin } \\ 6 & \text { engrave } \\ 6 & \text { entice } \\ 6 & \text { entrepreneurial } \\ 6 & \text { episodic } \\ 6 & \text { epithet } \\ 6 & \text { ermine } \\ 6 & \text { espionage } \\ 6 & \text { ethologist } \\ 6 & \text { eusocial } \\ 6 & \text { fable } \\ 6 & \text { fair } \\ 66 & \text { fanny } \\ 6 & \text { fawn } \\ 6 & \text { fibrillation } \\ 6 & \text { fingerlike } \\ 6 & \text { fireball } \\ 6 & \text { flamingo } \\ 6\end{array}$

2 telomerase

2 tepee

2 tepid

2 terrapin

2 tetramer

2 tetroxide

2 theocracy

2 theology

2 thereupon

2 thermocline

2 thrasher

2 threadbare

2 thrombocytes

2 thromboxane

2 thrush

2 thug

2 thundercloud

2 thyrotropin

2 tidbit

2 tinge

2 tiptoe

2 tit

2 titrant

2 toadstool

2 tock

2 toehold

2 toil 


\begin{tabular}{llll}
6 & florist & 2 & tomography \\
6 & flytrap & 2 & tonic \\
6 & folic & 2 & Tono plast \\
6 & foresee & 2 & tooting \\
6 & fortitude & 2 & tootsie \\
6 & fringelike & 2 & topmost \\
6 & gangrene & 2 & topoisomerase \\
6 & gazelle & 2 & touchstone \\
6 & gluconeogenesis & 2 & tourmaline \\
6 & glue & 2 & toxoplasmosis \\
6 & gobstopper & 2 & trachomatis \\
6 & goldsmith & 2 & tramp \\
6 & gong & 2 & transposition \\
6 & grit & 2 & trawl \\
6 & groomsmen & 2 & trepidation \\
6 & guanosine & 2 & triad \\
6 & guppy & 2 & trice \\
6 & hairline & 2 & trichomonas \\
6 & hairstreak & 2 & trident \\
6 & handmade & 2 & triose \\
6 & harmony & 2 & tripod-cauldron \\
6 & hassle & 2 & trochanter \\
6 & hawkweed & 2 & troglodyte \\
6 & haze & 2 & trop \\
6 & heath & 2 & tropomyosin \\
6 & hematoma & 2 & troponin \\
6 & hemi & 2 & troublemaker \\
& & \\
\hline
\end{tabular}




\begin{tabular}{llll}
6 & hemophiliacs & 2 & trousers \\
6 & hijack & 2 & trove \\
6 & hobbyist & 2 & trudge \\
6 & hodge-podge & 2 & tumult \\
6 & holt & 2 & turbocharged \\
6 & homeodomain & 2 & turbocharger \\
6 & homicide & 2 & turmoil \\
6 & honeyeater & 2 & turnover \\
6 & hotplate & 2 & turnstone \\
6 & housecat & 2 & tweak \\
6 & hull & 2 & type-setter \\
6 & hyper & 2 & unbend \\
6 & hyperventilation & 2 & undocking \\
6 & hypodermis & 2 & undue \\
6 & icebreaker & 2 & uninhabitable \\
6 & icecap & 2 & uniporter \\
6 & ide & 2 & unison \\
6 & immunology & 2 & unlit \\
6 & impervious & 2 & untrammeled \\
6 & income-beneficiary & 2 & up \\
6 & incriminating & 2 & uppercase \\
6 & incumbent & 2 & upslope \\
6 & inflexible & 2 & uptight \\
6 & infuse & 2 & urologic \\
6 & ingenious & 2 & utero \\
6 & inhospitable & 2 & valance \\
6 & insipidus & 2 & valor \\
\hline & & \\
\hline
\end{tabular}




\begin{tabular}{ll}
6 & invagination \\
6 & irresponsible \\
6 & irrupt \\
6 & ivory \\
6 & jalapeno \\
6 & jig-saw \\
6 & jumble \\
6 & keratinocytes \\
6 & kerosene \\
6 & kiloliters \\
6 & kilowatt \\
6 & knuckle \\
6 & kth \\
6 & kw \\
6 & lapse-rate \\
6 & lax \\
6 & leatherback \\
6 & lecture \\
6 & legionella \\
6 & levitate \\
6 & licorice \\
6 & lifelike \\
6 & limerick \\
6 & linen \\
6 & lm \\
6 & load \\
6 & loam \\
\hline
\end{tabular}

2 vancomycin

2 vanguard

2 vanity

2 varnish

2 varve

2 vasodilation

2 vassal

2 vaulter

2 vax

2 velociraptor

2 vendor

2 venetian

2 vermillion

2 vesta

2 vicious

2 videotape

2 virally

2 vitreous

2 vizier

2 vulgaris

2 wabbit

2 waddle

2 wag

2 wain

2 wally

2 wannabe

2 wardrobe 


$\begin{array}{ll}6 & \text { lob } \\ 6 & \text { lodging-house } \\ 6 & \text { loess } \\ 6 & \text { logger } \\ 6 & \text { lounge } \\ 6 & \text { luminous } \\ 6 & \text { luteal } \\ 6 & \text { mag } \\ 6 & \text { mainstream } \\ 6 & \text { malfunction } \\ 6 & \text { mama } \\ 6 & \text { manhood } \\ 6 & \text { mantra } \\ 6 & \text { mitigate } \\ 6 & \text { mapmaker } \\ 6 & \text { midterms } \\ 6 & \text { marcel } \\ 6 & \text { mayfly } \\ 6 & \text { mediation } \\ 6 & \text { meg } \\ 6 & \text { meninges } \\ 6 & \text { mercenary } \\ 6 & \text { mesh-length } \\ 6 & \text { meta-procedure } \\ 6 & \\ 6 & \\ 6 & \\ 6 & \\ 6 & \\ 6 & \\ 6 & \\ 6 & \end{array}$

2 wary

2 waterfowl

2 wattage

2 waxwing

2 wayside

2 welch

2 weld

2 welt

2 wert

2 whatsoever

2 whet

2 whir

2 whup

2 willy

2 wimp

2 wink

2 wintergreen

2 wintertime

2 wistful

2 withal

2 witty

2 wiz

2 wolfram

2 woodshop

2 woodsman

2 woodwork

2 workflow 


\begin{tabular}{ll}
6 & mitogen \\
6 & monologue \\
6 & moo \\
6 & moray \\
6 & motherboard \\
6 & mozzarella \\
6 & muffled \\
6 & multidisciplinary \\
6 & mustang \\
6 & mutagenesis \\
6 & muzzle \\
6 & myopathy \\
6 & nestle \\
6 & newsletter \\
6 & nicotinamide \\
6 & noisemaker \\
6 & nonelectrolytes \\
6 & nonstandard \\
6 & nope \\
6 & numb \\
6 & oats \\
6 & obscene \\
\hline 6 obsolete \\
6
\end{tabular}

2 workroom

2 worktime

2 wort

2 wrack

2 wrath

2 wren

2 wrought

2 wry

2 yap

2 yardstick

2 yearbook

2 yen

2 yoke

2 yo-yo

2 zebrafish

2 zest

2 zygotic

2 three-pointer

1 abalone

1 abash

1 Abbas

1 abbey

1 abbots

1 abduction

1 abettor

1 abeyance

1 abnegation 


\begin{tabular}{llll}
6 & outgoing & 1 & absentminded \\
6 & overheating & 1 & acclimated \\
6 & overrule & 1 & acclimatize \\
6 & oviparous & 1 & accomplice \\
6 & ox & 1 & acker \\
6 & paleontology & 1 & acoelomates \\
6 & palladium & 1 & acrobatic \\
6 & palsy & 1 & acromegaly \\
6 & panel & 1 & acropolis \\
6 & panhandle & 1 & actus \\
6 & papa & 1 & acumen \\
6 & parasympathetic & 1 & adduct \\
6 & parietal & 1 & adenoviruses \\
6 & parsley & 1 & adjudicate \\
6 & parvovirus & 1 & adjunct \\
6 & pastel & 1 & advert \\
6 & patchy & 1 & afferent \\
6 & patriarch & 1 & affray \\
6 & peat-digger & 1 & afield \\
6 & pension & 1 & afire \\
6 & pent & 1 & aflame \\
6 & peso & 1 & afoot \\
6 & petri & 1 & aftershave \\
6 & pharaoh & 1 & afterworld \\
6 & phosphor & 1 & agape \\
6 & phytochemicals & 1 & agate \\
6 & pigeonhole & 1 & ager \\
\hline & & \\
\hline
\end{tabular}



6 pinewood
6 plasm
6 polydactyly
6 polygamous
6 polymerize
6 posh
6 posse
6 postage
6 postcard
6 pot
6 precollege
6 predecessor
6 predicate
6 presidio
6 principia
6 procession
6 prometaphase
6 prophecy
6 prostitute
6 provost
6 pucker
6 pus-cell
6 quail
6 quanta
6 quench
6 quill
6 readership

1 agglutination

1 aggrieved

1 agoraphobia

1 agroforestry

1 aileron

1 airboats

1 airlift

1 airman

1 alameda

1 alcove

1 alderman

1 aldolase

1 algebra lab

1 allotrope

1 almagest

1 amateurish

1 ambidextrous

1 ameliorate

1 aminobutyric

1 amour

1 amperages

1 ampersand

1 amphipathic

1 ampicillin

1 amrita

1 anagoge

1 anchovy 


$\begin{array}{llll}6 & \text { recompose } & 1 & \text { andante } \\ 6 & \text { reenter } & 1 & \text { andiron } \\ 6 & \text { refreshing } & 1 & \text { aneurysm } \\ 6 & \text { refrigerate } & 1 & \text { angiotensin } \\ 6 & \text { regency } & 1 & \text { anglo } \\ 6 & \text { regionally } & 1 & \text { anhydrase } \\ 6 & \text { regress } & 1 & \text { anise } \\ 6 & \text { renovate } & 1 & \text { antennal } \\ 6 & \text { renowned } & 1 & \text { anterograde } \\ 6 & \text { retrovirus } & 1 & \text { anthropocentric } \\ 6 & \text { rhinitis } & 1 & \text { anticlinal } \\ 6 & \text { ribulose } & 1 & \text { anticlockwise } \\ 6 & \text { ridgetop } & 1 & \text { antielectron } \\ 6 & \text { rollercoaster } & 1 & \text { antigovernment } \\ 6 & \text { rookie } & 1 & \text { antileptons } \\ 6 & \text { rosette } & 1 & \text { antimacassar } \\ 6 & \text { ross } & 1 & \text { anti-malarial } \\ 6 & \text { royally } & 1 & \text { antiparallel } \\ 6 & \text { salesperson } & 1 & \text { antireligious } \\ 6 & \text { salsa } & 1 & \text { antisocialist } \\ 6 & \text { salvation } & 1 & \text { antiwar } \\ 6 & \text { sarcasm } & 1 & \text { antral } \\ 6 & \text { schooner } & 1 & \text { apartness } \\ 6 & \text { sclera } & 1 & \text { aphelion } \\ 6 & \text { screenplay } & 1 & \text { apicomplexans } \\ 6 & \text { scribble } & 1 & \text { apocalypse } \\ 6 & \text { semantic } & 1 & \text { apocopate } \\ & & \\ & & & \end{array}$




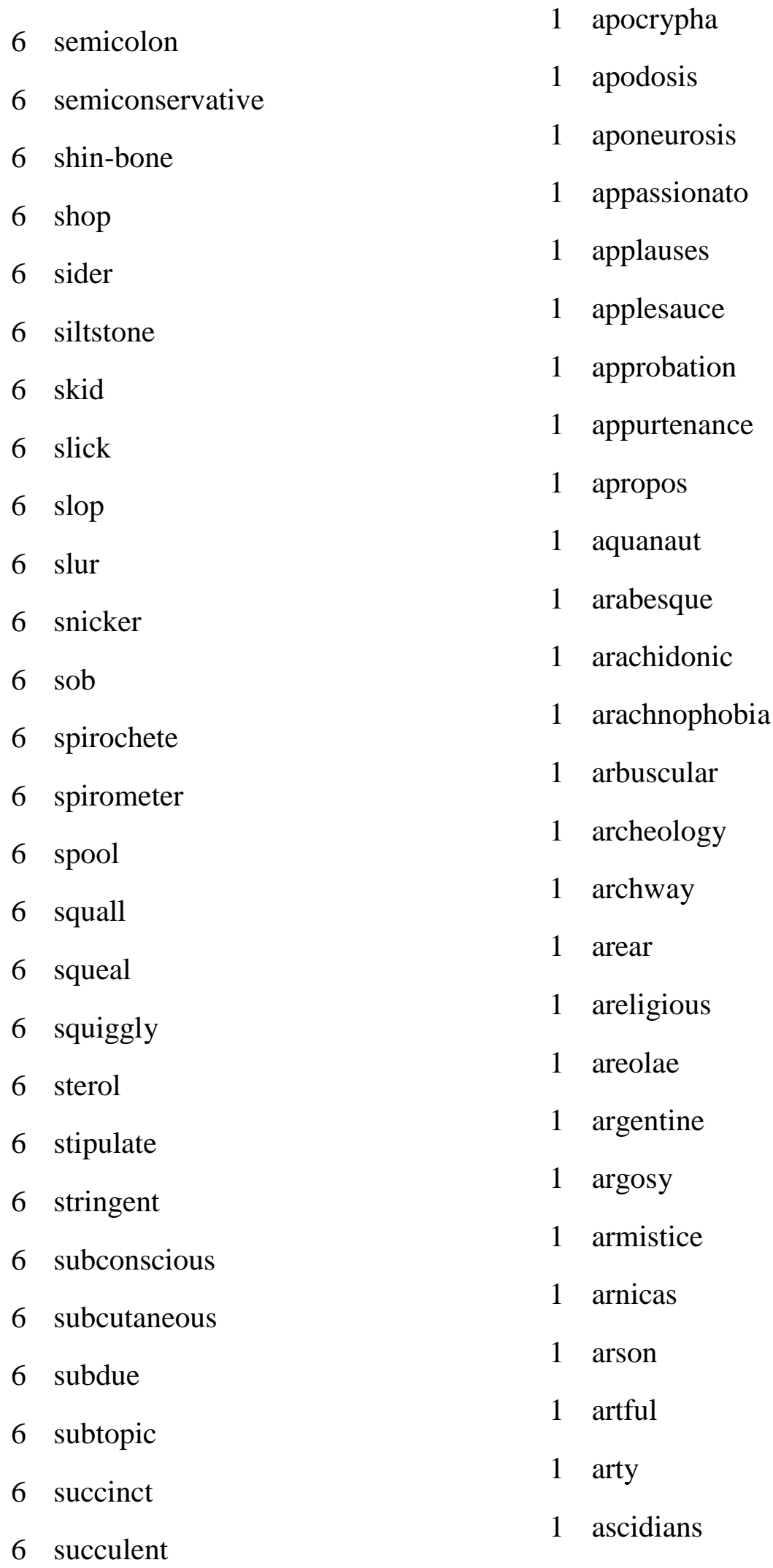




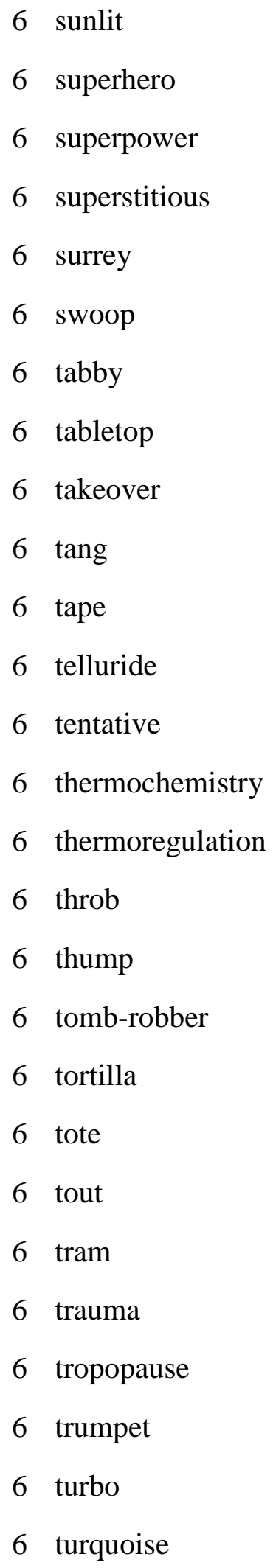

1 asunder

1 asylum

1 atelier

1 attacker

1 attar

1 atwitter

1 atypical

1 auricle

1 auspicious

1 austere

1 austral

1 automat

1 autopilot

1 autoradiography

1 autotomy

1 autoworkers

1 averse

1 babe

1 backbreaking 


\begin{tabular}{|c|c|}
\hline 6 & twilight \\
\hline 6 & two-footer \\
\hline ) & unction \\
\hline 6 & undecagon \\
\hline 6 & upheaval \\
\hline 6 & vesicular \\
\hline 6 & vet \\
\hline 6 & virology \\
\hline 6 & wallpaper \\
\hline 6 & waver \\
\hline 6 & wheelbarrow \\
\hline 6 & wildebeest \\
\hline 6 & witchcraft \\
\hline 6 & wither \\
\hline 6 & woodchuck \\
\hline 6 & yank \\
\hline 5 & accrete \\
\hline 5 & adamant \\
\hline 5 & alas \\
\hline 5 & alkaloid \\
\hline 5 & alkyne \\
\hline 5 & allude \\
\hline 5 & alma \\
\hline 5 & almighty \\
\hline 5 & amalgamate \\
\hline 5 & amylopectin \\
\hline & androgen \\
\hline
\end{tabular}

1 backlash

1 badminton

1 badness

1 bae

1 bag

1 bagpiper

1 bah

1 bailiff

1 baleen

1 ball

1 ballad

1 ballroom

1 balm

1 balsa

1 banco

1 bandanna

1 bandy

1 banister

1 bannister

1 banter

1 barbary

1 bargeman

1 barrette

1 bartender

1 baseload

1 baserunner

1 bash 


$\begin{array}{llll}5 & \text { animism } & 1 & \text { bashfulness } \\ 5 & \text { annotate } & 1 & \text { basidiomycetes } \\ 5 & \text { anoint } & 1 & \text { basilica } \\ 5 & \text { aperture } & 1 & \text { basilisk } \\ 5 & \text { applaud } & 1 & \text { baste } \\ 5 & \text { archers } & 1 & \text { bastion } \\ 5 & \text { archipelago } & 1 & \text { bathe } \\ 5 & \text { aristocratic } & 1 & \text { bathrobe } \\ 5 & \text { arrack } & 1 & \text { batik } \\ 5 & \text { arrowhead } & 1 & \text { batman } \\ 5 & \text { artesian } & 1 & \text { battleground } \\ 5 & \text { ascorbic } & 1 & \text { baud } \\ 5 & \text { astatine } & 1 & \text { beachfront } \\ 5 & \text { auger } & 1 & \text { beachgoers } \\ 5 & \text { avalanche } & 1 & \text { bearer } \\ 5 & \text { axillary } & 1 & \text { beaux } \\ 5 & \text { backstroke } & 1 & \text { becket } \\ 5 & \text { bacteriology } & 1 & \text { bedcover } \\ 5 & \text { balloon } & 1 & \text { bedspread } \\ 5 & \text { barbell } & 1 & \text { bedsprings } \\ 5 & \text { bard } & 1 & \text { beekeeping } \\ 5 & \text { beady } & 1 & \text { beeves } \\ 5 & \text { bedbug } & 1 & \text { beggar } \\ 5 & \text { beige } & 1 & \text { begirt } \\ 5 & \text { belch } & 1 & \text { begrimed } \\ 5 & \text { benefactor } & 1 & \text { begrudge } \\ 5 & \text { betty } & 1 & \text { belatedly } \\ & & \\ & & \end{array}$



5 bilingual
5 biotin
5 birthstone
5 bisphosphate
5 blacken
5 blockbuster
5 bluegrass
5 bookmark
5 bookshelf
5 boon
5 borehole
5 botulism
5 bra
5 bran
5 branes
5 bridle
5 briefcase
5 brink
5 budge
5 bullfrog
5 bullmastiff
5 burp
5 bushel
5 butler
5 cactuses
5 cag
5 canary

1 belladonna

1 bellhop

1 belli

1 bellicose

1 bellman

1 bellybutton

1 belter

1 bemoan

1 benzocaine

1 beriberi

1 berm

1 berth

1 beset

1 betroth

1 bettering

1 betterment

1 betting-slip

1 bettor

1 bewitch

1 bifida

1 biflagellate

1 biggish

1 bigotry

1 bigwig

1 bilge

1 billow

1 billowy 

5 card
5 carotenoid
5 carpal
5 carryon
5 carving
5 caseload
5 cassowary
5 casualty
5 cataract
5 cater
5 celeste
5 chancellor
5 chemotrophic
5 childbearing
5 chlorite
5 choreograph
5 cirque
5 clamp
5 clan
5 clitellum
5 cloak
5 clockmaker
5 clothesline
5 clothespin
5 cloudless
5 cloze
5 coaching-inn

1 bimetallic

1 bimolecular

1 bing

1 bio

1 biocontrol

1 bioinorganic

1 biomaterial

1 biomolecule

1 biopsy

1 biopsychology

1 biosensor

1 biotech

1 bipolar

1 birthplace

1 bisphenol

1 bistro

1 bitesize

1 bivalent

$1 \mathrm{biz}$

1 blackbody

1 blackout

1 blacksmithing

1 blah

1 blameworthy

1 blastocoel

1 blat

1 blatant 


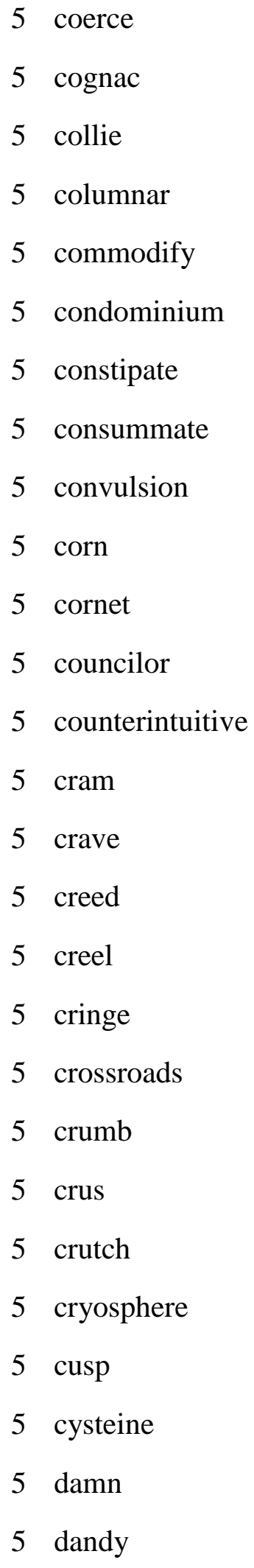

1 blear

1 bleat

1 bleh

1 bloc

1 block-buster

1 blockhead

1 blockhouse

1 blogosphere

1 bloodstain

1 bloodstained

1 blotchy

1 blowtorch

1 blueness

1 bluesman

1 bluestem

1 blunder

1 blustery

1 boatload

1 boatman

1 bodega

1 boggy

1 bogie

1 bogle

1 bohemia

1 bohemian

1 boking

1 bola 

5 daybreak
5 deamination
5 deerfly
5 defiance
5 demolish
5 deodorant
5 deregulate
5 dermatologist
5 detention
5 detour
5 diligence
5 dimly
5 dislocate
5 dispel
5 dissuade
5 doodle
5 doom
5 doom-monger
5 downdraft
5 drapery
5 drizzle
5 drum
5 dude
5 dumpling
5 dysentery
5 edict
5 eggplant

1 bondman

1 bookmaking

1 boomtowns

1 bootleg

1 boozy

1 borate

1 bottomless

1 bourbon

1 boutique

1 bovine

1 bowhead

1 bowie

1 bowlegged

1 bowstring

1 bozo

1 brachiopod

1 bracket

1 brainless

1 brainy

1 brash

1 brassica

1 brassier

1 brassiere

1 brassy

1 brawl

1 breakneck

1 bream 


\begin{tabular}{ll}
5 & eggshell \\
5 & elucidate \\
5 & embroider \\
5 & embryoblast \\
5 & emulate \\
5 & enamel \\
5 & endo \\
5 & engross \\
5 & enthusiast \\
5 & err \\
5 & erratic \\
5 & erythropoietin \\
5 & etch \\
5 & ethology \\
5 & etiquette \\
5 & exemplify \\
5 & exempt \\
5 & exogenesis \\
5 & exquisite \\
5 & extirpate \\
5 & extrasolar \\
5 & exult \\
5 & factsheet \\
5 & fallow \\
5 & falter \\
5 & fam \\
5 & fantail \\
\hline
\end{tabular}

1 breaststroke

1 breathtaking

1 brew-pub

1 briarwood

1 brigandage

1 brimstone

1 brinish

1 bris

1 britches

1 brittleness

1 broadband

1 broadcaster

1 broadleaf

1 broadleaved

1 broadside

1 broch

1 brokerage

1 bromate

1 brownout

1 brushfire

1 bub

1 buckminsterfullerene

1 buckram

1 bulldog

1 bulletproof

1 bullhead

1 bullion 

5 fecal
5 fervent
5 fiddlehead
5 filmy
5 firehouse
5 fireman
5 firmament
5 flue
5 follicular
5 foothold
5 footnote
5 foraminifera
5 foreclose
5 foremost
5 forfeit
5 formidable
5 fowl
5 fret
5 fro
5 fury
5 gam
5 garrison
5 geld
5 geoscience
5 glottis
5 glutton
5 gobble

1 bullock

1 bulwark

1 bumble

1 bungle

1 bunkum

1 bure

1 burg

1 burnet

1 burnup

1 burton

1 bushiness

1 butterflyfish

1 butterscotch

1 buttock

1 butyl

1 butyric

1 buzzword

1 bylaw

1 bystander

1 cabby

1 cabinetmaker

1 cadaver

1 caddisflies

1 calcareous

1 calendula

1 caliber

1 caliper 
5 goodwife

5 goshawk

5 gossamer

5 gouge

5 graft

5 granny

5 granola

5 griffin

5 grim

5 grime

5 grub

5 grunt

5 guts

5 gyroscope

5 hadean

5 halibut

5 halo

5 hamlet

5 handicap

5 hank

5 hawk

5 heel

5 hen-coop

5 hereof

5 hideout

5 high-flier

5 hindsight
1 calumny

1 calve

1 calypso

1 camaraderie

1 camcorder

1 cameraman

1 camshaft

1 candlelight

1 candlewick

1 candor

1 canfield

1 cannibalism

1 cannula

1 canonize

1 canopy

1 cantata

1 canteen

1 cap

1 capitation

1 capote

1 capricious

1 captor

1 capuchin

1 carat

1 carbonize

1 carburetors

1 cardiomyopathy 


$\begin{array}{llll}5 & \text { hippopotamus } & 1 & \text { cardiopulmonary } \\ 5 & \text { hire } & 1 & \text { carmaker } \\ 5 & \text { hoarse } & 1 & \text { carmine } \\ 5 & \text { hoary } & 1 & \text { carney } \\ 5 & \text { homecoming } & 1 & \text { carotid } \\ 5 & \text { hotshot } & 1 & \text { carper } \\ 5 & \text { hound } & 1 & \text { carrel } \\ 5 & \text { humankind } & 1 & \text { carry out } \\ 5 & \text { humongous } & 1 & \text { cartage } \\ 5 & \text { hydrocyanic } & 1 & \text { carte } \\ 5 & \text { hyperthermophiles } & 1 & \text { cartel } \\ 5 & \text { hypo } & 1 & \text { cartwheel } \\ 5 & \text { hypocritical } & 1 & \text { cassia } \\ 5 & \text { icicle } & 1 & \text { castanet } \\ 5 & \text { idol } & 1 & \text { castaway } \\ 5 & \text { imminent } & 1 & \text { catalase } \\ 5 & \text { impassable } & 1 & \text { catcall } \\ 5 & \text { incomprehensible } & 1 & \text { catenary } \\ 5 & \text { inconvenience } & 1 & \text { catharsis } \\ 5 & \text { incurable } & 1 & \text { caudex } \\ 5 & \text { inefficiency } & 1 & \text { caudillo } \\ 5 & \text { infringe } & 1 & \text { cauliflower } \\ 5 & \text { inosine } & 1 & \text { caulk } \\ 5 & \text { insecure } & 1 & \text { causeway } \\ 5 & \text { interject } & 1 & \text { cavalryman } \\ 5 & \text { intern } & 1 & \text { caveman } \\ 5 & \text { interplay } & 1 & \text { cavort } \\ & & \\ & & \end{array}$




$\begin{array}{llll}5 & \text { invalidate } & 1 & \text { cay } \\ 5 & \text { invincible } & 1 & \text { censure } \\ 5 & \text { inviolate } & 1 & \text { centennial } \\ 5 & \text { invoke } & 1 & \text { centermost } \\ 5 & \text { irrelevant } & 1 & \text { centigrade } \\ 5 & \text { isopropanol } & 1 & \text { cero } \\ 5 & \text { jingle } & 1 & \text { cerumen } \\ 5 & \text { jolt } & 1 & \text { cesspit } \\ 5 & \text { jumbo } & 1 & \text { cetera } \\ 5 & \text { kaleidoscope } & 1 & \text { chaetae } \\ 5 & \text { karst } & 1 & \text { chalcopyrite } \\ 5 & \text { kea } & 1 & \text { chard } \\ 5 & \text { keel } & 1 & \text { charismatic } \\ 5 & \text { kennel } & 1 & \text { charlatan } \\ 5 & \text { kicker } & 1 & \text { cheapskate } \\ 5 & \text { kindergarten } & 1 & \text { checkmark } \\ 5 & \text { labrum } & 1 & \text { cheeseburger } \\ 5 & \text { lapse } & 1 & \text { chemoreception } \\ 5 & \text { lariat } & 1 & \text { chemosensory } \\ 5 & \text { lars } & 1 & \text { chessman } \\ 5 & \text { latch } & 1 & \text { chest } \\ 5 & \text { lattes } & 1 & \text { chic } \\ 5 & \text { legacy } & 1 & \text { chickadee } \\ 5 & \text { leisure } & 1 & \text { chidden } \\ 5 & \text { lentil } & 1 & \text { chide } \\ 5 & \text { leopard-skin } & 1 & \text { childbirths } \\ 5 & \text { lf } & 1 & \text { chillum } \\ & & \\ & & \end{array}$




\begin{tabular}{ll}
5 & lick \\
5 & lilt \\
5 & lineage \\
5 & linoleic \\
5 & lipoprotein \\
5 & literate \\
5 & logy \\
5 & loiter \\
5 & loo \\
5 & looser \\
5 & lop \\
5 & lope \\
5 & lough \\
5 & lysozymes \\
5 & mage \\
5 & mandarin \\
5 & manic-depressive \\
5 & manometer \\
5 & marina \\
5 & marmoset \\
5 & master-craftsman \\
5 & mastiff \\
\hline 5 & mayo \\
\hline 5 & \\
5 & meabyte \\
5 & \\
5 &
\end{tabular}

1 chimera

1 chirr

1 chit

1 chitter

1 chivalry

1 chlorinated

1 chlorobenzene

1 chloroform

1 choicest

1 cholecalciferol

1 cholecystokinin

1 choline

1 chortle

1 chow

1 choy

1 christen

1 chromolithograph

1 chromos

1 chubby

1 churl

1 chymotrypsin

1 cig

1 cinch

1 circa

1 circumfix

1 cirri

1 cissy 


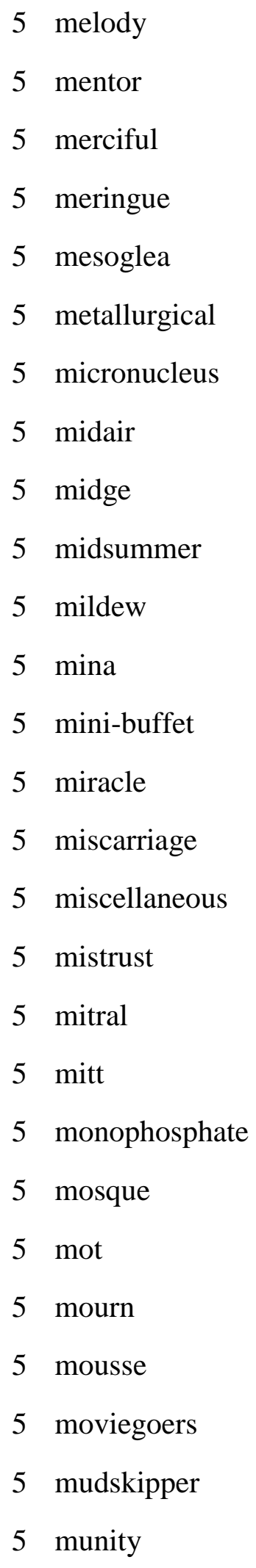




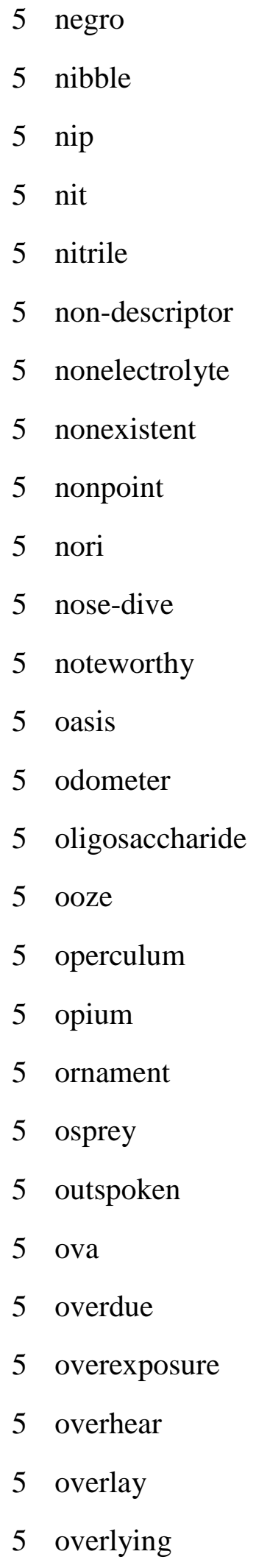




\begin{tabular}{llll}
5 & overpass & 1 & convoy \\
5 & oversized & 1 & cookware \\
5 & overthrew & 1 & coombs \\
5 & ovoid & 1 & coon \\
5 & pad & 1 & cootie \\
5 & pageant & 1 & copilot \\
5 & pall & 1 & copperhead \\
5 & palmitic & 1 & coprolites \\
5 & palp & 1 & cordial \\
5 & pamphlet & 1 & cording \\
5 & pane & 1 & corgis \\
5 & pantheon & 1 & corm \\
5 & pantry & 1 & corn-cob \\
5 & paperweight & 1 & cornice \\
5 & paradise & 1 & corny \\
5 & parry & 1 & coronet \\
5 & partway & 1 & corset \\
5 & patrol & 1 & corvette \\
5 & patrolman & 1 & councilman \\
5 & peccary & 1 & countdown \\
5 & pedestal & 1 & counterplots \\
5 & pelota & 1 & counterpoint \\
5 & pendent & 1 & counterstain \\
5 & perturbation & 1 & countess \\
5 & pessimist & 1 & countywide \\
5 & petiole & 1 & couscous \\
5 & photoautotrophic & 1 & covey \\
& & \\
\hline
\end{tabular}



5 photoelectrons
5 photolysis
5 photoperiod
5 pili
5 pillar-box
5 pinyon
5 pitfall
5 platy
5 polymerization
5 poplar
5 poppy
5 post-modifier
5 prestige
5 priestly
5 probe
5 prostaglandin
5 proximal
5 psychosis
5 psychrometric
5 pubis
5 pulse
5 pun
5 puppetry
5 putty
5 pyrotechnic
5 quartzite
5 quicksand

1 cowbell

1 cow-byre

1 cowl

1 crackdown

1 craftsmanship

1 craic

1 crampon

1 cranberry

1 crane

1 cranny

1 crate

1 cravings

1 crema

1 crepe

1 crevasse

1 crier

1 crimp

1 croft

1 croon

1 crossbreed

1 cross-compiler

1 crosscut

1 crosshatch

1 crosstown

1 croup

1 cruces

1 crud 


$\begin{array}{llll}5 & \text { quorum } & 1 & \text { cruse } \\ 5 & \text { rabbi } & 1 & \text { crusty } \\ 5 & \text { racquetball } & 1 & \text { crypt } \\ 5 & \text { radiolarian } & 1 & \text { cryptologic } \\ 5 & \text { raincoat } & 1 & \text { cryptosporidium } \\ 5 & \text { ramification } & 1 & \text { crystallographer } \\ 5 & \text { ratfish } & 1 & \text { crystallographic } \\ 5 & \text { rec } & 1 & \text { cuff } \\ 5 & \text { reconnect } & 1 & \text { cufflink } \\ 5 & \text { reek } & 1 & \text { cuisine } \\ 5 & \text { rehab } & 1 & \text { cum } \\ 5 & \text { rehabilitator } & 1 & \text { cummings } \\ 5 & \text { reindeer } & 1 & \text { cupola } \\ 5 & \text { re-model } & 1 & \text { cupric } \\ 5 & \text { repatriation } & 1 & \text { cuprous } \\ 5 & \text { rephrase } & 1 & \text { curdle } \\ 5 & \text { rescale } & 1 & \text { curium } \\ 5 & \text { restart } & 1 & \text { curt } \\ 5 & \text { retake } & 1 & \text { curtail } \\ 5 & \text { retroviral } & 1 & \text { curtsy } \\ 5 & \text { rhea } & 1 & \text { cutaneous } \\ 5 & \text { rheumatic } & 1 & \text { cutthroat } \\ 5 & \text { rib } & 1 & \text { cyanocobalamin } \\ 5 & \text { ribonucleoproteins } & 1 & \text { cycloalkane } \\ 5 & \text { rightmost } & 1 & \text { cyclohexane } \\ 5 & \text { romaine } & 1 & \text { cypripedium } \\ 5 & \text { rood } & 1 & \text { cytogenetic } \\ & & \\ & & & \end{array}$




\begin{tabular}{|c|c|}
\hline 5 & roost \\
\hline 5 & rotary \\
\hline & rubrum \\
\hline & rugby \\
\hline & rut \\
\hline & saclike \\
\hline & sari \\
\hline & sate \\
\hline 5 & sawed \\
\hline 5 & saxophone \\
\hline & scalpel \\
\hline 5 & schist \\
\hline 5 & schizophrenia \\
\hline 5 & scintillate \\
\hline 5 & scramjet \\
\hline 5 & scum \\
\hline 5 & seabed \\
\hline 5 & seagrass \\
\hline 5 & seamstress \\
\hline 5 & secular \\
\hline 5 & seethe \\
\hline 5 & self-inductance \\
\hline 5 & senescence \\
\hline 5 & serge \\
\hline & serotonin \\
\hline & sesamoid \\
\hline & setae \\
\hline
\end{tabular}

1 cytotechnologist

1 czar

1 dabble

1 dachshund

1 dactyl

1 dada

1 daguerreotype

1 dampen

1 damselfish

1 dang

1 danio

1 daredevil

1 dastardly

1 databank

1 datasheet

1 dative

1 dauphine

1 dawg

1 daycare

1 deaden

1 deaminase

1 deathwatch

1 debase

1 decaf

1 decalcified

1 decameter

1 decanal 


\begin{tabular}{ll}
5 & sf \\
5 & shank \\
5 & shareholder \\
5 & sheet \\
5 & shimmer \\
5 & shoebox \\
5 & shoelace \\
5 & shoemaker \\
5 & shotput \\
5 & silverfish \\
5 & sitcom \\
5 & skyway \\
5 & slate-quarry \\
5 & slaughter \\
5 & sluggish \\
5 & slumber \\
5 & smartphone \\
5 & sniff \\
5 & snorkeling \\
5 & snowmobile \\
5 & snowpack \\
5 & snuff \\
5 & soot \\
5 & southernmost \\
5 & spigot \\
5 & stagnant \\
5 & starchy \\
\hline 5
\end{tabular}

1 deckhand

1 deconstruct

1 decrepit

1 defrost

1 defunct

1 dehumanize

1 deicer

1 deindustrialization

1 delectable

1 delist

1 deluge

1 deme

1 demeaning

1 demeanor

1 demilitarized

1 demoniac

1 demoralize

1 demotion

1 demur

1 demystify

1 dene

1 denning

1 denture

1 deoxyadenosine

1 deoxynucleic

1 depo

1 depopulation 


\begin{tabular}{ll}
5 & stark \\
5 & starlight \\
5 & statin \\
5 & station \\
5 & steamship \\
5 & sternum \\
5 & stethoscope \\
5 & stolon \\
5 & stoplight \\
5 & streetlight \\
5 & streptococcal \\
5 & stroke \\
5 & subpoena \\
5 & subscriber \\
5 & subservient \\
5 & substitutive \\
5 & suffocate \\
5 & sultan \\
5 & summertime \\
5 & sunbathe \\
5 & superintendent \\
5 & supervision \\
5 & supple \\
5 & synergy \\
5 & takeout \\
5 & talkies \\
5 & tanner \\
\hline 5
\end{tabular}

1 deprave

1 deprecate

1 depredation

1 dervish

1 dese

1 desecrate

1 desensitizes

1 desiccated

1 desiderata

1 desperado

1 destitute

1 deterrent

1 detonate

1 devilish

1 devolution

1 devout

1 dewdrop

1 diabolism

1 diacritical

1 diarist

1 dickens

1 dickey

1 didactic

1 diglyceride

1 dilapidated

1 dilly

1 dimeter 


\begin{tabular}{|c|c|}
\hline 5 & tarsier \\
\hline 5 & tart \\
\hline & televised \\
\hline & ternary \\
\hline & tetrad \\
\hline & thermochemical \\
\hline & thermonuclear \\
\hline & thesaurus \\
\hline & tibia \\
\hline & timepiece \\
\hline & toenail \\
\hline & tokes \\
\hline & toolbar \\
\hline & toolkit \\
\hline & topaz \\
\hline & torment \\
\hline & toxoplasma \\
\hline & tradeoff \\
\hline & trample \\
\hline & transpose \\
\hline & triathlon \\
\hline & tufa \\
\hline & tularemia \\
\hline & tur \\
\hline & turboprop \\
\hline & turnout \\
\hline & twitter \\
\hline
\end{tabular}

1 diminution

1 dingle

1 dink

1 dinnertime

1 dint

1 diorama

1 diose

1 dioxygen

1 diphenhydramine

1 diphenyl

1 diphenylamine

1 dipsomaniac

1 disaffected

1 disaggregate

1 disallow

1 disco

1 discolor

1 discolored

1 discreet

1 disfigure

1 disheveled

1 dishonoring

1 dishpans

1 dishware

1 dishwater

1 disillusionment

1 disinterested 


$\begin{array}{llll}5 & \text { undergraduate } & 1 & \text { dismay } \\ 5 & \text { undermine } & 1 & \text { disoriented } \\ 5 & \text { uniramous } & 1 & \text { disown } \\ 5 & \text { upbeat } & 1 & \text { disrepair } \\ 5 & \text { upstate } & 1 & \text { disservice } \\ 5 & \text { uterine } & 1 & \text { dissimulation } \\ 5 & \text { vacate } & 1 & \text { dissonance } \\ 5 & \text { valine } & 1 & \text { disuses } \\ 5 & \text { vegan } & 1 & \text { dive-bomb } \\ 5 & \text { veliger } & 1 & \text { doable } \\ 5 & \text { verge } & 1 & \text { dobsonflies } \\ 5 & \text { versatile } & 1 & \text { docile } \\ 5 & \text { vinyl } & 1 & \text { docket } \\ 5 & \text { viviparous } & 1 & \text { dolomite } \\ 5 & \text { wad } & 1 & \text { dolphinkind } \\ 5 & \text { waggle } & 1 & \text { domelike } \\ 5 & \text { warhead } & 1 & \text { domineer } \\ 5 & \text { wartime } & 1 & \text { doming } \\ 5 & \text { welsh } & 1 & \text { doo } \\ 5 & \text { wetsuit } & 1 & \text { doo-dah } \\ 5 & \text { windowsill } & 1 & \text { doomsday } \\ 5 & \text { xerophyte } & 1 & \text { doorstep } \\ 5 & \text { yolk } & 1 & \text { dormouse } \\ 5 & \text { zig-zag } & 1 & \text { dost } \\ 5 & \text { zooxanthellae } & 1 & \text { downcast } \\ 5 & \text { park-keeper } & 1 & \text { downloadable } \\ 5 & \text { re-fuel } & 1 & \text { downplay } \\ & & \\ & & & \end{array}$




\begin{tabular}{ll}
5 & semi-fast \\
5 & pouch-seat \\
5 & re-assure \\
5 & non-golfer \\
4 & abbreviate \\
4 & abhor \\
4 & ablaze \\
4 & adept \\
4 & aerodynamic \\
4 & afterbirth \\
4 & agrochemical \\
4 & airflow \\
4 & amiss \\
4 & amphioxus \\
4 & apt \\
4 & amphoteric \\
4 & anagram \\
4 & anoxic \\
4 & ante \\
4 & antibacterial \\
4 & antic \\
\hline 4 & antidepressant \\
\hline 4 & aptipathy \\
\hline 4
\end{tabular}

1 downregulate

1 downtime

1 dozers

1 drafty

1 drat

1 drayman

1 dree

1 dressmaker

1 driftnet

1 dropdown

1 dropout

1 drudgery

1 druid

1 drumbeat

1 drumhead

1 duchy

1 ducking-stool

1 dumas

1 duodenal

1 dup

1 duplex

1 dustman

1 dyestuff

1 dysprosium

1 earmark

1 earmuffs

1 earwig 


\begin{tabular}{|c|c|}
\hline archaic & 1 easel \\
\hline areoles & 1 easygoing \\
\hline arginine & 1 ebony \\
\hline armchair & 1 eddy \\
\hline arsenide & 1 efface \\
\hline artisan & 1 efferent \\
\hline assail & 1 effervescent \\
\hline aster & 1 egad \\
\hline attire & 1 egghead \\
\hline autograph & 1 egotism \\
\hline auxiliary & 1 einsteinium \\
\hline axil & 1 eke \\
\hline backtrack & 1 elastin \\
\hline baggy & 1 electrocution \\
\hline bam & 1 electroscopes \\
\hline baptize & 1 electrovalent \\
\hline barbules & 1 elfin \\
\hline bathwater & 1 elide \\
\hline bawl & 1 eligibility \\
\hline beanbag & 1 emaciating \\
\hline beck & 1 embalmment \\
\hline bedclothes & 1 ember \\
\hline bedtime & 1 embezzle \\
\hline belie & 1 emblazon \\
\hline bibliography & 1 embodiment \\
\hline biff & 1 emboss \\
\hline biloba & 1 embryogenesi \\
\hline
\end{tabular}



4 biomimicry
4 biopolymer
4 birdlike
4 birdwatch
4 bitumen
4 blackwood
4 bland
4 blare
4 bolster
4 bomb
4 bomber
4 bonanza
4 booby
4 bossy
4 bothersome
4 bounty
4 brainstormed
4 breastfeeding
4 broach
4 bromothymol
4 brother
4 brotherhood
4 brunt
4 bryozoan
4 bumblebee
4 bunting
4 burly

1 emend

1 emir

1 emo

1 encampment

1 encephalopathy

1 enchilada

1 endogenous

1 endoribonuclease

1 enema

1 enfant

1 engorge

1 enkindle

1 enneagon

1 enol

1 enshrine

1 ensign

1 entomb

1 entrap

1 entreaty

1 entryway

1 enucleated

1 enwrap

1 epicuticle

1 equine

1 equisetum

1 ergonomic

1 espouse 


\begin{tabular}{|c|c|c|c|}
\hline 4 & burro & 1 & esterase \\
\hline 4 & caesarian & 1 & estradiol \\
\hline 4 & calamity & 1 & ethnolinguistic \\
\hline 4 & calico & 1 & euthanasia \\
\hline 4 & calif & 1 & euthanized \\
\hline & cam & 1 & eutherian \\
\hline 4 & calyx & 1 & eutrophic \\
\hline 4 & canola & 1 & \\
\hline 4 & cappuccino & 1 & eventful \\
\hline 4 & carbide & 1 & everlasting \\
\hline 4 & carcinoma & 1 & evermore \\
\hline 4 & & 1 & everyman \\
\hline & calt & 1 & evocative \\
\hline 4 & catastrophically & & \\
\hline 4 & caveat & 1 & exasperate \\
\hline 4 & caver & 1 & excavate \\
\hline & & 1 & excrement \\
\hline 4 & cellophane & & \\
\hline 4 & cellulosic & 1 & excruciatingly \\
\hline 4 & cerium & 1 & exergonic \\
\hline 4 & - & 1 & exfoliate \\
\hline & 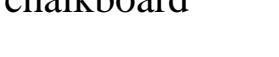 & 1 & exhort \\
\hline 4 & champ & & EXIIOU \\
\hline 4 & chapman & 1 & exhume \\
\hline 4 & chip & 1 & exonerations \\
\hline 4 & chicol & 1 & exopolysaccharides \\
\hline & & 1 & exorbitant \\
\hline 4 & chlorophyte & & \\
\hline 4 & chromate & 1 & exorcist \\
\hline 4 & chrysanthemum & 1 & expiate \\
\hline 4 & cirrocumulus & 1 & explant \\
\hline & civet & 1 & extant \\
\hline
\end{tabular}




\begin{tabular}{ll}
4 & clatter \\
4 & clementine \\
4 & clipboard \\
4 & clumsiness \\
4 & clumsy \\
4 & clunk \\
4 & coax \\
4 & coevolved \\
4 & cofactor \\
4 & cofounder \\
4 & commiserate \\
4 & compartmentalize \\
4 & compendium \\
4 & coroner \\
4 & concede \\
4 & confiscate \\
4 & conn \\
4 & consolation \\
4 & contrail \\
4 & contrive \\
4 & convoluted \\
4 & corndogs \\
\hline 4 & \\
4 &
\end{tabular}

1 extort

1 extradition

1 extravaganza

1 extrinsic

1 eyeless

1 eyestalks

1 eyewall

1 facers

1 factoid

1 fag

1 falafel

1 falsehood

1 famished

1 fangled

1 farad

1 farmyard

1 fascioliasis

1 fascism

1 fastball

1 fatherhood

1 fatlike

1 fatso

1 faunal

1 fax

1 fecundity

1 feedstock

1 felling 


\begin{tabular}{|c|c|}
\hline 4 & corpora \\
\hline 4 & corpuscle \\
\hline 4 & corroborate \\
\hline 4 & corundum \\
\hline 4 & couplet \\
\hline 4 & court \\
\hline 4 & coven \\
\hline 4 & cower \\
\hline 4 & cowpox \\
\hline 4 & cowrie \\
\hline 4 & $\operatorname{cox}$ \\
\hline 4 & coxa \\
\hline 4 & cozy \\
\hline 4 & cradle \\
\hline 4 & crap \\
\hline 4 & croc \\
\hline 4 & cryogenic \\
\hline 4 & curbside \\
\hline 4 & curry-powder \\
\hline 4 & cuss \\
\hline 4 & cutoff \\
\hline 4 & cutout \\
\hline 4 & dampers \\
\hline 4 & damselfly \\
\hline 4 & daze \\
\hline 4 & deadweight \\
\hline & dearth \\
\hline
\end{tabular}

1 fellow-conspirator

1 felts

1 femora

1 fennec

1 fermi

1 ferric

1 fervor

1 fess

1 fiat

1 fib

1 fickle

1 fid

1 fidelity

1 fidget

1 fiendish

1 fife

1 filigree

1 finesse

1 finicky

1 firebrats

1 fireproof

1 fishbowl

1 fistula

1 fizzle

1 flagship

1 flagstaff

1 flail 


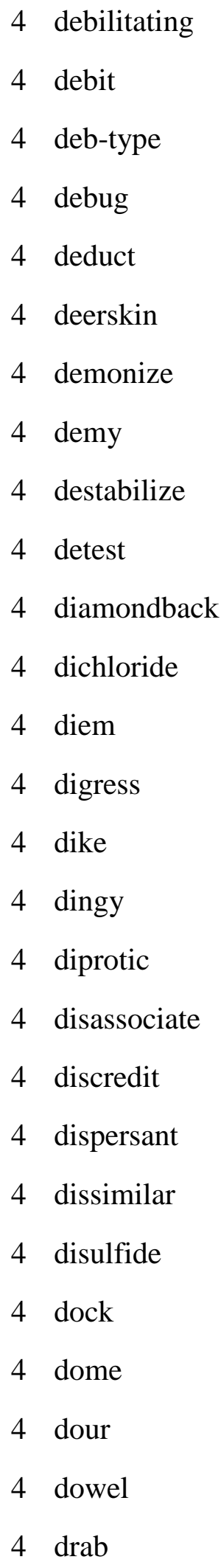

1 flair

1 flakey

1 flaky

1 flamboyant

1 flashbulb

1 flashcard

1 flatbreads

1 flatus

1 flection

1 flimsy

1 flipbooks

1 flirt

1 floorboard

1 floret

1 flowerbed

1 flowerlike

1 flume

1 flyaway

1 flybys

1 flyover

1 fodder

1 folioing

1 folly

1 foolhardy

1 footrest

1 forebrain

1 foreknow 


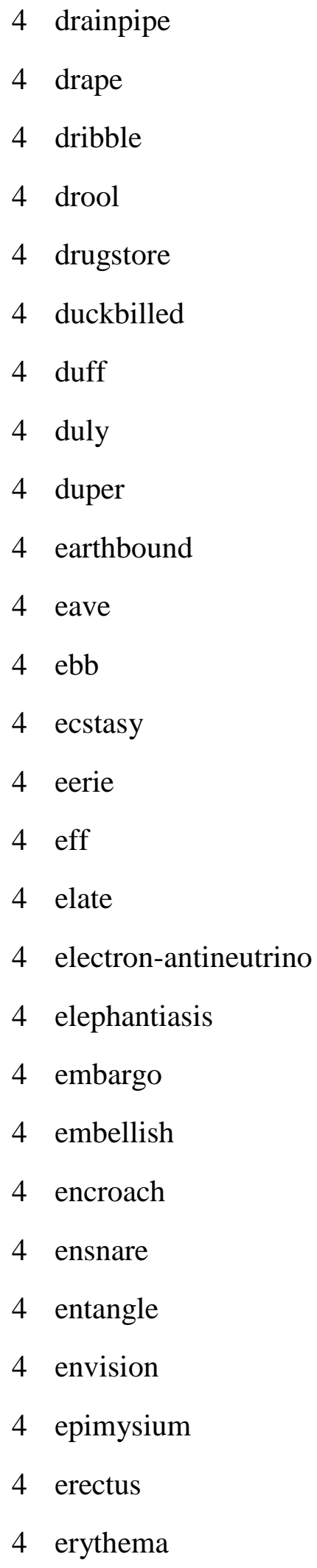

1 foreplay

1 forestland

1 forlorn

1 forsake

1 forthwith

1 fortissimo

1 fourscore

1 frag

1 franchise

1 freeborn

1 friar

1 frothy

1 frustule

1 fug

1 fulgurite

1 furlong

1 furtively

1 fuss

1 futility

1 gag

1 gaiety

1 gait

1 galactosidase

1 galilee

1 galleon

1 gallstone

1 garb 


\begin{tabular}{ll}
4 & erythematosus \\
4 & erythrocyte \\
4 & ese \\
4 & esker \\
4 & espresso \\
4 & eulogy \\
4 & evert \\
4 & examiner \\
4 & excursion \\
4 & exonuclease \\
4 & expressway \\
4 & extravagant \\
4 & eyehole \\
4 & floral \\
4 & flecies \\
4 & fanner \\
4 & fascicle \\
4 & fay \\
4 & feeble \\
4 & feral \\
4 & fibroblast \\
\hline 4
\end{tabular}

1 gasket

1 gasmask

1 gastro

1 gastrula

1 gaudy

1 gazette

1 gazillion

1 gees

1 genet

1 genocide

1 genu

1 geochronology

1 gests

1 getup

1 gharials

1 ghastly

1 ghrelin

1 gibberish

1 gilded

1 girt

1 girts

1 giveaway

1 glia

1 gloaming

1 glucometer

1 glum

1 glycosylases 


\begin{tabular}{llll}
4 & flounder & 1 & glycosylation \\
4 & flyway & 1 & gnash \\
4 & folklore & 1 & goatherd \\
4 & foo & 1 & gobbledygook \\
4 & foolproof & 1 & godlike \\
4 & forefinger & 1 & gonococcal \\
4 & forthcoming & 1 & gooier \\
4 & fortress & 1 & gook \\
4 & fray & 1 & gorgonian \\
4 & frenzy & 1 & gory \\
4 & fumble & 1 & goth \\
4 & fuselage & 1 & gowned \\
4 & fussy & 1 & grail \\
4 & gabby & 1 & grandkids \\
4 & gable & 1 & grandparenthood \\
4 & gaily & 1 & grandpop \\
4 & gar & 1 & granger \\
4 & gash & 1 & granitic \\
4 & gastrin & 1 & graven \\
4 & gastrovascular & 1 & gravestone \\
4 & gazebo & 1 & greenspace \\
4 & gearbox & 1 & greenwash \\
4 & geostationary & 1 & gregarious \\
4 & giganotosaurus & 1 & gridiron \\
4 & glen & 1 & grouch \\
4 & glisten & 1 & groundspeed \\
4 & glutaraldehyde & 1 & grueling \\
\hline & & \\
\hline & &
\end{tabular}




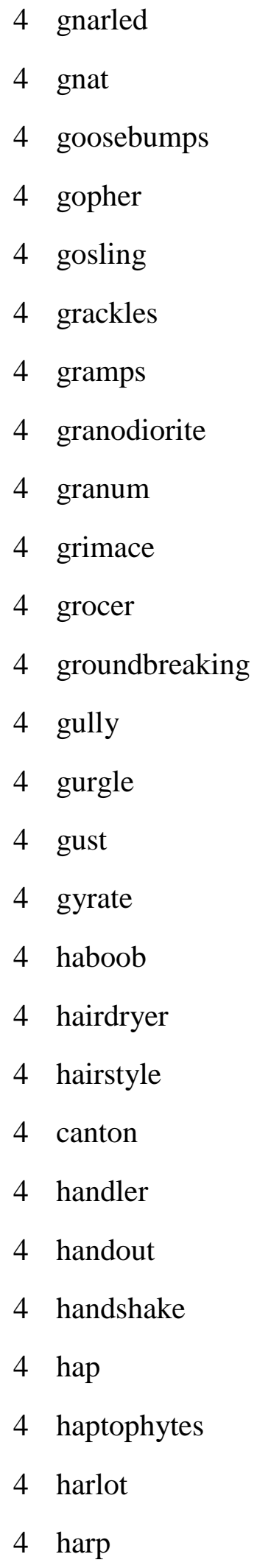

1 grumpy

1 guan

1 guanaco

1 guar

1 gubernatorial

1 guild

1 gulley

1 gulling

1 gumbo

1 gummer

1 gunboat

1 gunfire

1 gunky

1 gunsmith

1 gurnard

1 gusto

1 gusty

1 habitude

1 haemochromatosis

1 haft

1 hammerhead

1 handicraft

1 handspring

1 hanger

1 haphazardly

1 haram

1 hardboard 


$\begin{array}{llll}4 & \text { head-ach } & 1 & \text { hardcopy } \\ 4 & \text { headland } & 1 & \text { harpoon } \\ 4 & \text { headwind } & 1 & \text { harrow } \\ 4 & \text { heck } & 1 & \text { hassock } \\ 4 & \text { heriot } & 1 & \text { haywire } \\ 4 & \text { histone } & 1 & \text { headband } \\ 4 & \text { histoplasmosis } & 1 & \text { headdress } \\ 4 & \text { hobble } & 1 & \text { headfirst } \\ 4 & \text { holm } & 1 & \text { headgear } \\ 4 & \text { hop } & 1 & \text { headlock } \\ 4 & \text { hornblende } & 1 & \text { headset } \\ 4 & \text { horseback } & 1 & \text { heartfelt } \\ 4 & \text { hostess } & 1 & \text { heartland } \\ 4 & \text { houseplant } & 1 & \text { heartsick } \\ 4 & \text { hue } & 1 & \text { heathen } \\ 4 & \text { hunchback } & 1 & \text { heave } \\ 4 & \text { hurray } & 1 & \text { hebetate } \\ 4 & \text { hustle } & 1 & \text { hectic } \\ 4 & \text { hydrangea } & 1 & \text { hedge } \\ 4 & \text { hydrolase } & 1 & \text { hegemony } \\ 4 & \text { hymn } & 1 & \text { heifer } \\ 4 & \text { hype } & 1 & \text { helioseismology } \\ 4 & 1 & \text { inadvertently } & \text { infest }\end{array}$




\begin{tabular}{|c|c|}
\hline 4 infrequently & 1 hemlock \\
\hline inmost & 1 hemolytic \\
\hline Monose & 1 hemoproteins \\
\hline 4 inset & 1 henpecked \\
\hline 4 insidious & 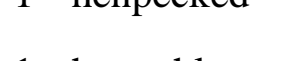 \\
\hline 4 insomnia & 1 heptathlon \\
\hline 4 interferon & 1 herculean \\
\hline 4 intergenic & 1 hereinafter \\
\hline 4 intermediary & 1 herewith \\
\hline 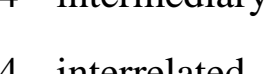 & 1 herpetic \\
\hline 4 interrelated & 1 herpetologists \\
\hline 4 interstitial & heterodimeric \\
\hline 4 inundate & I neterodimeric \\
\hline 4 ionosphere & 1 heterodox \\
\hline 4 ire & 1 hiatus \\
\hline 4 iron & 1 hiccup \\
\hline 4 irregularity & 1 hickey \\
\hline 4 isomerism & 1 hideaway \\
\hline 4 itinerary & 1 hieroglyphic \\
\hline 4 IIIILCaly & 1 hillslopes \\
\hline 4 jaundice & 1 hilt \\
\hline 4 jo & 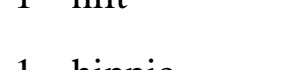 \\
\hline 4 jut & 1 hippie \\
\hline 4 kay & 1 hipping \\
\hline 4 kerchief & 1 histoire \\
\hline 4 keyhole & 1 histology \\
\hline 4 kinematic & 1 hob \\
\hline 4 knead & 1 hobo \\
\hline kwashiorkor & 1 holistic \\
\hline 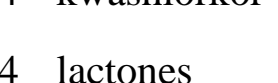 & 1 holmium \\
\hline
\end{tabular}




\begin{tabular}{ll}
4 & laminar \\
4 & lanceolate \\
4 & lanugo \\
4 & lawnmower \\
4 & ledger \\
4 & leftward \\
4 & legionnaire \\
4 & lesbian \\
4 & levitation \\
4 & lieutenant-colonel \\
4 & lightheadedness \\
4 & linings \\
4 & lip \\
4 & maiden \\
4 & muefaction \\
4 & litany \\
4 & livable \\
4 & loom \\
4 & loon \\
4 & lorry \\
4 & magietium \\
\hline 4 & magpie \\
4 & mane \\
4 &
\end{tabular}

1 hologram

1 homage

1 homebody

1 homeopathic

1 homepage

1 homesickness

1 homestretch

1 homoscedasticity

1 homosexuality

1 honeydew

1 honeypot

1 hoodie

1 hoody

1 hoppy

1 hora

1 hornet

1 horseman

1 horseplay

1 hospice

1 hotcakes

1 houseboat

1 hovercraft

1 hoverfly

1 hubris

1 humph

1 hunk

1 hutch 


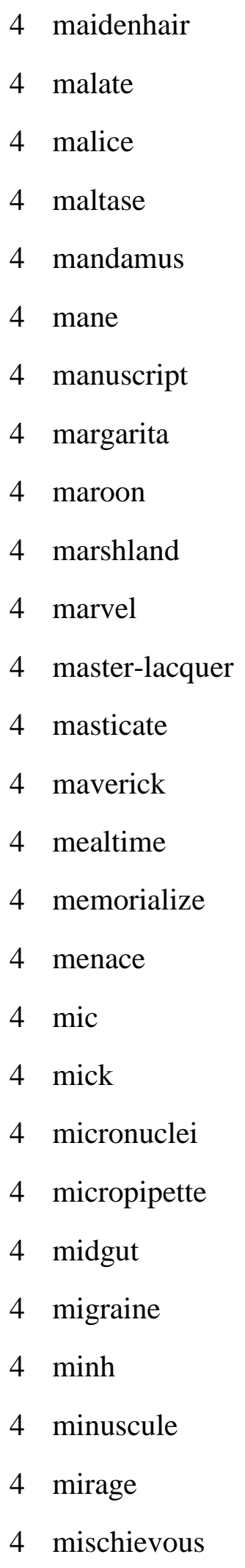

1 hyaline

1 hydrazine

1 hydrofluorocarbon

1 hydrophytes

1 hydrops

1 hydroscopic

1 hydrous

1 hyoid

1 hypercritical

1 hypergiant

1 hyperthermia

1 hypnotize

1 hypopharynx

1 hypothermia

1 hypothyroidism

1 hypoxic

1 ibn

1 ichthyosaur

1 idyllic

1 illegible

1 immunosuppression

1 impending

1 imperator

1 impetigo

1 impetuous

1 impetus

1 impinge 


\begin{tabular}{|c|c|}
\hline miscibility & 1 impious \\
\hline misdemeanor & 1 importunity \\
\hline misfortune & 1 improvise \\
\hline misread & 1 impulsive \\
\hline molybdenum & 1 inadvertent \\
\hline money-lender & 1 inapplicable \\
\hline monotheistic & 1 inappropriately \\
\hline monotonically & 1 inattentive \\
\hline morbid & 1 incant \\
\hline morph & 1 incapacitate \\
\hline morrow & 1 incendiary \\
\hline morsel & 1 incessant \\
\hline mottle & 1 incision \\
\hline mucilage & 1 incisive \\
\hline mudstone & 1 incognita \\
\hline mullein & 1 incognito \\
\hline multilingual & 1 incoherently \\
\hline myocardial & 1 incompetence \\
\hline myoglobin & 1 incomprehensibly \\
\hline naphthalene & 1 inconsiderate \\
\hline nasty & 1 incontinence \\
\hline navel & 1 inconveniently \\
\hline needy & 1 incursion \\
\hline nelly & 1 incus \\
\hline neurotransmission & 1 indecisive \\
\hline newcomer & 1 indefatigable \\
\hline nimbostratus & 1 indelible \\
\hline
\end{tabular}




$\begin{array}{ll}4 & \text { nitro-organic } \\ 4 & \text { no } \\ 4 & \text { nomad } \\ 4 & \text { nonconsecutive } \\ 4 & \text { nonequivalent } \\ 4 & \text { nonstop } \\ 4 & \text { nontoxic } \\ 4 & \text { northland } \\ 4 & \text { nosepiece } \\ 4 & \text { nota } \\ 4 & \text { notify } \\ 4 & \text { notwithstanding } \\ 4 & \text { nozzle } \\ 4 & \text { ort } \\ 4 & \text { np } \\ 4 & \text { obsidian } \\ 4 & \text { occipital } \\ 4 & \text { ocular } \\ 4 & \text { odyssey } \\ 4 & \text { offence } \\ 4 & \text { oominous } \\ 4 & \text { optout } \\ 4 & \\ 4 & \end{array}$

1 indignant

1 indispensable

1 indisputably

1 indistinctly

1 indoctrinate

1 ineligible

1 inequity

1 inestimable

1 inexperienced

1 inexpertly

1 inextricable

1 infallibility

1 infamy

1 infantile

1 infantry

1 infill

1 infinites

1 infinitive

1 infirm

1 inflame

1 inflamer

1 infuriate

1 inhuman

1 inhumanity

1 inions

1 inkjet

1 inky 


\begin{tabular}{llll}
4 & osmium & 1 & innings \\
4 & ossifies & 1 & inordinately \\
4 & osteogenesis & 1 & insensitive \\
4 & oust & 1 & insensitivity \\
4 & outstretched & 1 & inseparable \\
4 & over-abstraction & 1 & insincere \\
4 & overgrown & 1 & insinuate \\
4 & overkill & 1 & insolation \\
4 & overshadow & 1 & instate \\
4 & overt & 1 & instep \\
4 & oxoacids & 1 & instill \\
4 & padlock & 1 & insubstantial \\
4 & palisade & 1 & insula \\
4 & palooka & 1 & insular \\
4 & pan & 1 & insurgency \\
4 & panicked & 1 & intangible \\
4 & pap & 1 & interconnectedness \\
4 & papillae & 1 & interconnecting \\
4 & paraffin & 1 & interconnection \\
4 & pariah & 1 & interconversion \\
4 & parmesan & 1 & interdisciplinary \\
4 & parsec & 1 & intergenerational \\
4 & pasty & 1 & interglacial \\
4 & peacekeeping & 1 & interminable \\
4 & pending & 1 & intermission \\
4 & 1 & intermural \\
& 1 & internee \\
\hline & & \\
4 & &
\end{tabular}




\begin{tabular}{|c|c|}
\hline & perfringens \\
\hline & periwinkle \\
\hline & pertinacity \\
\hline & pestle \\
\hline & petit \\
\hline & phoebe \\
\hline & phosphatidylinositol \\
\hline & phototroph \\
\hline & phototrophs \\
\hline & piezoelectric \\
\hline & pinecones \\
\hline & pipe \\
\hline & pique \\
\hline & plesiosaur \\
\hline & plough \\
\hline & plump \\
\hline & pneumocystis \\
\hline & poi \\
\hline & polypoid \\
\hline & polytheistic \\
\hline & ponens \\
\hline & porcelain \\
\hline & porter \\
\hline & prawn \\
\hline & predate \\
\hline & premenstrual \\
\hline & prentice \\
\hline
\end{tabular}

1 internship

1 interpose

1 interposition

1 interrelate

1 interrelatedness

1 inters

1 interstellar

1 interwoven

1 intoxication

1 intoxications

1 intramolecular

1 introspective

1 inveterate

1 inviable

1 invincibility

1 invulnerable

1 irate

1 iridescent

1 ironclad

1 ironsides

1 irradiated

1 irrationally

1 irrelevance

1 irreparable

1 irreplaceable

1 irresolution

1 irrespective 


$\begin{array}{llll}4 & \text { preprophase } & 1 & \text { irreversibly } \\ 4 & \text { preschool } & 1 & \text { isocyanates } \\ 4 & \text { prickle } & 1 & \text { isogloss } \\ 4 & \text { pristine } & 1 & \text { isomerase } \\ 4 & \text { propanone } & 1 & \text { isomerases } \\ 4 & \text { propene } & 1 & \text { isoprene } \\ 4 & \text { protonated } & 1 & \text { isotretinoin } \\ 4 & \text { prowess } & 1 & \text { jackhammer } \\ 4 & \text { prudence } & 1 & \text { jackpot } \\ 4 & \text { pseudogenes } & 1 & \text { jadeite } \\ 4 & \text { psoriasis } & 1 & \text { jangle } \\ 4 & \text { ptarmigan } & 1 & \text { jap } \\ 4 & \text { pterosaur } & 1 & \text { jar } \\ 4 & \text { pygidium } & 1 & \text { jects } \\ 4 & \text { pylon } & 1 & \text { jeer } \\ 4 & \text { pyruvates } & 1 & \text { jellylike } \\ 4 & \text { quack } & 1 & \text { jezebel } \\ 4 & \text { quadrate } & 1 & \text { jigsaw } \\ 4 & \text { quadrillion } & 1 & \text { jilt } \\ 4 & \text { quintillion } & 1 & \text { jive } \\ 4 & \text { quo } & 1 & \text { jock } \\ 4 & \text { racket } & 1 & \text { jubilant } \\ 4 & \text { racy } & 1 & \text { judicious } \\ 4 & \text { radioed } & 1 & \text { junkyard } \\ 4 & \text { railing } & 1 & \text { junkyards } \\ 4 & \text { rainbowfish } & 1 & \text { juris } \\ 4 & \text { reassuringly } & 1 & \text { jurist } \\ \end{array}$




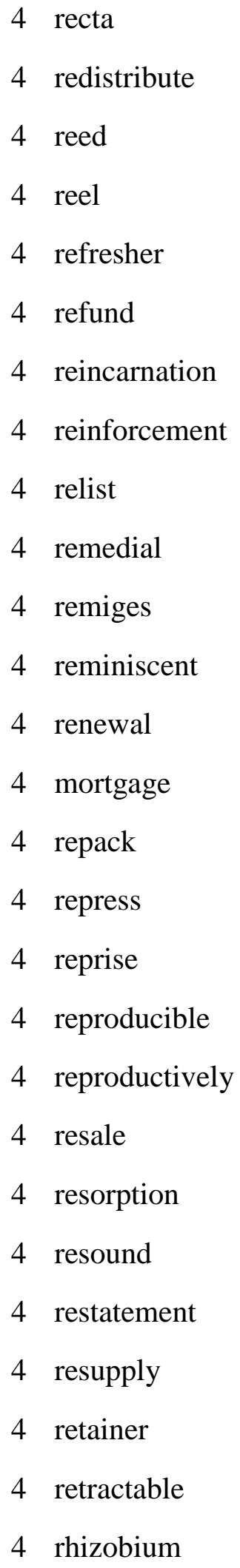

1 kabbalists

1 kai

1 kanga

1 kapok

1 karyotyping

1 kelps

1 kemp

1 keratinized

1 keratitis

1 keta

1 keypad

1 kiddo

1 kilopascals

1 kimchi

1 kina

1 kinematical

1 kinesthetic

1 kingly

1 kingship

1 kinkajou

1 kinship

1 kirk

1 knick-knack

1 knitter

1 knoblike

1 kombu

1 kookaburra 


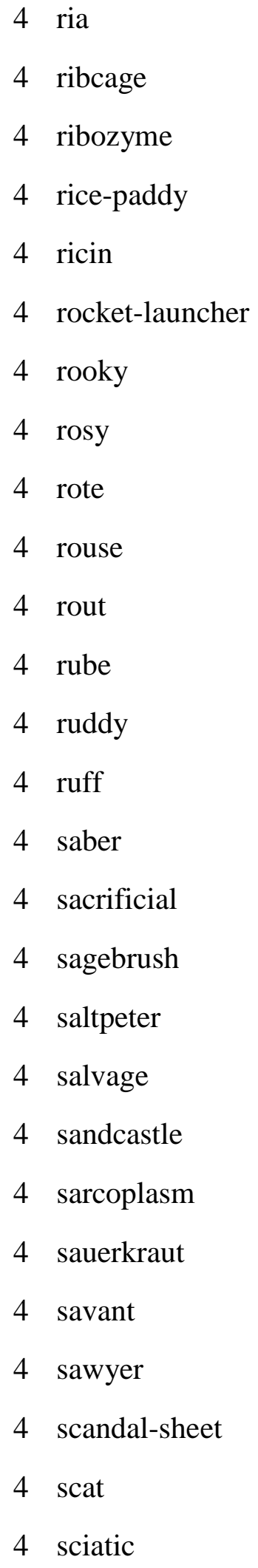

1 kowtow

1 krater

1 krypton

1 kung

1 kuru

$1 \mathrm{kwh}$

1 labile

1 laburnum

1 lacerate

1 lacunae

1 lair

1 laissez

1 lakeside

1 lamella

1 lamellae

1 lameness

1 lament

1 laminate

1 lampshade

1 landholding

1 landmine

1 landward

1 lanthanide

1 lapis

1 largemouth

1 largo

1 lark 


\begin{tabular}{ll}
4 & screech \\
4 & scrubland \\
4 & seaboard \\
4 & seafarer \\
4 & seagull \\
4 & sea-loch \\
4 & secluded \\
4 & sedan-chair \\
4 & self-reproach \\
4 & semiarid \\
4 & semifinalists \\
4 & sentiment \\
4 & sire \\
4 & sentimental \\
4 & sentinel \\
4 & signal \\
4 & serene \\
4 & serum \\
4 & serviceman \\
4 & sheikh \\
4 & shelly \\
\hline 4 & shred \\
\hline 4 & \\
4 & simoid \\
\hline 4
\end{tabular}

4 screech

4 scrubland

4 seaboard

seafarer

4 self-reproach

semiarid

4 sentiment

4 sentimental

4 sentinel

4 serene
1 laryngitis

1 lasagna

1 latrine

1 laundromat

1 lavishness

1 lazuli

1 lazybones

1 leaden

1 leastways

1 lection

1 lector

1 leggy

1 legible

1 legion

1 legit

1 leigh

1 lemur

1 leniency

1 lenticular

1 leotard

1 leptin

1 letterbox

1 ley

1 liaison

1 lifeline

1 lifesaving

1 liftoff 


$$
\begin{aligned}
& 4 \text { smother } \\
& 4 \text { snarl } \\
& 4 \text { snowbird } \\
& 4 \text { snowboard } \\
& 4 \text { snowfield } \\
& 4 \text { snug } \\
& 4 \text { sojourner } \\
& 4 \text { solace } \\
& 4 \text { someplace } \\
& 4 \text { sourcebook } \\
& 4 \text { souvenir } \\
& 4 \text { specular } \\
& 4 \text { speedometer } \\
& 4 \text { spencer } \\
& 4 \text { sphinx } \\
& 4 \text { spinneret } \\
& 4 \text { splay } \\
& 4 \text { splint } \\
& 4 \text { spokesperson } \\
& 4 \text { sprain } \\
& 4 \text { springtime } \\
& 4 \text { squat-urn } \\
& 4 \text { stag } \\
& 4 \text { stairway } \\
& 4 \text { stake } \\
& 4 \text { stearate } \\
& 4 \text { steed }
\end{aligned}
$$

1 lime

1 limeade

1 limey

1 limo

1 limulus

1 lint

1 lithograph

1 livings

1 loathing

1 lodgings

1 logograph

1 loner

1 longstanding

1 loofah

1 lookup

1 loot

1 loth

1 lotto

1 lotus-eater

1 lowdown

1 luciferase

1 lugworm

1 luminescent

1 lune

1 lupine

1 lute

1 lyre-bird 


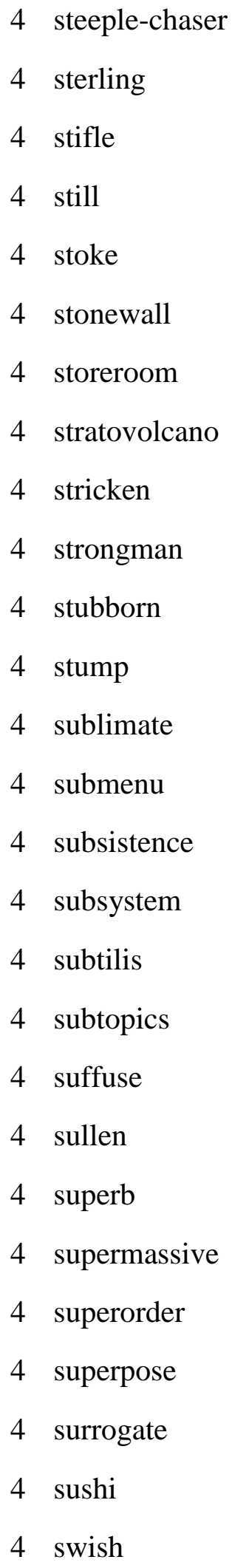

1 lyses

1 lysosomal

1 macaque

1 machinist

1 mackerel

1 mackintosh

1 macromolecular

1 macular

$1 \mathrm{mad}$

1 madam

1 madeira

1 madras

1 maharaja

1 mahatma

1 mailer

1 mailroom

1 mainstay

1 majordomo

1 malar

1 maleness

1 malformed

1 malicious

1 mallard

1 man-hater

1 manicotti

1 manifold

1 manila 


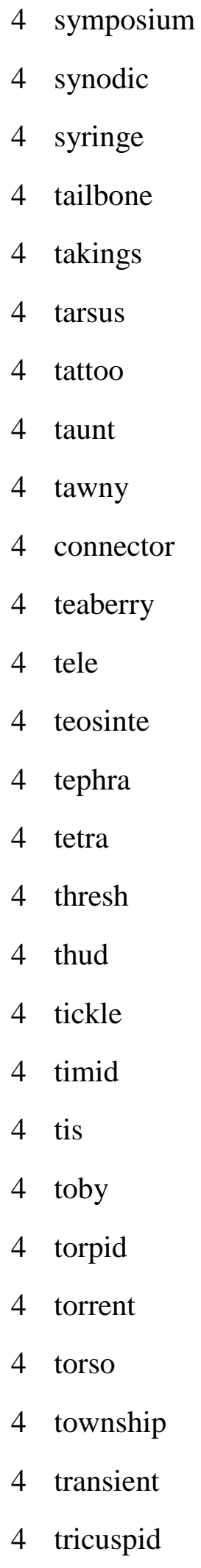

1 manmade

1 mannose

1 mansion

1 mantelpiece

1 manzanita

1 mare

1 marinade

1 marinara

1 markka

1 marlin

1 marten

1 masse

1 mastermind

1 mastitis

1 matchbox

1 maternally

1 maternity

1 maxi

1 meager

1 measly

1 meatloaf

1 mecca

1 meddle

1 mediastinum

1 medusas

1 megalomaniac

1 megastore 


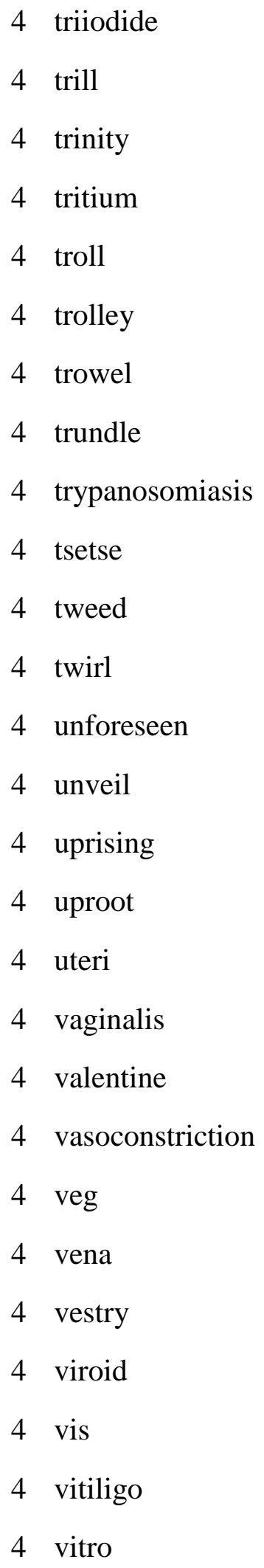

1 mellow

1 memento

1 memo

1 memorabilia

1 menagerie

1 menthe

1 mercer

1 meritocratic

1 mesentery

1 mesh

1 mesmerize

1 mesopelagic

1 mesotrophic

1 mess

1 mestizo

1 metazoan

1 metheg

1 methylated

1 methylbenzene

1 metropolis

1 mew

1 miasma

1 mickey

1 micro

1 microalgae

1 microarrays

1 microblog 


\begin{tabular}{|c|c|c|c|}
\hline & waft & & microcirculation \\
\hline & wail & 1 & microcontroller \\
\hline & wherewithal & 1 & microfarad \\
\hline & whirlpool & 1 & microliters \\
\hline & whitewater & 1 & micrometeorite \\
\hline & whorl & 1 & micron \\
\hline & widget & 1 & microspore \\
\hline 7 & widower & 1 & microvillus \\
\hline t & windbreak & 1 & midfield \\
\hline 4 & woe & 1 & miens \\
\hline 4 & womb & 1 & millet \\
\hline 7 & woodrat & 1 & milliard \\
\hline & workload & 1 & millpond \\
\hline 4 & wot & 1 & millstone \\
\hline 4 & wraith & 1 & mimosa \\
\hline & yea & 1 & minable \\
\hline 4 & vooa & 1 & minaret \\
\hline & yoga & 1 & minefield \\
\hline 4 & zooid & 1 & mingle \\
\hline 4 & zoospores & 1 & mingie \\
\hline 4 & cargo-ship & 1 & ministerial \\
\hline 4 & anti-fungal & 1 & minnow \\
\hline 3 & abate & 1 & minuteman \\
\hline 3 & acclivity & 1 & misalignment \\
\hline 3 & acrylate & & misapply \\
\hline 3 & acrylic & 1 & misattributed \\
\hline 3 & adjoin & & misbehave \\
\hline & aforementioned & 1 & miscalled \\
\hline
\end{tabular}



3 afresh
3 aggravate
3 agribusiness
1 miscellany
3 airboat
3 airbus
3 albedo
3 allay
3 aloof
3 alveolar
3 amalgam
3 amble
3 amidst
3 amphibole
3 amphipods
3 amputation
3 amyotrophic
3 anabaena
3 anathema
3 anisole
3 anon
3 antifederalists
3 antigenic
3 antimicrobial
3 antiproton
3 antiquark
3 antisense
3 apolipoprotein
1 misdoings
1 misfolded
1 mish-mash
1 misinform
1 mismanagement
1 misname
1 misnomer
1 mispronounces
1 misquotation
1 mistreat
1 misty
1 moil
1 molasses
1 moll
1 molluscan
1 monas
1 mongo
1 mongoose
1 mongrel
1 monoatomic
1 monocotyledon
1 monoculture
1 monogenean
1 monogeneans
1 monohybrids
1 monomeric 


\begin{tabular}{llll}
3 & apparition & 1 & mononucleotide \\
3 & appendicular & 1 & monophyletic \\
3 & archosaur & 1 & monopolist \\
3 & aristocracy & 1 & monotonous \\
3 & arties & 1 & monstrous \\
3 & ascomycete & 1 & moody \\
3 & asterisk & 1 & moonrise \\
3 & astern & 1 & moonscape \\
3 & astray & 1 & moonset \\
3 & astrobiology & 1 & moor \\
3 & astrodome & 1 & moot \\
3 & asylum-seeker & 1 & mora \\
3 & auburn & 1 & morphogenesis \\
3 & aunty & 1 & mortify \\
3 & aurum & 1 & mortis \\
3 & autoimmunity & 1 & motorway \\
3 & autolysis & 1 & mournful \\
3 & automaker & 1 & moustache \\
3 & aversion & 1 & mouthpiece \\
3 & awry & 1 & mouthwash \\
3 & axiom & 1 & mouton \\
3 & bactericide & 1 & muck \\
3 & bacteriologist & 1 & muckraker \\
3 & baffle & 1 & mucoid \\
3 & bafflement & 1 & bandit \\
3 & bale & 1 & mukluk \\
3 & 1 & mulattoes \\
\hline & &
\end{tabular}



3 banknote
3 banyan
3 baptism
3 basolateral
3 bates
3 bathypelagic
3 batt
3 bayside
3 beastly
3 beget
3 benzoic
3 besiege
3 bestow
3 bf
3 bibliotheca
3 bicuspid
3 bicuspids
3 bifocal
3 bingo
3 biphenyls
3 bird
3 birdhouse
3 birdseed
3 birth
3 bisexual
3 bismuth
3 blackberry

1 mulch

1 mull

1 multidimensional

1 multifaceted

1 multilayer

1 multimillion

1 multiplayer

1 multiplex

1 multiscale

1 multistate

1 multitask

1 multitasking

1 multivalent

1 mumble

1 mummy

1 murky

1 musket

1 muss

1 muster

1 mutable

1 myasthenia

1 mycology

1 mycotoxin

1 myelinated

1 myofilament

1 myotonic

1 myrtle 

3 blackjack
3 blackmail
3 blanche
3 blastula
3 blindfold
3 bloodshed
3 boa
3 boatlift
3 bois
3 bolivar
3 bollock
3 bonsai
3 booty
3 borax
3 boredom
3 bottommost
3 botulinum
3 boulevard
3 brachiate
3 brainteaser
3 bravo
3 breakaway
3 breech
3 brevis
3 bridegroom
3 brim
3 bro

1 naively

1 namesake

1 nannie

1 nanostructures

1 nanotechnologists

1 naphthoquinone

1 narcotic

1 nark

1 natal

1 natively

1 natty

1 naughty

1 nauseous

1 nemesis

1 neodymium

1 neo-fascist

1 neoliberalism

1 neomycin

1 neoprene

1 nep

1 net

1 netball

1 netlike

1 neuronal

1 neurophysiology

1 neurosurgeon

1 neuter 

3 brocade
3 broker
3 brusque
3 buckskin
3 buckthorn
3 buff
3 bug
3 bulbous
3 burgh
3 bursa
3 businessperson
3 buttercup
3 cadence
3 caiman
3 calligraphy
3 campgrounds
3 campo
3 candela
3 canvass
3 carabineer
3 caramelizes
3 carbo
3 cardinalfish
3 careen
3 cargo
3 carotene
3 carwash

1 neve

1 newscast

1 newsroom

1 newsworthy

1 nexus

1 nifty

1 nightingale

1 nightjar

1 nimble

1 nimbus

1 nimby

1 nineties

1 ninetieth

1 nine-to-fiver

1 niobium

1 nitrobenzene

1 nitrocellulose

1 nock

1 nonadjacent

1 nonbonding

1 nonce

1 non-deviant

1 nonessential

1 nonfarm

1 nonflammable

1 nonionic

1 nonmagnetic 

3 cash
3 cassava
3 cassette
3 celiac
3 celibate
3 centaur
3 centime
3 centralize
3 cerebrospinal
3 cetacean
3 chance
3 checkbook
3 chemoreceptor
3 chloric
3 chomp
3 chylomicron
3 chylomicrons
3 circumvent
3 cisco
3 clamber
3 clang
3 clank
3 clavicle
3 clearinghouse
3 cleat
3 clinometer
3 coal

1 nonmilitary

1 nonobvious

1 nonorganic

1 nonpresidential

1 nonprofits

1 nonreactive

1 nonrenewal

1 nonresponse

1 nonscientist

1 nonsensical

1 nonspecialized

1 nontaxable

1 nontechnical

1 nonvirulent

1 nonvisible

1 nonwhite

1 nook

1 northbound

1 northernmost

1 notepaper

1 notoriety

1 noxious

1 nub

1 nucleobases

1 nucleoli

1 nucleoside 

3 coca
3 co-chair
3 cochlear
3 cocktail
3 coenzyme
3 coffin
3 cog-wheel
3 columbine
3 comeback
3 come-hither
3 condole
3 conduit
3 constable
3 coo
3 copier
3 coriander
3 cortical
3 cote
3 countenance
3 counterweight
3 coup
3 courier
3 coursework
3 covert
3 crawdad
3 cream
3 cress

1 nude

1 numbersome

1 numeri

1 nunnery

1 oared

1 obfuscate

1 oblivious

1 obnoxious

1 obstreperous

1 oceangoing

1 oceanology

1 ocotillo

1 octane

1 odious

1 oilrig

1 oilseed

1 ollie

1 omelet

1 omniscient

1 onboard

1 onlooker

1 on-looker

1 ono

1 onslaught

1 opal

1 ophthalmologist

1 opulence 

3 croissant
3 crossbow
3 crowbar
3 culminate
3 cup
3 curator
3 curio
3 custard
3 cuttlebone
3 cyclase
3 cymbal
3 cytomegalovirus
3 dab
3 das
3 dateline
3 deb
3 decapods
3 defame
3 defile
3 delocalized
3 depolarize
3 depopulate
3 depute
3 derision
3 desegregate
3 diaphysis
3 diatribe

1 orc

1 ordeal

1 oregano

1 oriole

1 orthopsychiatry

1 orthorhombic

1 osseous

1 ostentation

1 ostium

1 oud

1 ouds

1 ouns

1 out-bluff

1 outboard

1 outbound

1 outcast

1 outdated

1 outdid

1 outdrew

1 outflow

1 outjump

1 outlast

1 outlies

1 outpace

1 outperform

1 outpouring

1 oved 


\begin{tabular}{llll}
3 & difficile & 1 & overactive \\
3 & dilatation & 1 & overarching \\
3 & dinnerware & 1 & overcast \\
3 & disclaimer & 1 & overcharge \\
3 & disclose & 1 & overcoat \\
3 & discontinue & 1 & overcompensate \\
3 & discourse & 1 & overconfident \\
3 & dislodge & 1 & overeaten \\
3 & dismember & 1 & overeater \\
3 & disorganized & 1 & overeats \\
3 & disqualification & 1 & over-embalm \\
3 & dix & 1 & overexposed \\
3 & dog & 1 & overgraze \\
3 & dole & 1 & overgrazed \\
3 & dope & 1 & overhunt \\
3 & doss & 1 & overhyped \\
3 & dote & 1 & overlain \\
3 & downfall & 1 & overmastered \\
3 & downwind & 1 & overpopulate \\
3 & downy & 1 & overproduce \\
3 & dragster & 1 & overrated \\
3 & duet & 1 & overreliance \\
3 & dysfunction & 1 & overridden \\
3 & earthlight & 1 & overseen \\
3 & eavesdrop & 1 & oversimplification \\
3 & eccrine & 1 & oversize \\
3 & ecotourism & 1 & overspent \\
\hline & & \\
\hline & &
\end{tabular}




\begin{tabular}{llll}
3 & eczema & 1 & overstretch \\
3 & eek & 1 & overtop \\
3 & effrontery & 1 & overture \\
3 & eft & 1 & overwork \\
3 & electroencephalogram & 1 & overworked \\
3 & elope & 1 & oviduct \\
3 & emanate & 1 & oviparity \\
3 & emerald & 1 & oxalate \\
3 & emery & 1 & oxalic \\
3 & endnote & 1 & oxidant \\
3 & ennoble & 1 & oxidase \\
3 & ensemble & 1 & oxidoreductase \\
3 & entrench & 1 & oxyacid \\
3 & entrust & 1 & pacifist \\
3 & epicycle & 1 & paddleball \\
3 & equivocate & 1 & page \\
3 & erne & 1 & painstaking \\
3 & escalate & 1 & pajama \\
3 & escort & 1 & palatial \\
3 & escribe & 1 & palaver \\
3 & esophagitis & 1 & paleomagnetism \\
3 & estrus & 1 & palimpsest \\
3 & ethylamine & 1 & palmate \\
3 & eugenol & 1 & evalpably \\
3 & evince & 1 & pamper \\
3 & 1 & panacea \\
& 1 & panicky \\
& & \\
\hline
\end{tabular}



3 exacerbate
3 expatriate
3 expound
3 expulsion
3 extensor
3 extenuate
3 eyewitness
3 facade
3 fakir
3 fanwort
3 farads
3 farmhouse
3 fascia
3 ferrous
3 fetid
3 fetish
3 fide
3 fieldtrip
3 finger
3 fink
3 fireweed
3 fiscal
3 fivefold
3 flaunt
3 flax
3 fleck
3 fledge

1 pantaloons

1 paperboard

1 paperwork

1 papillary

1 papulation

1 paramilitary

1 paramount

1 paranoia

1 parapet

1 paraphernalia

1 paraplegia

1 paraplegics

1 paratrooper

1 parenchyma

1 parkland

1 parley

1 parrotfish

1 parsimony

1 parsons

1 participle

1 partings

1 partridge

1 pasha

1 passerby

1 passible

1 pastoralist

1 patchwork 


\begin{tabular}{llll}
3 & floodway & 1 & pathfinder \\
3 & fluorite & 1 & patria \\
3 & foe & 1 & patsy \\
3 & formalin & 1 & patter \\
3 & formyl & 1 & pavilion \\
3 & forte & 1 & peafowl \\
3 & fourfold & 1 & peaty \\
3 & frankfurter & 1 & pectin \\
3 & freehand & 1 & pectoralis \\
3 & frivolity & 1 & peddle \\
3 & frogfish & 1 & pediatrics \\
3 & gage & 1 & peduncle \\
3 & gallant & 1 & pegmatite \\
3 & gallbladder & 1 & pen \\
3 & gallows & 1 & penance \\
3 & gametocyte & 1 & pendant \\
3 & gantry & 1 & penknife \\
3 & gaping & 1 & penmanship \\
3 & gargoyle & 1 & pentoxide \\
3 & garibaldi & 1 & peptidyl \\
3 & gat & 1 & percale \\
3 & gator & 1 & gerf \\
3 & geophysicist & 1 & gerforin \\
3 & geosynchronous & 1 & gerfunctorily \\
3 & 1 & 1 & peotritonitis \\
3 & 1 & perpend \\
& 1 & pertussis \\
& & \\
\hline
\end{tabular}



3 girth
3 glockenspiel
3 glycerin
3 gnome
3 goad
3 goon
3 gorge
3 gourmet
3 graben
3 gran
3 grandeur
3 graylag
3 greenwood
3 greyhound
3 greyish
3 grotesque
3 gruesome
3 guesstimate
3 gular
3 gun
3 halfpipe
3 handball
3 handprint
3 hangman
3 hark
3 harper
3 haughty

1 peruse

1 perverse

1 petabytes

1 petitioner

1 pettiness

1 phal

1 pharmacopoeia

1 phenol

1 philatelic

1 philologer

1 phony

1 phosphide

1 phosphoenolpyruvate

1 phosphoinositide

1 phosphorescence

1 phosphorescent

1 photodegrade

1 phytochemical

1 pia

1 piezo

1 piezoelectricity

1 pigtail

1 pilothouse

1 pinion

1 pink

1 pinnace

1 piper 

3 haunch
1 piranha
3 headphone
1 piss-up
3 headwater
3 hearken
1 piteous
1 pix
3 heather
1 plait
3 hectometer
1 planarian
3 hematocrit
1 plantings
3 hendecagon
1 plantlet
3 hetero
1 plasmodia
3 hew
1 plasterboard
3 hex
3 hexafluoride
1 playhouse
3 hexose
3 hic
3 hilltop
3 hoax
3 hobbit
3 hoist
3 homeward
3 hominem
3 homocercal
3 horde
3 horoscope
3 horrendous
3 horst
3 hourglass
3 housebreaker
1 playmate
1 plebeian
1 plethora
1 pliable
1 plover
1 plunger
1 pocketbook
1 pogo
1 poignant
1 poinsettia
1 polaroid
1 poliomyelitis
1 polity
1 polliwogs
1 polyacrylamide
1 polycystic 

3 hugger
1 polyether
3 hulk
1 polymorphic
3 hullo
1 polyposis
3 husk
3 hydrocephalus
1 polypropylene
3 hydroid
3 hydroxylase
3 hyperactive
3 hyperlink
3 hypochondriac
1 polyspermy
1 polyvinyl
1 pompom
1 ponderosa
1 poodle
1 poolroom
3 hyrax
1 poon
3 ibis
3 ident
3 immaculate
3 immunotherapy
1 pope-burning
3 implore
3 impound
3 inadequately
3 inanimate
3 incarnation
3 incest
3 incompressible
3 incorrigible
1 popup
1 porphyry
1 porta
1 portage
1 portly
1 portraitures
1 postcolonial
1 postman
1 postmortem
1 postorbital
1 postpartum
3 indebted
3 indenture
3 indigent
3 indium
1 postsecondary
1 postsynaptic
1 postwar
1 potency 

3 indomitable
3 inexplicable
3 inflatable
3 inflow
3 innervate
3 innumerable
3 inquisitive
3 intercalate
3 intercellular
3 interconvert
3 intercostal
3 interlocking
3 interplanetary
3 intravenously
3 involuntarily
3 irradiance
3 irradiate
3 irradiation
3 isoleucine
3 isopod
3 isthmus
3 jaguar
3 jeep
3 jetliner
3 jimsonweed
3 jumpsuit
3 jute

1 potentate

1 potentiometer

1 potholder

1 pothole

1 potion

1 potpourri

1 pout

1 praseodymium

1 precancerous

1 precipitously

1 preclude

1 precocious

1 precolonial

1 predefined

1 preeminent

1 preen

1 preimplantation

1 premarital

1 premed

1 premenopausal

1 premiere

1 prepetition

1 preponderance

1 prepress

1 preschooler

1 prescience

1 presentative 


\begin{tabular}{llll}
3 & kale & 1 & presentiment \\
3 & kidnap & 1 & preset \\
3 & killdeer & 1 & preteen \\
3 & kiloliter & 1 & pretrial \\
3 & kitty & 1 & pretzel \\
3 & knobby & 1 & pricey \\
3 & komodo & 1 & prick \\
3 & kylie & 1 & primeval \\
3 & lace & 1 & primo \\
3 & lacrosse & 1 & procrastinator \\
3 & lam & 1 & prodigal \\
3 & lambda & 1 & profanity \\
3 & landfall & 1 & profligate \\
3 & lard & 1 & prognostic \\
3 & leafcutter & 1 & pro-imperialist \\
3 & leafhopper & 1 & promo \\
3 & leek & 1 & promontory \\
3 & lei & 1 & promulgate \\
3 & leprosy & 1 & pronghorns \\
3 & lev & 1 & proofreads \\
3 & leveling & 1 & propionate \\
3 & lifeform & 1 & propitious \\
3 & lifeless & 1 & propter \\
3 & lighten & 1 & propylene \\
3 & lignite & 1 & proselytize \\
3 & linden & 1 & prosy \\
3 & lionfish & 1 & prothorax \\
& & \\
\hline
\end{tabular}




\begin{tabular}{llll}
3 & lipopolysaccharide & 1 & provirus \\
3 & lipstick & 1 & proxy \\
3 & listeria & 1 & psychotherapist \\
3 & lithographic & 1 & psyllid \\
3 & lithography & 1 & pubertal \\
3 & loan & 1 & pudgy \\
3 & lodestone & 1 & pug \\
3 & loge & 1 & pummeled \\
3 & longevity & 1 & punchline \\
3 & longwave & 1 & punitive \\
3 & lopsided & 1 & purplish \\
3 & lotion & 1 & pushdown \\
3 & lull & 1 & putrescent \\
3 & lulu & 1 & putrescine \\
3 & lumberjack & 1 & puzzlement \\
3 & macaroni & 1 & pyelonephritis \\
3 & madly & 1 & pyogenes \\
3 & madman & 1 & pyridoxine \\
3 & magistrate & 1 & pyriformis \\
3 & magnolia & 1 & pyro \\
3 & mailbox & 1 & qi \\
3 & mamma & 1 & quadrangle \\
3 & mango & 1 & quadrillions \\
3 & manic & 1 & quadrillionth \\
3 & mannequin & 1 & quagmire \\
3 & maracas & 1 & quasar \\
3 & marginalize & 1 & quash \\
& & \\
\hline
\end{tabular}




\begin{tabular}{llll}
3 & marmot & 1 & queer \\
3 & marque & 1 & quell \\
3 & mart & 1 & quiche \\
3 & massacre & 1 & quintillions \\
3 & massage & 1 & quintillionth \\
3 & materialistic & 1 & quizzical \\
3 & matte & 1 & quoll \\
3 & mattress & 1 & qv \\
3 & maximal & 1 & radiological \\
3 & medina & 1 & radiology \\
3 & melatonin & 1 & raff \\
3 & meltdowns & 1 & rag \\
3 & membranous & 1 & raingear \\
3 & memorandum & 1 & raj \\
3 & meow & 1 & rami \\
3 & mercantile & 1 & rampart \\
3 & metacarpal & 1 & ramshackle \\
3 & metalworker & 1 & rancid \\
3 & metameres & 1 & rangeland \\
3 & mete & 1 & rangy \\
3 & meth & 1 & ransom \\
3 & microgravity & 1 & rant \\
3 & microphotograph & 1 & ranunculus \\
3 & microsatellite & 1 & rapist \\
3 & microsatellites & 1 & rascal \\
3 & midsection & 1 & rasp \\
3 & midterm & 1 & raster \\
& & \\
\hline
\end{tabular}




$$
\begin{array}{ll}
3 & \text { mineable } \\
3 & \text { miniscule } \\
3 & \text { mirror } \\
3 & \text { miserably } \\
3 & \text { misrepresent } \\
3 & \text { mock } \\
3 & \text { molarities } \\
3 & \text { monotonic } \\
3 & \text { morbidity } \\
3 & \text { morel } \\
3 & \text { morphemic } \\
3 & \text { mosasaur } \\
3 & \text { motto } \\
3 & \text { mug-shot } \\
3 & \text { mullet } \\
3 & \text { multicolored } \\
3 & \text { multinational } \\
3 & \text { multistage } \\
3 & \text { multistep } \\
3 & \text { mummified } \\
3 & \text { mutagenic } \\
3 & \text { mutilate } \\
3 & \text { nacre } \\
3 & \text { nanocrystals } \\
3 & \text { nanoparticles } \\
3 & \text { nay } \\
3 & \text { neap } \\
\hline
\end{array}
$$

1 rave

1 rawhide

1 rayon

1 readme

1 reallocate

1 reallots

1 reappearance

1 reapply

1 reappoint

1 reapportion

1 rearms

1 reassign

1 rebate

1 reboot

1 recaps

1 recapture

1 re-christen

1 reclusive

1 recollect

1 recompense

1 reconfigure

1 re-configure

1 reconnaissance

1 reconnection

1 reconstitute

1 reconversion

1 recrystallizing 


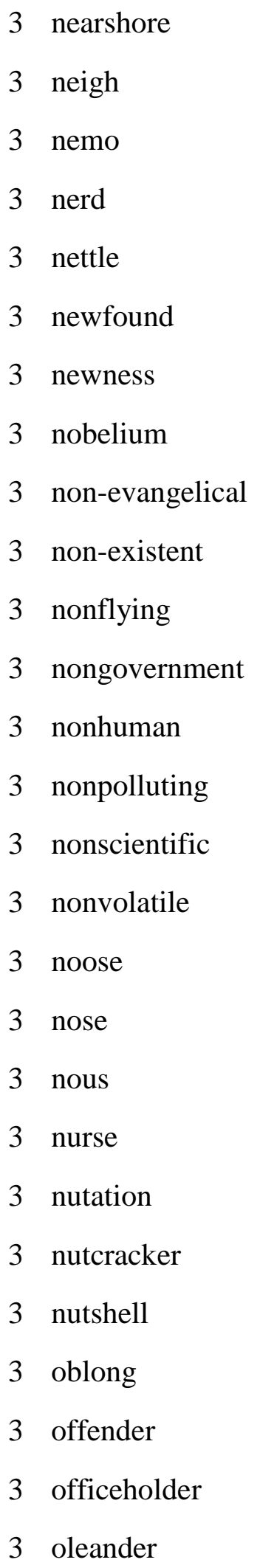

1 rectitude

1 rector

1 redbelly

1 redbreast

1 redcoat

1 redden

1 redeliver

1 redevelop

1 redraft

1 redux

1 reelected

1 reenactment

1 reentry

1 reexam

1 refi

1 refillable

1 refiner

1 reformation

1 refrozen

1 regale

1 regather

1 regiment

1 registrant

1 registry

1 rehash

1 reheat

1 reinterpret 


$\begin{array}{llll}3 & \text { oligonucleotide } & 1 & \text { reinterpretation } \\ 3 & \text { ology } & 1 & \text { reintroduction } \\ 3 & \text { oncogenesis } & 1 & \text { reinvent } \\ 3 & \text { onstage } & 1 & \text { reinvestment } \\ 3 & \text { oops } & 1 & \text { re-kindle } \\ 3 & \text { opt } & 1 & \text { relabeled } \\ 3 & \text { organdy } & 1 & \text { relabeling } \\ 3 & \text { ornate } & 1 & \text { relapse } \\ 3 & \text { orthoclase } & 1 & \text { relaxant } \\ 3 & \text { osteoid } & 1 & \text { relight } \\ 3 & \text { osteon } & 1 & \text { reline } \\ 3 & \text { otherworldly } & 1 & \text { relish } \\ 3 & \text { outback } & 1 & \text { remand } \\ 3 & \text { outburst } & 1 & \text { remarriage } \\ 3 & \text { outfield } & 1 & \text { remiss } \\ 3 & \text { outing } & 1 & \text { remix } \\ 3 & \text { outpost } & 1 & \text { remodel } \\ 3 & \text { overage } & 1 & \text { rendezvous } \\ 3 & \text { overbearing } & 1 & \text { renin } \\ 3 & \text { overcrowd } & 1 & \text { renter } \\ 3 & \text { overcrowded } & 1 & \text { reparation } \\ 3 & \text { overjoyed } & 1 & \text { repayment } \\ 3 & \text { overproduction } & 1 & \text { repercussion } \\ 3 & \text { overrun } & 1 & \text { repertory } \\ 3 & \text { overwinter } & 1 & \text { repine } \\ 3 & \text { ovoviviparous } & 1 & \text { repo } \\ 3 & \text { owlet } & 1 & \text { reprogram } \\ & & \end{array}$



3 oxaloacetate
3 oxygenase
3 painkiller
3 pajamas
3 papaya
3 parchment-seller
3 parishioner
3 pastry
3 paunch
3 peaceable
3 peacemaker
3 peal
3 pediatrician
3 penalize
3 pen-pal
3 penumbral
3 peptic
3 peptidase
3 perchlorate
3 pericardium
3 peril
3 perpetrator
3 petrochemical
3 petty
3 phalange
3 pheasant
3 photocopier

1 requited

1 rerun

1 rese

1 resold

1 restroom

1 resupplies

1 resurface

1 resuscitation

1 resynthesized

1 rete

1 retinue

1 retrace

1 retrospect

1 reuptake

1 revel

1 reverberate

1 reverberation

1 revile

1 revue

1 rhapsody

1 rhinestone

1 rhinoceroses

1 rhizobia

1 rhodium

1 rhodopsin

1 rhombohedra

1 rhombohedral 


\begin{tabular}{|c|c|c|c|}
\hline 3 & photojournalist & & ricing \\
\hline 3 & photosystems & 1 & rickettsia \\
\hline 3 & phototrophic & 1 & rig \\
\hline 3 & picket & 1 & ringtones \\
\hline 3 & piggyback & 1 & riverboat \\
\hline 3 & pillow & 1 & riverhead \\
\hline 3 & pillowcase & 1 & rly \\
\hline 3 & pinecone & 1 & roach \\
\hline 3 & pinnacle & 1 & roadblock \\
\hline 3 & pinnately & 1 & roadmap \\
\hline 3 & pinto & 1 & robe \\
\hline 3 & pip-pip & 1 & roc \\
\hline 3 & pit & 1 & rodeo \\
\hline 3 & placid & 1 & roentgenogram \\
\hline 3 & planetoid & 1 & rogue \\
\hline 3 & plantlike & 1 & roil \\
\hline 3 & plasmolysis & 1 & romp \\
\hline 3 & plat & 1 & roomers \\
\hline 3 & platonic & 1 & roomy \\
\hline 3 & pleat & 1 & roro \\
\hline 3 & plunder & 1 & rouge \\
\hline 3 & pock & 1 & roulette \\
\hline 3 & polka & 1 & rowboat \\
\hline 3 & polystyrene & 1 & rowdy \\
\hline 3 & nolvuunsaturated & 1 & ruefully \\
\hline 3 & poo-poo & & ruffle \\
\hline 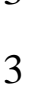 & porosity & 1 & ruination \\
\hline
\end{tabular}



3 port
3 porthole
3 posit
3 post-audit
3 postponement
3 potash
3 power-loom
3 precut
3 predetermined
3 prehensile
3 presynaptic
3 pretense
3 prima
3 primase
3 primordial
3 probiotic
3 procure
3 prodigious
3 prof
3 promethium
3 proponent
3 prosimian
3 prostrate
3 protocell
3 prune
3 pummel
3 pungent

1 rulebook

1 runaround

1 ruthenium

1 ruthlessly

1 sabal

1 sachem

1 sacral

1 sadistic

1 safflowers

1 saffron

1 sago

1 salability

1 salient

1 saloonkeepers

1 samara

1 sandaled

1 sandbag

1 sanddabs

1 sanders

1 sandlot

1 sandstorm

1 sans

1 saponification

1 saprobic

1 sassafras

1 saturnine

1 saucepan 


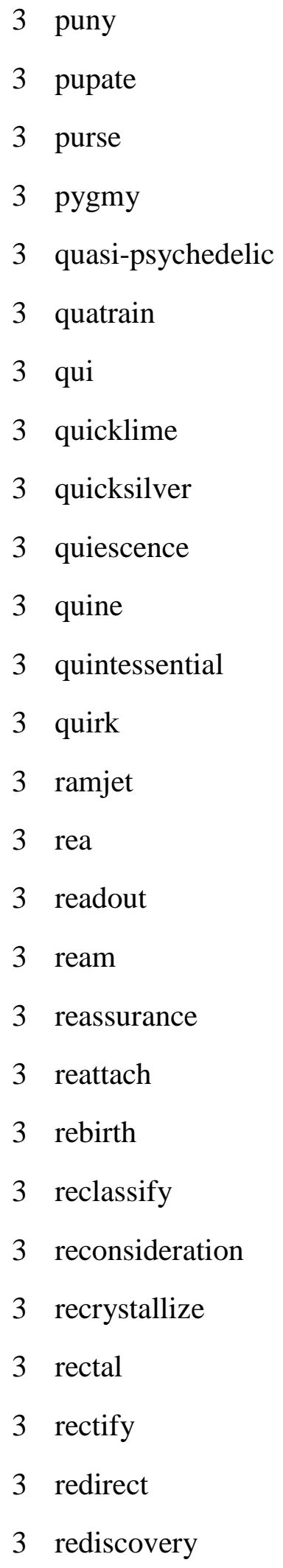

1 sawgrass

1 sawn

1 scalawags

1 scalloped

1 scam

1 scandium

1 scavenging

1 schadenfreude

1 schemer

1 schism

1 schoolbook

1 schoolfellow

1 schwa

1 scoff

1 scorpionfish

$1 \mathrm{scot}$

1 scourge

1 scowl

1 scram

1 scrapbook

1 scrapbooking

1 scrapie

1 scrapyard

1 scree

1 screenwriter

1 scrimmage

1 scrip 

3 redshifted
3 reductase
3 reformulate
3 refreshment
3 rei
3 reinstate
3 reissue
3 re-iterate
3 relic
3 relinquish
3 remonstrate
3 remora
3 remorse
3 rennin
3 renounce
3 mob
3 repaint
3 repopulate
3 repression
3 reprieve
3 reprocessing
3 reputable
3 resilience
3 resurgence
3 retaliate
3 retic
3 retract

1 scud

1 scull

1 scullery

1 scurvy

1 scuttle

1 scythe

1 seaborne

1 sealant

1 sears

1 seasick

1 seaward

1 sedative

1 self-contemplation

1 self-efficacy

1 self-immolation

1 selfishly

1 selfless

1 semiannually

1 semiconducting

1 semifixed

1 semiliquid

1 semilunar

1 semiprofessional

1 semisolid

1 semitrailer

1 semitransparent

1 sentry 


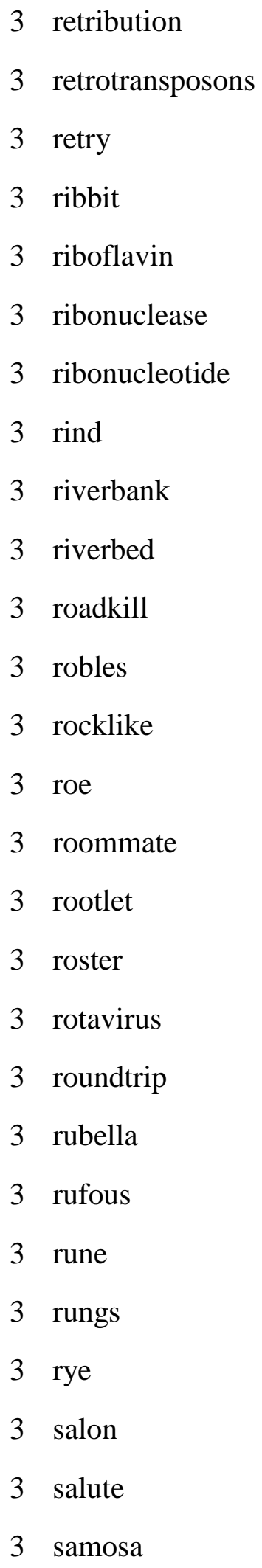

1 sepsis

1 sequel

1 serf

1 serfdom

1 serial

1 servant-maid

1 sextupled

$1 \mathrm{sg}$

1 shabbiness

1 shag

1 shamefacedly

1 shawl

1 sheen

1 sheepherding

1 sheetrock

1 shenanigans

1 shih

1 shipbuilder

1 shire

1 shirtwaist

1 shish

1 shoat

1 shoddy

1 shoe

1 shopkeeper

1 shorthorn

1 shotgun 


$\begin{array}{ll}3 & \text { sapphire } \\ 3 & \text { sarcolemma } \\ 3 & \text { satire } \\ 3 & \text { sawdust } \\ 3 & \text { scaly } \\ 3 & \text { scamper } \\ 3 & \text { scape } \\ 3 & \text { sceptic } \\ 3 & \text { schistosomiasis } \\ 3 & \text { schoolgirl } \\ 3 & \text { schoolwork } \\ 3 & \text { schoolyard } \\ 3 & \text { shipyard } \\ 3 & \text { sclerenchyma } \\ 3 & \text { scrawny } \\ 3 & \text { shiitake } \\ 3 & \text { scrimp } \\ 3 & \text { sear } \\ 3 & \text { searchlight } \\ 3 & \text { seaway } \\ 3 & \text { self-appraisal } \\ 3 & \text { self-delusion } \\ 3 & \\ 3 & \text { shadiff } \\ 3 & \\ 3 & \\ 3 & \\ 3 & \end{array}$

1 showdown

1 showroom

1 shrimplike

1 shutdown

$1 \mathrm{sib}$

1 sibilance

1 side-chapel

1 sideline

1 sideshow

1 sidestroke

1 sidetrack

1 sidle

1 sightseeing

1 signage

1 signatory

1 silage

1 silverback

1 sinew

1 sitar

1 sitter

1 sixtieth

1 sizzle

1 skiff

1 skimobile

1 skincare

1 skittle

1 skulk 


\begin{tabular}{|c|c|}
\hline & shrapnel \\
\hline & sidestep \\
\hline & signer \\
\hline & silhouette \\
\hline & silicone \\
\hline & silo \\
\hline & silverware \\
\hline & simian \\
\hline & sinewave \\
\hline 3 & singsong \\
\hline 3 & sinoatrial \\
\hline 3 & sinuses \\
\hline 3 & sinusoid \\
\hline 3 & situ \\
\hline 3 & skirmish \\
\hline 3 & slack \\
\hline 3 & slaughterhouse \\
\hline 3 & sleek \\
\hline 3 & slouch \\
\hline 3 & slue \\
\hline 3 & slum \\
\hline 3 & sly \\
\hline 3 & smock \\
\hline 3 & snowboarder \\
\hline 3 & snow-plough \\
\hline 3 & sober \\
\hline & sockeye \\
\hline
\end{tabular}

1 skullcap

1 skyward

1 slalom

1 slander

1 slaveholding

1 slaws

1 sleigh

1 slingshot

1 slog

1 slough

1 slovenly

1 sluice

1 slurp

1 slushes

1 slushy

1 slyly

1 smatter

1 smirk

1 smolder

1 smuggle

1 snarl-up

1 sneer

1 snide

1 snip

1 snobbery

1 snowman

1 softeners 


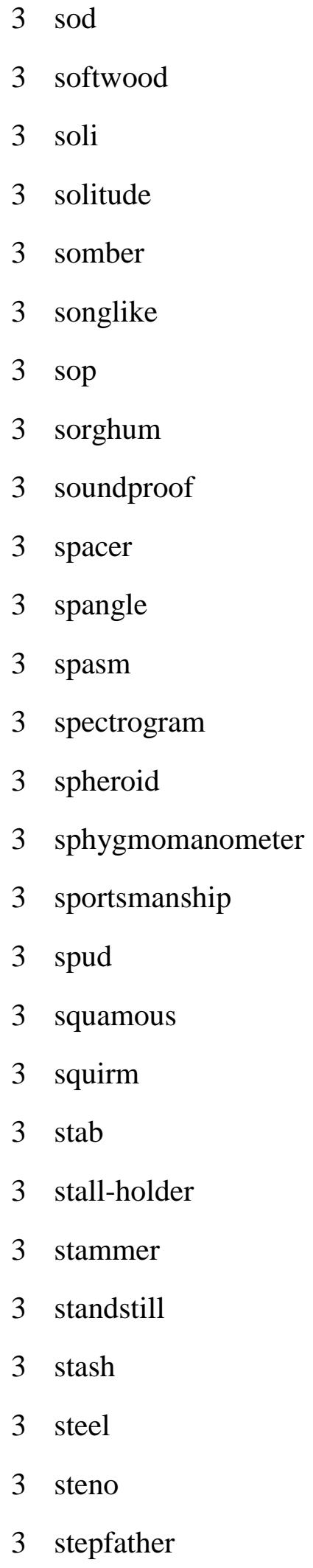

1 sola

1 solder

1 solicitude

1 soliloquy

1 sombrero

1 someway

1 sonny

1 sorbet

1 sordid

1 southerly

1 sou'wester

1 spacious

1 spank

1 spasmodically

1 spasticity

1 spate

1 spatula

1 spay

1 spearfishing

1 spearmint

1 speckled

1 speedboat

1 spermatozoon

1 sphalerite

1 spidery

1 spina

1 splatter 

3 stim
3 stitch-up
3 stocking-filler
3 stocking-top
3 storeowner
3 strait
3 s-transferase
3 stratocumulus
3 streetcars
3 strobilation
3 subcompact
3 subshell
3 substantive
3 subtly
3 subversive
3 succinate
3 sulfite
3 sump
3 sumptuous
3 sunbeam
3 sunburst
3 sundew
3 superball
3 superbugs
3 supereon
3 superficially
3 superhuman

1 spliceosome

1 splintery

1 splotch

1 spokeswoman

1 sprig

1 springboard

1 spunky

1 spurn

1 sputter

1 sputum

1 spymasters

1 squabble

1 squadron

1 squalid

1 squalor

1 squander

1 squawk

1 stagecoach

1 stairwell

1 stalemate

1 stallion

1 stalwart

1 standout

1 staphylococcal

1 startup

1 statuary

1 staunch 


\begin{tabular}{llll}
3 & supernovae & 1 & stave \\
3 & supplant & 1 & steamer \\
3 & surcingle & 1 & stearic \\
3 & swat & 1 & steelmaking \\
3 & sweatshirt & 1 & steelworker \\
3 & swerve & 1 & stellateing \\
3 & swimsuit & 1 & stent \\
3 & symphony & 1 & stepchildren \\
3 & sync & 1 & stepwise \\
3 & tad & 1 & stereoscopic \\
3 & tagmata & 1 & stereotyping \\
3 & tail-skid & 1 & steward \\
3 & taint & 1 & stickler \\
3 & talkie & 1 & stile \\
3 & taut & 1 & stint \\
3 & tautology & 1 & stockade \\
3 & technetium & 1 & stockroom \\
3 & telepathy & 1 & stoles \\
3 & tempeh & 1 & stolid \\
3 & tenacious & 1 & stonebreaker \\
3 & tenant & 1 & stonefish \\
3 & tenet & 1 & stoneflies \\
3 & tether & 1 & storied \\
3 & tetherball & 1 & storyboard \\
3 & tetrachloride & 1 & storyline \\
3 & textbox & 1 & stovepipe \\
3 & thaliana & 1 & stow \\
\hline & & \\
\hline
\end{tabular}



3 thallus
1 stowaway
3 thatch
1 strass
3 thermohaline
1 streptomycin
3 thicket
1 strongbox
3 three-putt
3 throng
3 thru
3 thunderbolt
3 thuringiensis
1 stronghold
1 stupider
1 sturgeon
1 styli
3 tian
3 tice
3 tightrope
3 tillage
3 timetable
3 tine
3 tingle
3 tint
3 tombstone
3 tong
3 torch
3 toucan
3 tow
3 townspeople
3 tradesman
3 trance
3 transfix
3 trek
1 suave
1 subbituminous
1 subcompacts
1 subcontinents
1 subcontract
1 subgenre
1 subhead
1 maxims
1 submetallic
1 suborders
1 sub-schema
1 subscripted
1 subsection
1 subservience
1 subsonic
1 substantia
1 subsume
1 subtend
1 subtests 


\begin{tabular}{llll}
3 & trichinosis & 1 & subtlety \\
3 & trifle & 1 & subvention \\
3 & trilogy & 1 & suchlike \\
3 & triode & 1 & suit \\
3 & trioxide & 1 & suitor \\
3 & trisphosphate & 1 & sumac \\
3 & trombone & 1 & sunbelt \\
3 & tsar & 1 & sunbird \\
3 & tuition & 1 & sunder \\
3 & turpentine & 1 & sunroof \\
3 & tympanum & 1 & sunup \\
3 & typhoid & 1 & superbug \\
3 & typography & 1 & supercapacitor \\
3 & uncontrollable & 1 & supercell \\
3 & underscore & 1 & superclass \\
3 & underway & 1 & supercool \\
3 & underwood & 1 & superdeep \\
3 & unwieldy & 1 & ego \\
3 & upholstery & 1 & superjumbo \\
3 & upland & 1 & supernatant \\
3 & usher & 1 & supersaturation \\
3 & vantage & 1 & supersonic \\
3 & vat & 1 & supinate \\
3 & velocipede & 1 & surly \\
3 & velum & 1 & surmise \\
3 & vent & 1 & surreptitiously \\
3 & ventriloquist & 1 & suture \\
& & \\
\hline
\end{tabular}




\begin{tabular}{|c|c|}
\hline & venue \\
\hline & verbatim \\
\hline & veronica \\
\hline & vert \\
\hline & viceroy \\
\hline & vid \\
\hline 3 & villain \\
\hline 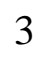 & vindicate \\
\hline & vintage \\
\hline 3 & viridian \\
\hline 3 & visa \\
\hline 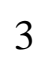 & vise \\
\hline 3 & vocation \\
\hline 3 & volley \\
\hline 3 & vulcanization \\
\hline 3 & wade \\
\hline 3 & waistband \\
\hline 3 & wan \\
\hline 3 & wat \\
\hline 3 & waterwheel \\
\hline 3 & weakling \\
\hline 3 & weal \\
\hline 3 & weatherman \\
\hline 3 & whack \\
\hline 3 & whim \\
\hline & whine \\
\hline & whipworm \\
\hline
\end{tabular}

1 suzerainty

1 swab

1 swallowtail

1 swami

1 swatch

1 swath

1 sweepstake

1 swindler

1 switchman

1 swordsman

1 syllabus

1 syncopated

1 syndicate

1 tacky

1 tactile

1 tai

1 tailfin

1 taillights

1 tallow

1 tam

1 tambura

1 tammy

1 tamp

1 tamper

1 tantalize

1 tantrum

1 tapa 


\begin{tabular}{llll}
3 & whit & 1 & tapioca \\
3 & whittle & 1 & tarmac \\
3 & whiz & 1 & tarn \\
3 & whopping & 1 & tavern \\
3 & willie & 1 & taws \\
3 & windblown & 1 & taxman \\
3 & windfarm & 1 & teacup \\
3 & windpipe & 1 & teapot \\
3 & wizened & 1 & teat \\
3 & wondrous & 1 & telemedicine \\
3 & woodpecker & 1 & teleology \\
3 & workday & 1 & tenement \\
3 & wretch & 1 & tenfold \\
3 & yam & 1 & tenor \\
3 & yearling & 1 & tenuous \\
3 & yum & 1 & terrarium \\
3 & zap & 1 & terrier \\
3 & zoroastrian & 1 & tesseract \\
3 & fruit-bat & 1 & tetragonal \\
3 & thank-offering & 1 & thalidomide \\
3 & railway-wagon & 1 & thallium \\
2 & abacus & 1 & thecae \\
2 & abase & 1 & thein \\
2 & ablation & 1 & thiamin \\
2 & abrogate & 1 & thiamine \\
2 & abut & 1 & thickset \\
2 & accede & 1 & thimble \\
& & \\
\hline
\end{tabular}




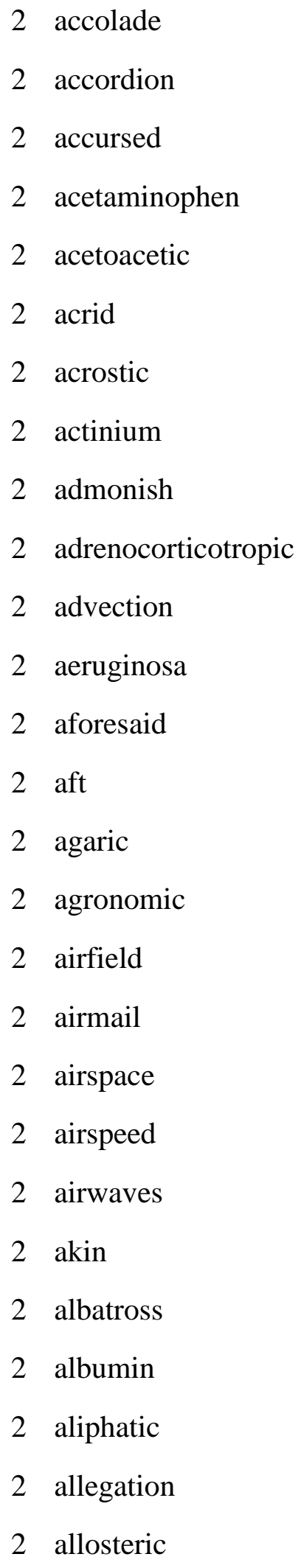

1 thistle

1 thither

1 thong

1 thorp

1 threefold

1 thrift

1 thromboplastin

1 thrombosis

1 thwart

1 thyroxin

1 thyself

1 tier

1 tiff

1 tiller

1 timberland

1 timeliness

1 tinea

1 tined

1 tingly

1 tinkle

1 tipis

1 tithe

1 titian

1 tocopherol

$1 \operatorname{tog}$

1 toggle

1 toile 
2 alphonso

2 amoxicillin

2 amphitheater

2 anarchy

2 android

2 anew

2 angiogenesis

2 antibaryons

2 anticonvulsant

2 antimalarial

2 antiporter

2 anyplace

2 apache

2 aphasic

2 aplasia

2 apocryphal

2 apostle

2 apperception

2 appraise

2 aptitude

2 aquamarine

2 archaebacterial

2 archbishop

2 archery

2 areal

2 areole

2 argentum
1 tonto

1 topo

1 tori

1 torpedo

1 tort

1 totipotent

1 tourniquet

1 towboats

1 towhees

1 trabecular

1 transglutaminase

1 transhumance

1 transliterate

1 trashcan

1 travers

1 treble

1 tree-creeper

1 treetop

1 trespass

1 triangulate

1 tribespeople

1 tricarboxylic

1 trichloroethylene

1 triclinic

1 tricolored

1 triiodothyronine

1 trike 
2 aria

2 arteriosclerosis

2 artichoke

2 articulation

2 ascariasis

2 astrocyte

2 astute

2 atlatl

2 atman

2 atoll

2 atrocity

2 attest

2 audit

2 audition

2 auld

2 auspices

2 autocrat

2 autocratic

2 autoinfection

2 autopsy

2 avow

2 awash

2 azalea

2 baccalaureate

2 backcountry

2 backfire

2 backflow
1 tringle

1 trinitrotoluene

1 trinket

1 trinucleotide

1 triplex

1 triplicate

1 triploblastic

1 tripod

1 triticale

1 trivet

1 trochee

1 troubleshoot

1 trouble-shooter

1 truce

1 trump

1 tuberosity

1 tumbleweeds

1 tunic

1 turbidity

1 turbo-alternator

1 turbofan

1 turducken

1 tut

1 twain

1 tweet

1 twill

1 twine 

2 backseat
2 backside
2 backstage
2 bacteriorhodopsin
2 bailor
2 baleful
2 balk
2 ballerina
2 ballistic
2 balsam
2 bandana
2 bane
2 bantam
2 banzai
2 barbershop
2 barleycorn
2 barney
2 baroque
2 barrio
2 baseboard
2 basketful
2 bastille
2 bathyal
2 bawdy
2 bazaar
2 beadle
2 beany

1 unbridled

1 underdog

1 undergrad

1 underprivileged

1 underwear

1 undying

1 unheralded

1 unicorn

1 unilateral

1 unis

1 unkempt

1 unpalatable

1 unpasteurized

1 unperturbed

1 unruly

1 unstrung

1 unsung

1 upbraid

1 upbringing

1 upkeep

1 upperclassmen

1 upriver

1 uproar

1 upscale

1 upturn

1 urate

1 uric 

2 bedlam
2 beehive
2 befit
2 belfry
2 belittle
2 belle
2 beluga
2 bequeath
2 berkelium
2 betel
2 betoken
2 bib
2 bicker
2 biconcave
2 bicultural
2 bier
2 bine
2 bioscience
2 biotechnologists
2 bipyramid
2 birdie
2 birdlife
2 birdsong
2 bireme
2 birthdate
2 bitterroot
2 bittersweet

1 utmost

1 utopian

1 valent

1 vanillin

1 vanquish

1 varlet

1 vasculature

1 vaudeville

1 veer

1 vehemence

1 venae

1 venality

1 veneration

1 vengeance

1 vengeful

1 verbiage

1 vernacular

1 vestibular

1 vex

1 vey

1 viand

1 vicissitude

1 victual

1 villa

1 vineyard

1 visage

1 vison 
2 biuret

2 blackhead

2 blackish

2 blaspheme

2 blasphemy

2 blithe

2 bloodedness

2 bloodhound

2 bloodletting

2 bloodthirsty

2 blotch

2 blowdown

2 blowhole

2 blowout

2 bluestone

2 bluffs

2 boardinghouse

2 boardwalk

2 bobsled

2 bobtail

2 bodybuilder

2 bog

2 boggle

2 bolus

2 bona

2 bondholder

2 bong
1 vita

1 vitriol

1 vodka

1 voluminous

1 wallow

1 wand

1 warden

1 warlike

1 warp

1 washi

1 wassail

1 watchman

1 watercolor

1 watercourse

1 waterfront

1 waterhole

1 waterpower

1 weathercock

1 webmaster

1 weevil

1 wellhead

1 wend

1 wharf

1 whimsical

1 whippersnapper

1 whirlwind

1 whirr 

2 bongo
2 bonk
2 boob
2 bookkeeping
2 bookseller
2 bookshelves
2 borer
2 bosom
2 bourgeois
2 bourgeoisie
2 bouzouki
2 boxy
2 brahma
2 brainer
2 brat
2 brawn
2 bray
2 breadbasket
2 breastbone
2 brickyard
2 bridge
2 brig
2 brindle
2 brio
2 bristlecone
2 bristletails
2 bronzy

1 whitefly

1 whiteout

1 whitetip

1 whizzbang

1 whoa

1 whomever

1 wiener

1 wigwam

1 wildland

1 wile

1 wily

1 wince

1 windfall

1 windowpane

1 windscreen-wiper

1 windshield

1 windsurfer

1 windup

1 wireframe

1 wishbone

1 wizard

1 woo

1 woodcut

1 woodwind

1 wordplay

1 workbench

1 workhorse 


\begin{tabular}{ll}
2 & broomrape \\
2 & bubo \\
2 & bucker \\
2 & bulbourethral \\
2 & bunkhouse \\
2 & burgeoning \\
2 & burgundy \\
2 & bursa \\
2 & businesspeople \\
2 & butadiene \\
2 & buttermilk \\
2 & bygone \\
2 & byway \\
2 & cacao \\
2 & cackle \\
2 & caeca \\
2 & caecum \\
2 & calabash \\
2 & calcified \\
2 & calicle \\
2 & californium \\
2 & callas \\
2 & callosum \\
2 & callus \\
2 & candlestick \\
2 & canebrake \\
2 & canid \\
\hline
\end{tabular}

1 workmanship

1 workshare

1 worktop

1 workweek

1 world-beater

1 wreath

1 wrench

1 wristwatch

1 writhe

1 xenon

1 xylophone

1 xylose

1 yak

1 yawn

1 yean

1 yearn

1 yellowhammer

1 yew

1 yip

1 yon

1 yonder

1 yuck

1 yurt

1 zag

1 zenial

1 zeppelin

1 zines 
2 cantaloupe

2 capitulate
1 zoonosis

1 super-ego 


\section{K-12 Academic Word List}

The Academic Word List, displayed in Table 19, has 461 lemmas and is divided into two sub-lists of higher and lower frequency words. With regard to the developing of academic and STEM-related words, I took a semantic perspective toward word inclusion in the lists (Flowerdew, 2004). In developing the academic list, words that are common among three content areas out of the four (math, science, social studies, and language arts) are included on the list.

Table 19. K-12 Academic Word List.

\begin{tabular}{ll}
\hline Higher Freq. & Lower Freq. \\
\hline area & converse \\
chapter & convince \\
data & exclude \\
factor & exclusive \\
vary & finite \\
function & infinite \\
volume & mutual \\
proportion & community \\
ratio & register \\
coordinate & valid \\
evaluate & revolution \\
formula & credit \\
formulate & revise \\
negate & context \\
negative & reside \\
& \\
\hline
\end{tabular}




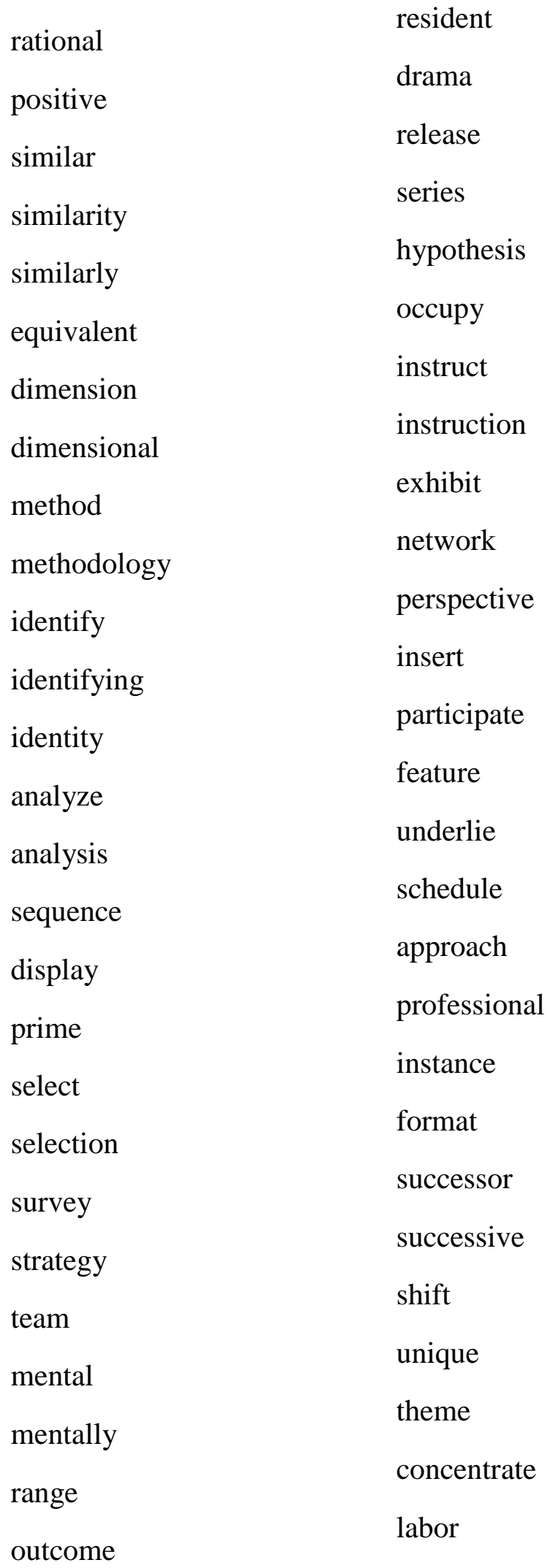




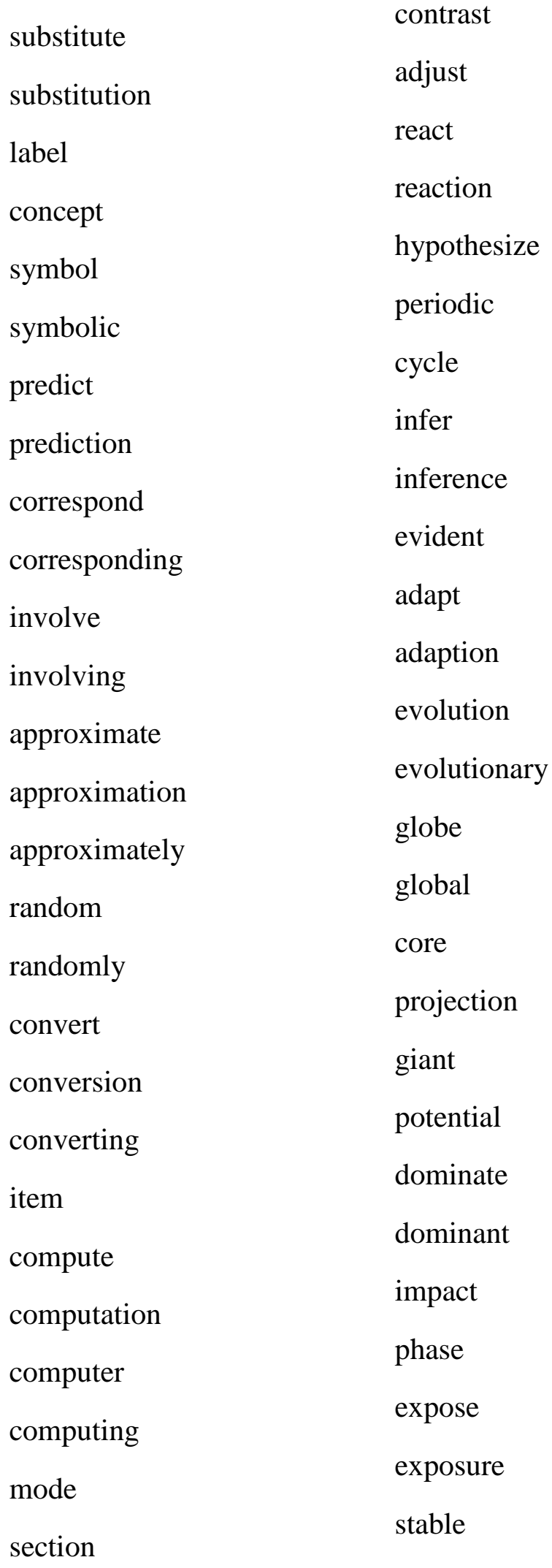




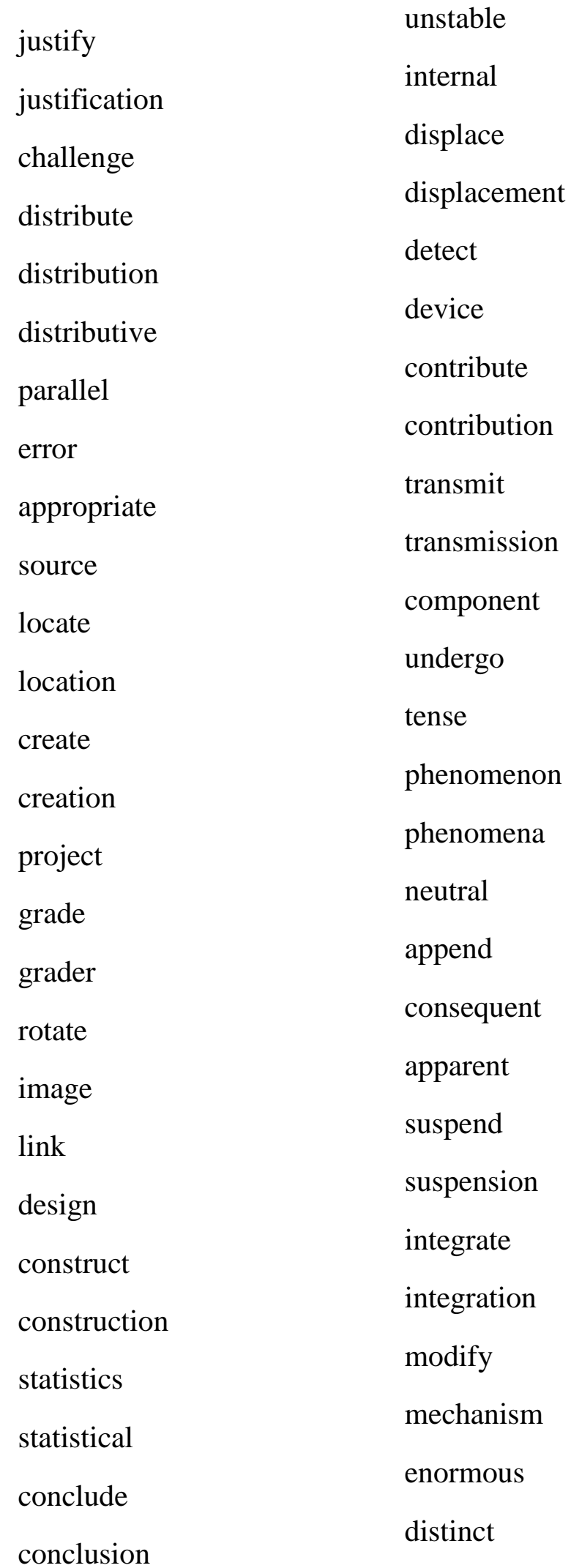




\begin{tabular}{|c|c|}
\hline odd & regulate \\
\hline & derive \\
\hline define & adjustment \\
\hline definition & rigid \\
\hline undefined & dispose \\
\hline indicate & disposal \\
\hline constant & collapse \\
\hline plus & trigger \\
\hline transform & parameter \\
\hline transformation & virtual \\
\hline output & issue \\
\hline region & incline \\
\hline investigate & prior \\
\hline investigation & dynamic \\
\hline occur & highlight \\
\hline goal & passive \\
\hline interval & manipulate \\
\hline purchase & decade \\
\hline adult & acquire \\
\hline process & acquisition \\
\hline compound & accumulate \\
\hline respond & margin \\
\hline response & recover \\
\hline complement & modifier \\
\hline complementary & draft \\
\hline chart & tension \\
\hline domain & quote \\
\hline
\end{tabular}




\begin{tabular}{|c|c|}
\hline previous & quotation \\
\hline target & tradition \\
\hline & traditional \\
\hline period & assignment \\
\hline illustrate & fragment \\
\hline illustration & imagery \\
\hline supplement & standardize \\
\hline & thesis \\
\hline annual & version \\
\hline objective & aspect \\
\hline spreadsheet & civil \\
\hline theory & perception \\
\hline theoretical & intelligence \\
\hline theorize & legal \\
\hline maximize & illegal \\
\hline maximum & confer \\
\hline summary & conference \\
\hline final & convene \\
\hline job & convention \\
\hline require & attitude \\
\hline affect & automate \\
\hline bias & automatic \\
\hline unbiased & abandon \\
\hline tape & submit \\
\hline radical & submission \\
\hline technology & military \\
\hline capacity & mature \\
\hline
\end{tabular}




\begin{tabular}{|c|c|}
\hline available & panel \\
\hline eliminate & minor \\
\hline elimination & foundation \\
\hline assume & unify \\
\hline principal & ignorance \\
\hline logic & ignorant \\
\hline logical & assist \\
\hline trace & assistant \\
\hline sphere & monitor \\
\hline interpret & media \\
\hline interpretation & mediate \\
\hline topic & medical \\
\hline simulate & policy \\
\hline invest & retain \\
\hline investment & sustain \\
\hline option & sufficient \\
\hline expand & welfare \\
\hline fee & vision \\
\hline sector & violate \\
\hline income & via \\
\hline principle & utilize \\
\hline trend & status \\
\hline accurate & qualitative \\
\hline accuracy & notion \\
\hline route & norm \\
\hline compatible & motive \\
\hline generate & inspect \\
\hline
\end{tabular}




\begin{tabular}{|c|c|}
\hline generation & insight \\
\hline precise & integral \\
\hline precision & integrity \\
\hline terminate & deduce \\
\hline minimum & decline \\
\hline focus & crucial \\
\hline reverse & allocate \\
\hline proceed & analogy \\
\hline procedure & arbitrary \\
\hline commission & assemble \\
\hline research & bond \\
\hline element & brief \\
\hline layer & bulk \\
\hline consume & capable \\
\hline category & fluctuate \\
\hline portion & hierarchy \\
\hline code & debate \\
\hline technique & compile \\
\hline index & compensate \\
\hline vehicle & deviate \\
\hline consist & diminish \\
\hline site & offset \\
\hline resource & ongoing \\
\hline physical & invoke \\
\hline partner & paradigm \\
\hline energy & subsidy \\
\hline initial & revenue \\
\hline
\end{tabular}




\begin{tabular}{|c|c|}
\hline isolate & restrict \\
\hline specific & temporary \\
\hline journal & enhance \\
\hline visual & ethic \\
\hline visualize & ethnic \\
\hline overlap & exceed \\
\hline normal & explicit \\
\hline complex & implicit \\
\hline task & exploit \\
\hline demonstrate & exploitation \\
\hline medium & extract \\
\hline equip & facilitate \\
\hline identical & devote \\
\hline alter & federal \\
\hline alternate & ministry \\
\hline voluntary & prospect \\
\hline volunteer & protocol \\
\hline transport & pursue \\
\hline transportation & orient \\
\hline conduct & restore \\
\hline assign & restrain \\
\hline obtain & practitioner \\
\hline fund & pose \\
\hline fundamental & nuclear \\
\hline maintain & inhibit \\
\hline documentary & $\begin{array}{l}\text { inhibition } \\
\text { denote }\end{array}$ \\
\hline
\end{tabular}




\section{K-12 STEM-related Word Lists}

The STEM-related word lists, shown in Tables 20 and 21, are composed of two sub-lists of Math (184 lemmas) and Science (228 lemmas). With respect to the STEMrelated list, words that are domain specific are included on the list; in other words, all words appearing only in one content area (math or science) but not in others are included in the STEM-related word list. In addition, each sub-list is divided into two sections of higher and lower frequency words.

Table 20. K-12 STEM-related words: Math.

\begin{tabular}{ll}
\hline Higher Freq. & Lower Freq. \\
\hline equate & arithmetic \\
equation & cumulative \\
graph & lateral \\
graphic & tank \\
fraction & associative \\
fractional & assess \\
triangle & assessment \\
triangular & adjacent \\
percent & finite \\
percentage & infinite \\
decimal & infinitely \\
factorization & diagram \\
math & altitude \\
mathematical & angle \\
mathematician & arc \\
meter & arithmetic sequence \\
\hline
\end{tabular}




\begin{tabular}{|c|c|}
\hline centimeter & array \\
\hline kilometer & asymptote \\
\hline metric & average \\
\hline millimeter & balance \\
\hline estimate & base \\
\hline estimation & binomial \\
\hline rectangle & bisect \\
\hline rectangular & cardinal number \\
\hline subtract & central angle \\
\hline subtraction & certainty \\
\hline integer & circle \\
\hline variable & circumcenter \\
\hline variation & coefficient \\
\hline sum & collinear \\
\hline algebra & combination \\
\hline algebraic & compass \\
\hline height & congruent \\
\hline cube & conjecture \\
\hline cubic & converse \\
\hline perimeter & corner \\
\hline denominator & opposites \\
\hline exponent & operation \\
\hline exponential & ordinate \\
\hline plot & permutation \\
\hline prism & pictograph \\
\hline linear & pie graph \\
\hline nonlinear & place value \\
\hline score & polyhedron \\
\hline
\end{tabular}




\begin{tabular}{|c|c|}
\hline geometry & postulate \\
\hline geometric & probability \\
\hline tile & protractor \\
\hline congruous & quadrant \\
\hline congruence & quantity \\
\hline polygon & quarter \\
\hline vertex & radian \\
\hline quotient & remainder \\
\hline median & resultant \\
\hline intercept & rhombus \\
\hline axis & root \\
\hline diameter & scalar \\
\hline segment & scale \\
\hline cylinder & secant \\
\hline polynomial & semicircle \\
\hline parallelogram & sine \\
\hline notate & slope \\
\hline inequalities & solution \\
\hline pyramid & square \\
\hline numerator & tessellation \\
\hline radius & trinomial \\
\hline circumference & vector \\
\hline marble & $\mathrm{x}$-axis \\
\hline divisor & $\mathrm{x}$-intercept \\
\hline divisible & $y$-axis \\
\hline vertical & $y$-intercept \\
\hline ounce & decagon \\
\hline symmetry & degree \\
\hline
\end{tabular}




\begin{tabular}{ll} 
quadratic & determinant \\
rotate & diagonal \\
rotation & dilation \\
rotational & dime \\
cone & direct variation \\
inverse & discriminant \\
trapezoid & dividend \\
reciprocal & dodecahedron \\
quadrilateral & ellipse \\
perpendicular & equals \\
sketch & event \\
discount & factorial \\
spinner & figure \\
grid & frequency \\
horizontal & histogram \\
acute & inequality \\
obtuse & matrix \\
parenthesis & mode \\
hypotenuse & monomial \\
commutative & scatterplot \\
\hline
\end{tabular}


Table 21. K-12 STEM-related words: Science.

\begin{tabular}{|c|c|}
\hline Higher Freq. & Lower Freq. \\
\hline cell & balloon \\
\hline organism & sperm \\
\hline atom & beaker \\
\hline atomic & equator \\
\hline chemistry & sodium \\
\hline chemical & mercury \\
\hline chemicals & seismic \\
\hline volcano & beach \\
\hline volcanic & magnitude \\
\hline carbon & algae \\
\hline molecule & aluminum \\
\hline oxygen & respire \\
\hline atmosphere & respiration \\
\hline planet & organic \\
\hline environment & polar \\
\hline environmental & hemisphere \\
\hline fossil & reptile \\
\hline dense & radioactive \\
\hline density & groundwater \\
\hline solar & helium \\
\hline sediment & wavelength \\
\hline sedimentary & thermometer \\
\hline species & lithosphere \\
\hline electron & drift \\
\hline acid & spectrum \\
\hline acidic & marine \\
\hline
\end{tabular}




\begin{tabular}{|c|c|}
\hline gene & contour \\
\hline genetic & metamorphic \\
\hline gravity & vascular \\
\hline gravitational & lever \\
\hline continent & rocket \\
\hline continental & era \\
\hline tissue & ozone \\
\hline muscle & buoy \\
\hline erode & buoyant \\
\hline erosion & hurricane \\
\hline physical & elevate \\
\hline climate & elevation \\
\hline ecosystem & embryo \\
\hline bacterium & jar \\
\hline bacteria & mirror \\
\hline trait & injure \\
\hline hydrogen & injury \\
\hline ion & metamorphosis \\
\hline ionic & biotic \\
\hline chromosome & abiotic \\
\hline dioxide & producer \\
\hline nucleus & consumer \\
\hline fuel & herbivore \\
\hline laboratory & carnivore \\
\hline lab & omnivore \\
\hline fluid & scavenger \\
\hline radiate & decomposer \\
\hline radiation & food web \\
\hline
\end{tabular}




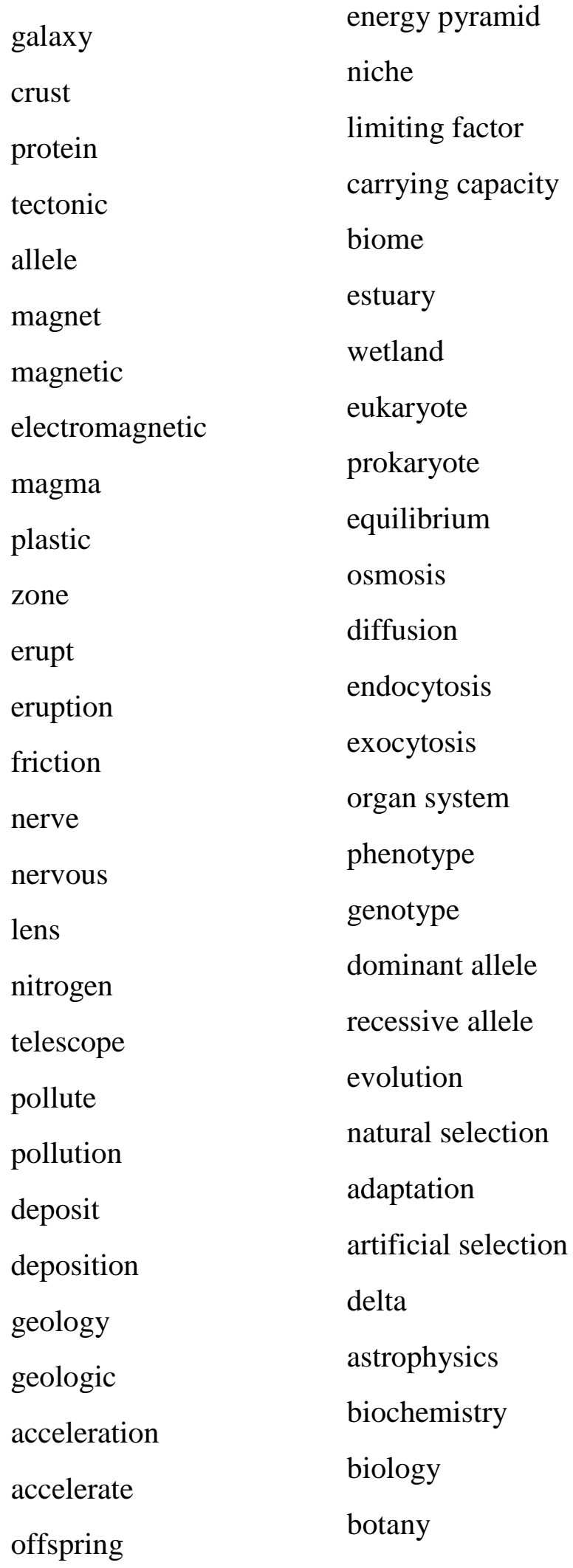




\begin{tabular}{|c|c|}
\hline precipitate & Bunsen burner \\
\hline nutrient & burette \\
\hline nutrition & funnel \\
\hline glacier & genetics \\
\hline orbit & geophysics \\
\hline mammal & glassware \\
\hline velocity & graduated cylinder \\
\hline proton & herpetology \\
\hline dissolve & ichthyology \\
\hline mantle & immunology \\
\hline absorb & magnetism \\
\hline photosynthesis & mass \\
\hline crystal & matter \\
\hline fungus & measure \\
\hline fungi & meteorologist \\
\hline lava & meteorology \\
\hline astronomy & microbiologist \\
\hline astronomer & microbiology \\
\hline microscope & mineral \\
\hline vapor & mineralogy \\
\hline vaporize & ornithology \\
\hline neutron & quantum \\
\hline membrane & scale \\
\hline thermal & science \\
\hline humid & scientist \\
\hline humidity & seismology \\
\hline igneous & temperature \\
\hline tropic & test tube \\
\hline
\end{tabular}




$\begin{array}{ll}\text { tropical } & \text { theory } \\ \text { nuclear } & \text { zoology } \\ \text { kinetic } & \text { experiment } \\ \text { latitude } & \text { extrapolation }\end{array}$

\section{Essential Word List (EWL) for K-12 ELLs}

The Essential Word List is composed of three sub-lists, presented in Tables 22, 23, and 24: K1 (first 1,000 most frequent words), K2 (second 1,000 most frequent words), and academic words. Each sub-list has two levels of higher and lower frequency words.

Table 22. Essential Word List: K1.

\begin{tabular}{llll}
\hline Freq. & Word & Freq. & Word \\
\hline 775747 & the & 2489 & separate \\
378097 & be & 2486 & basic \\
361295 & of & 2481 & division \\
297511 & a & 2480 & random \\
247446 & and & 2478 & degree \\
243373 & to & 2478 & rational \\
185046 & in & 2475 & carry \\
118803 & way & 2467 & sometime \\
107940 & you & 2466 & vocabulary \\
105481 & that & 2465 & require \\
73894 & have & 2463 & social-service \\
63724 & this & 2462 & inside \\
\hline
\end{tabular}




63014 use
62504 they
61359 or
59402 we
56463 by
55294 as
55130 on
50510 can
49647 with
47797 what
45749 from
44462 home
41166 at
41010 how
35937 he
35336 not
33120 will
32618 one
31693 if
30657 each
29789 example
28771 equate
27267 find
26131 make
25125 when
24169 point
23958 which

2462 odd-job

2461 sing-along

2457 conclude

2447 mid-late

2447 wind

2445 liquid

2445 stamping-ground

2443 cover

2431 protect

2429 tennis-court

2421 history

2417 design

2412 secretary-general

2410 re-form

2407 vertical

2405 ball

2395 bird

2394 quadratic

2387 bacterium

2385 across

2384 teach

2382 horizon

2373 reach

2360 enter

2359 inverse

2352 polynomial

2350 discuss 


$\begin{array}{llll}22929 & \text { other } & 2349 & \text { individual } \\ 22798 & \text { more } & 2342 & \text { text } \\ 22668 & \text { do } & 2340 \text { muscle } \\ 22455 & \text { about } & 2336 & \text { introduction } \\ 22401 & \text { all } & 2332 & \text { specific } \\ 20163 & \text { so } & 2331 & \text { technology } \\ 18698 & \text { these } & 2322 & \text { purple-blue } \\ 18504 & \text { there } & 2316 & \text { mark } \\ 18461 & \text { many } & 2313 & \text { major } \\ 18412 & \text { differ } & 2313 & \text { room-key } \\ 18356 & \text { write } & 2312 & \text { bond } \\ 18231 & \text { nobody } & 2304 & \text { record } \\ 18185 & \text { time } & 2298 & \text { little } \\ 17947 & \text { water } & 2294 & \text { rotate } \\ 17807 & \text { value } & 2293 & \text { two-pound } \\ 17728 & \text { form } & 2287 & \text { sure } \\ 17561 & \text { line } & 2286 & \text { independence } \\ 17458 & \text { figure } & 2285 & \text { pay } \\ 17171 & \text { than } & 2276 & \text { presidency } \\ 17041 & \text { cell } & 2272 & \text { video } \\ 16934 & \text { would } & 2269 & \text { white } \\ 16855 & \text { function } & 2265 & \text { woman } \\ 16464 & \text { answer } & 2263 & \text { consist } \\ 16396 & \text { but } & 2261 & \text { axis } \\ 16323 & \text { may } & 2260 & \text { outgoing } \\ 16069 & \text { solve } & 2252 & \text { tell } \\ 15915 & \text { energy } & 2250 & \text { interval } \\ & & \end{array}$




\begin{tabular}{|c|c|c|c|}
\hline 15882 & also & 2244 & easy \\
\hline 15855 & into & 2239 & pseudo-operation \\
\hline 15664 & first & 2237 & friend \\
\hline 15631 & graph & 2236 & enough \\
\hline 15553 & see & 2236 & exact \\
\hline 15519 & like & 2234 & characterize \\
\hline 15402 & problem & 2230 & something \\
\hline 15091 & it & 2227 & west \\
\hline 15085 & out & 2226 & war \\
\hline 15082 & below & 2221 & temple-complex \\
\hline 14445 & some & 2209 & balance \\
\hline 14414 & up & 2205 & today \\
\hline 14344 & give & 2204 & over-correct \\
\hline 13714 & follow & 2197 & indicate \\
\hline 13713 & between & 2197 & lonely-heart \\
\hline 13626 & angle & 2196 & metal \\
\hline 13444 & same & 2192 & letter \\
\hline 13311 & area & 2185 & self-interest \\
\hline 12884 & need & 2185 & variety \\
\hline 12829 & people & 2180 & sex-role \\
\hline 12772 & work & 2179 & environment \\
\hline 12660 & numbers & 2178 & chromosome \\
\hline 12377 & state & 2175 & symbol \\
\hline 12258 & table & 2174 & intercept \\
\hline 11751 & take & 2165 & out-flow \\
\hline 11737 & system & 2165 & sense-organ \\
\hline 11557 & get & 2163 & evolution \\
\hline
\end{tabular}




$\begin{array}{llll}11538 & \text { change } & 2162 & \text { cross } \\ 11347 & \text { add } & 2154 & \text { vote } \\ 11186 & \text { look } & 2153 & \text { decide } \\ 11183 & \text { plant } & 2150 & \text { feel } \\ 11122 & \text { because } & 2149 & \text { life-choice } \\ 11020 & \text { help } & 2148 & \text { build } \\ 10970 & \text { year } & 2148 & \text { motion-picture } \\ 10913 & \text { most } & 2139 & \text { pass } \\ 10829 & \text { left } & 2138 & \text { warm } \\ 10778 & \text { quarter } & 2133 & \text { share } \\ 10609 & \text { both } & 2127 & \text { light-curve } \\ 10568 & \text { data } & 2127 & \text { until } \\ 10439 & \text { call } & 2122 & \text { building } \\ 10299 & \text { where } & 2122 & \text { soil } \\ 10151 & \text { she } & 2122 & \text { station-building } \\ 9899 & \text { show } & 2117 & \text { release } \\ 9885 & \text { explain } & 2116 & \text { three-month } \\ 9874 & \text { why } & 2115 & \text { re-appear } \\ 9872 & \text { lesson } & 2110 & \text { micro-electric } \\ 9613 & \text { such } & 2103 & \text { green } \\ 9590 & \text { through } & 2102 & \text { behave } \\ 9515 & \text { right } & 2096 & \text { self-control } \\ 9487 & \text { move } & 2093 & \text { evidence } \\ 9487 & \text { new } & 2088 & \text { member } \\ 9354 & \text { relate } & 2085 & \text { approximate } \\ 9354 & \text { order } & 2076 & \text { drive } \\ 9297 & \text { image } & \text { lose } \\ & & \end{array}$




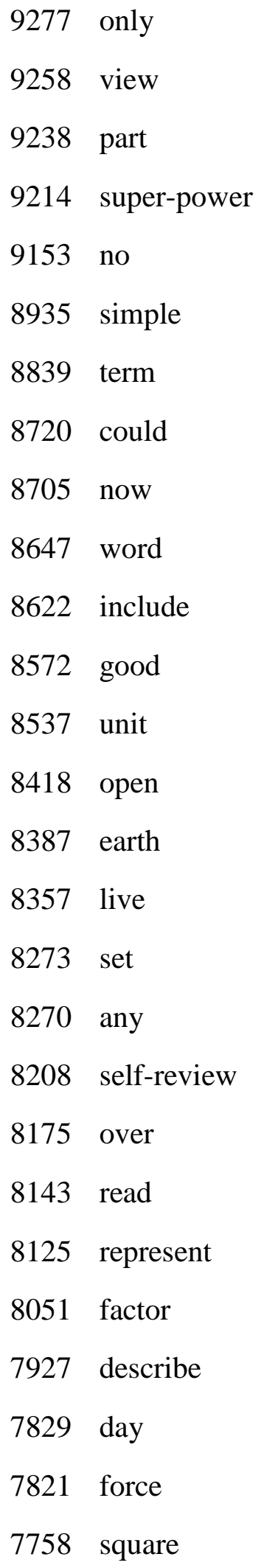

2072 big-wig

2071 sea-wind

2069 magnet

2067 lifter

2065 over-balance

2063 sell

2049 am

2048 primary

2031 hydrogen

2029 atmosphere

2028 gravity

2027 heart

2027 position

2018 transport

2008 normal

2003 dense

2001 super-store

1999 ice

1997 integer

1996 fact

1991 egg

1990 receive

1985 plate

1978 hear

1976 membrane

1973 proportion

1958 eye 


$\begin{array}{llll}7660 & \text { determine } & 1955 & \text { round } \\ 7655 & \text { two-step } & 1951 \text { river } \\ 7645 & \text { place } & 1950 \text { run } \\ 7602 & \text { per } & 1940 & \text { chart } \\ 7533 & \text { group } & 1940 & \text { exist } \\ 7520 & \text { after } & 1931 \text { card } \\ 7493 & \text { direct } & 1931 & \text { flower } \\ 7428 & \text { know } & 1929 & \text { perform } \\ 7394 & \text { great } & 1928 & \text { discover } \\ 7388 & \text { grow } & 1928 & \text { reflect } \\ 7367 & \text { cause } & 1927 & \text { meaningful } \\ 7366 & \text { much } & 1925 & \text { quick } \\ 7330 & \text { chapter } & 1921 & \text { hard } \\ 7318 & \text { length } & 1917 & \text { vertex } \\ 7311 & \text { who } & 1915 & \text { source-text } \\ 7296 & \text { probable } & 1912 & \text { pie-chart } \\ 7272 & \text { divide } & 1912 & \text { row } \\ 7247 & \text { high } & 1908 & \text { south-westerly } \\ 7170 & \text { test } & 1907 & \text { meter } \\ 7129 & \text { body } & 1906 & \text { never } \\ 7019 & \text { result } & 1906 & \text { rise } \\ 6984 & \text { life } & 1895 & \text { suppose } \\ 6965 & \text { must } & 1893 & \text { plate-layer } \\ 6948 & \text { equal } & 1892 & \text { self-seed } \\ 6943 & \text { let } & 1883 & \text { spend } \\ 6912 & \text { triangle } & 1876 \text { fossil } \\ 6894 & \text { side } & \text { physical } \\ & & \end{array}$




\begin{tabular}{|c|c|c|c|}
\hline 6836 & org & 1873 & particular \\
\hline 6835 & & 1869 & t-short \\
\hline 6785 & common & 1868 & middle \\
\hline 6752 & still-large & 1865 & meet \\
\hline 6735 & very & 1864 & planet \\
\hline 6716 & food & 1861 & believe \\
\hline 6685 & & 1857 & tissue \\
\hline 0000 & 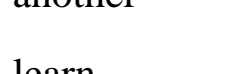 & 1853 & weather \\
\hline & & 1851 & widen \\
\hline 6634 & world & 1849 & \\
\hline 6618 & real & & \\
\hline 6450 & law & 1845 & collect \\
\hline 6429 & here & 1845 & house-hold \\
\hline 6413 & express & 1845 & six-year-old \\
\hline 6375 & down & 1840 & bar \\
\hline 6375 & multiply & 1837 & substitute \\
\hline 6370 & atom & 1828 & life-history \\
\hline 6362 & small-animal & 1823 & instead \\
\hline 6308 & process & 1822 & meaning \\
\hline 6249 & compare & 1822 & think \\
\hline 6227 & student & 1819 & lot \\
\hline 6129 & object & 1818 & decrease \\
\hline 6126 & importance & 1815 & translate \\
\hline 6103 & long & 1810 & face \\
\hline 6093 & measure & 1810 & micro-climate \\
\hline 6085 & sub-process & 1810 & micro-fossil \\
\hline 6081 & distance & 1798 & parent \\
\hline 6073 & just & 1796 & count \\
\hline
\end{tabular}




\begin{tabular}{|c|c|c|c|}
\hline 6060 & formula & 1795 & present \\
\hline 6049 & product & 1792 & multiplication \\
\hline 5920 & name & 1791 & author \\
\hline 5859 & above & 1781 & deviate \\
\hline 5795 & identified & 1778 & female \\
\hline 5790 & amount & 1777 & previous \\
\hline 5757 & population & 1775 & re-write \\
\hline 5738 & should & 1767 & non-local \\
\hline 5686 & human & 1764 & extend \\
\hline 5650 & temperature & 1763 & care \\
\hline 5647 & scientific & 1763 & game \\
\hline 5635 & contain & 1763 & room \\
\hline 5630 & light & 1763 & block \\
\hline 5629 & even & 1762 & pre-condition \\
\hline 5624 & total & 1762 & short-fall \\
\hline 5623 & rate & 1761 & $\operatorname{mix}$ \\
\hline 5598 & theory & 1760 & play \\
\hline 5592 & complete & 1758 & near \\
\hline 5572 & next & 1752 & nerve \\
\hline 5553 & standard & 1751 & non-national \\
\hline 5536 & practice & 1750 & focus \\
\hline 5528 & increase & 1747 & clear \\
\hline 5513 & occur & 1747 & geometry \\
\hline 5454 & personalize & 1745 & repeat \\
\hline 5440 & define & 1740 & bring \\
\hline 5428 & since & 1724 & health \\
\hline 5388 & means & 1724 & necessitate \\
\hline
\end{tabular}




\begin{tabular}{|c|c|c|c|}
\hline 5384 & thing & 1723 & research \\
\hline 5353 & & 1719 & prose-character \\
\hline 5303 & end & 1718 & seem \\
\hline 5300 & become & 1708 & though \\
\hline 5291 & gas & 1708 & waste \\
\hline 5280 & re-found & 1705 & die \\
\hline 5230 & surface & 1705 & non-male \\
\hline 5218 & start & 1704 & segment \\
\hline 5197 & fraction & 1695 & against \\
\hline 5189 & role-model & 1689 & young \\
\hline 5188 & base & 1680 & re-buy \\
\hline 5186 & chemical & 1676 & culture \\
\hline 5167 & mean & 1673 & potential \\
\hline 5076 & during & 1672 & bone \\
\hline 5072 & center & 1672 & organize \\
\hline 5039 & hour & 1670 & walk \\
\hline 5037 & go & 1666 & obtain \\
\hline 5023 & render & 1665 & prove \\
\hline 5018 & explore & 1663 & politic \\
\hline 5005 & circle & 1655 & full \\
\hline 4982 & less & 1654 & spread \\
\hline 4981 & token & 1651 & statistic \\
\hline 4948 & blood & 1650 & stop \\
\hline 4947 & type & 1650 & strong \\
\hline 4930 & begin & 1647 & $\begin{array}{l}\text { octave- } \\
\text { combination }\end{array}$ \\
\hline 4923 & direction & 1646 & correspond \\
\hline
\end{tabular}




\begin{tabular}{|c|c|c|c|}
\hline 4911 & around & 1646 & significance \\
\hline 4907 & therefore & 1645 & machine \\
\hline 4891 & small-scale & 1642 & run-up \\
\hline 4883 & organic & 1641 & near-synonym \\
\hline 4877 & want & 1640 & absolute \\
\hline 4876 & domain & 1639 & east \\
\hline 4849 & social-science & 1637 & expect \\
\hline 4838 & self-concept & 1625 & sense-unit \\
\hline 4825 & gene & 1624 & outside \\
\hline 4811 & $\operatorname{cost}$ & 1623 & label \\
\hline 4772 & act & 1623 & radius \\
\hline 4767 & produce & 1622 & re-connect \\
\hline 4760 & mass-murderer & 1621 & top-to-bottom \\
\hline 4745 & non-event & 1616 & over-fill \\
\hline 4742 & slope & 1615 & definition \\
\hline 4733 & foot & 1615 & over-exercise \\
\hline 4692 & electron & 1615 & strategic \\
\hline 4683 & sub-section & 1613 & convert \\
\hline 4665 & sub-rule & 1604 & skin \\
\hline 4663 & summarize & 1599 & advance \\
\hline 4650 & however & 1597 & black \\
\hline 4647 & check & 1594 & locate \\
\hline 4605 & government & 1594 & step-mother \\
\hline 4605 & watch & 1593 & multiple-unit \\
\hline 4585 & similar & 1593 & stage \\
\hline 4567 & before & 1592 & boy \\
\hline 4548 & create & 1590 & although \\
\hline
\end{tabular}




\begin{tabular}{|c|c|c|c|}
\hline 4538 & understand & 1587 & among \\
\hline 4536 & click & 1584 & concentrate \\
\hline 4511 & happen & 1577 & treat \\
\hline 4504 & molecule & 1572 & cut \\
\hline 4503 & low & 1571 & send \\
\hline 4498 & $\operatorname{man}$ & 1568 & semi-double \\
\hline 4450 & together & 1562 & tide-mark \\
\hline 4438 & ratio & 1559 & quantify \\
\hline 4431 & well & 1557 & criticize \\
\hline 4423 & re-heat & 1556 & biology \\
\hline 4418 & hydro-carbon & 1556 & brain \\
\hline 4402 & element & 1549 & grade \\
\hline 4357 & calculate & 1543 & elect \\
\hline 4332 & pair & 1542 & evolve \\
\hline 4315 & inequality & 1542 & side-chain \\
\hline 4314 & back & 1539 & essence \\
\hline 4314 & tie-back & 1538 & night \\
\hline 4270 & true & 1537 & purpose \\
\hline 4255 & sub-sample & 1536 & solar \\
\hline 4252 & ask & 1535 & insect \\
\hline 4250 & re-calculate & 1534 & generate \\
\hline 4249 & apply & 1533 & digest \\
\hline 4242 & far & 1533 & equivalence \\
\hline 4238 & volume & 1531 & median \\
\hline 4230 & speed & 1530 & already \\
\hline 4220 & scale & 1530 & bill \\
\hline 4218 & idea & 1527 & language \\
\hline
\end{tabular}




\begin{tabular}{|c|c|c|c|}
\hline & mile & 1525 & dioxide \\
\hline 4207 & public & 1521 & turn \\
\hline 4181 & & 1520 & pollute \\
\hline 4157 & land & 1519 & oil-spill \\
\hline & often & 1518 & due \\
\hline 4151 & list & 1516 & mineral \\
\hline 4140 & tyne-case & 1514 & cold-store \\
\hline 4115 & semi-negative & 1513 & construct \\
\hline 4111 & structure & 1509 & nucleus \\
\hline 4091 & $\sin$ & 1509 & slave-girl \\
\hline 4081 & wrist & 1506 & two-leg \\
\hline 4067 & subject & 1502 & location \\
\hline 4053 & compound & 1496 & tool \\
\hline 4050 & re-consider & 1487 & safe \\
\hline 4049 & three-inch & 1486 & rest \\
\hline 4045 & box & 1484 & dimension \\
\hline 4034 & root & 1484 & say \\
\hline 4028 & resource & 1483 & cup \\
\hline 4027 & $\cos$ & 1482 & replace \\
\hline 4024 & twin-car & 1478 & efficiency \\
\hline 4020 & material & 1475 & stem \\
\hline 4008 & species & 1474 & ever \\
\hline 4007 & subject-matter & 1474 & pdf \\
\hline 4004 & level & 1471 & score \\
\hline 3989 & rock & 1468 & polar \\
\hline 3963 & sun-worshipper & 1467 & trade \\
\hline 3950 & able & 1467 & serve \\
\hline
\end{tabular}


3941 possible-world

3936 original

3920 always

3913 page

3910 class

3882 distribution

3869 keep

3831 every

3823 without

3815 study

3801 co-worker

3798 red

3783 charge

3780 those

3777 choose

3770 human-being

3739 ocean thought-

3706 experiment

3702 close

3690 early

3685 positive

3683 half

3668 property-owner

3660 under

3659 analyze

3656 develop

3648 involve
1463 coefficient

1460 perpendicular

1452 thousand

1447 skill

1441 survey

1440 talk

1437 removable

1434 bear

1432 dog

1426 component

1420 contrast

1418 display

1413 earthquake

1408 ago

1392 accord

1388 ray

1388 return

1384 deep

1384 outline

1379 resist

1378 asymptote

1376 virus

1374 thus

1372 socialism

1371 succeed

1370 fit

1364 recall 


\begin{tabular}{|c|c|c|c|}
\hline 3633 & height & 1361 & party \\
\hline 3628 & while & 1358 & tone-poem \\
\hline 3616 & few & 1357 & nature \\
\hline 3611 & eat & 1354 & available \\
\hline 3577 & plot & 1354 & leave \\
\hline 3559 & particle & 1352 & $\operatorname{tax}$ \\
\hline 3558 & space & 1351 & thought-content \\
\hline 3548 & re-unit & 1350 & typical \\
\hline 3520 & reason & 1344 & column \\
\hline 3488 & exponent & 1340 & entire \\
\hline 3484 & provide & 1339 & team \\
\hline 3477 & off & 1338 & super-company \\
\hline 3474 & continue & 1337 & front \\
\hline 3457 & ordinate & 1333 & death \\
\hline 3453 & try & 1333 & finality \\
\hline 3436 & picture & 1333 & shall \\
\hline 3434 & respond & 1330 & pseudo-objective \\
\hline 3431 & notice & 1330 & raise \\
\hline 3422 & allow & 1330 & respiration \\
\hline 3394 & re-charge & 1329 & citizen \\
\hline 3388 & decimate & 1328 & stay \\
\hline 3377 & activity & 1325 & match \\
\hline 3363 & guide & 1324 & engineer \\
\hline 3353 & again & 1322 & vary \\
\hline 3350 & plan & 1320 & win \\
\hline 3311 & put & 1318 & generalize \\
\hline 3302 & limit & 1313 & lake \\
\hline
\end{tabular}




\begin{tabular}{ll}
3283 & refer \\
3253 & diagram \\
3245 & zero \\
3243 & lead \\
3226 & parallel \\
3197 & foundation \\
3177 & sound \\
3174 & effect \\
3171 & last \\
3162 & plane \\
3138 & average \\
3132 & press \\
3111 & mini-city \\
3110 & member-country \\
3104 & affect \\
3094 & linear \\
3088 & note \\
3078 & too \\
3071 & correct \\
3071 & property \\
3069 & pattern \\
3065 & size-class \\
3045 & depend \\
3044 & tale \\
3041 & usual \\
3037 & song-cycle \\
3036 & color \\
\hline
\end{tabular}

1310 parabola

1309 continent

1308 review-article

1308 super-computer

1307 retro-fit

1305 throughout

1304 branch

1304 polygon

1304 toward

1301 photo-pass

1300 fungus

1293 fly

1291 self-reflection

1290 notable

1289 derive

1288 topic-shift

1287 large

1285 almost

1285 item

1285 trouser-front

1282 source

1281 run-past

1281 tall

1277 rain

1276 dissolve

1276 link

1275 account 


\begin{tabular}{|c|c|c|c|}
\hline 3030 & story & 1274 & associate \\
\hline 3012 & leaf & 1269 & mammal \\
\hline 3010 & support & 1266 & short-change \\
\hline 3005 & acid & 1264 & agree \\
\hline 2994 & small & 1264 & wood \\
\hline 2989 & frequency & 1261 & photo \\
\hline 2983 & break & 1261 & yes \\
\hline 2982 & select & 1255 & sexuality \\
\hline 2977 & within & 1248 & matrix \\
\hline 2976 & natural & 1243 & electromagnet \\
\hline 2968 & house & 1241 & combine \\
\hline 2967 & still-room & 1240 & $\log$ \\
\hline 2965 & sub-region & 1240 & recognition \\
\hline 2964 & main & 1238 & course \\
\hline 2963 & protein & 1236 & extreme \\
\hline 2956 & best-seller & 1235 & tail \\
\hline 2949 & remember & 1233 & saw-mill \\
\hline 2924 & control & 1229 & wall \\
\hline 2916 & oppose & 1228 & fire \\
\hline 2915 & connect & 1228 & wide \\
\hline 2908 & take-away & 1226 & non-essential \\
\hline 2906 & least & 1224 & accelerate \\
\hline 2902 & money-winner & 1224 & prevent \\
\hline 2897 & math & 1218 & rule \\
\hline 2890 & disease & 1218 & supply \\
\hline 2885 & electricity & 1216 & appropriate \\
\hline 2883 & book & 1216 & pump \\
\hline
\end{tabular}




\begin{tabular}{|c|c|c|c|}
\hline 2878 & actual & 1215 & soil-nutrient \\
\hline 2875 & predict & 1212 & cancer \\
\hline 2871 & come & 1212 & visit \\
\hline 2871 & sit-com & 1208 & over-extend \\
\hline 2853 & manage & 1207 & converge \\
\hline 348 & several & 1207 & tangency \\
\hline 2836 & north & 1205 & ease \\
\hline 2826 & tree & 1203 & re-discover \\
\hline 2824 & whole & 1202 & industrial \\
\hline 2823 & top & 1202 & short-circuit \\
\hline 2823 & travel & 1202 & wiki \\
\hline 2822 & remain & 1201 & adult \\
\hline 2815 & congruence & 1193 & tri-gram \\
\hline 2811 & constant & 1192 & spring \\
\hline 2809 & commons & 1188 & non-identity \\
\hline 2807 & observe & 1188 & re-build \\
\hline 2788 & rectangle & 1188 & semi-final \\
\hline 2786 & substance & 1188 & symmetry \\
\hline 2765 & once & 1187 & change \\
\hline 2756 & two-piece & 1183 & numerator \\
\hline 2751 & field & 1178 & mechanic \\
\hline 2749 & denominate & 1178 & sugar \\
\hline 2738 & detail & 1177 & pine-cone \\
\hline 2733 & map & 1176 & ion \\
\hline 2714 & certain & 1176 & pull \\
\hline 2710 & free & 1176 & yellow \\
\hline 2707 & sentence & 1174 & re-assume \\
\hline
\end{tabular}




\begin{tabular}{ll}
2698 & special \\
2698 & child \\
2695 & age \\
2691 & solidify \\
2666 & vector \\
2663 & student-teacher \\
2660 & current \\
2649 & hold \\
2644 & old \\
2639 & paper \\
2634 & million \\
2633 & families \\
2629 & either \\
2626 & work-situation \\
2620 & whether \\
2586 & song \\
2574 & fill \\
2564 & oxygen \\
2563 & for \\
2558 & week \\
2550 & reduce \\
2547 & moon \\
2542 & minute \\
2526 & cannot \\
2525 & fish \\
2524 & weight \\
2522 & subtract \\
\hline
\end{tabular}

1173 bag

1173 trait

1170 volcano

1166 town

1164 decay

1162 interpret

1161 congress

1159 drop

1157 sunlight

1155 religion

1155 stand

1153 three-iron

1151 miss

1147 sea-salt

1146 net

1146 rather

1145 experience

1144 lie

1143 digit

1138 difficulty

1138 hair

1136 weigh

1134 composite

1133 shade

1126 billion

1126 error

1125 semi-colony 
2510 kind

2499 head

2489 separate
1119 apart

1117 trouser-press

1116 ride

1115 tube 
Table 23. Essential Word List (EWL): K2.

\begin{tabular}{|c|c|c|c|}
\hline Freq. & Word & \multicolumn{2}{|c|}{ Freq. Word } \\
\hline 1111 & issue & 590 & sheet \\
\hline 1108 & hearing-aid & 589 & crystal \\
\hline 1107 & slow-match & 589 & sample \\
\hline 1105 & favor & 589 & sleep \\
\hline 1104 & king & 588 & modify \\
\hline 1103 & love & 588 & transit \\
\hline 1100 & long-hair & 587 & nitrogen \\
\hline 1099 & floor & 587 & re-group \\
\hline 1097 & non-native & 586 & mass \\
\hline 1096 & sea-floor & 585 & covalent \\
\hline 1095 & transfer & 585 & international \\
\hline 1094 & classified & 585 & p-orbital \\
\hline 1091 & dark & 584 & string \\
\hline 1090 & iniquity & 583 & confide \\
\hline 1088 & train & 583 & depth \\
\hline 1081 & maintain & 583 & tit-bit \\
\hline 1080 & amendment & 583 & university \\
\hline 1080 & damage & 582 & brighten \\
\hline 1079 & modern & 581 & biodiverse \\
\hline 1079 & upon & 581 & literature \\
\hline 1078 & yet & 578 & mid-year \\
\hline 1073 & report & 578 & re-absorb \\
\hline 1072 & guidance & 578 & scatter \\
\hline 1069 & courtesy & 577 & alga \\
\hline
\end{tabular}




$\begin{array}{llll}1066 & \text { false } & 577 \text { drug } \\ 1065 & \text { totem-pole } & 577 \text { push-up } \\ 1063 & \text { fair } & 577 & \text { vascular } \\ 1062 & \text { suggest } & 576 & \text { media } \\ 1060 & \text { re-combine } & 576 & \text { parameter } \\ 1060 & \text { reproduction } & 576 & \text { step-sister } \\ 1058 & \text { storage } & 575 & \text { intense } \\ 1057 & \text { sub-project } & 575 & \text { mitosis } \\ 1050 & \text { pseudo-device } & 575 & \text { portion } \\ 1050 & \text { re-examine } & 575 & \text { smart-drug } \\ 1047 & \text { lung } & 574 & \text { investigate } \\ 1045 & \text { whose } & 574 & \text { stick } \\ 1043 & \text { swimming-pool } & 573 & \text { felt } \\ 1042 & \text { straight-jacket } & 573 & \text { regard } \\ 1039 & \text { chance } & 573 & \text { sixth-former } \\ 1039 & \text { semi-regular } & 572 & \text { space-arc } \\ 1037 & \text { sky } & 571 & \text { beyond } \\ 1036 & \text { cool } & 571 & \text { reciprocal } \\ 1030 & \text { non-decision } & 571 & \text { paint } \\ 1029 & \text { fruit } & 571 & \text { passage } \\ 1027 & \text { business } & 571 & \text { slow } \\ 1024 & \text { sine } & 570 & \text { brother } \\ 1024 & \text { trigonometry } & 569 & \text { arrow } \\ 1023 & \text { rain-forest } & 568 & \text { conduct } \\ 1022 & \text { communicate } & 568 & \text { wrong } \\ 1022 & \text { hi } & 567 & \text { balloon } \\ 1022 & \text { respect } & & \\ & & & \text { melt } \\ & & \end{array}$




\begin{tabular}{|c|c|c|c|}
\hline 1022 & trunk-road & 567 & smooth \\
\hline 1021 & goal & 566 & circumference \\
\hline 1020 & establish & 565 & capital \\
\hline 1020 & influence & 565 & trace \\
\hline 1020 & rewrite & 564 & own \\
\hline 1019 & circulate & 563 & solute \\
\hline 1018 & salt-burn & 562 & morning \\
\hline 1018 & spirit & 559 & coming \\
\hline 1017 & mode & 556 & adjacent \\
\hline 1016 & speak & 556 & precipitate \\
\hline 1015 & non-writer & 555 & income \\
\hline 1012 & over-dry & 555 & metric \\
\hline 1012 & radiance & 555 & pack \\
\hline 1009 & visual & 554 & cancel \\
\hline 1007 & reproduce & 553 & prep \\
\hline 1006 & perfect & 553 & sport \\
\hline 1001 & parenthesis & 553 & tile \\
\hline 998 & short & 552 & newton \\
\hline 995 & yard & 552 & truth-claim \\
\hline 992 & hit & 551 & compete \\
\hline 992 & step-father & 551 & spoon-feed \\
\hline 991 & diameter & 550 & mirror \\
\hline 1 & extra & 550 & pick \\
\hline 990 & vision & 550 & print \\
\hline 988 & glass & 550 & zone \\
\hline 86 & settle & 549 & bake \\
\hline 981 & contribute & 549 & grass \\
\hline
\end{tabular}




981 expand
981 introduce
980 ship
980 kill
978 island
978 themselves
975 attract
975 organization
974 attend
973 fat
973 pyramid
971 integral
969 unique
968 century
966 core
966 eukaryote
966 thunder-cloud
966 wire
963 centimeter
963 petro-dollar
962 date
962 interest
961 opinion
959 summer
959 harm
957 hormone
957 literacy
99

549 radio-wave

548 detect

548 revise

547 price

546 size

545 valley

544 empty

544 lock

544 pre-arthropod

544 village

543 ten-year-old

542 district

542 himself

542 manufacture

542 restrict

542 ribosomal

541 fundamental

541 obvious

541 wing

540 land-bridge

540 sub-shell

539 fault

539 rolling-pin

539 wash

538 radioactive

537 re-arrangement

536 movie 


\begin{tabular}{|c|c|c|}
\hline velocity & 535 & carbohydrate \\
\hline 954 ten-foot & 534 & flight \\
\hline 952 park & 534 & listen \\
\hline 952 re-fuel & 533 & agriculture \\
\hline 951 exercise & 532 & stomach \\
\hline 951 fast & 531 & violate \\
\hline 951 site & 530 & fear \\
\hline 950 benefit & 529 & grid \\
\hline 950 gold & 528 & compose \\
\hline 949 earn & 527 & rich \\
\hline 949 winter & 526 & cook \\
\hline 947 someone & 525 & street-woman \\
\hline 947 universe & 524 & para-military \\
\hline 946 save & 524 & band \\
\hline 945 cosine & 522 & attempt \\
\hline 943 message & 522 & plastic \\
\hline 942 habitat & 522 & sea-grass \\
\hline 940 twice & 522 & simulate \\
\hline 936 snow-bank & 521 & effort \\
\hline binomial & 521 & ended \\
\hline 933 interact & 520 & inner \\
\hline 931 principle & 520 & rope \\
\hline 931 trial & 518 & hunt \\
\hline 929 fertility & 517 & mentally \\
\hline 928 tend & 516 & oxidation \\
\hline 927 eventuality & 516 & realize \\
\hline 27 go-fast & 516 & wild \\
\hline
\end{tabular}




$\begin{array}{lll}927 \text { path } & 515 \text { justify } \\ 926 \text { fix } & 515 \text { soft-drink } \\ 925 \text { except } & 514 \text { oxide } \\ 924 \text { magnitude } & 514 \text { san } \\ 921 \text { voice } & 513 \text { proctor } \\ 920 \text { challenge } & 511 \text { altitude } \\ 918 \text { consumption } & 511 \text { copper } \\ 917 \text { surround } & 510 \text { index } \\ 916 \text { hole } & 510 \text { tooth } \\ 914 \text { cube } & 509 \text { clue } \\ 912 \text { immune } & 509 \text { newspaper } \\ 908 \text { inter-connection } & 509 \text { oh } \\ 908 \text { proof } & 507 \text { nine-year-old } \\ 907 \text { loss } & 506 \text { inquire } \\ 905 \text { photosynthesis } & 506 \text { km } \\ 905 \text { six-hit } & 506 \text { sudden } \\ 904 \text { tiny } & 505 \text { bed } \\ 903 \text { self-description } & 505 \text { contact } \\ 900 \text { dominance } & 505 \text { senate } \\ 900 \text { isolate } & 504 \text { sort } \\ 899 \text { office } & 503 \text { copy } \\ 897 \text { vessel } & 502 \text { anniversary } \\ 895 \text { six-cylinder } & 502 \text { two-shoe } \\ 893 \text { prism } & 502 \text { promote } \\ 892 \text { intersect } & 501 \text { decompose } \\ 890 \text { big } & 501 \text { factory } \\ 890 \text { mountain-top } & 501 \text { logarithm } \\ & & \\ 902 & & \end{array}$




\begin{tabular}{|c|c|c|c|}
\hline 889 & recent & 501 & secondary \\
\hline 888 & proton & 501 & supreme \\
\hline 887 & arrive & 501 & threat \\
\hline 886 & interior & 500 & embryo \\
\hline 885 & technique & 500 & prior \\
\hline 883 & histogram & 500 & seat \\
\hline 883 & prokaryote & 500 & silver \\
\hline 882 & built-in & 500 & synthesis \\
\hline 882 & sub-program & 500 & hat \\
\hline 882 & ton & 499 & army \\
\hline 881 & plug & 498 & operate \\
\hline 880 & bind & 498 & reveal \\
\hline 879 & dead & 498 & search-party \\
\hline 879 & shape & 497 & cord \\
\hline 878 & wear & 497 & isosceles \\
\hline 875 & pan & 497 & satellite \\
\hline 873 & improve & 497 & worth \\
\hline 873 & door & 496 & contract \\
\hline 872 & nation-state & 496 & expend \\
\hline 870 & minimum & 495 & burn \\
\hline 867 & danger & 495 & lack-of-pulse \\
\hline 866 & sphere & 495 & photo-story \\
\hline 865 & setting & 494 & assess \\
\hline 863 & publish & 494 & bus-ticket \\
\hline 862 & riding-crop & 494 & houses \\
\hline 862 & sand & 494 & sodium \\
\hline 861 & trumpet-player & 493 & radian \\
\hline
\end{tabular}




\begin{tabular}{|c|c|c|c|}
\hline 856 & advantage & 492 & aspect \\
\hline 856 & $\begin{array}{l}\text { counter- } \\
\text { argument }\end{array}$ & 492 & surprise \\
\hline 856 & rough & 490 & colonial \\
\hline 855 & especial & 490 & non-customer \\
\hline 854 & enzyme & 490 & transcribe \\
\hline 853 & bad & 489 & parasite \\
\hline 853 & theme & 489 & staging-post \\
\hline 852 & arm & 488 & cytoplasm \\
\hline 852 & glucose & 488 & pump-prime \\
\hline 852 & revolt & 487 & wrap \\
\hline 851 & future & 485 & neutron \\
\hline 851 & quadrilateral & 484 & glacier \\
\hline 849 & invert & 483 & crime \\
\hline 849 & window & 483 & persuade \\
\hline 848 & rose-garden & 483 & pollen \\
\hline 847 & partner & 482 & address \\
\hline 846 & heavy & 482 & carrying-on \\
\hline 844 & behind & 482 & medium \\
\hline 844 & trouble-spot & 482 & purple \\
\hline 841 & edge & 482 & reverse-punch \\
\hline 840 & seven-year-old & 481 & chloroplast \\
\hline 839 & instance & 481 & street-fight \\
\hline 838 & risk & 480 & convention \\
\hline 837 & accept & 480 & neuron \\
\hline 837 & customer & 480 & rare \\
\hline 837 & dimensional & 480 & re-capture \\
\hline 837 & touch & 480 & taste \\
\hline
\end{tabular}




\begin{tabular}{|c|c|c|c|}
\hline 835 & emp & 480 & t-shirt \\
\hline 835 & slave & 479 & institute \\
\hline 834 & pathogen & 479 & sale-room \\
\hline 830 & boundaries & 479 & stretch \\
\hline 830 & erode & 478 & co-act \\
\hline 830 & tying & 476 & gather \\
\hline 829 & input-output & 476 & hide \\
\hline 828 & trip & 476 & journal \\
\hline 827 & internal & 476 & overlap \\
\hline 827 & polka-dot & 476 & $\begin{array}{l}\text { sub-sub- } \\
\text { committee }\end{array}$ \\
\hline 827 & race & 474 & plasma \\
\hline 827 & signal & 473 & infect \\
\hline 826 & hill & 472 & condition \\
\hline 825 & fish-farm & 472 & forward \\
\hline 825 & freeze & 472 & presence \\
\hline 825 & sand-hill & 472 & snake \\
\hline 824 & coin-op & 471 & labor \\
\hline 824 & gallon & 470 & pain \\
\hline 823 & subtraction & 470 & principal \\
\hline 819 & shadow & 469 & consider \\
\hline 818 & infinite & 469 & worm \\
\hline 818 & power & 468 & hyperbola \\
\hline 818 & station & 468 & reject \\
\hline 817 & battery & 467 & occupy \\
\hline 816 & conserve & 467 & upward \\
\hline 815 & education & 466 & coin \\
\hline
\end{tabular}




\begin{tabular}{|c|c|c|c|}
\hline 814 & host & 466 & frog \\
\hline 814 & intersection & 466 & wife \\
\hline 814 & poor & 465 & cake \\
\hline 813 & adant & 465 & sink \\
\hline 809 & thin & 465 & wealth \\
\hline 804 & bicect & 463 & letter-collection \\
\hline 804 & steam_enoine & 462 & clock \\
\hline 802 & 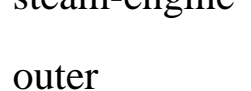 & 462 & frame \\
\hline 801 & molecular & 462 & peter \\
\hline 800 & tradition & 461 & tire \\
\hline 797 & join & 460 & arithmetic \\
\hline 797 & super-market & 460 & broad-bean \\
\hline 796 & allele & 460 & elevate \\
\hline 796 & jpg & 460 & kidney \\
\hline 795 & sales-force & 459 & dust \\
\hline 795 & semi-desert & 459 & genome \\
\hline 793 & poet & 459 & greenhouse \\
\hline 793 & representative & 459 & judge \\
\hline 791 & ear & 459 & library \\
\hline 791 & hypotenuse & 458 & evaporate \\
\hline 790 & mind-reader & 458 & seek \\
\hline 790 & orbit & 457 & housing \\
\hline 789 & art & 456 & beauty \\
\hline 789 & spy-fly & 456 & department \\
\hline 788 & ancient & 456 & photograph \\
\hline 788 & deliver & 455 & ancestor \\
\hline 788 & prepare & 454 & scene \\
\hline
\end{tabular}




\begin{tabular}{|c|c|c|c|}
\hline 786 & avoid & 453 & complicate \\
\hline 784 & coal-tip & 453 & kilometer \\
\hline 784 & offer & 453 & medicine \\
\hline 781 & license & 452 & chief \\
\hline 780 & diverse & 451 & artery \\
\hline 780 & perimeter & 451 & compass \\
\hline 780 & throw & 451 & fish-finger \\
\hline 780 & invest & 451 & marine \\
\hline 779 & mountain & 451 & playing-field \\
\hline 779 & style & 451 & reside \\
\hline 777 & leader & 450 & smell \\
\hline 775 & clean & 449 & encourage \\
\hline 775 & plus-point & 449 & float \\
\hline 774 & ellipse & 449 & kilogram \\
\hline 774 & tide & 449 & underline \\
\hline 773 & distinguish & 448 & painting \\
\hline 773 & sperm & 447 & enjoy \\
\hline 772 & diagonal & 447 & rank \\
\hline 772 & extinct & 446 & horse \\
\hline 772 & music & 446 & mitochondria \\
\hline 772 & soon & 442 & amphibian \\
\hline 770 & still-birth & 441 & street-corner \\
\hline 769 & demand & 440 & march \\
\hline 769 & reproductive & 440 & ozone \\
\hline 768 & amino-acid & 440 & plain \\
\hline 767 & unlike & 439 & lunch \\
\hline 767 & vertebrate & 439 & none \\
\hline
\end{tabular}




\begin{tabular}{|c|c|c|}
\hline 766 ready & 439 & ovary \\
\hline 766 topic & 438 & phylum \\
\hline everything & 438 & trap \\
\hline 764 anything & 437 & replicate \\
\hline 764 red-brown & 435 & externality \\
\hline 761 strike & 435 & latitude \\
\hline 的 & 434 & brief \\
\hline 760 output & 434 & sediment \\
\hline option & 433 & null \\
\hline 759 sea-flat & 432 & famous \\
\hline 758 geology & 431 & eclipse \\
\hline season & 430 & pollinate \\
\hline 757 gland & 429 & kinetic \\
\hline 757 numeric & 429 & prize-giving \\
\hline 755 else & 428 & beside \\
\hline 754 distinct & 428 & excite \\
\hline kingdom & 428 & fresh \\
\hline 752 minute-book & 428 & gain \\
\hline 751 paragraph & 428 & tens \\
\hline 750 classification & 427 & border \\
\hline 750 ion-exchange & 427 & pizza \\
\hline 750 midpoint & 426 & geography \\
\hline 750 southern & 425 & huge \\
\hline re-arrange & 423 & beat \\
\hline 748 renewable & 423 & modeled \\
\hline 745 thick & 423 & recycle \\
\hline 4 election & 423 & american \\
\hline
\end{tabular}


744 god

740 meiosis

739 supplement

734 colonize

734 ticket

733 eliminate

731 familiar

730 defend

730 guess

727 official

726 mole

725 marble

725 sea-coast

724 sketch-pad

724 union

723 dilate

723 mouth

722 fuel

721 re-gain

$720 \mathrm{~cm}$

719 board

719 nation

719 over-control

719 physician

717 consume

717 self

716 erupt
422 definite

421 astronomy

421 expose

421 quartile

420 everyday

420 haploid

419 preimage

418 aquatic

418 catch

418 puberty

418 re-assign

417 coffee

416 fall

415 night-club

415 sub-sector

414 diamond

414 diet

413 amplitude

413 decline

412 desire

412 please

412 shore

412 smile

412 tropics

411 archaea

411 soft

410 mercury 


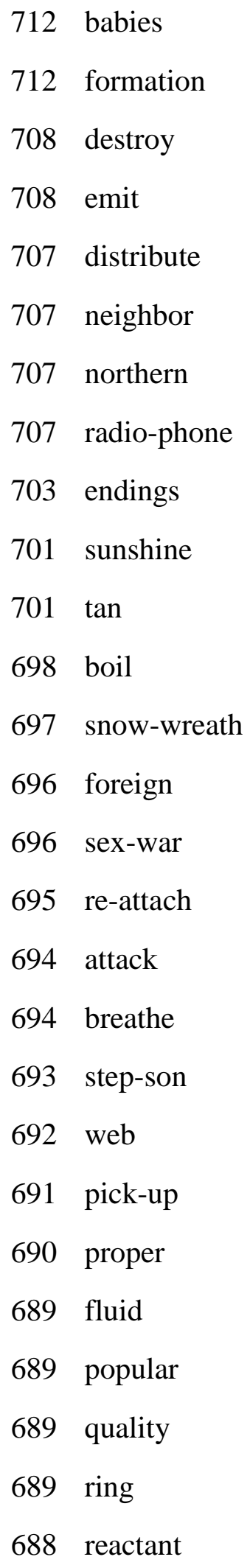

409 homeostasis

407 flowed

406 fiber

405 feat

404 biochemist

404 endpoint

404 title

403 breathing-space

403 immediacy

403 justice

403 succession

403 whenever

402 cry

402 lipid

401 bread-winner

401 stream-water

400 non-document

400 soldier

399 thermal

399 voluntary

398 corn

398 expanse

398 football

398 pet

398 route

397 medical

397 micro-instruction 


\begin{tabular}{|c|c|c|c|}
\hline 686 & efficient & 396 & butterfly \\
\hline 686 & friction & 395 & commute \\
\hline 685 & non-consumer & 394 & cream \\
\hline 685 & push & 394 & motor-vehicle \\
\hline 685 & screen & 393 & hydrocarbon \\
\hline 683 & strength & 392 & deposit \\
\hline 682 & puppet & 392 & induction \\
\hline 681 & overall & 392 & magma \\
\hline 680 & whisker & 392 & mantle \\
\hline 679 & lay & 392 & network \\
\hline 678 & tenant-farmer & 392 & push-bike \\
\hline 677 & gamete & 392 & teacher-researcher \\
\hline 676 & bounded & 391 & semi-conductor \\
\hline 676 & everyone & 391 & wet \\
\hline 673 & flip & 390 & sir \\
\hline 673 & hope & 389 & chordate \\
\hline 673 & rapid & 389 & grain \\
\hline 673 & speaker & 389 & migration \\
\hline 673 & thunder-storm & 389 & photo-cd \\
\hline 672 & partial & 389 & tidal \\
\hline 672 & quotient & 388 & secure \\
\hline 671 & buy & 387 & argue \\
\hline 670 & representation & 387 & non-executive \\
\hline 670 & toilet-roll & 385 & exterior \\
\hline 669 & copyright & 385 & toxin \\
\hline 669 & permutation & 384 & fence \\
\hline 668 & mega-deal & 384 & slide \\
\hline
\end{tabular}




\begin{tabular}{|c|c|c|c|}
\hline 667 & belong & 383 & immigrant \\
\hline 666 & fold & 383 & repair \\
\hline 666 & & 383 & steel-worker \\
\hline 666 & & 382 & debate \\
\hline 666 & speech & 382 & drink \\
\hline 666 & upper & 382 & fund \\
\hline 662 & inherit & 382 & perspective \\
\hline 661 & pre-adaptation & 382 & swim \\
\hline 661 & substitution & 381 & museum \\
\hline 660 & prefer & 380 & sensor \\
\hline 659 & quite & 380 & terminal \\
\hline 656 & bottle & 380 & wavelength \\
\hline 655 & milk-yield & 379 & alter \\
\hline 654 & checkpoint & 379 & sec \\
\hline 653 & weak & 379 & stock-take \\
\hline 652 & honey-guide & 378 & conic \\
\hline 649 & nothing & 378 & decade \\
\hline 648 & fail & 378 & mar \\
\hline 648 & slight & 378 & nest \\
\hline 648 & vehicle & 378 & ounce \\
\hline 646 & offspring & 378 & stone-thrower \\
\hline 646 & purchase & 377 & confuse \\
\hline 646 & toffee-apple & 377 & elephant \\
\hline 646 & toss & 377 & gray \\
\hline 645 & exchange & 377 & strand \\
\hline 645 & investigation & 376 & propose \\
\hline & perhaps & 376 & vitamin \\
\hline
\end{tabular}




\begin{tabular}{|c|c|c|c|}
\hline 643 & backoround & 375 & deck \\
\hline 643 & compute & 375 & thank \\
\hline 643 & stand-alone & 374 & alcohol \\
\hline 642 & environ & 374 & pie \\
\hline 642 & yield & 374 & postulate \\
\hline 641 & profit & 373 & beneath \\
\hline 640 & onto & 373 & loose-liver \\
\hline 636 & diffuse & 373 & workbook \\
\hline 635 & procedural & 372 & enclose \\
\hline 635 & self-interaction & 372 & photo-copy \\
\hline 634 & eating-disorder & 372 & poison \\
\hline 634 & regression & 372 & re-mark \\
\hline 634 & wheel & 372 & review \\
\hline 632 & sit & 371 & authority \\
\hline 632 & wonder & 371 & comprehend \\
\hline 631 & concern & 371 & lab \\
\hline 630 & moment & 371 & load \\
\hline 629 & experiment & 371 & mistake \\
\hline 629 & possibility & 370 & split \\
\hline 628 & precise & 369 & capability \\
\hline 627 & animate & 369 & solubility \\
\hline 627 & equilibrate & 369 & whatever \\
\hline 627 & neither & 368 & target \\
\hline 627 & trapezoid & 367 & ensure \\
\hline 626 & news-stand & 367 & prize \\
\hline 626 & predator & 366 & alike \\
\hline 624 & galaxy & 366 & anyone \\
\hline
\end{tabular}




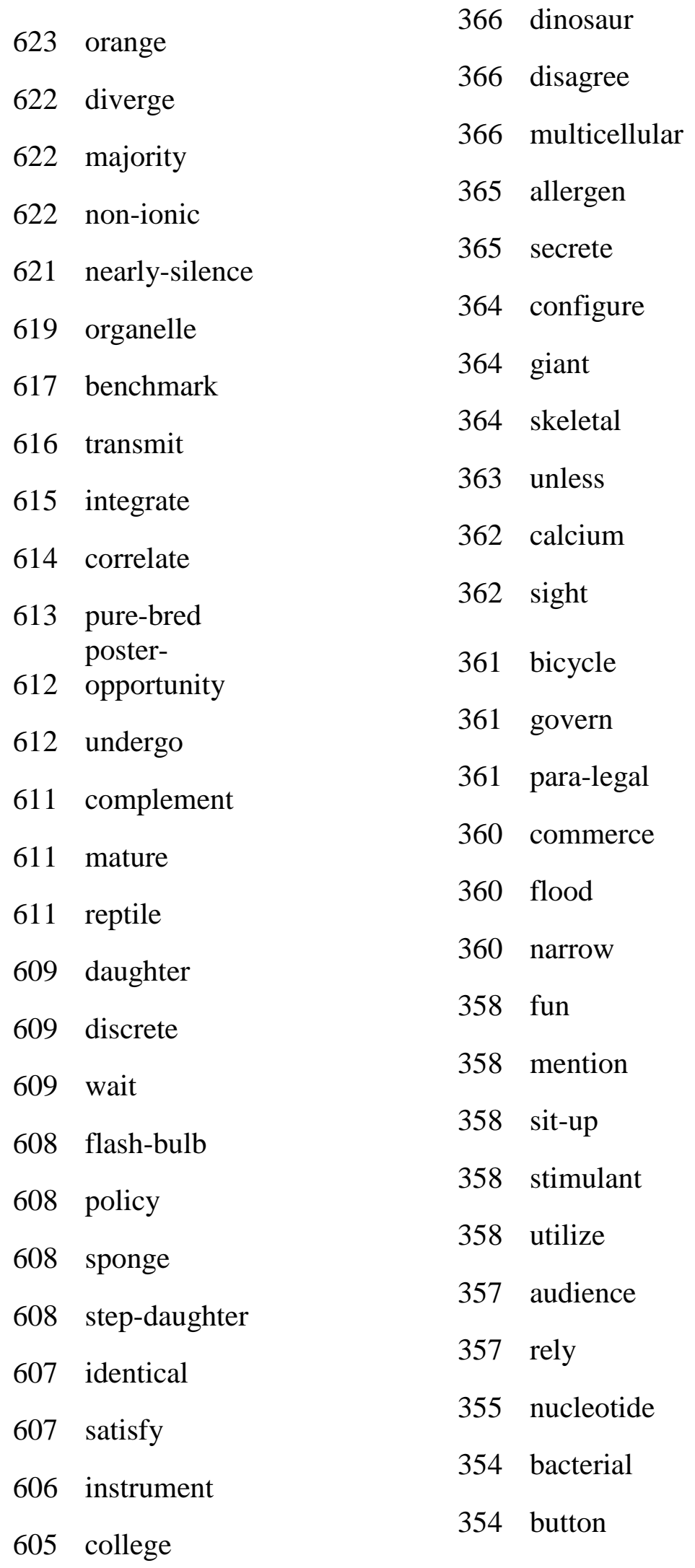




\begin{tabular}{|c|c|c|c|}
\hline 605 & crust & 354 & exposed \\
\hline 605 & & 354 & rose-pink \\
\hline 603 & ideal & 353 & appearance \\
\hline 603 & serious & 353 & capillary \\
\hline 603 & smoke & 353 & council \\
\hline 601 & tip & 353 & revisit \\
\hline 600 & wish & 352 & memory-jogger \\
\hline 599 & prey & 351 & currant \\
\hline 597 & tom-cat & 351 & voltage \\
\hline 596 & candy & 350 & fell \\
\hline 596 & daily & 350 & shop \\
\hline 596 & quadrant & 350 & triple \\
\hline 594 & telescope & 350 & verb \\
\hline 593 & over-determine & 350 & warn \\
\hline 593 & vapor & 350 & I \\
\hline 591 & candidate & 349 & cotton-spinner \\
\hline 590 & biome & 349 & happy \\
\hline 590 & pencil & 349 & lava \\
\hline
\end{tabular}

Table 24. Essential Word List (EWL): Academic words.

\begin{tabular}{ll}
\hline \hline Higher Freq. & Lower Freq. \\
\hline area & undefined \\
chapter & indicate \\
data & constant \\
factor & plus \\
vary & transform
\end{tabular}




\begin{tabular}{|c|c|}
\hline function & transformation \\
\hline volume & output \\
\hline proportion & region \\
\hline ratio & investigate \\
\hline coordinate & investigation \\
\hline evaluate & occur \\
\hline formula & goal \\
\hline formulate & interval \\
\hline negate & purchase \\
\hline negative & adult \\
\hline rational & process \\
\hline positive & compound \\
\hline similar & respond \\
\hline similarity & response \\
\hline similarly & complement \\
\hline equivalent & complementary \\
\hline dimension & chart \\
\hline dimensional & domain \\
\hline method & previous \\
\hline methodology & target \\
\hline identify & remove \\
\hline identifying & period \\
\hline identity & illustrate \\
\hline analyze & illustration \\
\hline analysis & supplement \\
\hline sequence & supplementary \\
\hline display & annual \\
\hline
\end{tabular}




\begin{tabular}{|c|c|}
\hline prime & objective \\
\hline select & spreadsheet \\
\hline selection & theory \\
\hline survey & theoretical \\
\hline strategy & theorize \\
\hline team & maximize \\
\hline mental & maximum \\
\hline mentally & summary \\
\hline range & final \\
\hline outcome & job \\
\hline substitute & require \\
\hline substitution & affect \\
\hline label & bias \\
\hline concept & unbiased \\
\hline symbol & tape \\
\hline symbolic & radical \\
\hline predict & technology \\
\hline prediction & capacity \\
\hline correspond & available \\
\hline corresponding & eliminate \\
\hline involve & elimination \\
\hline involving & assume \\
\hline approximate & principal \\
\hline approximation & logic \\
\hline approximately & logical \\
\hline random & trace \\
\hline randomly & sphere \\
\hline
\end{tabular}




\begin{tabular}{|c|c|}
\hline convert & interpret \\
\hline conversion & interpretation \\
\hline converting & topic \\
\hline item & simulate \\
\hline compute & invest \\
\hline computation & investment \\
\hline computer & option \\
\hline computing & expand \\
\hline mode & fee \\
\hline section & sector \\
\hline justify & income \\
\hline justification & principle \\
\hline challenge & trend \\
\hline distribute & accurate \\
\hline distribution & accuracy \\
\hline distributive & route \\
\hline parallel & compatible \\
\hline error & generate \\
\hline appropriate & generation \\
\hline source & precise \\
\hline locate & precision \\
\hline location & terminate \\
\hline create & minimum \\
\hline creation & focus \\
\hline project & reverse \\
\hline grade & proceed \\
\hline grader & procedure \\
\hline
\end{tabular}




\begin{tabular}{ll} 
rotate & commission \\
image & research \\
link & element \\
design & layer \\
construct & consume \\
construction & category \\
statistics & portion \\
statistical & code \\
conclude & technique \\
conclusion & index \\
odd & vehicle \\
input & consist \\
define & site \\
definition & resource \\
\hline
\end{tabular}




\section{Word list validation}

To validate the word lists, I decided to compare their text coverage of TUSK and SMACK against three major word lists: New General Service List (NGSL) (Brown, 2017), Coxhead's AWL (2000), and Gardner and Davies's AVL (2013) (see Chapter 2 for a detailed description of these studies). These word lists were chosen because they are the most recent and reliable general and academic word lists that have been used commonly over the last decade. According to the instruction of AntWordProfiler, I compiled the words of NGSL, AWL, and AVL into baseword files, a plain text format document that can be uploaded into the software through the provided option in the setting. I uploaded 1000 word families in each baseword file. I also uploaded a total of 20 baseword files including 19,327 word families. Table 24 presents an overview of the total number of lemmas in each word list and the text coverage that they provide.

Table 25. Text coverage of each word list in this study.

\begin{tabular}{lrrr} 
Word list type & Total lemma & Total token & Text coverage \\
\hline High Freq. & 3,606 & $9,808,239$ & $92.78 \%$ \\
Mid Freq. & 5,006 & 176,317 & $1.66 \%$ \\
Low Freq. & 8,080 & 25,670 & $0.24 \%$ \\
Academic words & 461 & 430,143 & $4.06 \%$ \\
STEM & 412 & 130,690 & $1.23 \%$ \\
Total Corpus & 17,565 & $10,571,059$ & $100.00 \%$ \\
\hline
\end{tabular}


In order to have a clear profile of the word lists and to make a validated index, I compared the word lists (HF, MF, LF, STEM-related, and academic list) against the three base lines mentioned above in four genres or K-12 content areas of math, science, social studies, and language arts. Table 25 shows that the three frequency word lists provide a higher text coverage than that of NGSL.

Table 26. Text coverage of three frequency lists against NGSL in four K-12 content areas.

\begin{tabular}{lcccc}
\hline Corpus genre & Math & Science & Social studies & Lang Arts \\
\hline Gap (HF - NGSL) & 8.30 & 7.21 & 5.58 & 2.07 \\
Gap (MF - NGSL) & 5.51 & 4.23 & 4.81 & 1.10 \\
Gap (LF - NGSL) & 3.01 & 2.28 & 1.91 & 1.00 \\
\hline
\end{tabular}

Figures are in percentages.

As shown in Table 26, the smallest gap superiority is for Language Arts, demonstrating its rich context with respect to high frequency words in general English. However, in math and science we see larger gaps. All three frequency lists outperformed NGSL in the four K-12 content areas. This higher text coverage could be related to the fact that the three frequency lists are directly derived from K-12 textbooks while NGSL is based on a corpus of general English. This higher text coverage shown in Table 26 confirms the validity of the three frequency lists in this study. To validate the academic and STEMrelated word lists, I also compared their text coverage of the K-12 corpora against AWL and AVL (Coxhead, 2000; Gardner \& Davies, 2013). Results of the comparisons obtained from AntWordProfiler are presented in Table 27. 
Table 27. Text coverage of my Academic and STEM-related word Lists against AWL and AVL in four K-12 content areas.

\begin{tabular}{lcccc}
\hline Corpus genre & Math & Science & Social S & Lang A. \\
\hline Gap (Academic word list - AWL, AVL) & 1.45 & 3.20 & 2.98 & 4.23 \\
Gap (STEM-related - AWL, AVL) & 1.62 & 3.73 & 1.91 & 3.55 \\
\hline
\end{tabular}

Figures are in percentages.

The gap in four content areas is always larger than $1 \%$, thereby demonstrating the validity of the academic and STEM-related word lists of the present study. Nation (2016) claims that larger gaps show weaker text coverage. Both Tables 26 and 27 show that our word lists have smaller gaps. A further finding from these comparisons substantiates the value of adjusted frequency word lists in making word lists with a relatively high text coverage.

Finally, Figures 6 and 7 demonstrate Zipf's (1949) law that a small portion of text token covers a considerable part of the corpus. In accordance with Zipf's notion of lemma offering more bank for the buck, in this research, high frequency and academic words account for approximately $23 \%$ of the 17,565 lemmas; however, these two categories have a text coverage of $96.84 \%$, meaning that, learning only these two classes of words will likely provide ELLs with sufficient word knowledge (Nation, 2013) to obtain a successful reading comprehension. 
Figure 6. Text coverage vs lemma percentage of academic and high frequency words for the entire corpus.

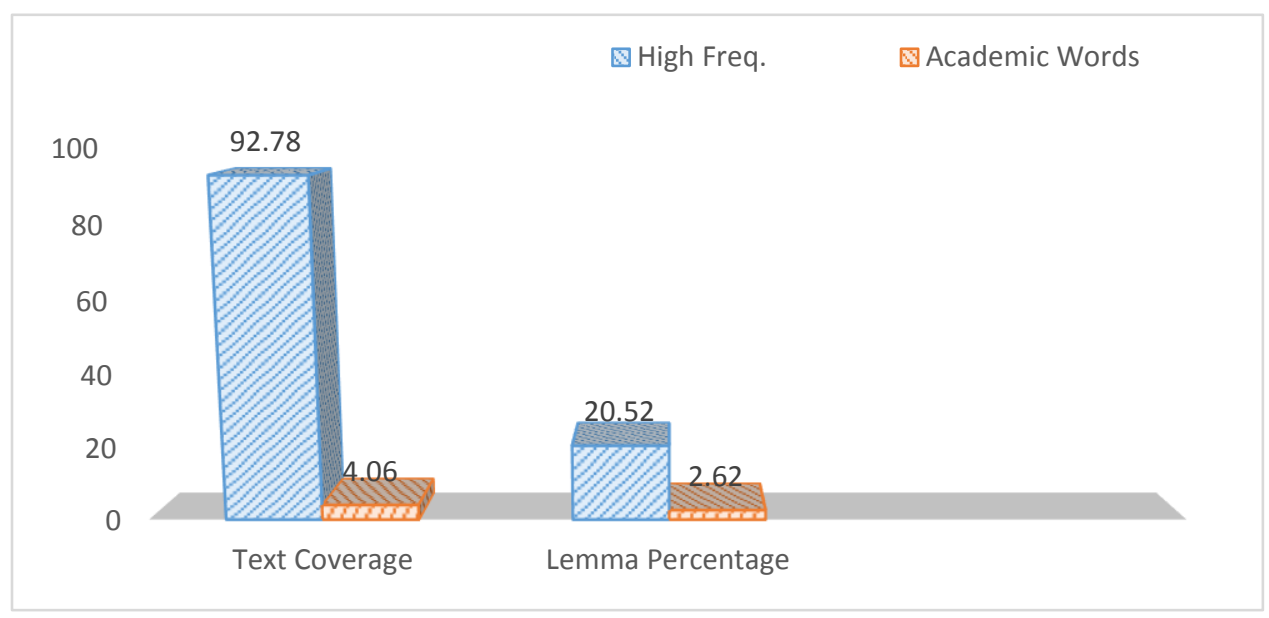

Figure 7. Academic vocabulary vs STEM vocabulary in TUSC and SMACK by percent.

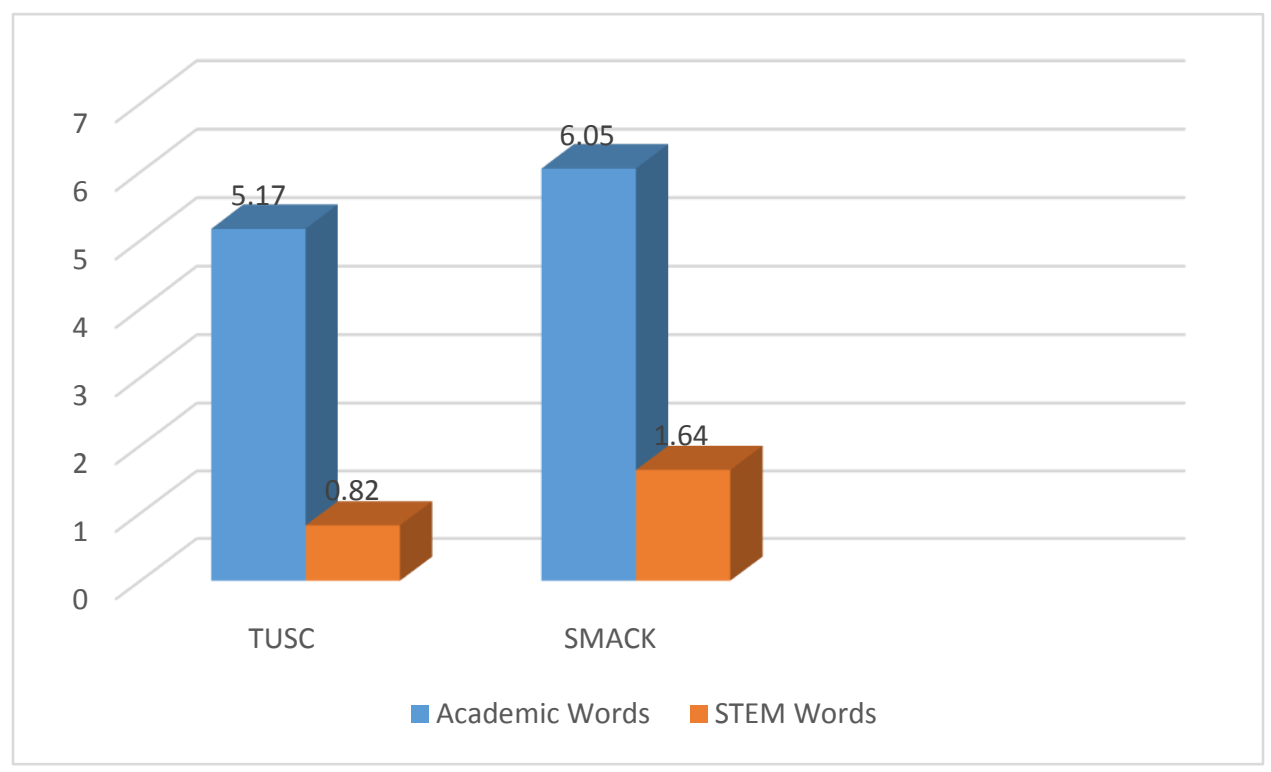


The rate of STEM words is lower than academic words in both TUSC and SMACK (see Chapter 2 for a typology of vocabulary in this study). However, this might be because I used the AntConc software, and a selective process is still needed to make the final decision about the STEM words and this might change the balance. Figure 6 compares STEM words in TUSC (a general corpus) and SMACK (a specialized corpus) showing the importance of academic words in specialized corpora.

\section{Essential word list (EWL) considerations}

So far, I developed new academic and essential word lists. Figure 8 displays what I found with regard to K-12 EWL which is re-answering RQ \#1 with the K-12 data of this dissertation. As maybe be seen in Figure 8, a good portion of text coverage in both TUSC and SMACK comes from the first thousand most common words. It also shows that basic academic words (only 200 of the first most common lemmas) cover more than 7 percent

of the textbooks represented by SMACK. Overall, Figure 8 substantiates the significance of K-12 EWL with respect to text coverage. 
Figure 8. EWL by K1, K2, and Basic Academic Words in TUSC and SMACK by percent

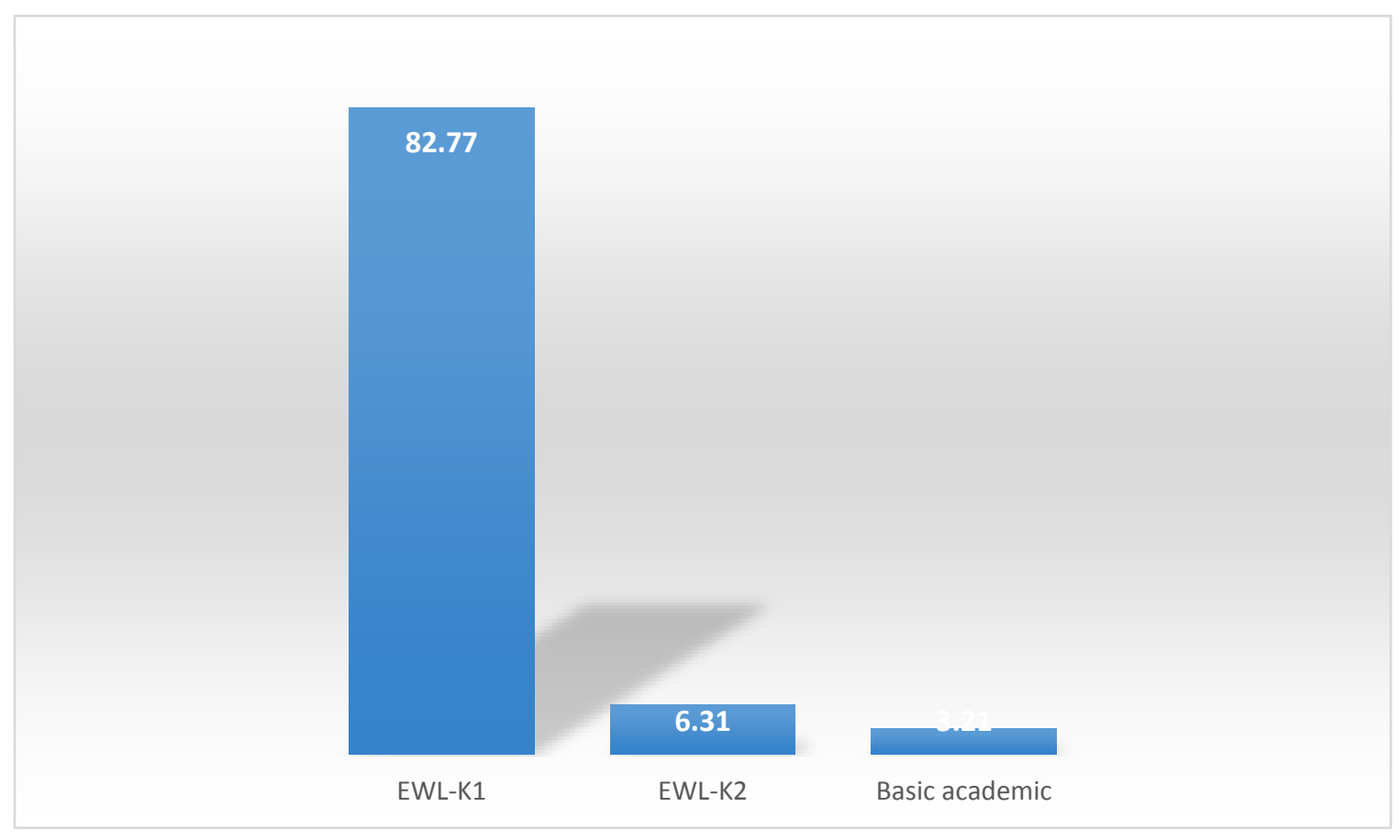




\section{CHAPTER V}

\section{The mobile app and website: Vocabulary in Reading Study - VIRS}

\section{Introduction}

We live in a society with an ever growing technological tools and we are becoming more dependent to its applications and uses. Therefore, it is now a high priority in K-12 schools to apply technology to teach content areas and English as a second language, as well. Cristen (2009) writes that with the emphasis that Common Core Standards put on technology in K-12 education, the use of technology in classrooms is essential if teachers hope to have a positive impact on students' learning and prepare them for the real life situation.

Future research recommended by the National Reading Panel (2017) was the incorporation of computer and mobile apps in reading instruction. Therefore, a key outgrowth of this project is the development of a mobile app-Vocabulary in Reading Study (VIRS), available on the APP Store, Android, and Google Play — and a website (www.myvirs.com). In this respect, I answer the third research question in this chapter, whose focus is on developing VIRS as a mobile app for teaching reading and vocabulary to ELLs.

I have been working with three computer teams in College of Computer Science at FIU from January 2017 to May 2018 to develop VIRS. So far, we have developed three versions of the app and Version 4 is currently under construction. In the first version, we set the foundation of the website and color-coded reading method. In Versions 2 and 3, we 
added School Dictionary, iTranslate, Vocabulary Tests, and Profile. In Version 4, we hope to add Essential Word List and improve text analysis.

With the use of the website and the app, teachers are able to analyze any type of text which may be sifted through OCR technology to create a vocabulary profiler. The app synthesizes the academic vocabulary found in K-12 textbooks and features an enhanced reading method that expedites the L2 reading process using a color-coded system.

The app uses six categories for sifting the words: high, mid, and low frequency words, STEM-related and academic words, plus a category for names and off-lists. Therefore, teachers can use VIRS in choosing the appropriate reading texts to work on in their classes.

Figure 9. The home page of the app - VIRS.

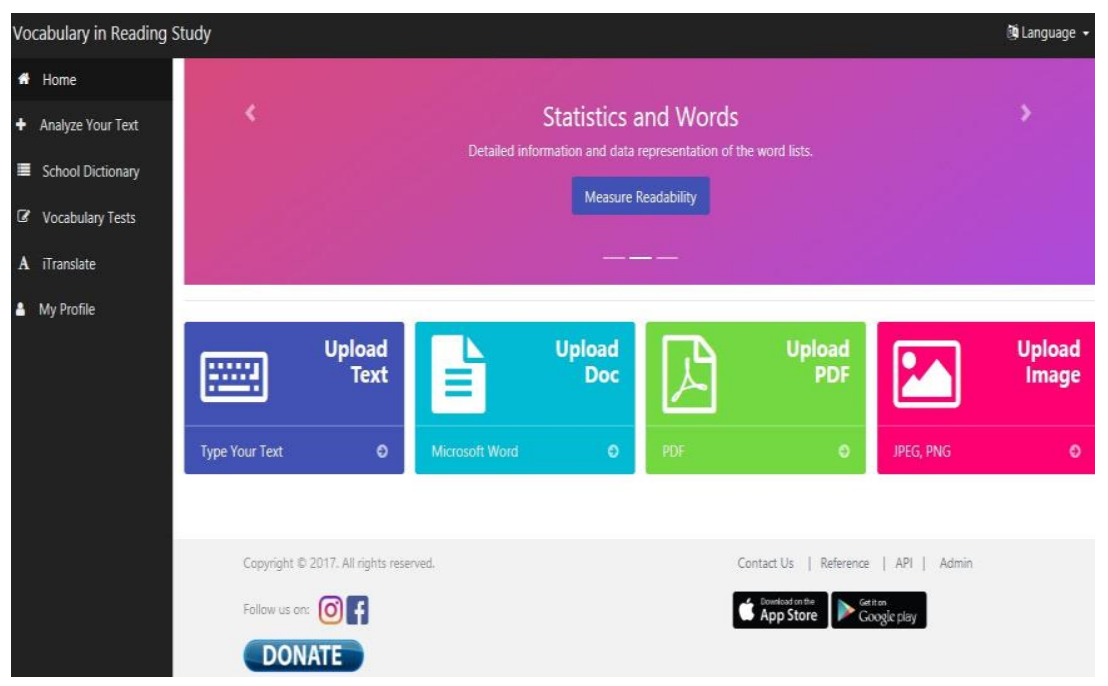

In addition, teachers can sign in by creating a user name and password. This way, all teachers can have their own profile to save their data for future use. The option from which 
teachers can benefit is the readability measurement function which analyzes the text. VIRS has the following features:

1. It produces enhanced texts through a color-coded system.

2. It gives a detailed analysis of texts that will help K-12 teachers develop course materials, and

3. It helps teachers to take a picture of a text through OCR technology and then sifts it through a vocabulary profiler,

The current version of VIRS also has six vocabulary tests for all proficiency levels from beginner to advanced. Each test has 100 questions that randomly scramble each time the user starts a test. Two out of the six tests are Nation's Vocabulary Size Test (Nation, 2001) that I divide them into two versions of A and B. Other main functionalities of VIRS include:

1. VIRS analyzes texts quickly in four different input modes.

2. It raising students' awareness to different word categories such as academic and STEM-related words through a different color.

3. It gives a result table for vocabulary tests and recommends on what to do next,

4. It has a pop-up dictionary that hopefully makes the reading for ELLs easier and quicker, and

5. VIRS has an online translation tools that saves users' time. 


\section{Overview of tools}

VIRS has four tools for analyzing texts, improving reading, and conducting corpus linguistic research. These tools are a) Analyze your text, b) School dictionary, c) vocabulary tests, and d) iTranslate. Analyze your text is designed to be used by teachers for material development, the other tools may be used by ELLs in classroom or while doing self-study. Below, I will explain each tool in order.

\section{Analyze your text}

This tool allows teachers and ELLs to upload texts and then the app turns it into enhanced text. There are four modes for uploading texts: type the text (max 30,000), word document files (max $5 \mathrm{MB}$ ), PDF files (max $25 \mathrm{MB}$ ), and image files (max $25 \mathrm{MB}$ ).

Figure 10. Color-coded system for reading comprehension

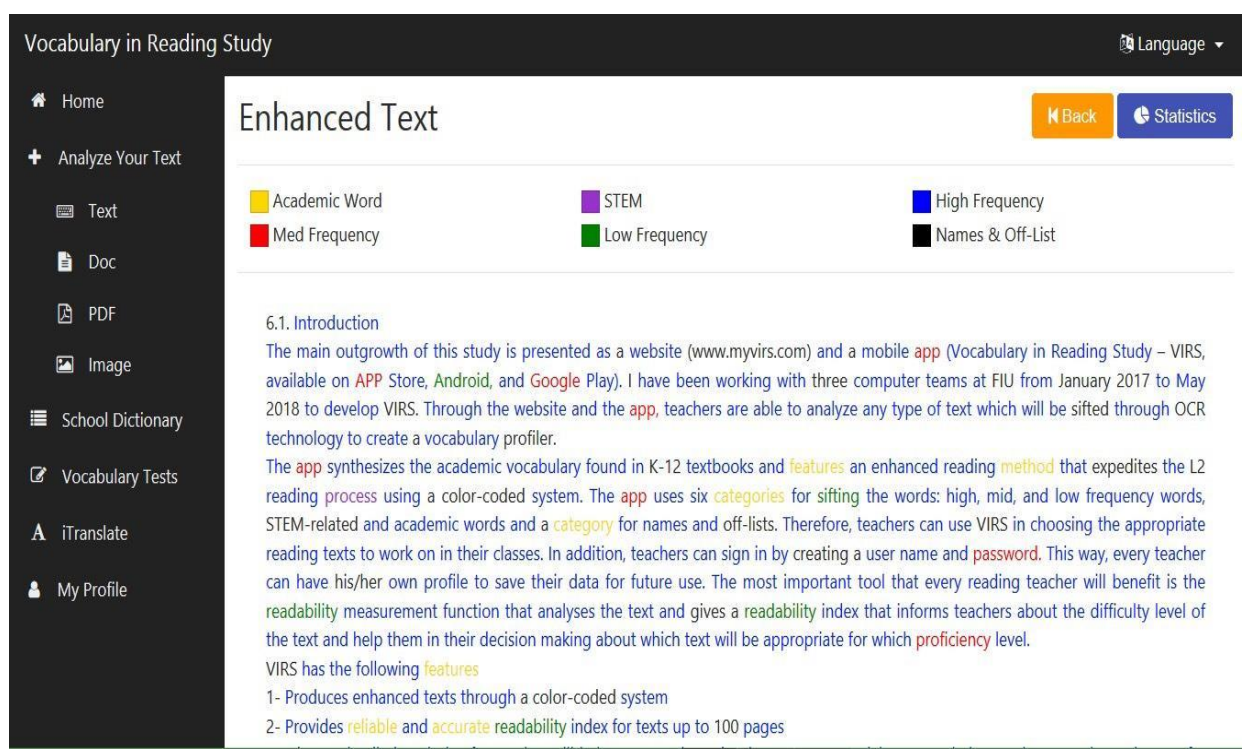


By pressing the Enhanced Text option, VIRS analyzes the text and presents in a different page in a color-coded enhanced format. Each word has a different color such that ELLs will hopefully be more engaged in reading processes.

An important feature of enhanced texts is their link to a pop up dictionary such that the meaning of the word pops up by clicking or touching the word. This way ELLs do not need to search every word in a dictionary that helps save time and energy. Also on this page is a detailed statistics of the uploaded text, including the number of academic and STEM-related words as well as high frequency vocabulary.

\section{School dictionary}

I used the K-12 corpora, TUSC and SMACK, to compile a new school dictionary which may make it easier for students to learn new vocabularies while reading their textbooks through VIRS. This is a frequency-based dictionary which categorizes words into five categories of lemmas which are in harmony with the color-coded system in the enhanced text option. The five categories include high (3,750 lemmas), medium (5,030 lemmas) and low frequency vocabularies (8,089 lemmas), academic words (423 lemmas), and a section for STEM-related words (238 lemmas) as well. In total, our school dictionary has 16,500 lemmas plus derivational and inflectional forms. 
Figure 11. School dictionary.

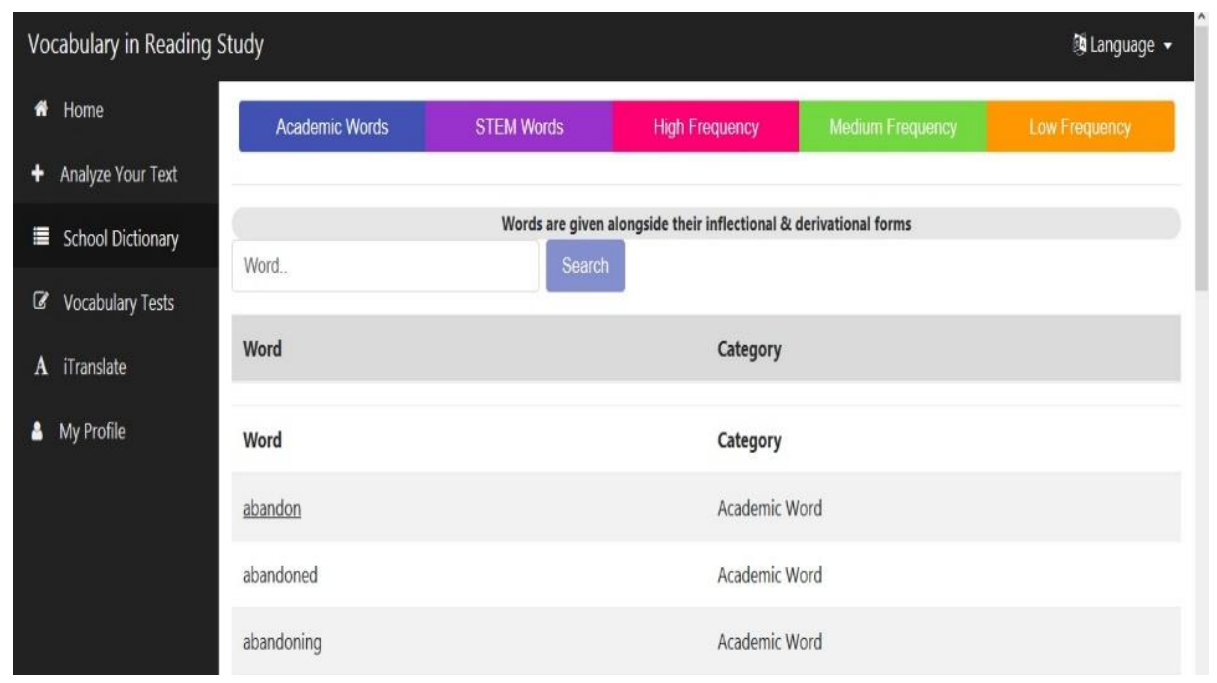

\section{Pilot vocabulary tests}

There are six test categories in this tool through which ELLs can check their vocabulary knowledge. Tests are ordered in terms of difficulty from beginner to advanced level (Cambridge vocabulary tests, 2016). Also, there are two versions of Nation's (2013) Levels Test. Each test has a different number of questions that will be shuffled each time an ELL takes the test so that the chance of having repeated questions will be low. For each question, ELLs will have 60 seconds to answer. Test results will be presented in a table alongside some recommendations based on the ELL's score on the test. 
Figure 12. Categories of pilot vocabulary test

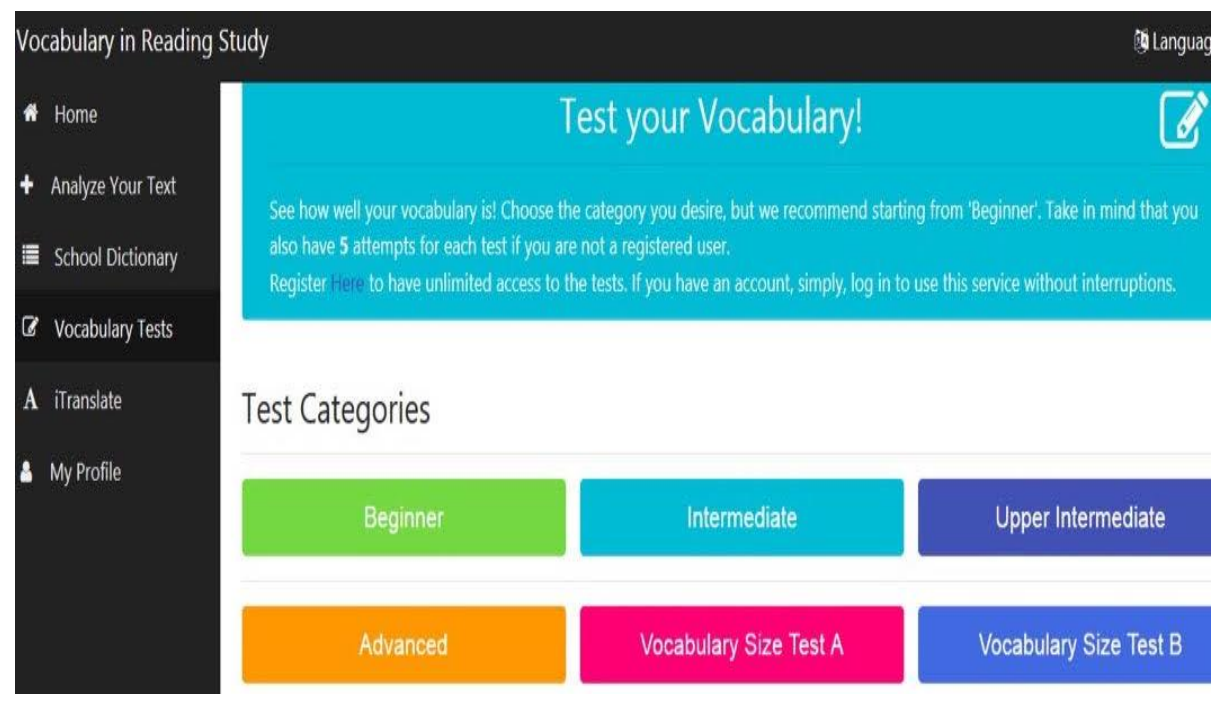

\section{iTranslate}

The iTranslate tool is linked to Google translation (www.translate.google.com) and has the same function, as well. Its purpose is to save ELLs time and make the reading easier. This tool allows ELLs to switch to their native language while reading on VIRS help them scaffolding reading through translanguaging (Nation, 2016). 
Figure 13. iTranslate home page.

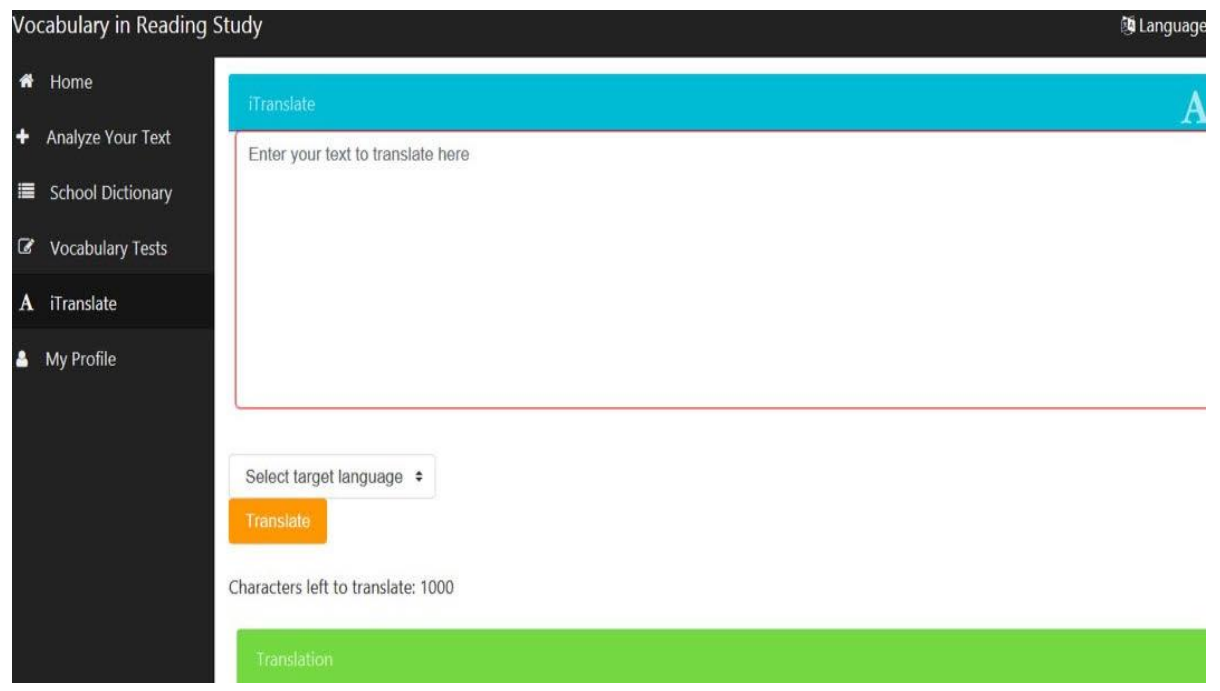




\title{
CHAPTER VI
}

\section{Teaching-learning implications of this dissertation and conclusion}

\begin{abstract}
Synopsis
For this dissertation, I created two corpora-The Teacher's U.S. Corpus (TUSC) and the Science/Math Academic Corpus for Kids (SMACK); six word lists emerging from these corpora- high frequency, mid frequency, and low frequency words, as well as lists for academic words and STEM-related words, and an Essential Word List; and a mobile app which is synchronized with a website offering four main tools (text analysis, school dictionary, vocabulary tests, and iTranslate).
\end{abstract}

I created the two corpora, and then based on Cobb's LexTutor, I developed a profile of textbooks for the States of Florida and California. The main findings of this dissertation are as follows:

1. I developed a new typology of vocabulary knowledge including K-12 STEMrelated words (Chapter 2).

2. I developed a new model for developing vocabulary knowledge based on mental process (Chapter 2).

3. The text coverage of academic vocabulary in Florida and California K-12 textbooks is $4.12 \%$, which is way lower than recommended $10 \%$ used in college texts (Chapter 4).

4. Based on proportions of academic vocabulary, Social Studies seemingly uses the most difficult language, while Language Arts employs the easiest (Chapter 4). 
5. I created the largest K-12 STEM-related and academic corpus to date, SMACK, with more than 8 million words (Chapter 4).

6. All five word lists are more valid than the NGSL, AWL, and AVL (Chapter 5).

7. High frequency words cover $91.81 \%$ of K-12 textbooks; meaning, that ELLs can survive in school with only 3,750 lemmas (Chapter 5).

8. The high frequency words with about 3,750 lemmas include both the essential and survival words that ELLs need to survive in school (Nation, 2016) (Chapter 5).

9. For having a better comprehension in K-12 content areas, focusing on domainspecific words, both academic and STEM-related word lists, can likely improve ELLs' text coverage (Chapters 3 and 5).

10. I developed a new K-12 dictionary that is specifically designed for ELLs (Chapter 6).

\section{Implications for teaching English as a second language in U.S.-based schools}

\section{Course design}

Setting realistic language learning goals is an important part of designing a course. There is a rich line of research on text coverage (Nation, 2006; Nation, 2013; Schmitt \& Schmitt, 2014) that has suggested low, mid, and high frequency levels considered as learning goals for ELLs. Thus, the six word lists developed in this study, as well as the two corpora, may hopefully provide K-12 teachers and textbook writers with a guidelines about which words and how many are needed at different learning stages for ELLs. However, this needs further research to be confirmed statistically. 
Nation (2013) claims that, in designing a course, high and mid frequency words are taken as receptive vocabulary knowledge learning goals for learners who want to use it for everyday purposes. In this study, however, the high and mid frequency words are more than 8,000 lemmas that ELLs need to survive through K-12. Nation (2016, p. 172) believes that textbook writers and course designers do not use word lists and vocabulary levels systematically. This is why he thinks that the influence of word lists in K-12 curriculum development is uncertain. Designing an effective course for ELLs in K-12 requires using an appropriate word list which is driven out of K-12 textbooks that meet the needs of ELLs.

\section{Reading material development for ELLs}

While ELLs read for the purpose of understanding messages, incidental vocabulary acquisition from meaning-focused input may happen. Appropriate materials can expedite this process (Hulstijn, 2001). In the selection process and preparation of such reading materials for ELLs, word lists can have a central role. The word lists in this study may provide teachers with a tool from which they can select the words that ELLs should develop first. For those ELLs in content areas who are beginners in academic English, the STEMrelated and academic word lists of this study are resources that ELLs can start with as a precursor before learning AWL and AVL. Range and AntWordProfiler (Webb \& Nation, 2008) are also other tools but with different functionality that teachers can use.

\section{Readability measurement for ELLs}

With using three text analysis programs (VocabProfiler on Cobb's Lextutor, AntWordProfiler, and Range - see Chapters 4 and 5 for the description of these programs), 
there is an upward trend of research on the different types of vocabulary load of texts ELLs read. For example, VocabProfiler is a tool on LexTutor that analyzes a text with respect to frequency level and academic words as well. The program determines the frequency level of words and which and how many are off-list. In the next step, the program makes a judgement on the difficulty level or vocabulary load based on the proportion of text tokens at the low frequency or off-list levels.

Such programs and other research carried out on vocabulary load depends on wellresearched word lists. List makers fortunately share their lists freely through publications or websites and this may improve the quality of readability measurement tools.

\section{Developing K-12 vocabulary tests}

An area affected the most by the use of word lists is vocabulary tests. In developing the vocabulary size tests (Nation \& Beglar, 2007; Coxhead, Nation \& Sirn, 2014) BNC and COCA have been used. Schmitt, Schmitt and Clapham (2001) and McLean and Kramer (2015) also used AWL for the vocabulary test development. With respect to levels tests (McLean, Kramer \& Beglar, 2015), BNC and COCA word lists were also used.

The difference between size and levels tests has always been misunderstood by language teachers. While vocabulary levels tests measure ELLs' vocabulary knowledge of a particular level, size tests focus on the ELLs' total word knowledge. For designing a language course, Nation (2016) believes that levels tests are more beneficial because they measure the actual words that ELLs need to know. The original levels tests are mainly based on Thorndike and Lorge's (1944) list, which is pretty old. There are now better and updated lists that could be used for developing new levels tests. In this regard, three of the 
word lists I developed through this study focus on three frequency levels that could be used for developing the K-12 levels test. Meanwhile, an appropriate vocabulary test has to use a sample of the words that represents the whole language. Dictionaries were the main source for such samples, but Nation (2013) claims that this sampling method results in a sampling error. He believes that word lists provide the best word samples because they are corpus-driven. As a result, the word lists of the present study may provide teachers and researchers with reliable samples for vocabulary test development. Furthermore, teachers may substitute the items of depth of vocabulary knowledge test (Read, 2000) with the items of the word lists to measure depth dimensions of word knowledge.

\section{Classroom activities that focus on word lists in teaching vocabulary to ELLs}

In this section of teaching-learning implications of the word lists that I developed in this study, I present some classroom activities that might help both teachers and students focus on words from the K-12 word lists. Each activity comes with a brief description and implementation in class, followed by some suggestions for how to modify it according to the needs of ELLs. My focus is on how to use these vocabulary instruction activities with the lists that I developed in this dissertation; however, these activities may also be applicable to other lists and learning contexts.

\section{Frayer model}

Frayer, Frederick, and Klausmeier (1969) developed the Frayer Model, which applies the graphic organizer technique to let students explore the deeper aspects of 
meanings of the words in word lists. Through the tasks below, Frayer et all found that students are able to clarify their understanding of the target words:

- Identifying the examples and non-examples of the meaning, and

- Identifying the essential and non-essential characteristics of the word in a particular word list.

\section{Implementation}

As such, through the implementation of VIRS - and indeed the word lists coming out of TUSC and SMACK - students may be able to

- Identify the target words from a word list, for example, some basic words such as tissue, cell, organism, atom from the Science sub-list of the STEM-related word list.

- Distribute the model's graphic organizer among student (this is available online).

- Brainstorming for completing the areas of the graphic organizer using the words from the lists.

- Ask students to make their individual graphic organizers with other similar words.

\section{Word sorts}

A word sorts is a hands-on activity (Gillett, Temple, \& Crawford, 2004) that seemingly improves ELLs' manipulating academic or STEM-related words into different groups of other words based on relationship or function. Teachers may use this activity to make comparisons between domain specific words to improve ELLs' word analogy. 


\section{Implementation}

- Choose 10-20 words from a word list which are related to the discussed topic.

- Choose between open or closed sort and then model word sorting for students.

- In small groups, ask ELLs to sort words based on the domain or word list the word is belong to. Then show the word in the original list and ask them to discuss.

\section{Triple-entry vocabulary journal}

The triple-entry vocabulary journal is a version of dual-entry diary (Berthoff, 1981) that teachers may use to help students make connections between words across different word lists. By using this activity, teachers can also communicate with their ELLs through feedback on their entries. Meanwhile, this activity can be used as a personal record of word list learning.

\section{Implementation}

- Choose a number of words from a particular word list that appear frequently in a topic that is discussed in class.

- Provide a template for this activity with three columns titled sentence in text, word, and my thought.

- According to the chosen words from word lists, ask ELLs to complete the Tripleentry vocabulary journals

- Share ELLs' thoughts and then give feedback 


\section{Semantic feature analysis}

A semantic feature analysis uses graphic organizers to improve ELLs' understanding of similarities and differences between academic and STEM-related words (Schmitt, 2000). Therefore, this activity will be effective for teaching synonyms or

antonyms. Also, this activity will be a good choice for teaching similar or opposite concepts.

\section{Implementation}

- Identify the words from word lists that represent similarities or differences, for example, a comparison between physical and chemical changes.

- Prepare a graphic organizer with the words and display it on the board.

- Present the words to ELLs and then discuss the similarities and differences.

\section{Identifying cognates}

Because of the same Latin roots, there are many Spanish-English cognates in English academic words (Nation, 2013). Bushong (2010) identified several SpanishEnglish cognates on AWL. The same is also true about the word lists of this study. This activity will be especially helpful for Spanish-speaking ELLs by making them aware and teaching the cognate recognition strategies through using the word lists. 


\section{Implementation}

- Introduce cognate to ELLs and explain that they can use their knowledge in Spanish to understand English texts.

- Work with students on a cognate pair from a word list.

- Ask students to use the words from the list in both languages.

\section{General implications for teaching English as a second language}

\section{Word cards and flash cards}

Vocabulary learning activities with word lists sometime is misunderstood with the idea of memorizing words from list of words which is out of context and is technically known as rote learning. However, learning words from word lists through doing activities such as word cards or flash cards has proven to be effective learning tools (Nation, 2013, 2016), if the right words chosen appropriately.

Nation (2013) suggests that using flash or word cards based on a well-designed word list is a kind of intentional vocabulary learning that will subsequently lead to learning the studied words. In Chapter 11 of his book, Nation (2013) reviews the research in support of using flash card apps. With respect to the findings of this study, the word lists may be used in developing flash cards for ELLs. In addition, developing the flash cards based on the STEM words from this study can help ELLs in ESP courses.

\section{Learners' dictionary}

An important tool in the app which is a direct outgrowth of the word lists is the K-12 dictionary. There is no doubt that a learners' dictionary has significant effect on 
ELLs' overall proficiency (Nation, 2013). With respect to this study, the six word lists developed may be used to annotate properly the words in the four content areas. A further application of the word lists in developing a K-12 learners' dictionary is the construction of well-controlled definitions for the words because many words have different meanings some of which are irrelevant to the K-12 context and by the use of K-12-based word lists we can determine the most relevant meanings that ELLs need to first learn.

\section{Designing graded readers}

Graded readers are books written within a specific level of word frequency with the intention of improving ELLs' vocabulary and finally their reading comprehension (Nation, 2001). Graded readers have a specific vocabulary scheme for each proficiency level. However, there are not well-designed graded readers for ELLs in the K-12 context and the sub-lists I developed in this study will lead to the integration of K-12 word lists into different series of graded readers.

\section{Limitations of this project}

A number of limitations regarding this project are worth mentioning:

1. The main limitation of this study is the size of the corpus and number of books. The two corpora involves books from California and Florida. Due to time, budget, and other resource limitations, I couldn't collect textbooks from other states especially New York and Texas, which are two main educational centers textbook companies often look to. A further related issue is the size of the corpora (more than 10 million 
in total) which is not a satisfactory size for making fair claims, as De Gardner and Davies (2013) believe that a way bigger corpus is needed to confirm the claims.

2. The second limitation of this study is the lack of grade by grade analysis of the four content areas with respect to vocabulary classification. This was mainly because of time limitation and it will be top on my research agenda for future research.

3. Because of the problems that I had in collecting the textbooks, the corpus is skewed toward middle and high school textbooks. This issue, however, will be solved by adding more K-5 science and social studies textbooks.

\section{Directions for future research}

For further research on corpus-driven and word list studies, there are various directions that I recommend:

1. Application of word lists based on frequency or so-called efficiency over time has never been fully researched. In other words, a frequency-based curriculum is needed in order to teach vocabulary in a need-based order. This line of research could also be extended to textbook development and syllabus design.

2. Corpus development for making a word list should be in accordance with the needs of the target audience and their language uses. Also, all corpora are only a rough representation of the actual needs of ELLs, especially in K-12 context, a research study is needed to focus on dispersion rather than frequency.

3. A readability index particularly designed for ELLs' texts is a needed research that has not been developed yet. This should be an interdisciplinary research with a team 
of statisticians. This readability measurement will be of great help to course developers and classroom teachers in choosing the appropriate reading materials.

4. TUSC is a Florida general corpus with more than 3 million word and SMACK is an academic corpus which is skewed toward middle and high school. Both corpora represent textbooks from States of Florida and California. Future research can focus on developing word lists based on larger and more comprehensive corpora. This way, the claims made by word lists will be more generalizable to K-12 school system.

5. A validated vocabulary test based on the current word lists is needed. Such a test which will be based on analysis of K-12 textbooks will help designing a curriculum for ELLs that best matches their needs.

6. There has never created a spoken corpus for ELLs in K-12 context. Developing such a corpus for improving learners' fluency is needed. Developing well-designed reading materials accompanied with audio files will also be beneficial for improving ELLs' fluency. 


\section{References}

Aitchison, J. (1994). Words in the Mind, (2nd ed.). Oxford: Blackwell.

Anthony, L. (2017). AntConc (Version 3.5.2) [Computer Software]. Tokyo, Japan: Waseda University. Available from http://www.laurenceanthony.net/software

Anthony, L. (2009). AntWordProfiler (Version 1.2w) [word profiler ]. Tokyo, Japan: Waseda University. Available from http://www.antlab.sci.waseda.ac.jp/software.html

Baddeley, A. (1990). Human Memory. London: Lawrence Erlbaum Associates.

Balota, D., Spieler, D. (1999). Word frequency, repetition, and lexicality effects in word recognition tasks: Beyond measures of central tendency. Journal of Experimental Psychology: General, 128(1): 32-55.

Bauer, L. \& Nation, P. (1993). Word families. International Journal of Lexicography, 6, 253-279.

Beck, L., McKeown, M., \& Kucan, L. (2002). Bringing Words to Life: Robust Vocabulary. Instruction. The Guilford Press.

Beglar, D. (2010). A Rasch-based validation of the Vocabulary Size Test. Language Testing, 27(1), 101-118.

Bernhardt, E. (2005). Progress and procrastination in second language reading. Annual Review of Applied Linguistics, 25, 133-150.

Biber, B. (2012). Corpus-based and corpus-driven analysis of language variation and use. The Oxford Handbook of Linguistic Analysis:

DOI:10.1093/oxfordhb/9780199544004.013.0008

Biemiller, A. (2010). Words Worth Teaching: Closing the Vocabulary Gap. McGrawHill. Bisson, M., van Heuven, J., Conklin, K., \& Tunney, R. (2015). The role of verbal and pictorial information in multimodal incidental acquisition of foreign language vocabulary. The Quarterly Journal of Experimental Psychology, 68(7): 1306-1326.

Brown, C. (1993). Factors affecting the acquisition of vocabulary: Frequency and saliency of words. In T. Huckin, M. Haynes, \& J. Coady (Eds.), Second language reading and vocabulary learning (pp. 263-286). Norwood, NJ: Ablex.

Brysbaert, M., \& New, B. (2009). Moving beyond Kucera and Francis: A critical evaluation of current word frequency norms and the introduction of a new and 
improved word frequency measure for American English. Behavior Research Method, 41(4), 977-990.

Campion, M., \& Elley, W. (1971). An academic vocabulary list. Wellington: New Zealand Council for Educational Research.

Carter, R. P. (1987). Is there a core vocabulary? Applied Linguistics, 8,178-193.

Carter, R. (2012). Vocabulary: Applied Linguistic Perspectives. Routledge.

Chall, J. (1996). Stages of Reading Development (2nd ed). Harcourt Brace.

Chen, C., \& Truscott, J. (2010). The effects of repetition and L1 lexicalization on incidental vocabulary acquisition. Applied Linguistics, 31: 693-713.

Cobb, T. (2017). LEXTUTOR (1998-2017), available at http://www.lextutor.ca/.

Coxhead, A. (2000). A new academic word list. TESOL Quarterly, 34: 213-38.

Coxhead, A. (2011). The Academic Word List 10 year on: research and teaching implications. TESOL Quarterly, 45: 355-62.

Coxhead, A., \& Hirsh, D. (2007). A pilot science-specific word list. Revue Francaise de Linguistique Appliquee, 12(2), 65-78.

Davies, M. (2012). Corpus of Contemporary American English (1990-2012), available at http://corpus.byu.edu/coca/.

de Bot, K., Paribakht, T. \& Wesche, M. (1997). Towards a lexical processing model for the study of second language vocabulary acquisition: evidence from ESL reading. Studies in Second Language Acquisition, 19, 309-329.

Ehsanzadeh, S.J. (2012). Depth versus Breadth of Lexical Repertoire: Assessing Their Roles in EFL Students' Incidental Vocabulary Acquisition. TESL Canada Journal, Volume 29, Issue 2, 24-41.

Ellis, N. (2002). Frequency effects in language processing: A review with implications for theories of implicit and explicit language acquisition. Studies in Second Language Acquisition, 24: 143-188.

Ellis, R. (1990). Instructed Second Language Acquisition. Basil Blackwell: Oxford.

Forster, K., \& Chambers, S. (1973). Lexical access and naming time. Journal of Verbal Learning and Verbal Behavior, 12: 627-635. 
Farrell, P. (1990). Vocabulary in ESP: a lexical analysis of the English of electronics and a study of semi-technical vocabulary. CLCS Occasional Paper No. 25. Dublin: Trinity College.

Foss, D. (1969). Decision processes during sentence comprehension: Effects of lexical item difficulty and position upon decision times. Journal of Verbal Learning and Verbal Behavior, 9: 699-706.

Gardner, D. (2013). Exploring Vocabulary: Language in Action. Routledge.

Gardner, D., \& Davies, M. (2013). A New Academic Vocabulary List. Applied Linguistics, 35/3: 305-327.

Graves, M. (2006). The Vocabulary Book: Learning and Instruction. International Reading Association.

Gardner, D., \& Miller, L. (1996). Tasks for independent language learning (Eds.). Alexandria, VA: TESOL.

Gass, M., Behney, J., \& Plonskey, L. (2013). Second Language Acquisition: An Introductory Course ( $4^{\text {th }}$ ed.). London: Routledge.

Ghadessy, P. (1979). Frequency counts, words lists, and materials preparation: A new approach. English Teaching Forum, 17, 24-27.

Gries, S. T. (2010). Dispersions and adjusted frequencies in corpora: further explorations. Language \& Computers, 71(1), 197-212.

Goulden, R., Nation, P., \& Read, J. (1990). How large can a receptive vocabulary be? Applied Linguistics, 11, 341-363.

Holec, H. (1981). Autonomy in Foreign Language Learning. Oxford: OUP.

Horst, M. (2005). Learning L2 vocabulary through extensive reading: A measurement study. The Canadian Journal of Language Review, 61(3), 355-382.

Hu, M., \& Nation, P. (2000). Unknown vocabulary density and reading comprehension. Reading in a Foreign Language, 13(1), 403-430.

Jarema, G., \& Libben, G. (2007). The Mental Lexicon: Core Perspective. Oxford Publication Ltd, London.

Jameson, J. (2012). Enriching content classes for secondary ESOL students. Center for Applied Linguistics, Delta Publishing Company. 
Koda, K. (1989). The Effects of Transferred Vocabulary Knowledge on the Development of L2 Reading Proficiency. Foreign Language Annals, 22(6), 529-540.

Komori, K., Mikuni, J., \& Kondo, A. (2004). What percentage of known words in a text facilitates reading comprehension: a case study for exploration of the threshold of known words coverage. Journal of Japanese Language Teaching, 125, 83-92.

Kucera, H., \& Francis, W. (1967). A computational analysis of present-day American English. Providence, R.I.: Brown University Press.

Kweon, S., \& Kim, H. (2008). Beyond raw frequency: Incidental vocabulary acquisition in extensive reading. Reading in a foreign Language, 20: 191-215.

Laufer, B. (1989b). What percentage of text-lexis is essential for comprehension? In C. Lauren \& M. Nordman (Eds.), Special Language: From Humans Thinking to Thinking Machines (PP. 105-123). Clevedon: Multilingual Matters.

Laufer, B. (1992b). How much lexis is necessary for reading comprehension? In Arnaud and Bejoint, 126-132.

Laufer, B. (2003). Vocabulary acquisition in a second Language: Do learners really acquire most vocabulary by reading? Some empirical evidence. Canadian Modern Language Review (59)4: 567-587.

Laufer, B., \& Sim, D. (1985a). Measuring and explaining the reading threshold needed for English for academic purposes texts. Foreign Language Annals, 18, 405-411.

Leech, G. (1991). The state of the art in corpus linguistics. In K. Aijmer \& B. Altenberg (Eds.), English corpus linguistics: Linguistic studies in honor of Jan Svartvik (pp. 8-29). London: Longman.

Long, M. (1988). Instructed interlanguage development. In L. Beebe (Ed.), Issues in second language acquisition (pp. 335-373). New York: Newbury House.

Lynn, R. W. (1973). Preparing word lists: a suggested method. RELC Journal, 4(1), 25-32. Nagy, W.E., Anderson, R.C., Schommer, M., Scott, J.A., \& Stallman, A. (1989). Morphological families in the internal lexicon. Reading Research Quarterly, 24, 263-282.

Nagy, W., \& Townsend, S. (2012). Words as tools: Learning academic vocabulary as language acquisition, Reading Research Quarterly, 47: 91-108.

Nassaji, H. (2004). The relationship between depth of vocabulary knowledge and L2 learners' lexical inferencing strategy use and success. Canadian Modern Language Review, 61, 107-134. 
Nassaji, H., \& Hu, M. (2012). The relationship between task-induced involvement load and learning new words from context. IRAL, 50: 69-86.

Nation, P. (1990). Teaching and Learning Vocabulary. Mass.: Newbury House.

Nation, P. (2001). Learning Vocabulary in Another Language. Cambridge: Cambridge University Press.

Nation, P. (2006). How large a vocabulary is needed for reading and listening? Canadian Modern Language Review, 63(1), 59-82.

Nation, P., \& Beglar, D. (2007). A vocabulary size test. The Language Teacher, 31(7), 9-13. Nation, P., \& Hwang, K. (1995). Where would general service vocabulary stop and special purposes vocabulary begin? System, 23, 35-41

Nation, P., \& Webb, S. (2011). Researching and analyzing vocabulary. Boston: Heinle Cengage Learning.

New, B., Brysbaert, M., Veronis, J., \& Pallier, C. (2007). The use of film subtitles to estimate word frequencies. Applied Psycholinguistics, 28(4), 661-677.

Ogden, C. (1936). The basic words. London: Kegan Paul, Trench and Trubner.

Ostyn, P., \& Godin, P. (1985). RALEX: an alternative approach to language teaching. Modern Language Journal, 69, 346-355.

Praninskas, J. (1972). American university word list. London: Longman.

Qian, D. (2002). Investigating the relationship between vocabulary knowledge and academic reading comprehension. Language Learning, 52, 513-536.

Read, J. (1995). Refining the word associates format as a measure of depth of vocabulary knowledge. New Zealand Studies in Applied Linguistics, 1, 1-17.

Read, J. (1998). Validating a test to measure depth of vocabulary knowledge. In A. Kunnan (Ed.), Validation in language assessment (pp. 41-60). Mahwah, NJ: Lawrence Erlbaum.

Rott, S. (1999). The effect of exposure frequency on intermediate language learners' incidental vocabulary acquisition and retention through reading. Studies in Second Language Acquisition, 21: 589-619.

Rubenstein, H., Garfield, L., \& Millikan, J.A. (1970). Homographic entries in the internal lexicon. Journal of Verbal Learning and Verbal Behavior, 9: 487-494. 
Salager, F. (1983). The lexis of fondamental medical English: classificatoire framework and rhetorical function (a statistical approach). Reading in a Forgien Language, 1, 54-64.

Saragi, T., Nation, P., \& Meister, G. (1978). Vocabulary learning and reading. System, 6: 72-80.

Schmitt, N. (2014). Size and Depth of Vocabulary Knowledge: What the Research Shows. Language Learning, 64:4, 913-951.

Schmitt, N., Jiang, X., \& Grabe, W. (2011). The Percentage of Words Known in a Text and Reading Comprehension. Modern Language Journal, 95(1), 26-43.

Schmitt, N., Schmitt, D., \& Clapham, C. (2001). Developing and exploring the behaviour of two new versions of the Vocabulary Levels Test. Language Testing, 18(1), $55-88$.

Schunk, D. H. (2012). Learning Theories: An Educational Perspective. Pearson Education, Inc.

Soria, J. (2001). A study of Ilocano learners' lexical inferencing procedures through think-aloud. Second Language Studies, 19, 77-110.

Stubbs, D., \& Halbe, D. (2013). Corpus linguistics: Overview. In C. A. Chapelle (Ed.), The encyclopedia of applied linguistics (pp. 1547-1550). Blackwell Publishing Ltd.

Tognini-Bonelli, E. \& Elena, D. (2001). Corpus linguistics at work: Studies in corpus linguistics. Amsterdam: John Benjamins.

Townsend, D., \& Collins, P. (2009). Academic vocabulary and middle school English learners: An intervention study. Reading and Writing, 22: 993-1019.

Vacca, R., \& Vacca, J. (1996). Content Area Reading (5th ed). Harper Collins.

Ward, J. (1999). How large a vocabulary do EAP Engineering students need? Reading in a Foreign Language, 12, 309-323.

Waring, R., \& Takaki, M. (2003). At what rate do learners learn and retain new vocabulary from reading a graded reader? Reading in a Foreign Language, 15:131-162. 
Wyse, D., \& Goswami, U. (2008). Synthetic phonics and the teaching of reading. British Educational Research Journal. 34 (6): 691-710.

Webb, S. (2007). The effects of repetition on vocabulary knowledge. Applied Linguistics, 28: 46-65.

Webb, S., \& Chang, C-S. (2012). Vocabulary learning through assisted and unassisted repeated reading. The Canadian Modern Language Review, 68: 276-290.

Webb, S., \& Chang, C-S. (2014). Second language vocabulary learning through extensive reading: How does frequency and distribution of occurrence affect learning? Language Teaching Research, 1-20. First published online, November 20, 2014.

Webb, S., Newton, J., \& Chang, C-S. (2013). Incidental learning of collocation. Language Learning, 63: 91-120.

West, M. (1953). A general service list of English words. London: Longman, Green.

Xue, G., \& Nation, P. (1984). A university word list. Language Learning and Communication, 3, 215-229.

Zipf, G. (1949). Human behavior and the principle of least effort. Reading, MA: AddisonWesley. 
VITA

\section{SEYEDJAFAR EHSANZADEHSORATI}

Born, Mazandaran, IRAN

Email: sehsa002@fiu.edu

2001-2005

B.A., English Language Translation, Azad University, Tehran, Iran

2006-2009

M.A., TESOL, Mazandaran University,

Mazandaran, Iran

2014-2018

Doctoral Candidate, Florida International University, Miami, Florida

Teaching and Research Assistant, College of Education, Florida International University, Miami, Florida

\section{PUBLICATIONS AND PRESENTATIONS}

Dwyer, E., \& Ehsanzadeh, S.J. (May 2018). Two corpora: TUSC and SMACK. Paper presented at Sunshine State TESOL 2018 Conference, Orlando, Florida.

Ehsanzadeh, S.J., \& Dwyer, E. (March 2018). The Science and Math Academic Corpus for Kids (SMACK). Paper presented at Annual TESOL International Convention and English Language Expo, TESOL International Association. Chicago, Illinois.

Ehsanzadeh, S.J. (October 2017). STEM-related Corpus for K-12 Context. Paper presenteAnnual Southeast TESOL Regional Conference (SETESOL), Birmingham, Alabama. 
Ehsanzadeh, S.J., \& Dwyer, E. (March 2017). Teachers' U.S. Corpus: A New

Perspective. Paper presented at Annual TESOL International Convention and English Language Expo, TESOL International Association, Seattle, Washington.

Ehsanzadeh, S.J., \& Dwyer, E. (October 2016). A new Academic Word List for K-12 Context. Paper presented at Annual Southeast TESOL Regional Conference (SETESOL), Louisville, Kentucky.

Dwyer, E., \& Ehsanzadeh, S.J. (October 2016). Academic Vocabulary: Then and Now. $12^{\text {th }}$ Annual MDTESOL/ Bilingual Education Association Fall Symposium 2016. Symposium conducted at MDC InterAmerican, Miami-Dade College, Miami, Florida.

Dwyer, E., \& Ehsanzadeh, S.J. (September 2016). The Teachers' U.S. Corpus (TUSC). Paper presented at International Vocab@Tokyo Vocabulary Conference, Meiji Gakuin University, Tokyo, Japan.

Ehsanzadeh, S.J., \& Dwyer, E. (May 2016). Academic Language in K-12 Context. Paper presented at Sunshine State TESOL 2016 Conference, West Palm Beach, Florida.

Ehsanzadeh, S.J., Dwyer, E., \& Carter, D. (October 2015). Situated Language of Mathematics. Paper presented at Annual Southeast TESOL Regional Conference (SETESOL) and K-12 Dream Day, University of New Orleans, New Orleans, Louisiana.

Ehsanzadeh, S.J. (October 2014). Strategies for Teaching Depth of Vocabulary Knowledge to English Language Learners. $10^{\text {th }}$ Annual MDTESOL/ Bilingual Education Association Fall Symposium 2014. Symposium conducted at MDC InterAmerican, Miami-Dade College, Miami, Florida.

Ehsanzadeh, S.J. (2012). Depth versus Breadth of Lexical Repertoire: Assessing their Role in EFL Students' Incidental Vocabulary Acquisition. TESL Canada Journal/ Revue TESL du Canada. 29 (2), 24-41. 